عدد خاص من مجلة "بحوث في العلوم والقنون النوعيه"

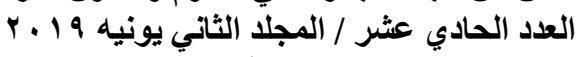

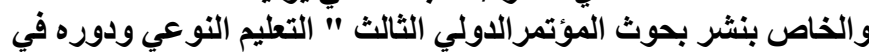

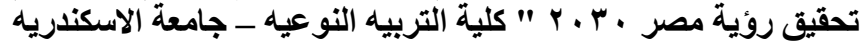

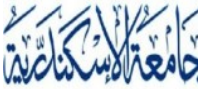

ALEXANDRIA

UN I VER S I T Y

Alexu Press

(بip

(7) البحث رقم

\title{
استراتيجيات المواجهة الإقدامية للضغوط لاى الزوجين وعلاقتها بجودة الحياة الأسرية
}

\section{د. حنان حنا عزيز}

مدرس إدارة المنزل بقسم الإقتصاد المنزلى

كلية التربية النوعية-جامعة المنصورة

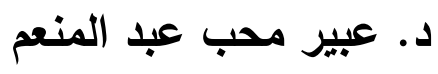

دكتوراه الفلسفة فى التربية النوعية

الإقتصاد المنزلى (إدارة المنزل)

كلية التربية النوعية-جامعة المنصورة 
يهاف البحث الحالى بصفة أساسية إلى التعرف على العلاقة بين استراتيجيات المواجهة

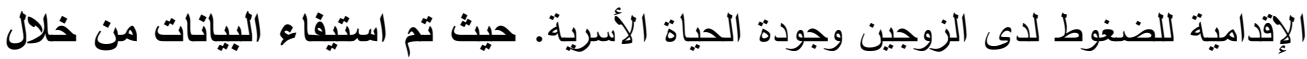
تطبيق أدوات البحث (من إعداد الباحثتان) على كلٍ من الزوجين، والمتمثلة فى إستمارة البيانات العامة، واستبيانى استراتيجيات المواجهة الإقدامية للضغوط إنئ بمحاورها (التحليل

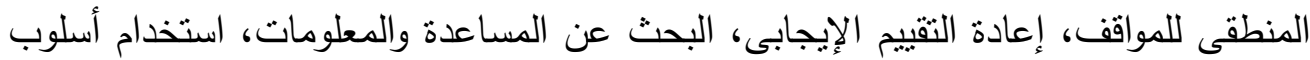
حل المشكلات)، وجودة الحياة الأسرية بمحاورها (جودة الحياة الزوجية، جودة الحياة النفسية

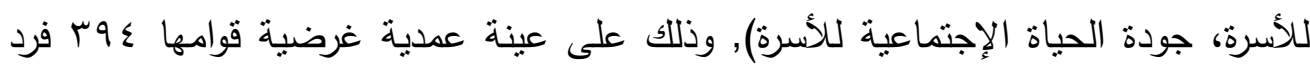
(بواقع VV ا زوج و 9V ا زوجة) المنتميين إلى مستويات إجتماعية وإقتصادية مختلفة، اختيرت

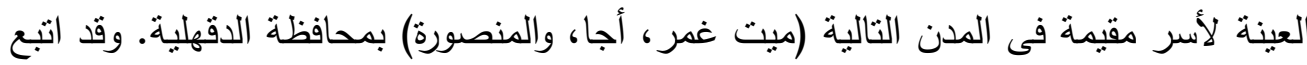
هذا البحث المنهج الوصفى التحليلى، و قد تم تحليل البيانات وإجراء المعالجات الإحصائية المناسبة بإستخدام برنامج (Spss). وكان من أهم نتائج البحث:

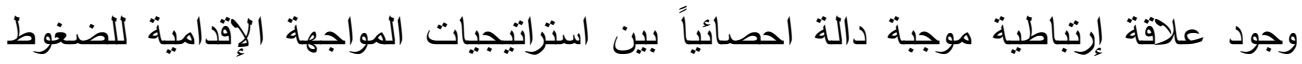
بمحاورها (التحليل المنطقى للمواقف، إعادة التقييم الإيجابى، البحث عن المساعدة والمعلومات، استخدام أسلوب حل المشكلات)، والإجمالى، وجودة الحياة الأسرية بمحاورها

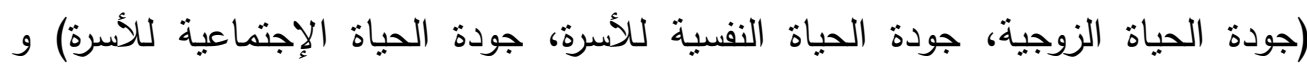
الإجمالى، وجود فروق بين متوسطات درجات عينة البحث فى استراتيجيات المواجهة الإقدامية

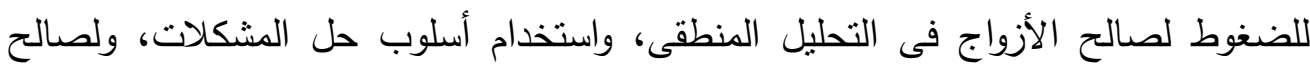
الزوجات فى إعادة التقييم الإيجابى، والبحث عن المساعدة والمعلومات, وجود فروق بين

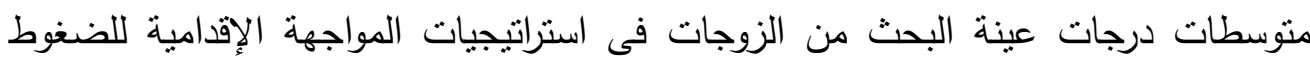
بمحاورها، والإجمالى لصالح الزوجات العاملات، عدم وجود فروق بين منوسطات درجات

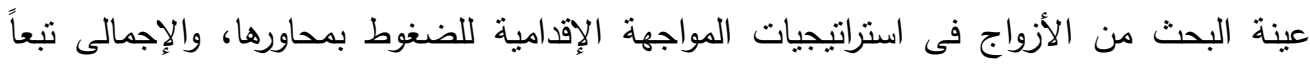
لطبيعة عمل الزوج (حكومى - حر)، وجود فروق دالة إحصائياً بين المنوسطات فى إجمالى الإنى 
عدد خاص من مجلة "بحوث في العلوم والقنون النوعيه" العزيه

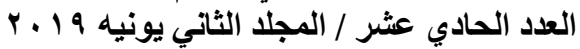

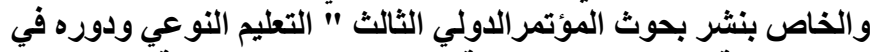

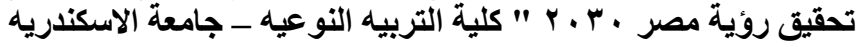

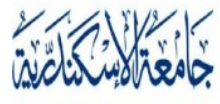

ALEXANDRIA

U N I V ER S I T Y

استراتيجيات المواجهة الإقدامية للضغوط لدى الزوجين لصالح المستوى التعليمى الأعلى، والعمر

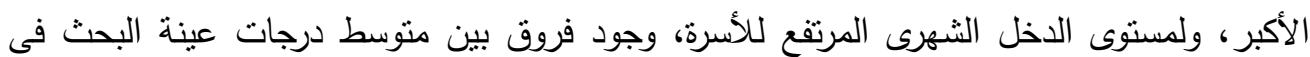

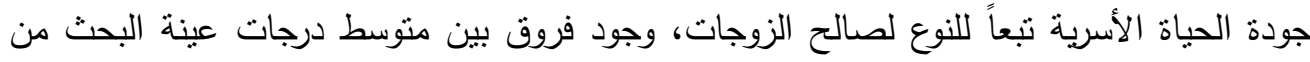

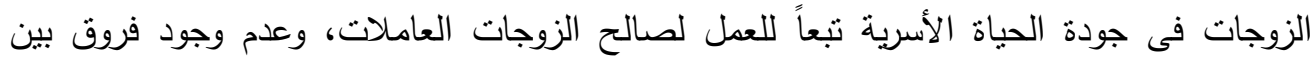

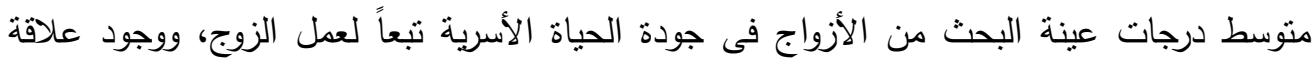

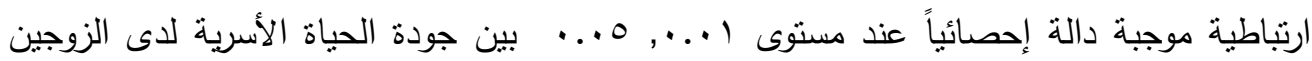
وكلٍ من العمر الأكبر، المستوى التعليمى الأعلى، ومستوى الدخل الثهرى المرتفع للأسرة. وكان من أهم التوصيات:

- تصميم برامج إرشادية لتتمية الجوانب الإيجابية للأزواج من الجنسين نوجه من خلد الجهات

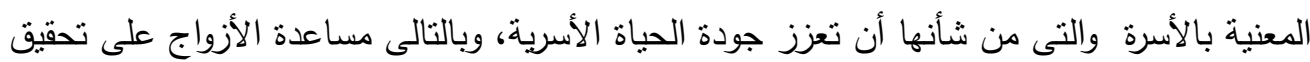

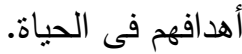

- إعداد دورات ندريبية من قبل الجهات المعنية بالأسرة، يقوم بها متخصصين فى مجال الإرشاد الأسرى، تهدف إلى اكساب الأزواج، والمقلين على الزواج الأساليب الإقدامية لمواجهة

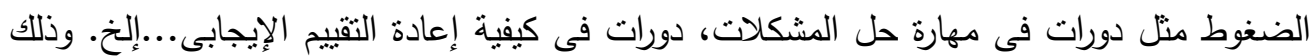
حتى يمكن امتلاكها كمهارات حياتية لاى كلٍ من الجنسين.

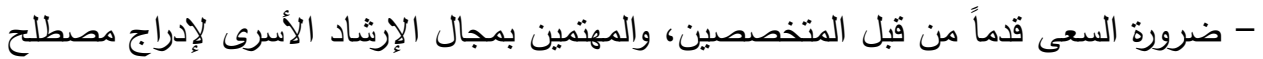

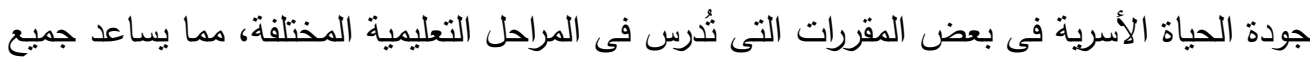
الطلاب على حد السواء لإدراك معناها وأهميتها فى الحياة؛ وبالتالى إعداد جيل قادر على نتمية

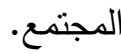
الكلمات الإفتتاحية:- استراتيجيات المواجهة الإقدامية للضغوط - جودة الحياة الأسرية 
عدد خاص من مجلة "بحوث في العلوم والقنون النوعيه" / التوبه

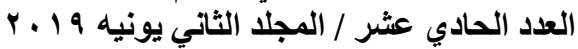

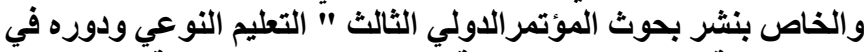

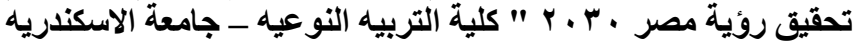

\section{المقدمة والمشكلة البحثية :-}

لا شك أن الزوجين بتعرضان أثناء دورة حياتهما الزوجية للعديد من الضغوط الناتجة عن تعقد الحياة وتزايد أعبائها ومنافساتها وصراعاتها والنطور فى كافة مجالات الحياة، هذه الضغوط لانيان بعضها قد يكون بسيطاً لدرجة أننا لا نكاد نشعر بها ونتوافق معه فى سياق الحياة اليومية وبعضها الآخر قد يكون شديد إلى المدى الذى تعجز فيه القدرة عن المواجهة والتوافق معه

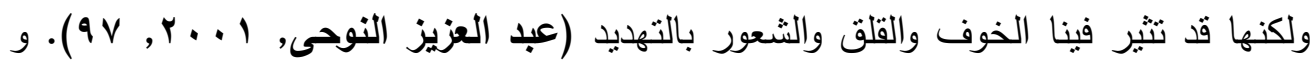
المشكلة ليست فى وجود موقف ضاغط أو خبرة مؤلمة لكن الخطر الحقيقى يكمن فى أسلوب كلٍ من المرأة والرجل فى مواجهة الضغوط وجئ وكيفة تجاوز الأزمة والخبرة المؤلمة، وكيفية

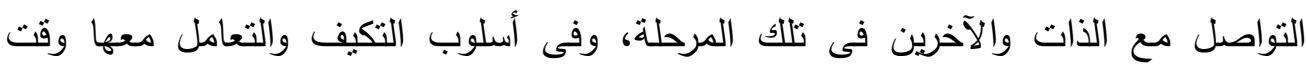
حدوثها. وفى نطاق الأسرة قد تتسبب الضغوط فى صعوبات لكل من الزوجين أو الوالدين

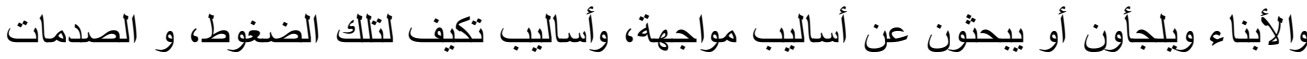

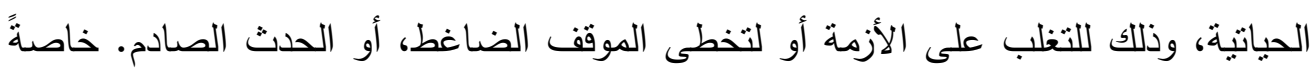

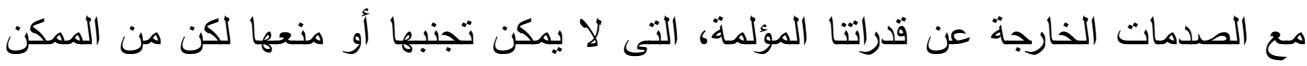
البحث عن أساليب لمواجهتها بطرق أكثر فعالية وأكثر إيجابية، فالأساليب التى يستخدمها

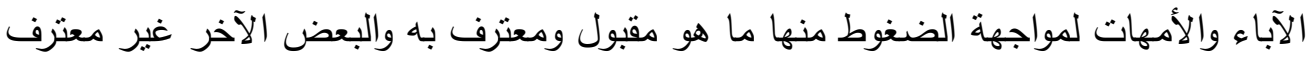

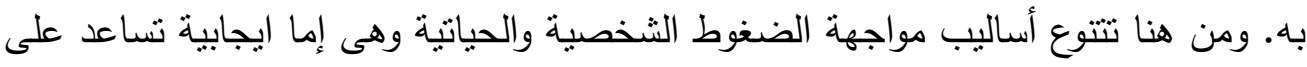

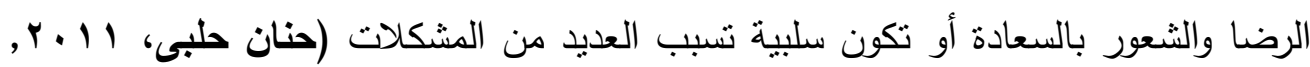

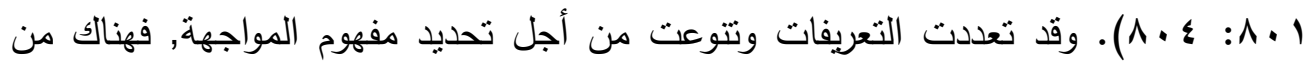
اعتبرها استراتيجية يستخدمها الفرد من أجل خفض شدة الضغط، والبعض الآخر اعتبرها

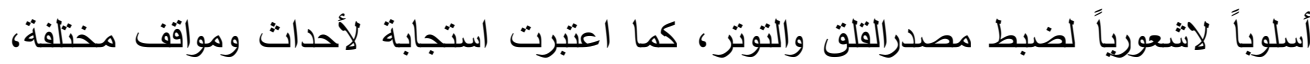

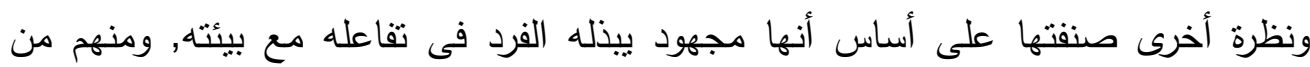

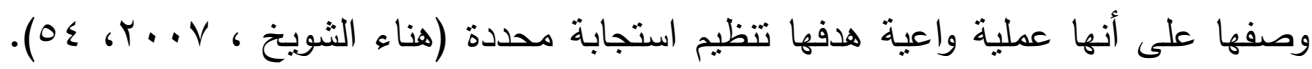


عدد خاص من مجلة "بحوث في العلوم والقنون النوعيه" العيه

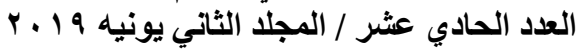

هذا ويُكن اعتبار استراتيجيات مواجهة الضغوط مجموعة من المحاولات المعرفية والسلوكية التى يقوم بها الفرد فى تعامله مع المواقف، والأحداث الضاغطة سواء كانت هذه المحاولات

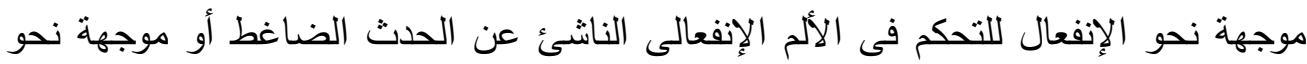
المشكلة لتعديل مصدر الحدث الضاغط والتحكم فى المشكلة (Lazarus,R. 2000:668). وقد ظهرت استراتيجيات المواجهة الإقدامية للضغوط فى مقابل استرتيجيات المواجهة الإحجامية للضغوط، وذللك نتيجة لجهود الكثير من الباحثين والعلماء، ثم نوالت الدراسات التى لهى

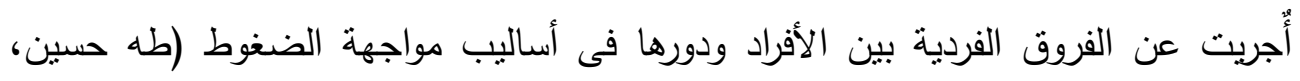

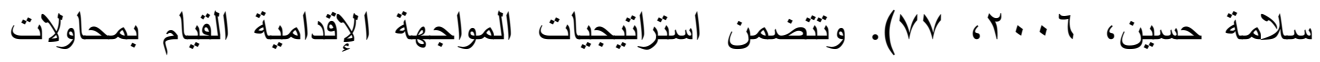
معرفية تغير أساليب التقكير لاى الفرد فى المشكلة مع محاولات سلوكية تهدف إلى الحصول

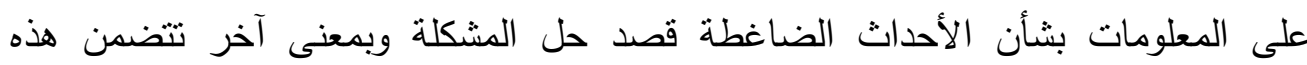
الإستراتيجية النزعة للإستجابة بشكلٍ فعالٍ نحو الأحداث الضاغطة، والسعى للحصول على الى

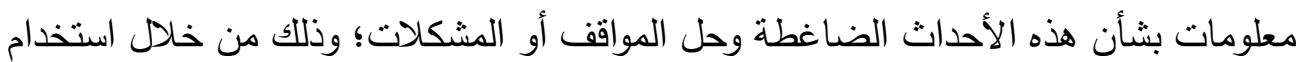
أساليب سلوكية ومعرفية محددة. وتتمثل الأساليب الإقدامية على التحليل المنطقى للموقف الضاغط ونتائجه، وإعادة التقييم الإيجابى للموقف أى إعادة بناء الموقف معرفياً بطريقة الإنها

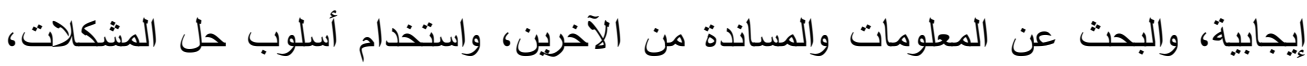
ويتميز الأفراد ذوى الإستراتيجيات الإقدامية بتصديهم للموقف الضاغط من خلاد أربع استراتيجيات وهى استراتيجية التحليل المنطقى للموقف الضاغط بغيه فهمه والتهيؤ الذهنى له ولما يترتب عليه، استراتيجية إعادة التقييم الإيجابى للموقف حيث يحاول الفرد معرفياً استجلاء

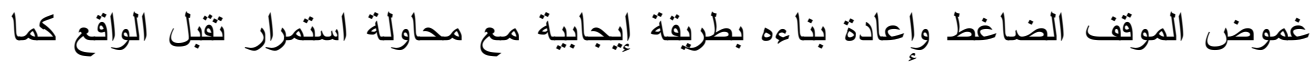
هو، استراتيجية البحث عن المعلومات والمساعدة حيث يحاول الفرد البحث عن المعلومات المتعلقة بالموقف الضاغط وطلب المساعدة من الآخرين، استراتيجية حل المشكلة يحاول الفرد من خلالها استتباط أفكار وحلول مبتكرة لمواجهة الضغوط ( طه حسين، سلامة حسين، 


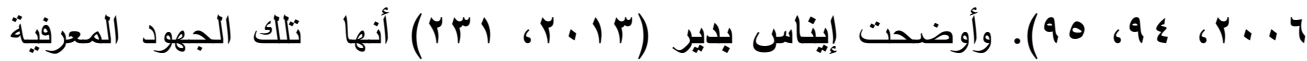
والسلوكية التى يوظفها الفرد فى إقتحام الحدث وتجاوز آثاره من خلال الطرق الإيجابية الآتية: التحليل المنطقى بهدف فهم والتهيؤ الذهنى لله ولمترتباته، إعادة التقبيم الإيجابى بهدف هـ إستجلاء الموقف وإعادة بناءه بطريقة إيجابية مع تقبل الواقع كما هو، البحث عن المساعدة والمعلومات بهدف الوصول للمعلومات والإرشادات المتعلقة بكيفية التعامل مع الحدث والمساعدة من الآخرين أو مؤسسات المجتمع المتوقع ارتباطها بهذا الحدث، استخدام اسلوب حل المشكلات بهدف التصدى للحدث بصورة مباشرة بدراسته ووضع الحلول المقترحة له

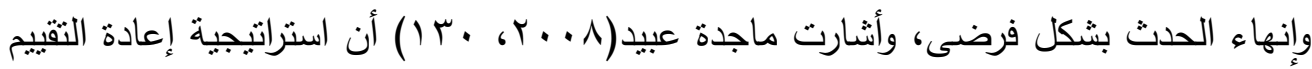
الإيجابى هى التى من خلالها يعيد الفرد تقييم إداركه، ومواجهته للموقف نتيجة للحصول على معلومات جديدة وأكدGarnefski\&Kraaij (2006, 1661 أنها نشير إلى الأفكار التى تعطى الحدث معنى إيجابى ويرى Dillon \&LaBar $(2005,1118$ أنها تتضمن تغيير معنى الموقف بطريقة معينة بحيث يكون هنالك تغيير فى الإستجابة الإنفعالية للأفراد،

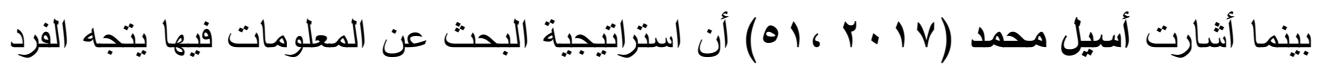
إلى جمع أكبر قدر من المعلومات عن المشاكل أو المواقف الضاغطة التى يتعرض لها مستعيناً بخبرات الآخرين كأصدقاء وأهل واختصاصيين, والمساندة من استراتيجيات المواجهة المركزة على المشكلة (Lazarus, R, 2000:668) وتتضمن محاولات الفرد البحث عمن يسانده فى محنته ويمده بالتوجه للتعامل مع الحدث وإيجاد المواساه والمساعدة لمواجهة هذه

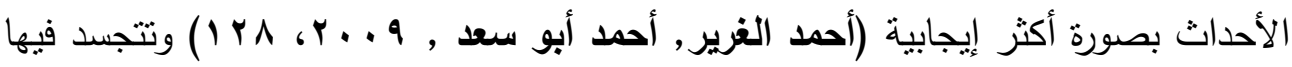
المجهودات المبذولة من طرف الفرد فى كسب تعاطف الغير ومساعدتهم من خلال البحث , et al 2002,359) عن المساندة المعنوبة كالإنصات أو الدعم المادى من طرف الغير (Bruchon بينما استراتجية حل المشكلة عبارة عن استجابات يحاول الفرد بواستطها تغبير المواقف الضاغطة أو احتواء آثارها ولهذه الإستراتيجية آثار مفيدة على الإنفعالات لكونها 
تعدل أو تقضى على الضغوطات (Aldao et al,2010, 975) فيحاول الفرد من خلالها استتباط أفكار وحلول مبتكرة لمواجهة الضغوط (طه حسين، سلامة حسين، 7 . . ؟، . . 1) فهى عملية منظمة تشتمل على خطوات متسلسلة للإستبصار عند تفكير الفرد لحل المشكلة

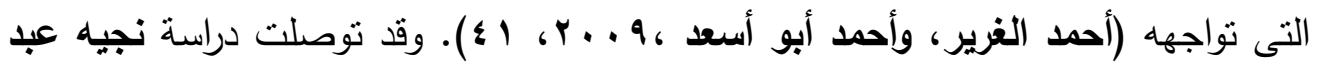
الله (1 ( + أن الإقداميون يتسمون بسمات شخصية إيجابية كالتيسير وسهوله الإتصال

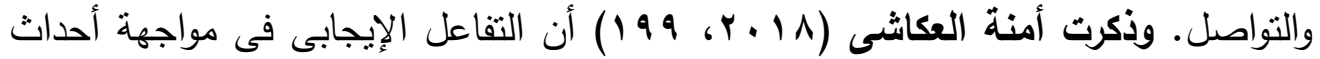
الحياة الضاغطة يتمثل فى بعض سمات الثخصية الإقدامية والإيجابية المرنة التى يتسم بها

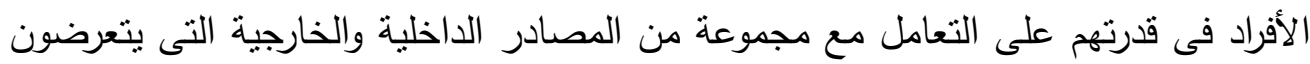

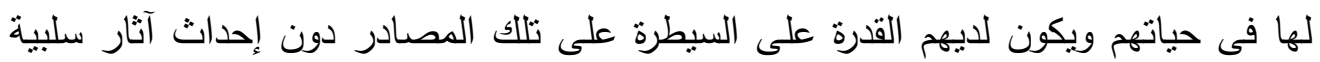

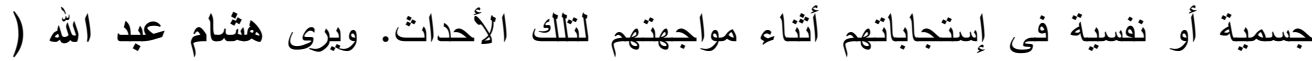

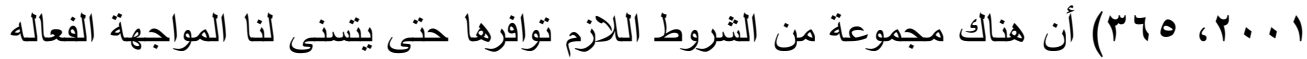
للضغوط والتكيف معها تتمنل فى استكثاف الواقع ومشكلاته، والبحث عن معلومات كافية، والقدرة على تحمل الإحباط, النَّعبير فى حرية عن المشاعر الموجبة والسالبة لما فى ذلك من تتفيس عن الضغوط، طلب العون من الآخرين والثّقة فيهم، وقبل ذللك التّقة فى النفس، وإبداء المرونة وتقبل الثَّغيير، تجزئة المشكلة إلى وحدات يمكن معها تتاولها ومعالجتها في وقت معين, ضبط الإنفعالات والتَّكمم فى المشاعر، والتَّغلب على التَّعب، ومقاومة الميل إلى الإضطراب، روح التَّاؤل والأمل فيما يُبذل من جهود لحل الأنمة.

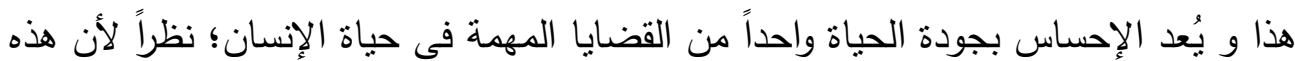
القضية تُعد نقطة البداية لكثير من المشكلات التى يمكن أن يعانيها ويعايشها ويشكو منها هذا الإنسان، فكثيراً ما يتزتب على إحساس الفرد بإنخفاض مستوى جودة الحياة مشكلات عديدة فى حباته كالإكتئاب والوحدة النفسية، وزيادة الضغوط (صلاح الدين عراقى، ومصطفى مظلوم

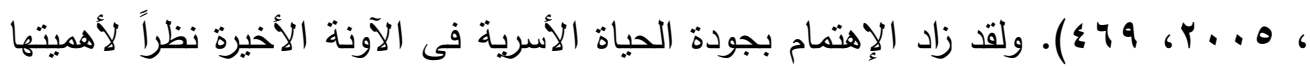


فى توافق الأبناء على المستوى الإجتماعى والإنفعالى ومن ثم تحسين الصحة النفسية لايهر

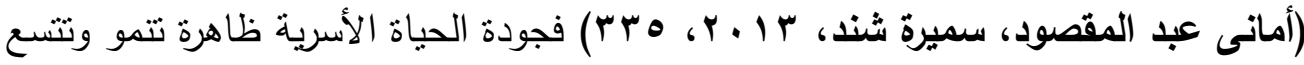

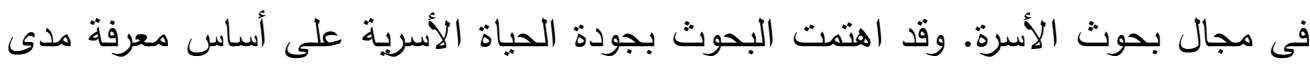

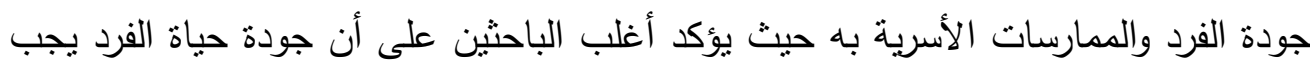
أن تشمل جودة المحيطين به حيث تتضمن قدرة الأسرة على تحسين العلاقات بين أفراد الأسرة لتحقيق صحة الأسرة والسعادة؛ فالأسرة التى لها القدرة على تحسين جودة الحياة بصفة عامة

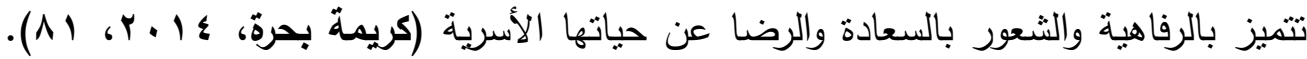

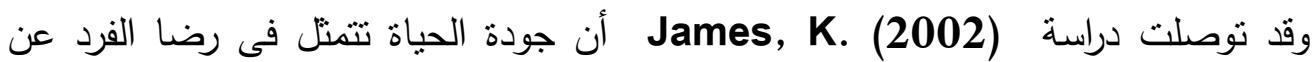

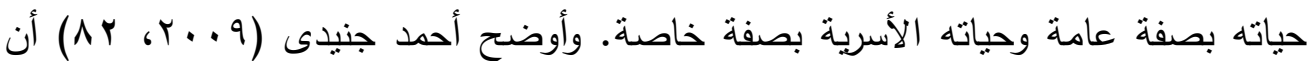
جودة حياة الأسرة لا تختلف فى مكوناتها عن جودة حياة الفرد، ولكنها تختلف فى تركيزها. فجودة الحياة الأسرية تتعلق بشكل كلى بالأفراد فى الأسرة وليس كل فرد على حدى. ومن ثم فهى من المفاهيم ذات الطابع الجدلى؛ حيث تختلف مضامينها ودلالتها من فرد لآخر ، ومن ثقافة إلى أخرى. ورغم ذلك يندرج خلفه الكثير من المضامين، والدلالات كالقناعة، والرضا والسعادة، والأمن النفسى، وتقدير الذات، وتحقيق الذات. وفى هذا الصدد توصلت دراسة Foehrkolb (2007) إلى أهية العلاقة بين جودة الحياة الأسرية وتقدير الفرد لذاته؛ لأنها تؤدى إلى إدراك و فهم الفرد لمدى تأثثر جودة الحياة بالأسرة على مظاهر الحياة المختلفة.

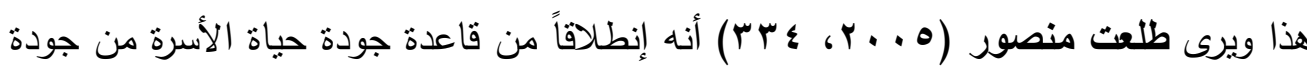
الحياة بإعتبار أن الأسرة تتظيم له بنائه ووظائفه وله أهدافه ودينامياته، ضماناً لهناخ إنهاء إجتماعى وثقافى وإقتصادى متغير من خلال تفاعلاته مع متغيرات نمط الحياة الإجتماعية الجديدة والتى تعدل من أسسها التتظيمية واتجاهاتها المعيشية لذلك فإن رد الفعل الإجتماعى

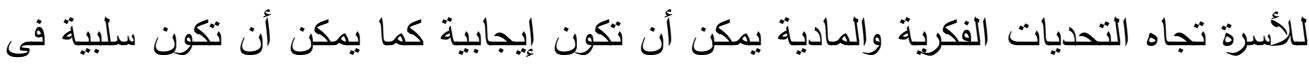

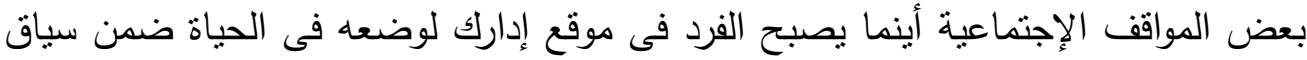


الثقافة التى يعيش فيها وما يناسب معه كل من أهدافه واهتماماته وتوقعاته، قيمه المتعلقة بصحته، علاقاته الإجتماعية، مستوى استقلاليته واعتقاداته الثخصية، وعلاقته بما يحيط به عموماً ليكون بذلك فى موضع تحقيق الجودة فى حياته بإعتبار أن جودة حياة الأسرة هى الإسئه

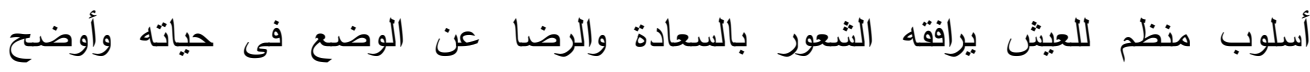
Gullberg et al, (2010,251) ارتفاع رضا الفرد عن ذاته وعن حياته بشكل عام، وسعيه المتواصل لتحقيق أهداف شخصية ذات قيمة ومعنى بالنسبة له، واستغلالها فى تحديد مسار حياته، وإقامته لعلاقات إجتماعية إيجابية منبادلة مع الآخرين، كما ترنبط بالإحساس العام بالسكينة والسعادة والطمأنينة

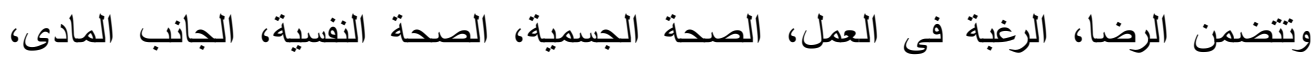
العلاقات الأسرية، العلاقات الإجتماعية، أنثطة الحياة اليومية. فى حين يرى ـ (2003) Park, et al , 367:384) أفراد الأسرة إلى الإلتقاء أو التجمع، واستمتاعهم بحياتهم معاً، وتوفر الفرص لإنجاء الإنهاز أهدافهر

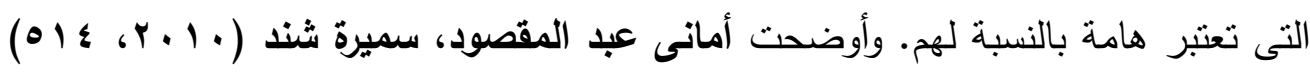
بأن جودة الحياة الأسرية هى العلاقات والممارسات الإيجابية التى يتبعها الوالدين فى تتشئة ولهئ الأبناء, وما تتسم به من دفه وتقبل ومشاركة وتشجيع وإستحسان فى المواقف الحياتية المختلفة، وإدراك الأبناء ذللك، وردود أفعالهم تجاه هذه الممارسات, والعلاقات المنبادلة بين أفراد الأسرة، وماتتسم به هذه العلاقات من أساليب سوية فى التعامل لتحقيق الأهداف، وإنجاز

al(2005:779) الأعمال والمهام، ودعم أفراد الأسرة فى المواقف المختلفة. ويوضحن Summers, et

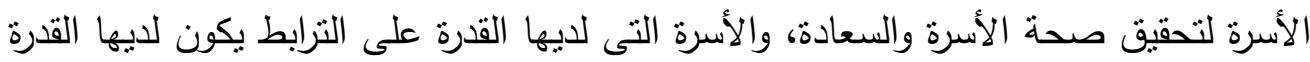

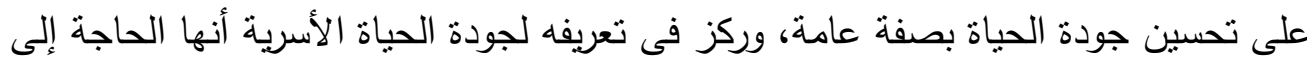

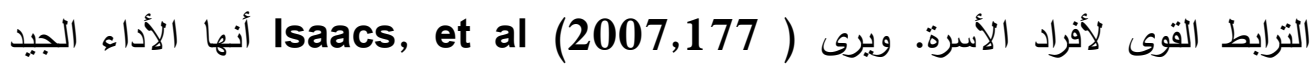




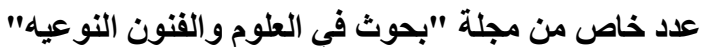

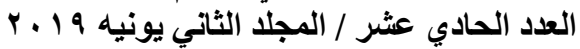

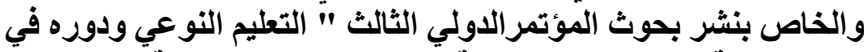

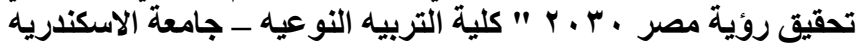

للوالدين أو السعادة الأسرية، ويعتبر الرضا والفرص المتاحة لزيادة دخل الأسرة أو فرص

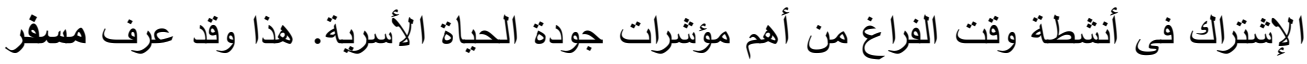

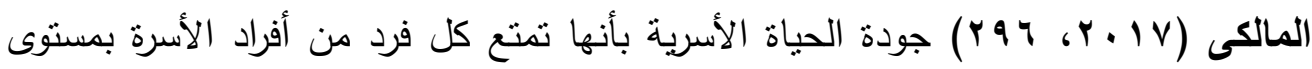
معتدل من الرضا والصحة النفسية وتقدير الذات وجودة العلاقات الإجتماعية, وشعور كل فرد من أفراد الأسرة بالرضا والسعادة والقدرة على اثباع حاجاته من خلال شعوره بالصحة العامة,

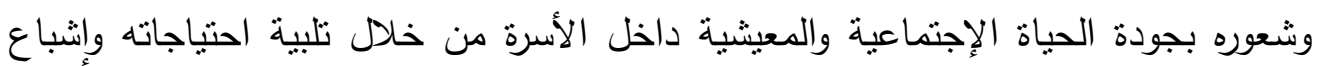

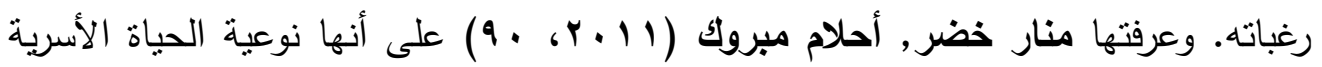

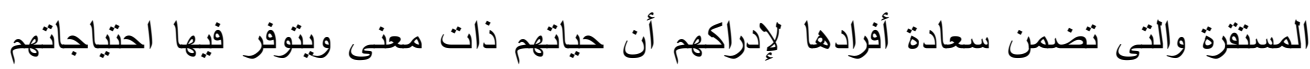
المختلفة، ويتحقق ذلك عن طريق التوافق بين الزوجين وقدرتهم على التواصل ومواجهة صعوبات الحياة معاً، وقدرة الزوجين على النجاح فى رعاية أبنائهم "بدنياً، نفسياً، إجتماعياً" لئل وقسمتها إلى جودة الحياة الزوجية والتى توضح طبيعة الحياة الزوجية ومدى استقرارها, جودة التهاة

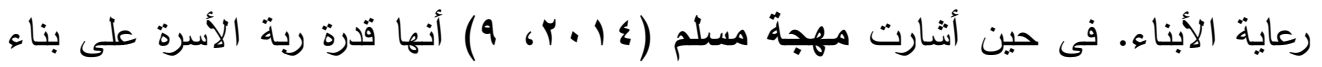
منظومة إدارية شاملة من أجل تحقيق حياة مثالية، وذللك من خلال السعى والتحقيق الدائم لأهداف أفراد الأسرة فى ضوء تطبيق معايير الجودة فى الحياة الأسرية والتى تشتمل على دلى (البعد الصحى - البعد الإقتصادى - البعد الإجتماعى - البعد النفسى). وأوضحت مليكة بن فئن

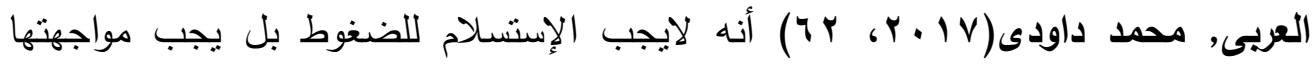

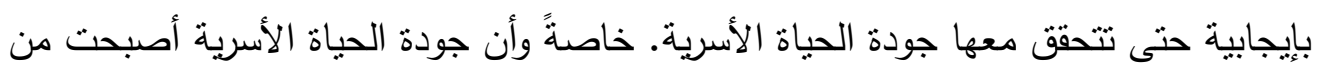
المتطلبات الأساسية للأفراد ولصحتهم النفسية فى ظل ما تتعرض لهاء له الأسرة من تحديات فى

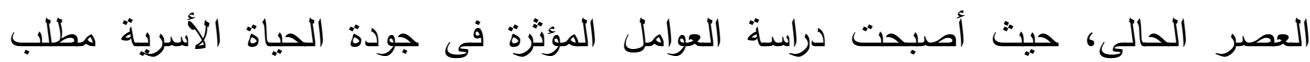
ضرورى، وعاجل، وهام يهدف لتحسين جودة حياة المجتمع بشكلٍ عام، وحياة الأسرة بوجٍٍ

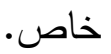


عدد خاص من مجلة "بحوث في العلوم والقنون النوعيه" العيه

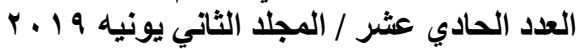

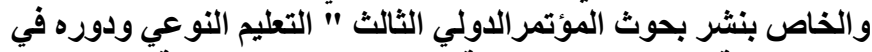

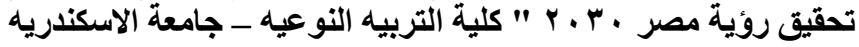

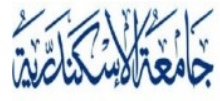

ALEXANDRIA

UN I VER S I T Y

Alexu Press

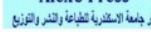

هذا وقد لاحظت الباحثتان أن الحياة وأحداثها وضغوطها يسيران جنباً إلى جنب؛ خاصةً وأن أحداث الحياة الضاغطة إحدى المظاهر الرئيسية التى يتصف بها عالمنا، فقد وصف كثير من الباحثين القرن الحالى بأنه عصر الضغوط؛ حيث تدل الإحصاءات الطبية التى نشرتها لبهاء منظمة الصحة العالمية فى تقريرها السنوى حول الوضع الصحى فى العالم إلى إرتقاع نسبة الإضطرابات الناتجة عن الضغوط، والظروف السلبية الأخرى وقد تراوحت النسبة مابين

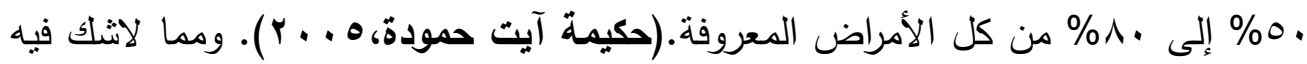

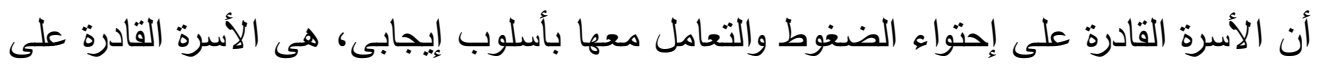

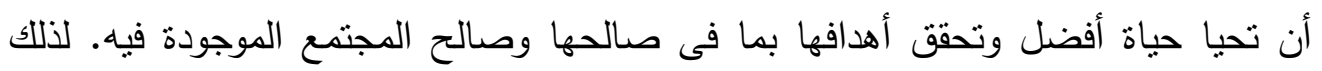
وجدت الباحثتان ضرورة دراسة العلاقة بين استراتيجيات المواجهة الإقدامية للضغوط لدى

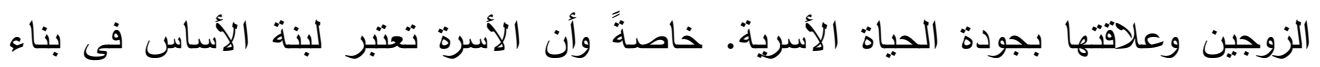
المجمعات؛ فقوة وضعف المجتمعات تُقاس بناءً على مدى قوة الأسرة أو ضعفها. فالأسرة الصالحة كالتربة الصالحة إن صلحت يصلح نباتها، وإن فسدت يفسد نباتها. والزوج والزوجة فلهاه هم عماد الأسرة فهم كالثجرة التى نظلل على أفرادها، والأبناء ماهم إلا ثمار لهذه الثجرة. ولكى تكون الثمار جيدة لايجب الإستسلام للضغوط بل مواجتها بإيجابية تتحقق معها جودة

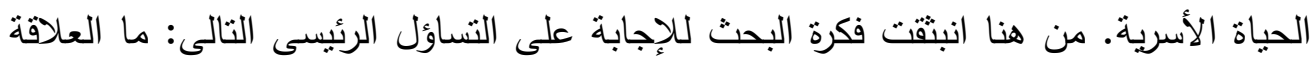
بين استراتيجيات المواجهة الإقدامية للضغوط ومحاورها (التحليل المنطقى للمواقف، إعادة التقييم الإيجابى، البحث عن المساعدة والمعلومات، استخدام أسلوب حل المشكلات)، والإجمالى، وجودة الحياة الأسرية بمحاورها (جودة الحياة الزوجية، جودة الحياة النفسية للأسرة،

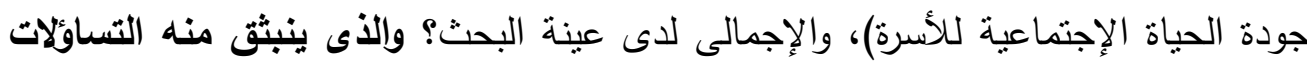

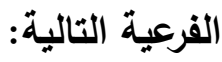
- ما مستوى كلٍ من استراتيجيات المواجهة الإقدامية للضغوط بمحاورها (التحليل المنطقى للمواقف، إعادة التقييم الإيجابى، البحث عن المساعدة والمعلومات، استخدام أسلوب حل 
عدد خاص من مجلة "بحوث في العلوم والقنون النوعيه" العزيه

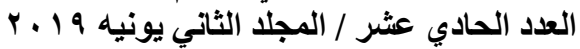

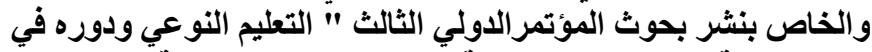

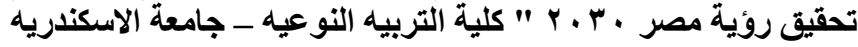

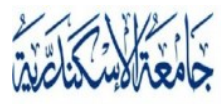

ALEXANDRIA

U N I VER S I T Y

المشكلات)، وكإجمالى, وجودة الحياة الأسرية بمحاورها (جودة الحياة الزوجية، جودة الحياة

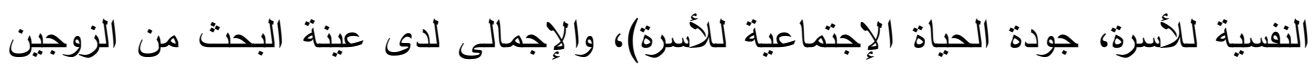

\section{والأوزان النسبية لهما؟}

- ما الفروق بين متوسطات درجات عينة البحث من الزوجين فى استراتيجيات المواجهة

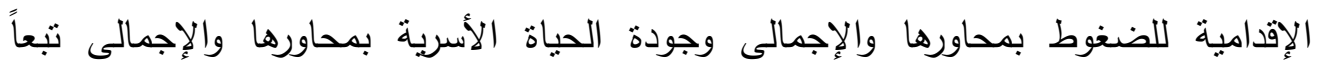

؟)

- ما الفروق بين متوسطات درجات العينة فى استراتيجيات المواجهة الإقدامية للضغوط

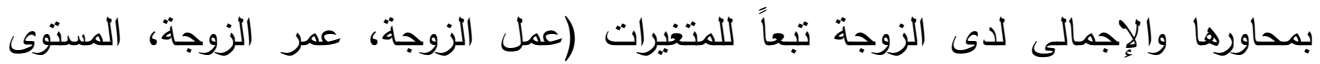

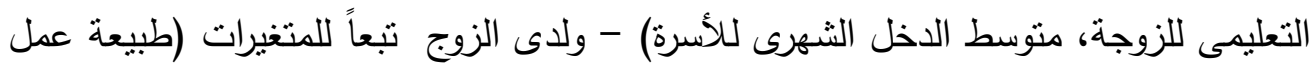
الزوج، عمر الزوج، المستوى التعليمى للزوج ، منوسط الدخل الثهرى للأسرة) ؟

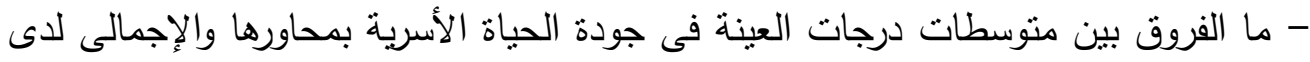

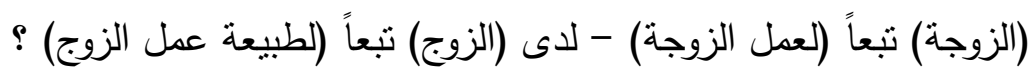

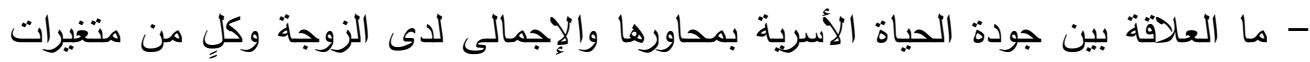
البحث (عمر الزوجة، المستوى التعليمى للزوجة، متوسط الدخل الثهرى للأسرة) - لدى الزوجه

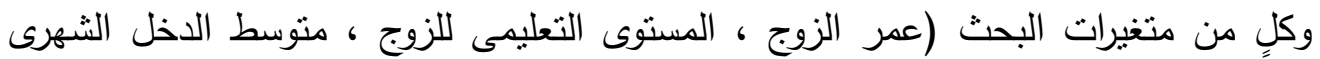
للأسرة) ؟ وكن من

- هل تختلف نسبة مشاركة المتغيرات المستقلة (استراتيجيات المواجهة الإقدامية للضغوط للزوجين) فى تفسير نسبة التباين على المتغير التابع (جودة الحياة الأسرية)؟ أهداف البحث: يهدف البحث الحالى الى التعرف على العلاقة بين استراتيجيات المواجهة الإقدامية للضغوط لدى الزوجين وجودة الحياة الأسرية من خلال: 1- تحديد مستوى كلٍ من استراتيجيات المواجهة الإقدامية للضغوط بمحاورها (التحليل المنطقى للمواقف، إعادة التقبيم الإيجابى، البحث عن المساعدة والمعلومات، استخدام أسلوب 
عدد خاص من مجلة "بحوث في العلوم والقنون النوعيه" العيه

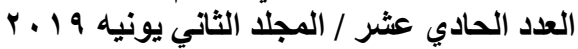

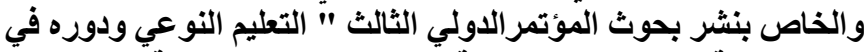

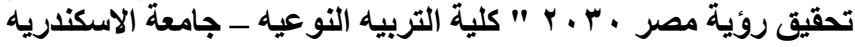

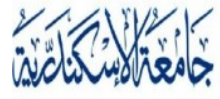

ALEXANDRIA

U N I VER S I T Y

حل المشكلات) والإجمالى, وجودة الحياة الأسرية بمحاورها (جودة الحياة الزوجية، جودة

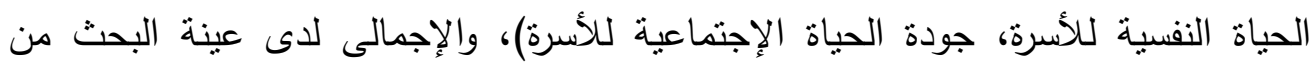

(الزوجين)، والأوزان النسبية لهما.

r- تحديد الفروق بين متوسطات درجات عينة البحث من (الزوجين) فى استراتيجيات

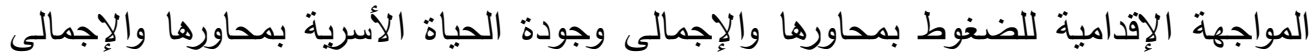
تبعاً (للنوع).

r- تحديد الفروق بين منوسطات درجات العينة فى استراتيجيات المواجهة الإقدامية للضغوط بمحاورها والإجمالى لدى الزوجة تبعاً للمتغيرات (عمل الزوجة، عمر الزوجة، المسنوى لينه

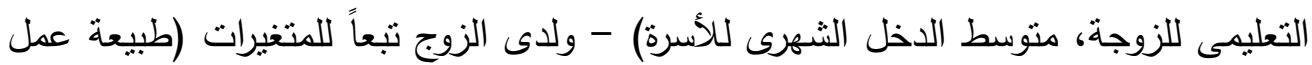
الزوج، عمر الزوج، المستوى التعليمى للزوج ، متوسط الدخل الثهرى للأسرة).

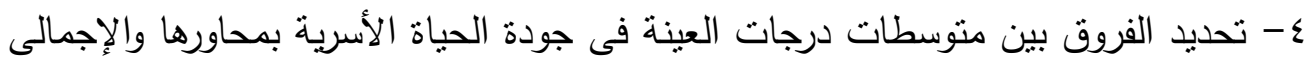

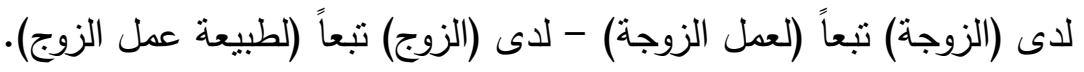

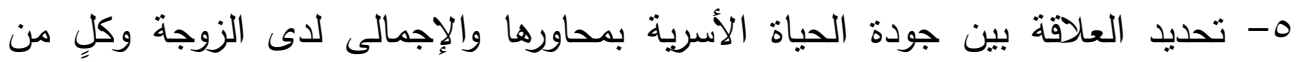
متغيرات البحث (عمر الزوجة ، المستوى التعليمى للزوجة، متوسط الدخل الثهرى للأسرة) لدى الزوج وكلٍ من متغيرات البحث (عمر الزوج ، المستوى التعليمى للزوج ، متوسط الدخل الثهرى للأسرة).

צ- تحديد نسبة مشاركة المتغيرات المستقلة (استراتيجيات المواجهة الإقدامية للضغوط لدى الزوجين) فى تفسير نسبة التباين على المتغير التابع (جودة الحياة الأسرية). أهمية البحث: الأهمية النظرية : النيز ا- إلقاء الضوء على استراتيجيات المواجهة الإقدامية للضغوط والتى تُعد بمثابة عوامل

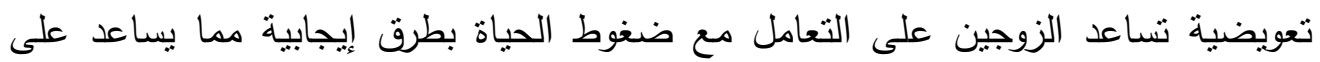
تحقيق جودة الحياة الأسرية . 
r - أصبحت الجودة هدفاً للاراسة والبحث بإعنبارها حاجة وطموح كل البشر، وخاصةً جودة الحياة الأسرية التى تعتبر الهدف الأسمى لتحقيق توافق نفسى، واجتماعى للأبناء للوصول إلى لي

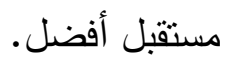

r- لم بعد النظر إلى جودة الحياة الأسرية على أنها مجرد لقمة العيش ولاغطاء بستر الجسد؛ بل ولم تعد تقتصر على تذليل الصعاب والتصدى للعقبات فقط؛ بل صارت تتطلع إلى تتمية النواحى الإيجابية؛ فأصبحت تعنى تطلع الأسرة للرفاهية فى مختلف المجالات .

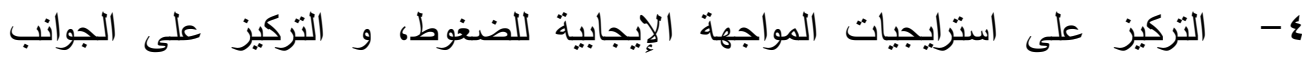
الإيجابية فى الثخصية؛ تلك التى تدعم وتزيد من ثقة الفرد بذاته، والتى يتوجه إليها

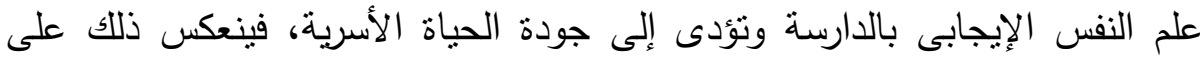

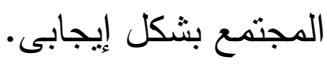

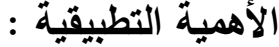

1 - قد تسهم الدراسة فى العمل على إزالة معوقات جودة الحياة الأسرية أو تخفيضها وتوجيه الأزواج،

والزوجات نحو الأسلوب الأمنل لمواجهة الضغوط لتحقيق جودة الحياة الأسرية. r- قد تفيد نتائج البحث الحالى فى إعداد برامج تدريبية (وقائية وعلاجية) تهدف إلى اكساب

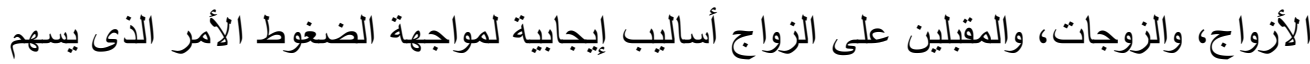
فى التكيف مع أحداث الحياة الضاغطة مما يؤدى إلى جودة الحياة الأسرية. فروض البحث:

1- توجد علاقة ارتباطية دالة إحصائياً بين استراتيجيات المواجهة الإقدامية للضغوط بمحاورها (التحليل المنطقى للمواقف، إعادة التقييم الإيجابى، البحث عن المساعدة والمعلومات، استخدام أسلوب حل المشكلات)، والإجمالى، وجودة الحياة الأسرية بمحاورها 
(جودة الحياة الزوجية، جودة الحياة النفسية للأسرة، جودة الحياة الإجتماعية للأسرة) والإجمالى لاى عينة البحث من (الزوجين).

r- - توجد فروق بين منوسطات درجات عينة البحث من (الزوجين) فى استراتيجيات المواجهة الإقدامية للضغوط بمحاورها والإجمالى وجودة الحياة الاسرية بمحاورها والاجمالى

$$
\text { تبعاً (للنوع). }
$$

r- توجد فروق بين متوسطات درجات العينة فى استراتيجيات المواجهة الإقدامية للضغوط

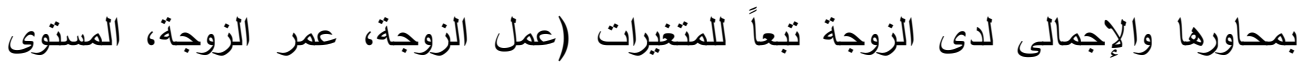

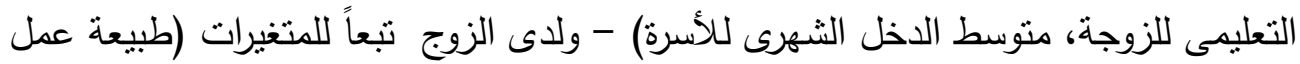
الزوج، عمر الزوج، المستوى التعليمى للزوج ، منوسط الدخل الثهرى للأسرة). ع - توجد فروق بين متوسطات درجات عينة البحث من (الزوجين) فى جودة الحياة الأسرية

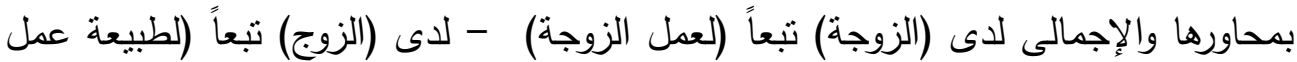

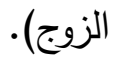
ه- نوجد علاقة ارتباطية دالة إحصائياً بين جودة الحياة الأسرية بمحاورها والإجمالى لدى الزوجة وكلٍ من متغيرات البحث (عمر الزوجة، المستوى التعليمى للزوجة، متوسط الدخل

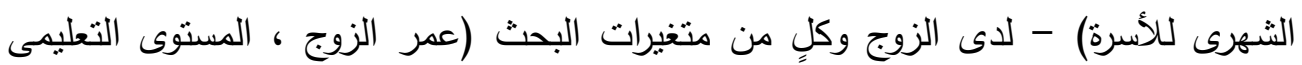
للزوج ، منوسط الاخل الثهرى للأسرة).

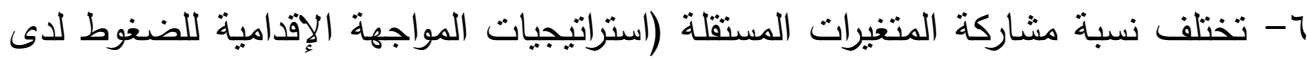
الزوجين) فى تفسير نسبة التباين على المتغير التابع (جودة الحياة الأسرية).

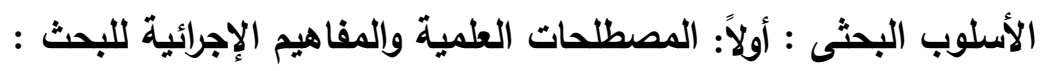

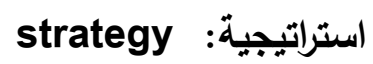

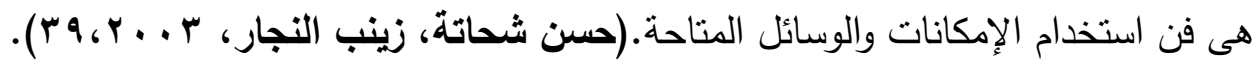


استراتيجيات المواجهة: Strategies of confrontation هى الأساليب التي يواجه بها الفرد أحداث الحياة اليومية الضاغطة، والتى تتوقف مقوماتها الإيجابية والسلبية نحو الإقدام والإحجام طبقاً لقدرات الفرد، وإطاره المرجعى للسلوك، ومهاراته فى تحمل أحداث الحياة اليومية الضاغطة، وطبقاً لإستجابته التكيفية نحو مواجهة هذه الأحداث دون آنار سلبية

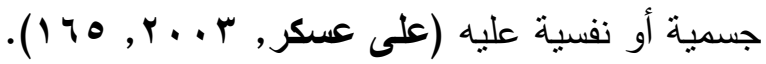

الإقدام: Progressive يشير إلى السلوكيات التى يعتقد الثخص أنها نتيح له التعامل بشكل مباشر مع المشكلة (طه حسين ، سلامة حسين، 7 ، . ب , ع ^). استراتيجيات المواجهة الإقدامية للضغوط:

\section{Strategies for the progressive confrontation of pressures:}

هى أساليب يوظفها الفرد فى مواجهة الحدث الضاغط وتجاوز آثاره السلبية على الفرد الجسمية أو النفسية، والأفراد ذوى المواجهة الإقدامية عندما يواجهون أزمة أو موقفاً ضاغطاً، فإنهم يستخدمون أسلوبين معرفيين وهما التحليل المنطقى هو محاولات معرفية للفهم والتهيؤ الذهنى للمواقف الضاغطة ومترتباتها، أى التعامل مع المشكلات معرفياً. وإعادة التقييم الإيجابى هو محاولة معرفية لبناء أو لإعادة بناء المشكلات بطريقة إيجابية مع استمرارية ثقبل

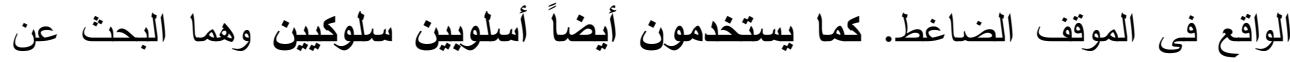
المساعدة والمعلومات وهى محاولات سلوكية للبحث عن المساعدة والمعلومات والإرشاد، أو لهري الحصول على الدعم، وأسلوب حل المشكلات و هو محاولات سلوكية للقيام بعمل ما للتعامل

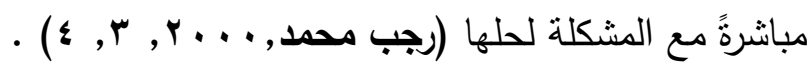

وتعرف الباحثتان استراتيجيات المواجهة الإقدامية للضغوط إجرائياً: على أنها الأساليب المعرفية، والسلوكية التى بستخدمها الزوجان بهذف التحكم فى المواقف الحياتية الضاغطة أو الو الهران التخفيف من آثارها فيستطيعان اقتحام المشاكل والمواقف الضاغطة وتجاوز آثارها وذللك عن 
التحليل المنطقى للمواقف: Logical Analysis of Attitudes يشير إلى قدرة الزوجين على التفكير فى الموقف الضاغط بموضوعية وواقعية، والنظر إلى كل مايحيط بالمواقف الضاغطة والتفكير فى عواقب النتائج، ووضع حلول متعددة لمواجهة المواقف الضاغطة. إعادة التقييم الإيجابى: Positive reassessment يشير إلى قدرة الزوجين على التفكير فى المواقف الضاغطة بصورة إيجابية والتى تمكنهم من تجاوزها بإحساسهم أنهم

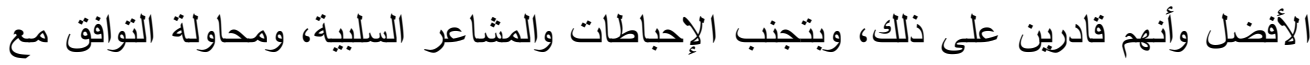

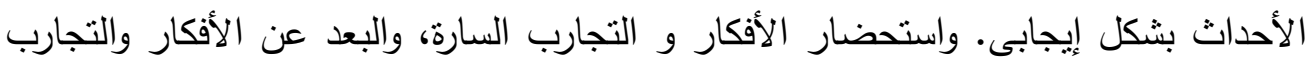

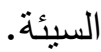

البحث عن المساعدة والمعلومات: Search for help and information يشير إلى قدرة الزوجين على الحصول على مزيد من المعلومات بخصوص الموقف الضاغط والعمل

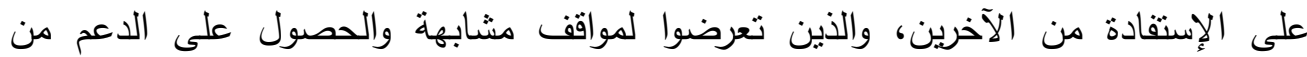

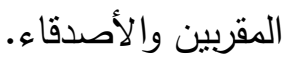
استخدام أسلوب حل المشكلات: Use the problem-solving method يشير إلى قدرة الزوجين على المواجهة الفعالة للمواقف الضاغطة، وبذل الجهر والتعامل معها بصورة ملموسة؛ للتحكم فيها وذلك من خلال القيام ببعض السلوكيات والتى من شأنها التعامل مباشرةً مع المشكلة، واستتباط أفكار ، وحلول مبتكرة لمواجهة الضغوط. جودة الحياة الأسرية: Quality of family life هى شعور كل فرد داخل الأسرة بالرضا، والسعادة، والقدرة على اثباع حاجاته من خلال شعوره بالصحة العامة، وشعوره بجودة الحياة

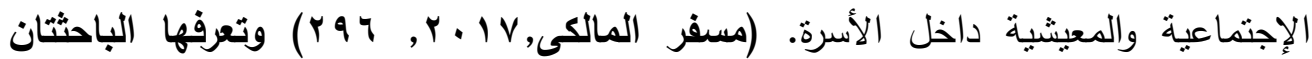
إجرائياً على أنها ق قدرة وكفاءة الأسرة على مواجهة مشكلاتها، وتمتع أفرادها بحياتهم كأسرة يسودها جو من التفاعل، والرضا، والسعادة، والحفاظ على نوعية معينة لحياة الأفراد فى الأسرة يسودها جودة الحياة الزوجية, والنفسية, والإجتماعية.

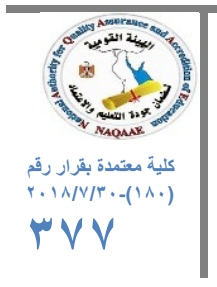

203/5454313 : شارع محمد أمين شهيب ـ مصطفى كامل ـ الاسكندريه ـ مصر تليفون

Alexandria - Egypt, Tel. : 203/5454313 - 203/5442776 Fax :203/5442776

E-mail : journal.edusp@alexu.edu.eg Web site: RSSA.edusp@lexu.edu.eg 
أ- جودة الحياة الزوجية: Quality of married life يقصد بها التوافق والسعادة فى الحياة الزوجية التى يعيشها الزوجين والتى تتميز بالمؤشرات التالية: التفاعل الزواجى، التوافق

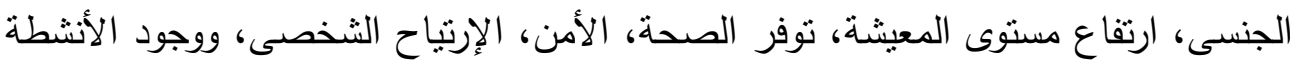

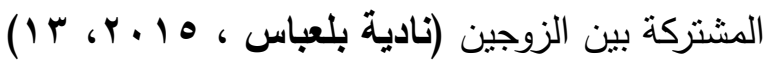
وتعرف الباحثتان جودة العياة الزوجية: على أنها تقدير الزوجين لبعضهما البعض, وحسن

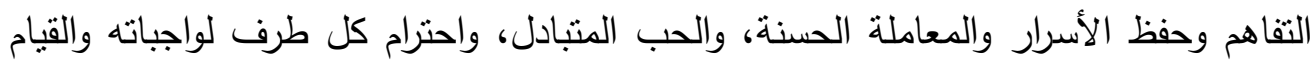
بها على أكمل وجه، والمشاركة وتقسيم المسؤليات.

ب- جودة الحياة النفسية: Quality of Life هى حالة كلية ذاتية توجد عندما ينوازن داخل الثخص مدى واسع من المشاعر منها الحيوية والإقبال على الحياة، الثقة فى الذات، دهاته الصراحة والأمانة مع الذات ومع الآخرين، البهجة والمرح، السعادة، الهدوء، والإهتمام

بالآخرين (Stewart-Brown,2000, 35) وعرفت مهجة مسلم (ـ ا ب r, q) البعد النفسى كأحد أبعاد جودة الحياة الأسرية على أنه: رضا الأسرة عن حالتها النفسية والتمتع بإتجاه مستقر مع خلوها من الإضطرابات النفسية من النه

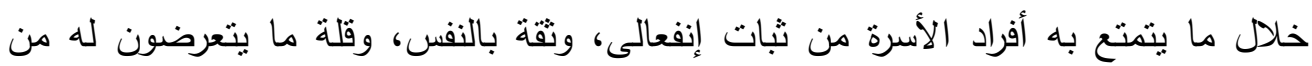
إحباطات وصراعات، ويشمل الإدراك والحاجات النفسية، إضافة الى القيم والطموح وتقدير باته

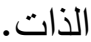

وتعرف الباحثتنان جودة الحياة النفسية للأسرة: على أنها إحساس عام بالسعادة الأسرية

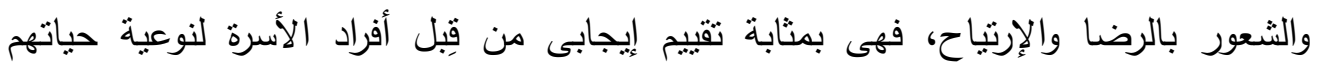
الأسرية، والثعور بحسن سير الأمور الأسرية، والبعد عن المشاعر السلبية المرتبطة بالمعاناة

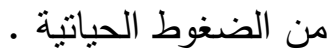
ج- جودة الحياة الإجتماعية: Quality of social life هى قدرة الفرد على تكوين علاقات إجتماعية والمشاركة الفعالة فى الأنشطة الإجتماعية مع احترام مبادىه، وقيم 


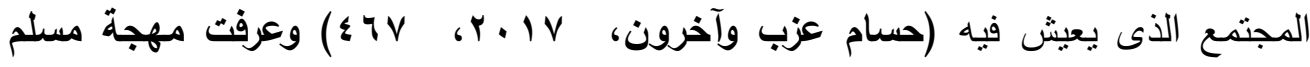

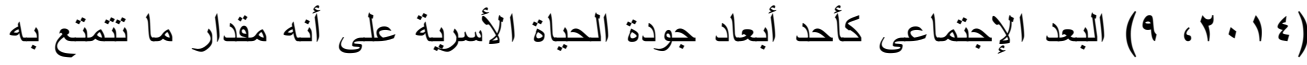

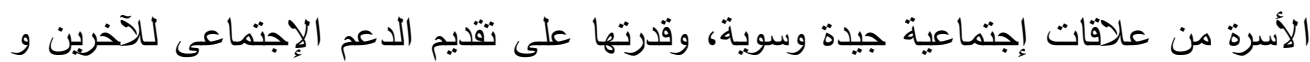

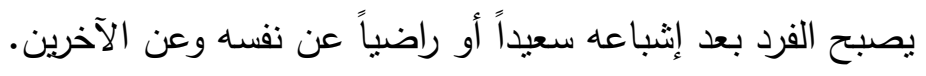
وتعرف الباحثتنان جودة الحياة الإجتماعية للأسرة: على أنها مقدار ما تتمتع به الأسرة من التهنين تفاعل اجتماعى فى محيطها الداخلى، بالإضافة إلى ما تتمتع به الأسرة من القدرة على إقامة علاقات اجتماعية سوية مع الأصدقاء والأقارب والجيران.

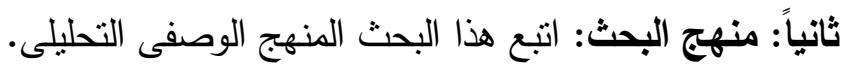
ثالثا: حدود البحث: تمثلت حدود البحث فى الآتى:

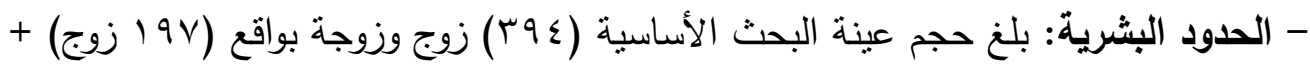

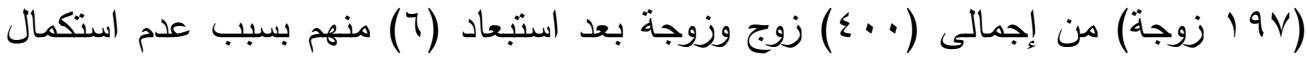
الإستجابات على بنود الإستبيان أوتضاربها، أو لعدم استتفاء الشروط إنهاء بعاء الخاصة بالأسرة، تم اختيارهم بطريقة عمدية غرضية من مستويات اجتماعية واقتصادية مختلفة، وتراوحت أعمارهم

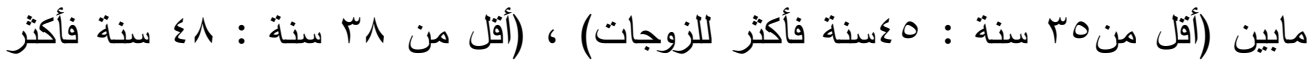
لكلزأزاج) - العدود المكانية: اختيرت العينة من المدن التالية(ميث غمر، أجا، والمنصورة) بمحافظة

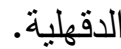
- الحدود الزمنية: نم التطبيق الميدانى لأدوات البحث فى صورتها النهائية بداية من منتصف

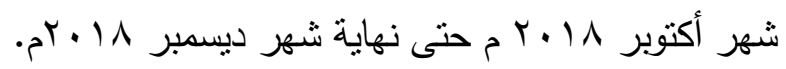
رابعاً: إعداد ويناء أدوات البحث وتقتينها: اشتملت الأدوات المستخدمة فى هذه الدراسة وفى دهى ضوء الأهداف البحثية على ما يلى: 
- استمارة البيانات العامة تم إعداد استمارة البيانات العامة بهذف الحصول على بعض الدعلومات التى تفيد الدراسة عن أنواع الضغوط التى تتعرض إليها عينة البحث، (النوع، مكان السكن، عمر الزوجين، المستوى التعليمى للزوجين، عمل الزوجة، طبيعة عمل الزوج، منوسط الاخل الثهرى للأسرة).

- - استبيانى استراتيجيات المواجهة الإقدامية للضغوط بمحاوره، وجودة الحياة الأسرية بمحاورها: (يجيب عليهما الزوج والزوجة) نم تقسيم مستوى (الإستنيانين ككل) إلى مستوى التى (منخفض- متوسط- مرتفع) إلى مستوى (منخفض- منوسط- مرتفع) من خلال حساب المدى وأبعاده تبعاً للبيانات المشاهدة نتيجة تطبيق الإستيان من المعادلات الآتية: المدى=

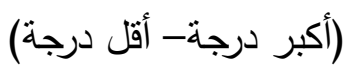
طول الفئة= [(المدى + (1)/ ب] وعليه تم تقسيم الإستجابات إلى ثلاث درجات للأداء كالتالى: مستوى منخفض: من أقل درجة إلى > (أقل درجة + طول الفئة)

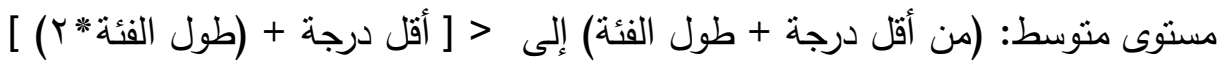

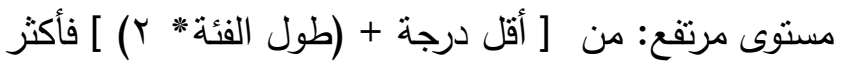
- أولاً: إستبيان استراتيجيات المواجهة الإقدامية للضغوط: تم إعداد الإستبيان فى ضوء الدراسات السابقة والتعريف الإجرائى لإستراتيجيات المواجهة الإقدامية للضغوط، وقد تحددت إستجابات عينة البحث وفق ثلاث استجابات (دائماً) ثلاث درجات، (أحياناً) درجتان، (نادراً) درجة واحدة، للعبارات الإيجابية، والعكس صحيح للعبارات السلبية واشتمل الإسنتيان فى لئه

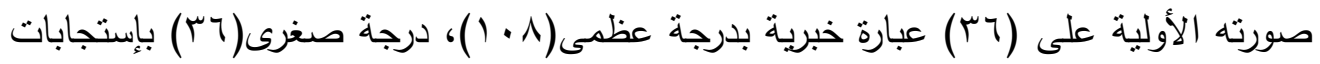

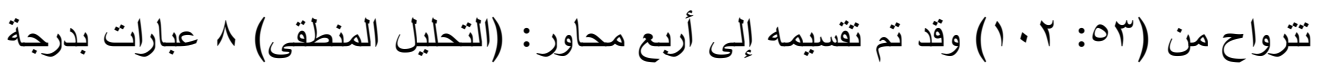
عظمى (Y乏) ودرجة صغرى (^) بإستجابات تترواح من (Y:9)، (Y)، (إعادة التقييم الإيجابى)

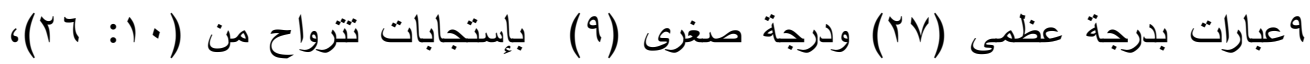
(البحث عن المساعدة والمعلومات) 9 عبارات بدرجة عظمى (YV) ودرجة صغرى (9) (9) 


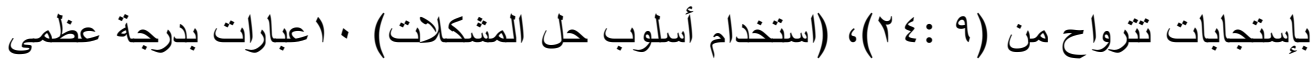

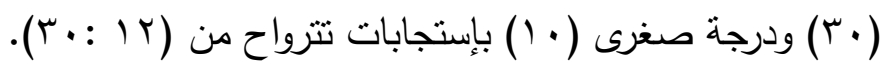

- ثانيا إستبيان جودة الحياة الأسرية: تم إعداد هذا الإسنتيان فى ضوء الدراسات السابقة والتعريف الإجرائى، وقد تحددت إستجابات عينة البحث وفق ثلاث استجابات (دائماً) ثلاث درجات، (أحياناً) درجتان، (نادراً) درجة واحدة، للعبارات الإيجابية، والعكس صحيح للعبارات

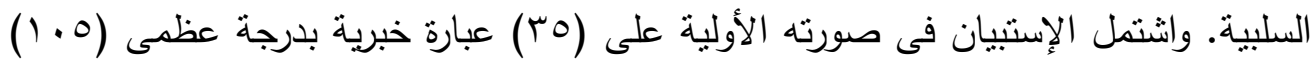

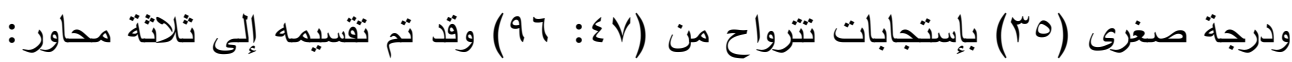

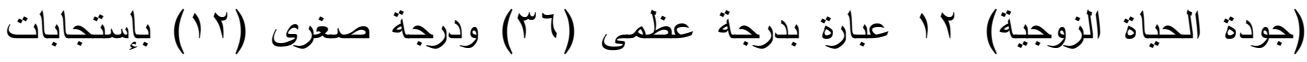

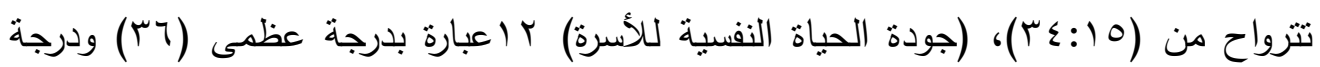

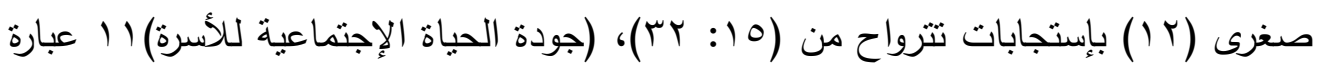

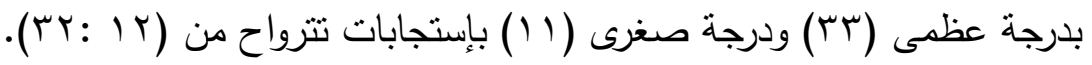

\section{تقنين الإستبيان: أولاً: حساب صدق الإستبيان:}

(أ)- صدق المحتوى (validity content): للتأكد من صدق محتوى المقياس نم عرضسه

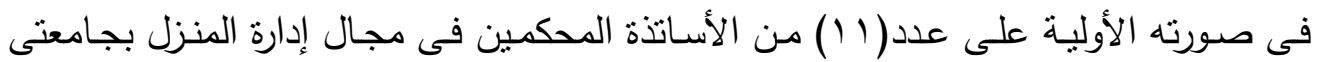

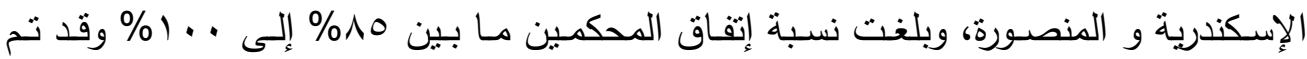
إجراء بعض التعديلات لبعض العبارات، وظل المجموع الكلى للعبارات كما هو ، وبذللك يكون قد خضع لصدق المحتوى. (ب) - صدق الإتساق الداخلى : 
عدد خاص من مجلة "بحوث في العلوم والقنون النوعيه" التونيه

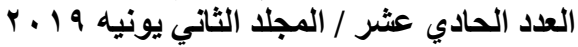

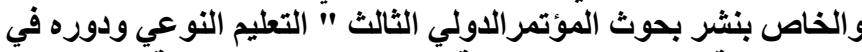

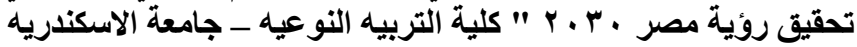

جدول (1) معاملات الإرتباط بين كل عبارة واللارجة الكلية لإستبيان

استراتيجيات المواجهة الإقدامية للضغوط ن= ( • (r)

\begin{tabular}{|c|c|c|c|c|c|c|c|}
\hline \multicolumn{2}{|c|}{ استخدام أسلوب حل المشكلات } & \multicolumn{2}{|c|}{ البحث عن المساعدة والمعلومات } & \multicolumn{2}{|c|}{ إعادة التقييم الإيجابى } & \multicolumn{2}{|c|}{ التحليل المنطقى } \\
\hline معامل الإرتباط & 5 & معامل الإرتباط & r & 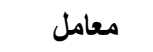 & b & 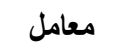 & م \\
\hline$" .7 \vee 4$ & 1 & $" .009$ & 1 & $" .017$ & 1 & " ".074 & 1 \\
\hline " & $r$ & $" .790$ & $r$ & $" 0 \leqslant r$ & r & " "VRr & $r$ \\
\hline .7 .1 & $r$ & " & $r$ & .779 & $r$ & "* . & $r$ \\
\hline$" .74 r$ & $\varepsilon$ & .780 & $\varepsilon$ & .297 & $\varepsilon$ & $" . \wedge .7$ & $\varepsilon$ \\
\hline .740 & 0 & $.0 \leq 9$ & $\bullet$ & $" .74 \Lambda$ & 0 & $" .07 \mathrm{~V}$ & 0 \\
\hline$\Rightarrow v r q$ & 7 &. $.0 \wedge V$ & 7 & ".vVr & 7 & $" .001$ & 7 \\
\hline ".* $.7 r V$ & $\mathrm{v}$ &. & 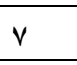 & ". . V V & $v$ & ".orr & 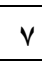 \\
\hline$" v \leq 0$ & $\wedge$ & "vor & $\wedge$ & ".MY & $\wedge$ & " $.00 \%$ & $\wedge$ \\
\hline ..$\leqslant \mu$ & 9 & " "ז. & 9 & ".TV. & 9 & & \\
\hline$" .079$ & 1. & & & & & & \\
\hline
\end{tabular}

يتضح من نتائج جدول (1) أن قيم معامل الإرتباط بين درجة كل عبارة من عبارات

استراتيجيات المواجهة الإقدامية للضغوط والدرجة الكلية لكل محور كانت دالة إحصائياً وقد

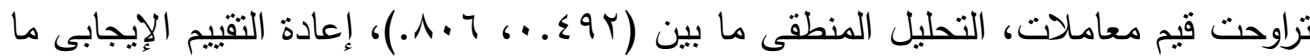

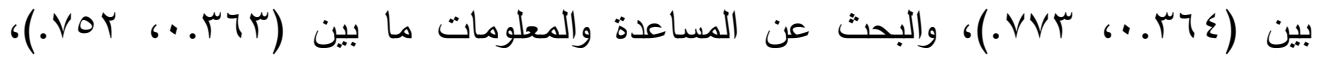

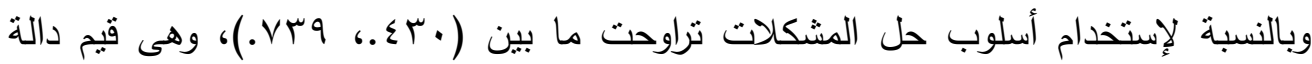

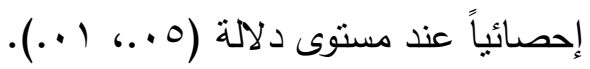


عدد خاص من مجلة "بحوث في العلوم والقنون النوعيه" التونيه

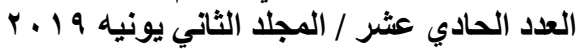

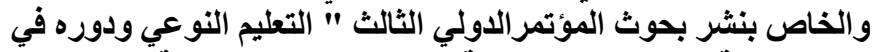

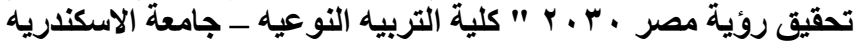

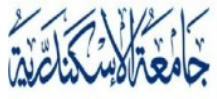

ALEXANDRIA

U N I V E R S I T Y

AlexU Press

(1)

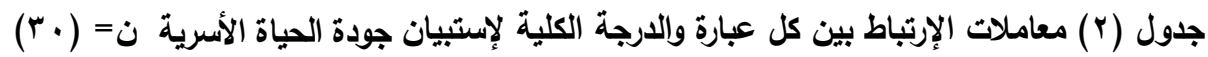

\begin{tabular}{|c|c|c|c|c|c|}
\hline \multicolumn{2}{|c|}{ جودة الحياة الإجتماعية للأسرة } & \multicolumn{2}{|c|}{ جودة الحياة النفسية للأسرة } & \multicolumn{2}{|c|}{ جودة الحياة الزوجية } \\
\hline معامل الإرتباط & b & معامل الإرتباط & م & معامل الإرتباط & b \\
\hline$* * . \varepsilon V Y$ & 1 & $* * .0 \leq \varepsilon$ & 1 & $* * . V \circ r$ & 1 \\
\hline$* * . \vee q$. & $r$ & $* * .71 \%$ & r & $* * .7 \vee r$ & $r$ \\
\hline$* * .77 r$ & $r$ & $* * .771$ & $r$ & $* * .7 \mu r$ & $r$ \\
\hline$* * .717$ & $\varepsilon$ & $* . \leqslant \diamond V$ & $\varepsilon$ & **.orr & $\varepsilon$ \\
\hline$* * .7 \mu r$ & 0 & $* * .0, V$ & 0 & $* * . \vee \leq 9$ & 0 \\
\hline$* * .777$ & 7 & $* * . \vee \wedge \varepsilon$ & 7 & $* * . \wedge \wedge \wedge$ & 7 \\
\hline$* * .7 \wedge r$ & V & $* * .0 \leq V$ & $V$ & $* * . \vee \wedge \wedge$ & V \\
\hline$* * . V V Y$ & $\Lambda$ & $* . M \vee q$ & $\Lambda$ & $* * . \wedge \bullet$. & $\Lambda$ \\
\hline$* * .000$ & 9 & $* * .71 \%$ & 9 & $* * . V$. & 9 \\
\hline$* * . V 1 \varepsilon$ & 1. & $* . \leqslant \diamond V$ & 1. & $* * . \vee \vee q$ & 1. \\
\hline$* . \varepsilon \cdot \Lambda$ & 11 & $* * .7 \% \Lambda$ & 11 & $* * . \vee 7$. & 11 \\
\hline & & $* * .779$ & Ir & $* * . V 1$. & Ir \\
\hline
\end{tabular}

يتضح من نتائج جدول (Y) أن قيم معامل الإرنباط بين درجة كل عبارة من جودة

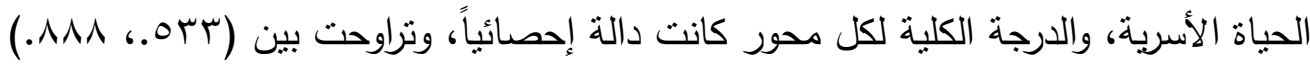
لجودة الحياة الزوجية، وتراوحت بين(TVr. ، 979 7.) لجودة الحياة النفسية للأسرة، و ما بين( (1 . ع... • و ..) لجودة الحياة الإجتماعية للأسرة وهى قيم دالة إحصائياً عند مستوى دلالة $\cdot(.+1,6.0)$

(ج) الصدق البنائى: يتم فيه النأكد من صدق أداة البحث بإستخدام طريقة حساب معامل الإرتباط بين الدرجة الكلية للإستبيان والمحاور المكونة له.

؛ أشارع محمد أمين شهيب ـ مصطفى كامل ـ الاسكندريه ـ مصر تليفون : 203/5454313 : 203/5454313

Alexandria - Egypt, Tel. : 203/5454313 - 203/5442776 Fax :203/5442776

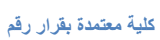

E-mail : journal.edusp@alexu.edu.eg Web site: RSSA.edusp@lexu.edu.eg

$\mu \wedge$ 
جدول(ب) قيم معاملات الإرتباط بين الدرجة الكلية لكل محور والدرجة الكلية لإستبيانى

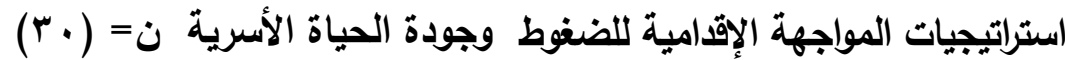

\begin{tabular}{|c|c|c|c|c|}
\hline مستوى الدلالة & معامل الإرتباط & عدد العبارات & المحاور & الإستبيان \\
\hline .1 & $* * . \vee \vee \leqslant$ & $\wedge$ & التحليل المنطقى & \multirow{4}{*}{ المواجهة الإقِّاتية } \\
\hline .1 & $* * . \wedge 9 \%$ & 9 & إعادة التقيمٍ الإيجابى & \\
\hline .1 & $* * .9 \cdot 1$ & 9 & البحث عن المساعدة والمعلومات & \\
\hline .1 & $* * . \wedge r$. & 1. & استخدام أسلوب حل المشكلات & \\
\hline .1 & $* * .91 \leq$ & ir & جودة الحياة الزوجية & \multirow{3}{*}{ جودة الحياة الأسرية } \\
\hline .1 & $* * . \vee \vee$. & ir & جودة الحياة النفسية للأسرة & \\
\hline .1 & $* * . \wedge \vee v$ & 11 & جودة الحياة الإجتماعية للأسرة & \\
\hline
\end{tabular}

يتضح من نتائج جدول (ץ) أن معاملات الإرتباط لمحاور استراتيجيات المواجهة الإقدامية

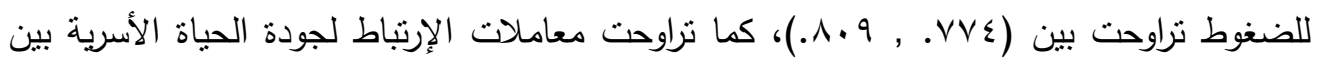

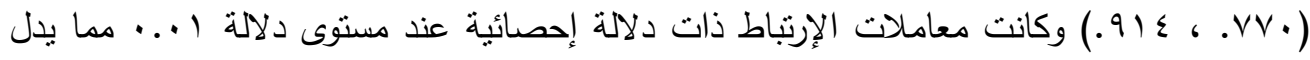
على تجانس محاور الإستيان والدرجة الكلية له ويسمح للباحثنان بإستخدامه فى بحثنهما الحالى.

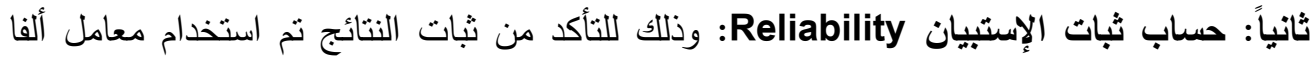
كرونباخ Alpha-Cronbach لحساب معامل الثبات: 
عدد خاص من مجلة "بحوث في العلوم والقنون النوعيه" التونيه

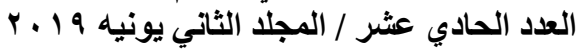

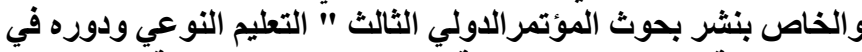

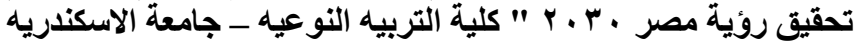

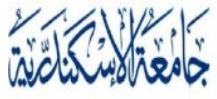
ALEXANDRIA

جدول (ء) قيم معامل الثبات لإستبيان استراتيجيات المواجهة الإقدامية للضغوط واستبيان جودة

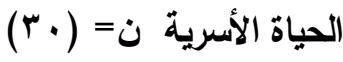

\begin{tabular}{|c|c|c|c|c|c|}
\hline جتمان & سبيرمان & معامل ألفا & عدد العبارات & المحاور & الإستبيان \\
\hline$\cdot V \leq$ & $\cdot . V \leq 4$ & $\cdot . V \leqslant \Lambda$ & $\wedge$ & التحليل المنطقى & \multirow{5}{*}{ اللتراتيجيات الإقدامية } \\
\hline$\cdot . \Lambda \cdot \vee$ & $\cdot . \wedge r \Delta$ & $\cdot .241$ & 9 & إعادة التقييم الإيجابى & \\
\hline$\cdot . \wedge \leq 1$ & $\cdot . \wedge \leq r$ & $\cdot$.vor & 9 & البحث عن المساعدة والمعلومات & \\
\hline - .9 $9 \leq \varepsilon$ & $\cdot .9 \leq 7$ & - .Arr & 1. & استخدام أسلوب حل المشكلات & \\
\hline - .9rq & $\cdot .9+9$ & $\cdot .917$ & $r$ & الإجمالى & \\
\hline$\cdot .90 \mathrm{~V}$ & $\cdot .901$ & $\because 9 r r$ & ir & جودة الحياة الزوجية & \multirow{4}{*}{ جودة الحياة } \\
\hline$\cdot . V 7 r$ & $\cdot . \vee 4 \varepsilon$ & $\cdot .^{\wedge}$ & Ir & جودة الحياة النفسية للأسرة & \\
\hline$\cdot . \wedge 91$ & $\cdot . \wedge 9 r$ & $\cdot . \wedge \leq \leq$ & 11 & جودة الحياة الإجتماعية للأسرة & \\
\hline$\cdot .901$ & $\cdot .909$ & $\cdot .9+\varepsilon$ & ro & الإجمالى & \\
\hline
\end{tabular}

يتضح من نتائج جدول (؛) أن قيم معاملات ثبات ألفا لمحاور استراتيجيات المواجهة

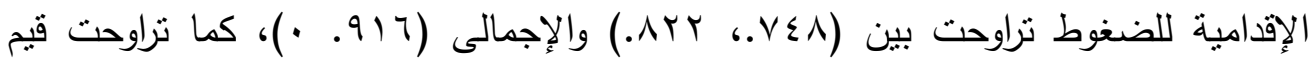

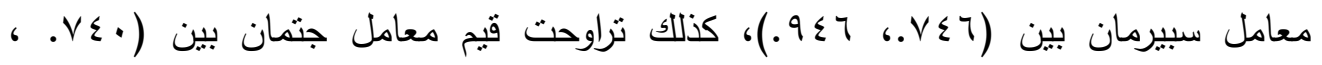

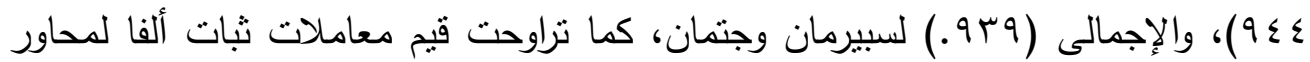

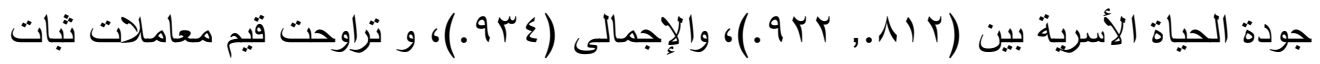

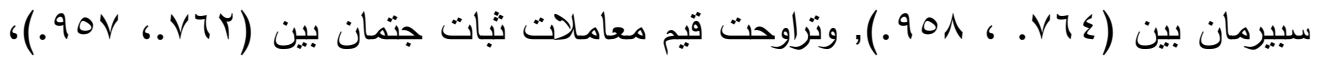

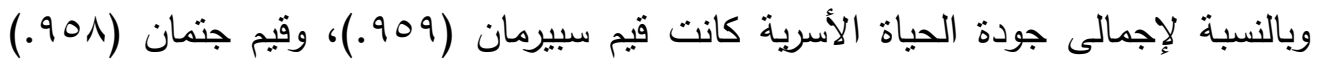
وهى قيم مرتفعة مما يؤكد ثبات الإستبيان وصلاحيته للنطبيق فى البحث الحالى. الأساليب الإحصائية المستخدمة: تم تحليل البيانات وإجراء المعالجات الإحصائية بإستخدام برنامج (Spss) وفيما يلى بعض الأساليب الإحصائية المستحدمة لكثف العلاقة بين متغيرات البحث واختبار صحة الفروض: العدد والنسب المئوية، والمتوسطات الحسابية والإنحراف المعيارى، معاملات الثبات- معامل ارتباط بيرسون Pearson- مربع كاى , Oئس

\section{T-test ,One Way Anova}

ع أشارع محمد أمين شهيب - مصطفى كامل ـ الاسكندريه ـ مصر تليفون : 203/5454313

Alexandria - Egypt, Tel. : 203/5454313 - 203/5442776 Fax :203/5442776

كلية معنمدة بقر ار رقم

E-mail : journal.edusp@alexu.edu.eg Web site: RSSA.edusp@lexu.edu.eg

H人 
عدد خاص من مجلة "بحوث في العلوم والقنون النوعيه" التونيه

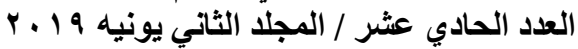

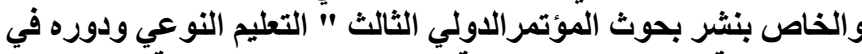

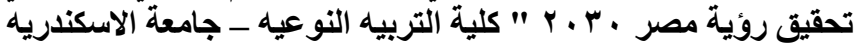

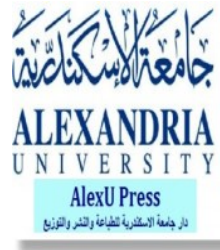

نتائج البحث:

أولاً: نتائج خصائص العينة: وصف المتغيرات المتعلقة بخصائص عينة البحث:

جدول (0) التوزيع النسبي للعينة وفقاً للخصائص الإجتماعية والإقتصادية

\begin{tabular}{|c|c|c|c|c|c|}
\hline$\%$ & العدد & عمل الزوجة & $\%$ & العدد & النوع \\
\hline$\varepsilon r . Y$ & $\Lambda V$ & تعمل & $0 \cdot$. & $19 V$ & زوج \\
\hline 00.1 & 11. & لا تعمل & $0 \cdot$. & $19 V$ & زوجة \\
\hline $1 \ldots$ & $19 V$ & الإجمالى & $1 \ldots$ & rqq & الإجمالى \\
\hline$\%$ & العدد & عمر الزوجة & $\%$ & العدد & طبيعة عمل الزوج \\
\hline$r \cdot .0$ & 7. & أقل من • & $\varepsilon 0 . V$ & 9. & عمل حكومى \\
\hline rr.. & 70 & من & $0 \leq . \mu$ & $1 \cdot v$ & عمل حر \\
\hline 19.0 & Vr & من 0 ؛ سنة فأكثر & \multirow{2}{*}{$1 \cdots$} & \multirow{2}{*}{198} & \multirow{2}{*}{ الإجمالى } \\
\hline $1 \ldots$ & $19 V$ & الإجمالىى & & & \\
\hline$\%$ & 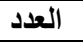 & المستوى التعليمى للزوجة & $\%$ & 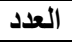 & عمر الزوج \\
\hline \multirow{2}{*}{ r. } & \multirow{2}{*}{$7 \varepsilon$} & \multirow{2}{*}{ مستوى تعليمى منخفض (دبلوم وما يعادلها) } & P7.9 & or & أقل من ^ب سنة \\
\hline & & & Mr.o & $7 \varepsilon$ & 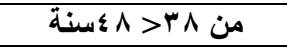 \\
\hline \multirow{2}{*}{ r^.l } & \multirow{2}{*}{ V० } & \multirow{2}{*}{ 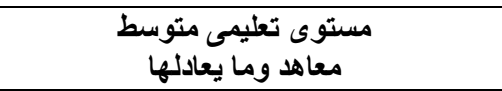 } & $\varepsilon \cdot .7$ & $\Lambda$. & من ^ § سنه فأكثر \\
\hline & & & $1 \ldots$ & $19 V$ & الإجمالى \\
\hline หq. & $\bullet \wedge$ & مستوى تعليمى مرتفع جامعى - فوق & $\%$ & العدد العد & المستوى التعليمى للزوج \\
\hline $1 \cdots$ & $19 \mathrm{~V}$ & الإجمالى & \multirow[t]{2}{*}{$r v . \varepsilon$} & \multirow{2}{*}{$0 \leq$} & \multirow{2}{*}{ 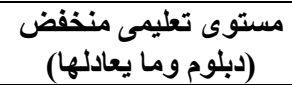 } \\
\hline$\%$ & العدد & مستوى الاخل الشهرى للاسرة & & & \\
\hline M. & 71 & دخل شهرى منخفض(> > . . . جنيه) & ro.o & V. & 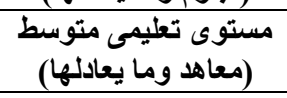 \\
\hline r.." & VI & 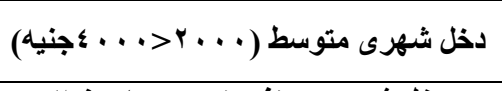 & MV.I & $v r$ & 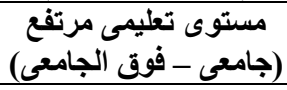 \\
\hline r.. & 70 & دخل شهرى مرتفع (> > . . ع جنيه) & \multirow{2}{*}{$1 \cdots$} & \multirow{2}{*}{$19 \mathrm{~V}$} & \multirow{2}{*}{ الإجمالى } \\
\hline $1 \cdots$ & $19 V$ & الإجمالّى & & & \\
\hline
\end{tabular}

يتضح من نتائج جدول (0) تساوى نسبة العينة من الزوجين بواقع ...٪\% أزواج ,

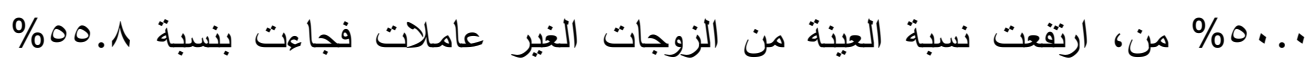

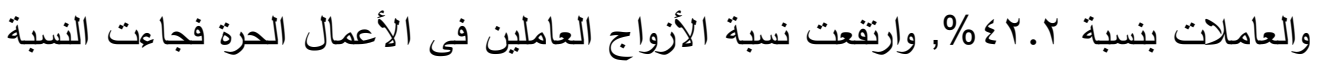

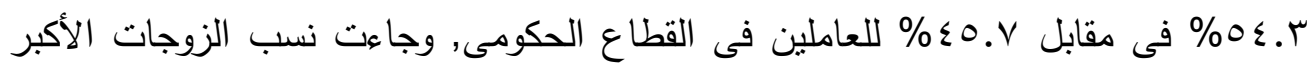
فى العمر من هء سنة فأكثر فى المركز الأول بنسبةه.بس\% يليها نسبة العمر المتوسط من

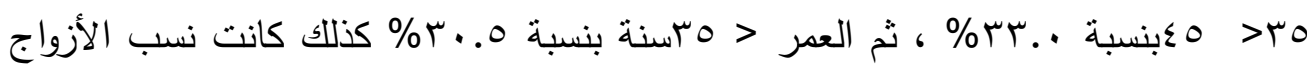

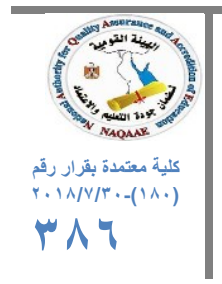

؛ أشارع محمد أمين شهيب ـ مصطفى كامل ـ الاسكندريه ـ مصر تليفون : 203/5454313

Alexandria - Egypt, Tel. : 203/5454313 - 203/5442776 Fax :203/5442776

E-mail : journal.edusp@alexu.edu.eg Web site: RSSA.edusp@lexu.edu.eg 


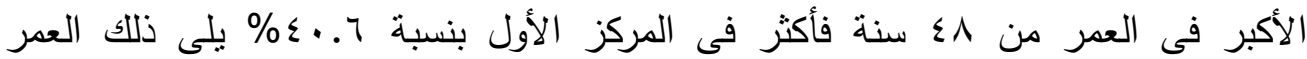

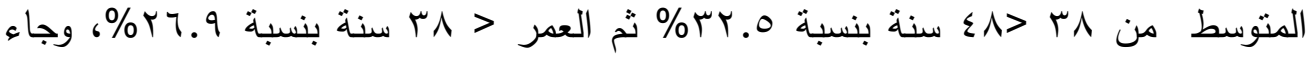

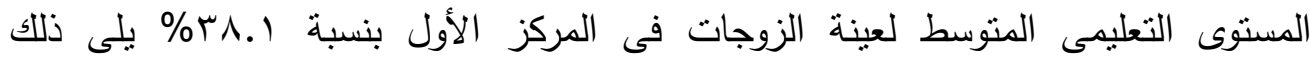

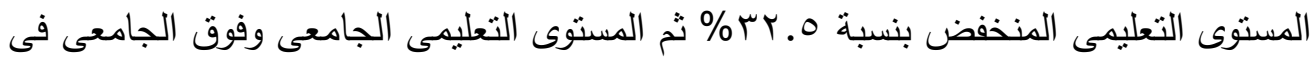
المركز الثالث بنسبة ع.9\%\% ، تقاربت نسب الأزواج من ذوى التعليم المرتفع وذوى التعليم

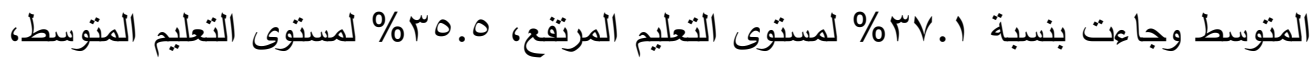

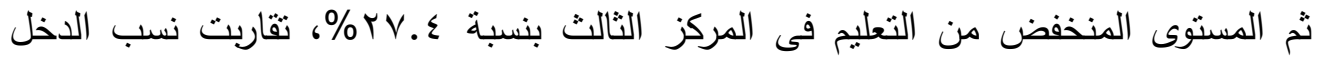

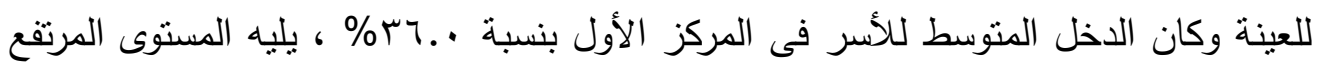

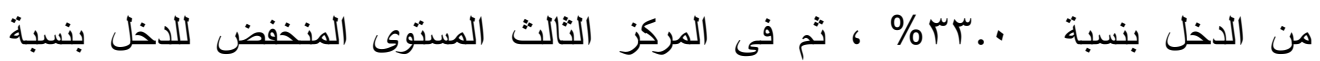
. \% r...

ويسؤال عينة البحث عن أنواع الضغوط التى تعرضوا اليها: تبين تعرض عينة البحث إلى

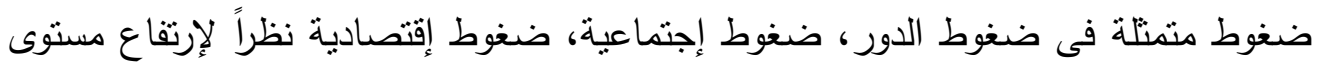

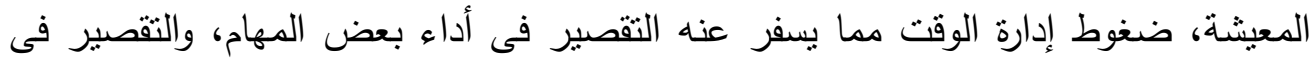

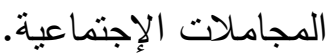
جدول (†) توزيع عينة البحث من الأزواج والزوجات وفقاً لتعرضهم للأنواع المختلفة من

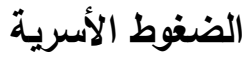

\begin{tabular}{|c|c|c|c|c|}
\hline \multicolumn{2}{|c|}{ الأزواج } & \multicolumn{2}{|c|}{ 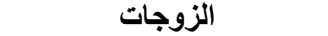 } & \multirow{2}{*}{ الضغوط الأسرية } \\
\hline$\%$ & العدد & $\%$ & العدد & \\
\hline$r 9.09$ & $\vee \wedge$ & $\varepsilon \Lambda . Y r$ & 90 & ضغوط الدور \\
\hline $10 . Y \mu$ & r. & $Y \leqslant . \wedge V$ & $\leqslant 9$ & ضغوط إجتماعية \\
\hline$\{0.79$ & 9. & IV.VV & ro & ضغوط إقتصادية \\
\hline $1 . .10$ & $r$. & $\varepsilon \cdot .71$ & $\Lambda$. & ضغوط إدارة الوقت \\
\hline
\end{tabular}

يتضح من جدول(7) أن أعلى نسبة ضغوط تتعرض لها الزوجات موضع البحث كانت

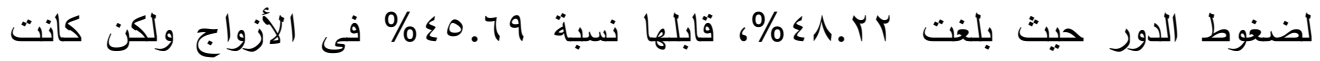

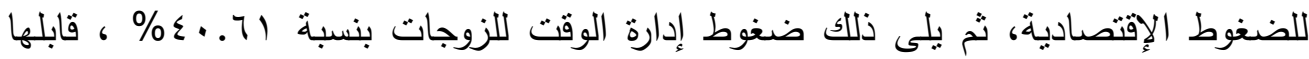


عدد خاص من مجلة "بحوث في العلوم والقنون النوعيه" التونيه

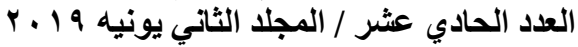

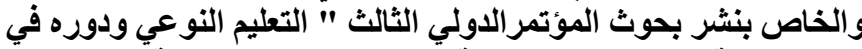

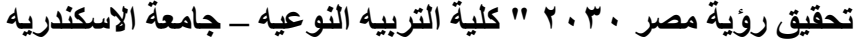

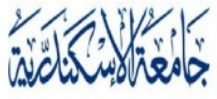

ضغوط الدور للأزواج بنسبة 9.09\%\% ، ثم فى الترتيب الثالث جاءت الضغوط الإجتماعية

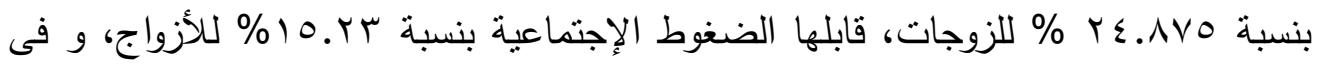

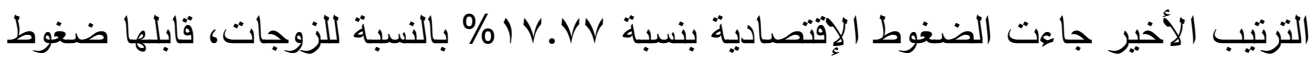

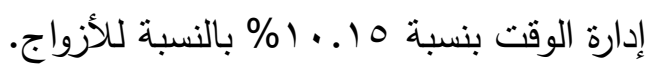

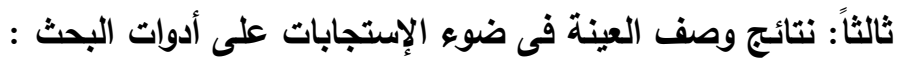

1- وصف استجابات أفراد العينة على استبيان استراتيجيات المواجهة الإقدامية للضغوط:

جدول(V) توزيع استجابات أفراد العينة على استراتيجية (التحليل المنطقى للمواقف) ن=

ع ج ب (عينة الزوج والزوجة)

\begin{tabular}{|c|c|c|c|c|c|c|c|c|c|c|c|}
\hline \multicolumn{3}{|c|}{ الإجمالي } & \multicolumn{3}{|c|}{ الزوجة } & \multicolumn{3}{|c|}{ الزوج } & & \multirow{2}{*}{ العبارة } & \multirow[b]{2}{*}{ e } \\
\hline نادراً & أحياتًاً & دائماً & نادراً & أحياناً & دائماً & نادراً & أحيانَاً & دائماً & & & \\
\hline 99 & IrV & 171 & 70 & $0 \wedge$ & $V \varepsilon$ & $r \leqslant$. & 79 & $9 \leqslant$ & عدد & أستقيل من خبراتى & \\
\hline ro.1 & TY.Y & \& . . & rr. & rq.६ & $r v . \bar{T}$ & IV.r & ro.e & $\varepsilon v . V$ & $\%$ & منطقيةِ لمواجهيبة & 1 \\
\hline \multicolumn{3}{|c|}{$* * \backslash \wedge . r \leq}$. & \multicolumn{3}{|c|}{ ه 9 ه اغير دالة } & \multicolumn{3}{|c|}{ **rv.740 } & كاץ & الصعوطا. & \\
\hline $1 \times 9$ & 179 & 97 & 71 & 19 & $\varepsilon$. & 71.0 & $\Lambda$. & 07 & عدد | علد & أفكر فى أفضل & \\
\hline rY.V & $\varepsilon$ \&.q & $r \leqslant . \varepsilon$ & $r \leqslant .0$ & $\varepsilon 0 . r$ & $r \cdot . r$ & rI.. & $\varepsilon . .7$ & $Y \Lambda . \xi$ & $\%$ & الطرق للتعامل & $r$ \\
\hline \multicolumn{3}{|c|}{$* * r \cdot r o$. r. } & \multicolumn{3}{|c|}{$* * 1 \wedge . \varepsilon \cdot 7$} & \multicolumn{3}{|c|}{ r^^^ء غير دالة } & كاr & مع الضغون فيها. التى & \\
\hline 117 & 179 & 1.9 & T4 & V4 & $0 \wedge$ & or. & 94 & 01 & عدد & يمكن أن تصل مل & \\
\hline rq.६ & $\leqslant$ ५.q & rV.V & rT. & r^. ${ }^{4}$ & rq.६ & r..9 & $\varepsilon v, r$ & ro.9 & $\%$ & تعاملت مع ــ & $r$ \\
\hline \multicolumn{3}{|c|}{$* * 17.491$} & \multicolumn{3}{|c|}{ 9 ץ T. " غير دالة } & \multicolumn{3}{|c|}{$* * 1 V_{.} .97$} & كاץ & معينة. & \\
\hline 107 & 149 & 19 & Ar & 71 & $\leqslant V$ & $9 \leqslant$ & 71 & $\leqslant r$ & عدد & \multirow{3}{*}{ 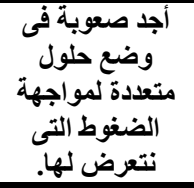 } & \multirow{3}{*}{$\varepsilon$} \\
\hline ะ «.V & TY.V & rY.T & $£ 1.7$ & $r \leqslant .0$ & rr.q & $\varepsilon v . v$ & r.. & r..r & $\%$ & & \\
\hline \multicolumn{3}{|c|}{$* * \curlyvee \wedge . \wedge \vee \wedge$} & \multicolumn{3}{|c|}{$* 9 . \leqslant$ or } & \multicolumn{3}{|c|}{$* * Y_{1} . \cdot 14$} & كاץ & & \\
\hline $9 \mathrm{~V}$ & IVA & 119 & $\leq V$ & 94 & $0 \leqslant$ & $\bullet \cdot$ & Ar & 70 & عدد & و أساليب واقطية & \\
\hline$r \leq .4$ & $\leqslant 0 . Y$ & $r \cdot . r$ & rr.q & $\varepsilon \wedge . \vee$ & $r v . \varepsilon$ & ro. & $\leqslant 1.7$ & rr.. & $\%$ & التى تقابلنا فى الصوق & 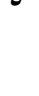 \\
\hline
\end{tabular}

؛ 1 شارع محمد أمين شهيب ـ مصطفى كامل ـ الاسكندريه ـ مصر تليفون : 203/5454313 : 203/5453/5442

Alexandria - Egypt, Tel. : 203/5454313 - 203/5442776 Fax :203/5442776

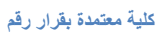

E-mail : journal.edusp@alexu.edu.eg Web site: RSSA.edusp@lexu.edu.eg

$\mu \wedge \wedge$ 
عدد خاص من مجلة "بحوث في العلوم والقنون النوعيه"

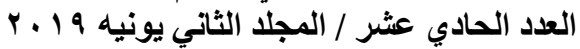

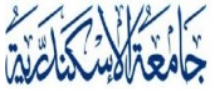

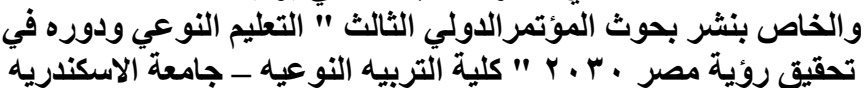

ALEXANDRIA

U N I V E R S I T Y

AlexUPress

Vip

\begin{tabular}{|c|c|c|c|c|c|c|c|c|c|c|c|}
\hline \multicolumn{3}{|c|}{ الإجمالى } & \multicolumn{3}{|c|}{ الزوجة } & \multicolumn{3}{|c|}{ الزوج } & & \multirow{3}{*}{ العبارة } & \\
\hline نادراً & أحياناً & دائماً & نادراً & أحياناً & دائماً & نادراً & أحيانًاً & دائماً & & & ? \\
\hline \multicolumn{3}{|c|}{$* * Y ५ . \vee 17$} & \multicolumn{3}{|c|}{$* * Y 1, r q 1$} & \multicolumn{3}{|c|}{$* V . \wedge \cdot \vee$} & كاr & & \\
\hline $1 \mathrm{rA}$ & 101 & $9 \wedge$ & v. & $\Lambda r$ & $\leqslant 0$ & $7 \wedge$. & V4 & or & عدد & \multirow{3}{*}{ 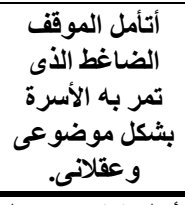 } & \\
\hline ro.. & $\varepsilon \cdot .1$ & $r \leqslant .9$ & ro.o & $\& 1.7$ & rY.A & $r \leqslant .0$ & $r \wedge .7$ & $r 7.9$ & $\%$ & & 7 \\
\hline \multicolumn{3}{|c|}{$* * 1 \leq . Y \mid r$} & \multicolumn{3}{|c|}{$* 1 \cdot . \wedge \circ r$} & \multicolumn{3}{|c|}{ ror ا ـ غير دالة } & كاr & & \\
\hline $11 \%$ & $1 \vee \wedge$ & $1 \cdot r$ & 7. & $9 r$ & $\leqslant 0$ & or.. & 14 & $0 \wedge$ & عدد & \multirow{3}{*}{ 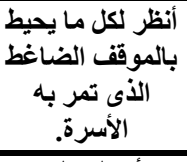 } & \\
\hline$r \wedge . \vee$ & $\varepsilon 0 . r$ & r५.1 & $r \cdot .0$ & $\leqslant 7 . V$ & rY.A & r..9 & $\leq r . V$ & rq. & $\%$ & & v \\
\hline \multicolumn{3}{|c|}{$* * Y 0 . Y \circ \leq$} & \multicolumn{3}{|c|}{$* * 1 V .00 r$} & \multicolumn{3}{|c|}{$* 9.740$} & كاY & & \\
\hline 118 & $|r|$ & 107 & 70 & $0 \wedge$ & $V \leq$ & Or.P & $7 r$ & Ar & عدد & \multirow{3}{*}{ اكتشاف العقل المقائق } & \\
\hline rq.V & $r \cdot . v$ & r9.7 & rr.. & หq. & $r v .7$ & r५.\& & rr.* & $\leqslant 1.7$ & $\%$ & & \\
\hline \multicolumn{3}{|c|}{$* V .+1}$. & \multicolumn{3}{|c|}{ 9 9 . 1 غير دالة } & \multicolumn{3}{|c|}{$* v_{.} \cdot 10$} & كاr & & \\
\hline
\end{tabular}

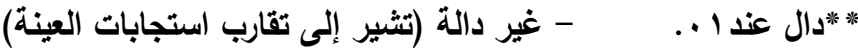
دال عند ه* ..

يتضح دن نتائج جدول (V) بالنسبة لإستراتيجية (التحليل المنطقى للمواقف) تقارب استجابات

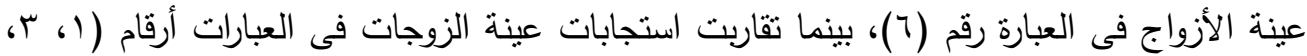
9) وكانت باقى العبارات لكل من الزوج والزوجة دالة حيث كانت كاب دالة عند مستوى (0. ..، 1 (..) ودرجة حرية (r). ويذلك كاتت إجمالى استجابات عينة البحث من الزوجين عن استخدامهم استراتيجية (التحليل المنطقى للمواقف) فى العبارات أرقام ( (، ^) لصالح (دائماً) حيث كانت كاب دالة عند مستوى (1 (..، 0. ..) ودرجة حرية (Y) وجاءت لتعبر أن معظم أفراد العينة يلجأون بدرجة كبيرة إلى الإستفادة من خبراتهم فى المواقف لوضع أساليب منطقية لمواجهة الضغوط, يعملون على اكتثاف الحقائق والمعلومات المؤدية للمشكلة، بينما جاءت عبارات أرقام (Y، Y، 0، 7، У) لصالح أحياناً حيث كانت كاب دالة عند مستوى دلالة (1 ..) لتعبر أن أفراد العينة أحياناً (يتوقعون ما تصل جلاعل إلبه الأمور , والتقكير بأساليب واقعية لمواجهة الضغوط، والنظر لكل ما يحيط بالأسرة, وتأمل المواقف بشكل موضوعى, التفكير فى أفضل الطرق للتعامل مع المواقف)، بينما جاءت العبارة رقم (ع) لصالح نادراً حيث جاءت كاب دالة عند مستوى دلالة (1 ..) لتعبر عن أن الغالبية العظمى منهم نادراً ما يجدون صعوبة فى وضع حلول متعددة لمواجهة الضغوط التى يتعرضون لها. وقد أوضحت لولو 
عدد خاص من مجلة "بحوث في العلوم والقنون النوعيه" التونيه

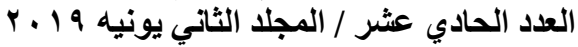

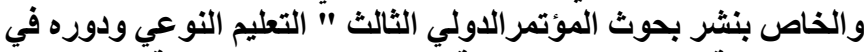

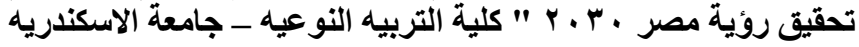

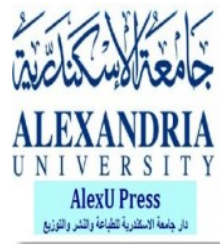

الرشيد (999 199 أن استراتيجية التحليل المنطقى للمواقف تتضمن التعرف على سبب المشكلة، وعدم

الهروب منها، والإستفادة من الخبرات السابقة، والإستعراض العقلى الدنطقى للأمور و التصرفات.

جدول(^) توزيع استجابات أفراد العينة على استراتيجية(إعادة التقييم الإيجابى)

ن= ؛ ؟ ب (عينة الزوج والزوجة)

\begin{tabular}{|c|c|c|c|c|c|c|c|c|c|c|c|}
\hline \multicolumn{3}{|c|}{ الإجمالي } & \multicolumn{3}{|c|}{ الزوجة } & \multicolumn{3}{|c|}{ الزوج } & & \multirow[b]{2}{*}{ العبارة } & \multirow[b]{2}{*}{ م } \\
\hline نادراً & أحياناً & دائماً & نادراً & أحياناً & دائماً & نادراً & أحياناً & دائماً & & & \\
\hline $1 \% 0$ & $17 \varepsilon$ & 90 & $\leqslant q$ & 10 & Tr & Аร & Vq & rY & عدد & \multirow{3}{*}{ 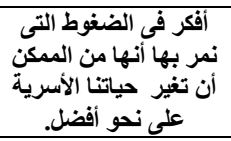 } & \multirow{6}{*}{$r$} \\
\hline$r \varepsilon . r$ & $\$ 1.7$ & $r \leqslant .1$ & $r \leqslant .9$ & $\varepsilon r .1$ & rr.e & $\varepsilon r . V$ & $\varepsilon \cdot .1$ & $17 . Y$ & \multirow{2}{*}{$\begin{array}{c}\% \\
Y L\end{array}$} & & \\
\hline \multicolumn{3}{|c|}{$* * 1 \wedge, r \vee q$} & \multicolumn{3}{|c|}{$* 1 \cdot . * r$} & \multicolumn{3}{|c|}{ **Yฯ.Yฯ } & & & \\
\hline 1Y0 & 11. & 109 & $\{9$ & 00 & 94 & VI & 00 & 74 & عدد & \multirow{3}{*}{ أنجى مواجهة المشاعر الضنلبية } & \\
\hline M.V & PV.q & $\varepsilon \cdot . \varepsilon$ & $r \leqslant .9$ & $r V . q$ & $\varepsilon V . Y$ & $r \wedge .7$ & rv.q & rr.o & $\%$ & & \\
\hline \multicolumn{3}{|c|}{$* 9.099$} & \multicolumn{3}{|c|}{$* * \mid V . r \leq$} & \multicolumn{3}{|c|}{ • ب.r. غير دالة } & SL & & \\
\hline IrY & 189 & $9 r$ & $\varepsilon \wedge$ & $q r$ & OV & $V \varepsilon$ & $\wedge \vee$ & $r q$ & عدد & \multirow{3}{*}{ 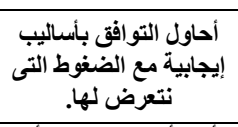 } & \multirow{3}{*}{$r$} \\
\hline M.. & $\varepsilon 0 . \varepsilon$ & YT.7 & $r \leqslant . \varepsilon$ & $\varepsilon 7 . V$ & $r \wedge . q$ & rv. & $\leqslant \leqslant . Y$ & $1 \wedge . r$ & $\%$ & & \\
\hline \multicolumn{3}{|c|}{$* * Y 9.10 r$} & \multicolumn{3}{|c|}{$* * 17 . \leqslant 0 \mathrm{~V}$} & \multicolumn{3}{|c|}{$* * Y 1 . r q 1$} & كاY & & \\
\hline $11 \mathrm{~V}$ & 174 & 118 & or & $\wedge 1$ & 74 & $7 \leq$ & $\Lambda r$ & 01 & عدد & \multirow{3}{*}{ أرى أسير الأمور بصو المكور أن } & \multirow{6}{*}{0} \\
\hline rq.V & $\varepsilon 1 . \varepsilon$ & $r \wedge . q$ & 57.9 & $\$ 1.1$ & r... & rY.o & $\$ 1.7$ & $r 0.9$ & $\%$ & & \\
\hline \multicolumn{3}{|c|}{$* * 11 . \leqslant \wedge \vee$} & \multicolumn{3}{|c|}{$* 4.1 r r$} & \multicolumn{3}{|c|}{ *V.rAI } & كاr & & \\
\hline $1 \leq 1$ & 107 & $9 V$ & 7. & $\Lambda r$ & $0 \leq$ & 11 & Vr & $\{r$ & عدد & \multirow{3}{*}{ 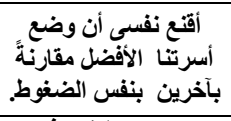 } & \\
\hline$r \Delta . \Lambda$ & rq. & $r \varepsilon .7$ & $r \cdot 0$ & $\varepsilon Y .1$ & $r V_{. \varepsilon}$ & $\leqslant 1.1$ & $r v .1$ & YI.A & $\%$ & & \\
\hline \multicolumn{3}{|c|}{ **1ะ.r } & \multicolumn{3}{|c|}{$* v .1 \mathrm{rv}$} & \multicolumn{3}{|c|}{$* * 1 r . r r r$} & كاY & & \\
\hline 17. & 119 & 110 & $1 \ldots$ & 0. & $\varepsilon V$ & 7. & 79 & 71 & عدد & & \\
\hline$\varepsilon \cdot .7$ & $r \cdot . r$ & YQ.Y & $0 . .1$ & ro.s & rr.q & $r \cdot .0$ & ro.. & $r \leqslant .0$ & $\%$ & العواقة العاق & 9 \\
\hline & $* q . \leqslant \leq V$ & & & 9.990 & & & $=. v \leq 1$ & & كاr & & \\
\hline $10 V$ & $1 Y 7$ & 111 & 9. & $7 V$ & $\varepsilon$. & TV & 09 & $\sqrt{11}$ & عدد & يسيطر على تفكيرى ما & \\
\hline$r 9.1$ & rr.• & $r \wedge . r$ & $\leqslant 0 . V$ & $r \varepsilon$. & $r \cdot . r$ & $r \varepsilon . \cdot$ & r9.9 & rч.• & $\%$ & & $v$ \\
\hline & $* 40.09$ & & & .077 & & دالة & $1.1 \mathrm{rV}$ & & كاr & التى مرت بها أسرتى فى مثابهة. & \\
\hline $1 \mathrm{H}$ & 187 & $\Lambda$. & 71 & 94 & $\varepsilon \leqslant$ & VV & $\Lambda \varepsilon$ & $r 9$ & عدد & أستحضر تجارب سـارة & \\
\hline ro.. & $\varepsilon \varepsilon . V$ & $r \cdot r$ & r.. & $\leq 7 . V$ & TY.r & rq.1 & $\leqslant r .7$ & $1 \wedge . r$ & $\%$ & في حياتى عند المرور & $\wedge$ \\
\hline & $* \wedge . r \wedge$ & & & $1 . \cdot \leq 1$ & & &.$\leqslant V V$ & & كاr & بصن الضغوط سنوالحالية. & \\
\hline 107 & 117 & IYY & $\leqslant \varepsilon$ & $7 \varepsilon$ & 19 & $\vee \wedge$ & Or & TV & عدد & أتقبل فكرة أن الموقف & \\
\hline rq.7 & rq. & r..• & YY.r & rY.o & $\leqslant 0 . Y$ & $r 9.7$ & 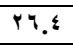 & $r \varepsilon$ & $\%$ & قد حدث وليس فى & 9 \\
\hline & $* v_{.} \cdot \Lambda=$ & & & $0 . \varepsilon \wedge r$ & & دالة & 0.111 & & كاY & الإمكاتية التغييز. & \\
\hline
\end{tabular}

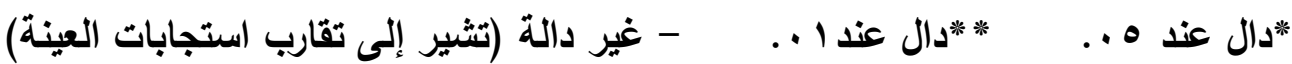


يتضح من نتائج جدول (^) تقارب استجابات عينة الأزواج على العبارات أرقام (؟، جا، Vا، 9) وجاءت باقى العبارات دالة، وجاءت استجابات عينة الزوجات على عبارات إعادة التقييم الإيجابى دالة حيث كانت كاب دالة عند مستوى (0... 1 ...) ودرجة حرية (Y). ويذلك كانت إجمالى استجابات عينة البحث من الزوجين عن استخدامهم استراتيجية (إعادة التقييم

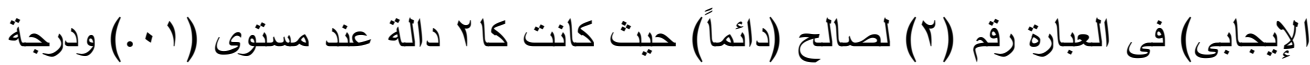
حرية (Y) وجاءت لتعبر عن أن معظم أفراد العينة دائماً يلجأون إلى تجنب المشاعر السلبية

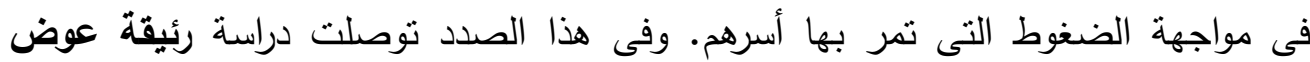

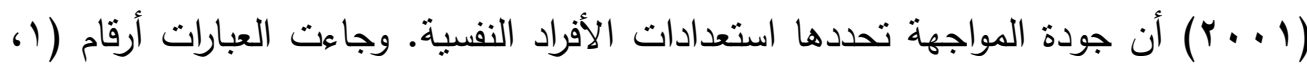

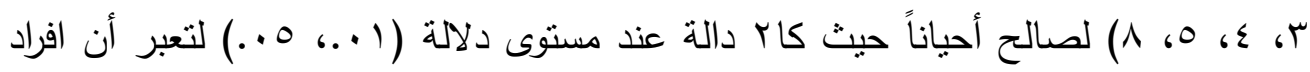

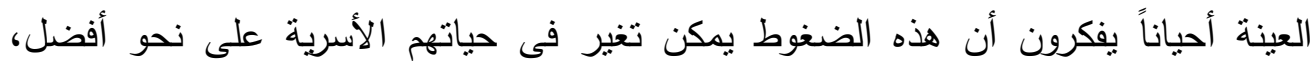

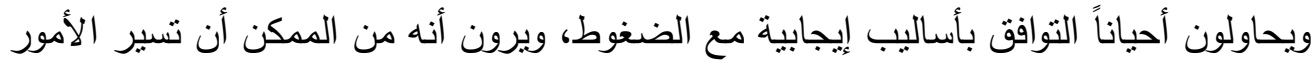
بصورة أسوء مما يحدث وأن الوضع لا يبدو سيئاً تماماً. وقد أكدت دراسة التهابة (1997) Huffiman et al

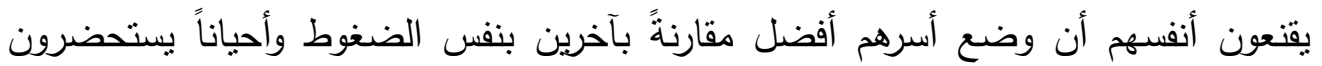
تجارب سارة فى حياتهم عند المرور بضغوط سابقة للتخفيف من الضغوط الحالية، بينما

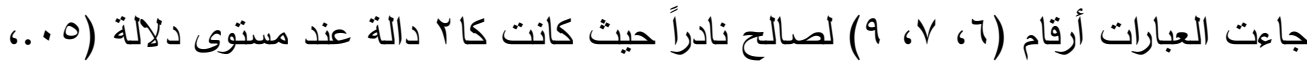
1...) لتعبر عن أن الغالبية العظمى منهم نادراً ما يراودهم التفكير فى العواقب السيئة

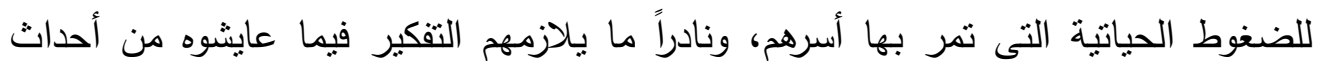

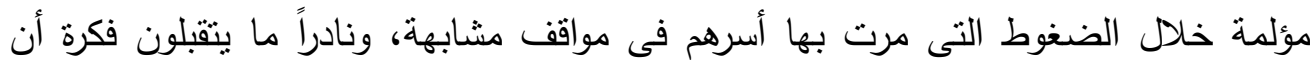
الموقف قد حدث وليس فى إمكانية للتغيير. وقد ربط العلماء بين مهارة الأفراد فى إدارة إنفعالاتهم وقدرتهم على إدارة المواقف الضاغطة فالأفراد الذين ينظمون إنفعالاتهم من خلال 
عدد خاص من مجلة "بحوث في العلوم والفنون النوعيه"

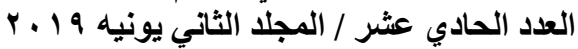

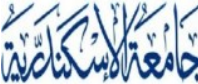

ALEXANDRIA

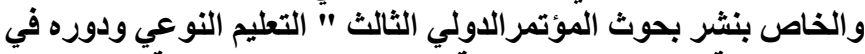

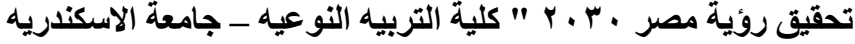

AlexUPress

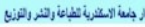

الإحتفاظ بصورة إيجابية مع الذات، و ينجحون فى عملية المواجهة؛يستطيعون حل المشكلات التى يتعرضون لها(Bootzin,Richard, 1999) ).

جدول(9) توزيع استجابات أفراد العينة على استراتيجية(البحث عن المساعدة والمعلومات)

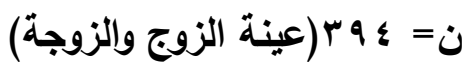

\begin{tabular}{|c|c|c|c|c|c|c|c|c|c|c|c|}
\hline \multicolumn{3}{|c|}{ الإجمالى } & \multicolumn{3}{|c|}{ الزوجة } & \multicolumn{3}{|c|}{ الزوج } & & \multirow{2}{*}{ أستفيد بأحداث } & \multirow[t]{2}{*}{5} \\
\hline نادراً (نادر & أحياناً & دائماً & نادراً & أحياناً & دائماً & نادراً & أحياناً & دائماً & & & \\
\hline 91 & 17. & $1+4$ & $\leqslant r$ & 79 & $\Lambda 7$ & 07 & 91 & 0. & عدد ( عد ) ع & الحياة الضاغطة & \\
\hline$r \leqslant .9$ & $\varepsilon \cdot .7$ & $r \leqslant .0$ & YI.r & ro. & $\varepsilon r . V$ & $r \wedge . \varepsilon$ & $\leqslant \square . Y$ & ro.s & $\%$ & التى حلثت لى فى & \\
\hline & $\div 1 \leq . \wedge 1$ & & & $\leqslant .990$ & & & ع 94 & & SL & لى للضغوط & \\
\hline $11 \pi$ & 174 & 111 & $\leqslant 9$ & $\Lambda \leqslant$ & $7 \leqslant$ & $7 \leqslant$ & $\sqrt{99}$ & $0 \leqslant$ & عدد ( عد & أستفيد من تجارب & \\
\hline$r \wedge . V$ & $\leqslant 1 . \leqslant$ & r9.9 & $r \leqslant .9$ & \&Y. & rY.O & rY.O & $\varepsilon \cdot .1$ & YV.q & $\%$ & وخبرات الآخرين & \\
\hline & $\div 11.0 \leq$ & & & $* q . r q$ & & & . & & كاr & للضفوط مواجهتهُ الحياتية & r \\
\hline 17. & 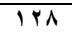 & 1.7 & $\Lambda V$ & 79 & « & $V r$ & TY & 45 & عدد & أتجنب مخالطة & \\
\hline$\varepsilon . .7$ & TY.O & $r 7.9$ & $\varepsilon \leqslant . Y$ & rT.O & YY.r & $r v .1$ & ri.0 & $r 1.0$ & $\%$ & الآخرين عند & r \\
\hline & $=11 . r$ & & & $* 1 \leq . .1$ & & & ا غير. & & SL & تعرضى لأى موقف & \\
\hline vi & $T \leq Y$ & $1 \wedge 1$ & $r \leq$ & 71 & $1 \cdot Y$ & $r v$ & $\Lambda 1$ & V9 & عدد & عندما تواجهنى & \\
\hline $11 .$. & r.. & $\leq 0.9$ & IV.r & ri.. & 01.1 & $1 \wedge . \wedge$ & $\$ 1.1$ & $\varepsilon \cdot .1$ & $\%$ & مشكلة ألجأ لمن & 4 \\
\hline & $\because \leqslant V . r 4$ & & & ro.v. & & & 11.1 & & كاr & يتصفون بالحكمة & \\
\hline $19 \mathrm{~V}$ & 94 & $1 \cdot \varepsilon$ & $1 . \varepsilon$ & or & «1 & 94 & « & זי & عدد & أواجه المو اقفف & \\
\hline $0 \cdot . \cdot$ & rr.t & YY.द & OY.A & Y..द & $r \cdot . \Lambda$ & $\varepsilon V . Y$ & $Y \cdot . \Lambda$ & rY.P & $\%$ & حصول علدي & \\
\hline & $\div \leqslant 9 . \vee 1$ & & & $r \leqslant . \leqslant \Lambda$ & & & $=r \cdot . V$ & & SL & كيفية مواجلومات عن المزيد. & \\
\hline 94 & 114 & 119 & $\varepsilon Y$ & $0 \leq$ & $1 \cdot 1$ & 01 & $0 \wedge$ & $\wedge \wedge$ & عدد & أسعى للحصول على & \\
\hline rr.t & $r \wedge . \varepsilon$ & $\leqslant \Lambda$. & rI.r & YV.q & $01 . r$ & $r 0.9$ & Yq. & $\varepsilon \leqslant . V$ & $\%$ & العون من الأقارب & \\
\hline & $=4.40$ & & & $* 49.7$ & & & $11 . v$ & & كاץ & المواقف الضاغطة & 7 \\
\hline$\Lambda \wedge$ & 10. & 107 & ¿0 & 4 & 9. & $\leqslant r$ & $\Lambda \Lambda$ & 79 & عدد ( عد ا & أسعى للحصول & \\
\hline YY.Y & $r \wedge .1$ & rq.7 & YY.A & ri.o & $\leqslant 0 . V$ & YI.A & $\varepsilon \leqslant . V$ & rr.o & $\%$ & على نصائح & \\
\hline & $=41.01$ & & & $* 10 . v$ & & & 10.5 & & SL & سأفعله لمواجهة الضاخين عما & $\mathrm{v}$ \\
\hline 19 & $1 T V$ & $1 \nabla \Lambda$ & $r \wedge$ & VI & 91 & 01 & 79 & $\wedge$. & عدد & أتحلثث مع مقربين & \\
\hline$r \cdot .1$ & $r \leqslant . \wedge$ & $\leqslant 0 . Y$ & $1 \leqslant . Y$ & r.." & $\leqslant 9.7$ & $r 0.9$ & rT.O & $\{\cdot .7$ & $\%$ & أو أصدقاء مروا & \\
\hline & : & & & $* r v . q$ & & & 4. & & SL & و أطلب مساعس الضفوطه & $\wedge$ \\
\hline 91 & $1 \pi \leq$ & 179 & $\varepsilon$. & $7 \leqslant$ & 94 & 01 & $v$. & $v 4$ & عدد & أبحث عن مفاتيح & 9 \\
\hline
\end{tabular}

ك أشارع محمد أمين شهيب ـ مصطفى كامل ـ الاسكندريه ـ مصر تليفون : 203/5454313

Alexandria - Egypt, Tel. : 203/5454313 - 203/5442776 Fax :203/5442776

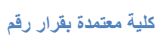

E-mail : journal.edusp@alexu.edu.eg Web site: RSSA.edusp@lexu.edu.eg 


\begin{tabular}{|c|c|c|c|c|c|c|c|c|c|c|}
\hline rr. & $r \leqslant . \cdot$ & $\leq Y .9$ & $r \cdot . r$ & rY.O & $\leqslant V . Y$ & $r 0.9$ & $r 0.0$ & $r \wedge .7$ & $\%$ & للحل من خلال \\
\hline \multicolumn{3}{|c|}{$* * Y Y, Y \leq \varepsilon$} & \multicolumn{3}{|c|}{$* * r 1 . \leqslant 0 r$} & \multicolumn{3}{|c|}{ ^^ ا ـه غير دالة } & كاY & مرتبطة بالمشكلة. معلومات \\
\hline
\end{tabular}

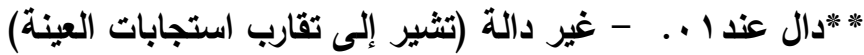

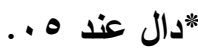
يتضح من نتائج جدول (9) نقارب استجابات عينة الأزواج فى استراتيجية (البحث عن المساعدة والمعلومات) فى العبارات أرقام (؟، r، 9)، وكانت باقى العبارات دالة، وجاءت جميع استجابات عينة الزوجات دالة حيث كانت كاب دالة عند مستوى (0..., 1 ..) ودرجة حرية (Y)، ويذلك كانت إجمالى استجابات عينة البحث من الزوجين عن استخدامهر

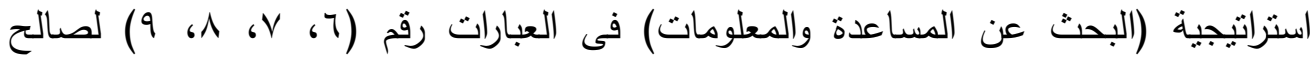

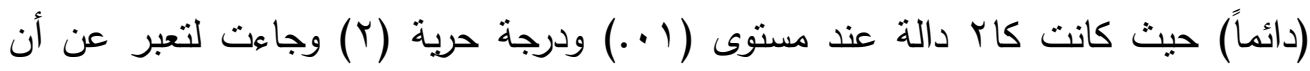

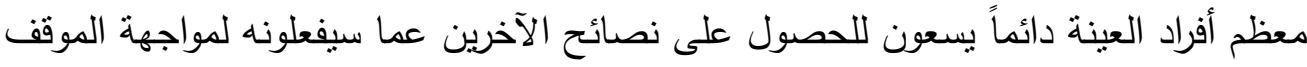
الضاغط، ويتحدثون مع مقربين أو أصدقاء مروا بنفس الضغوط ويطلبون مساعدتهم للوصول لحل، ويبحثون عن مفاتيح للحل من خلال استرجاع معلومات مرتبطة بالمشكلة، ويسعون

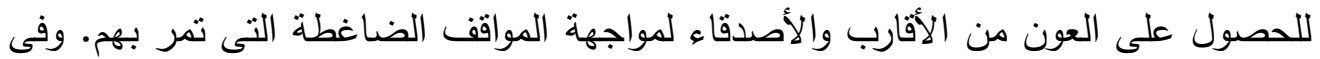

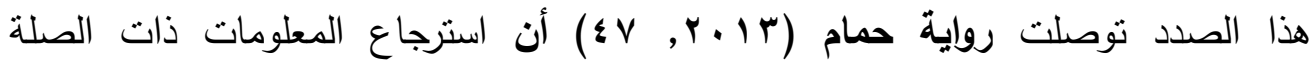
بالمشكلة، والبحث عن مفاتيح للحل يساعد على تجاوز المشكلة، بينما جاءت العبارات أرقام

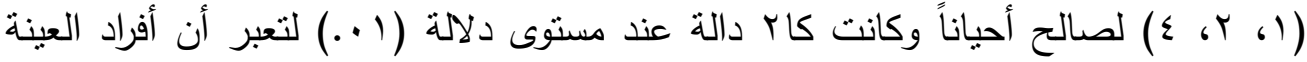

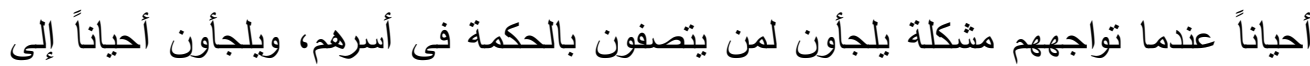

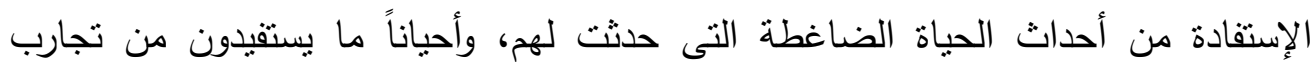

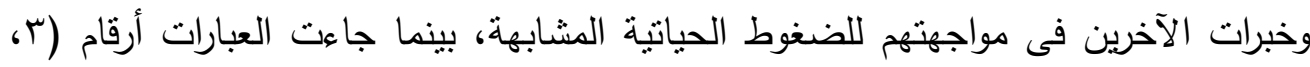
0) لصالح نادراً حيث جاءت كاب دالة عند مستوى دلالة (1 ...) لتعبر عن أن الغالبية

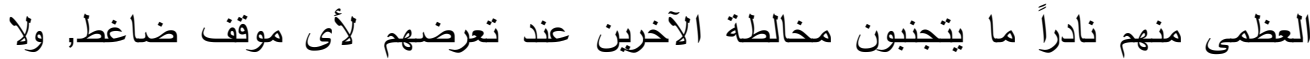
يواجهون المواقف الضاغطة بإندفاع دون الحصول على المزيد من المعلومات عن كيفية مواجنتها. وقد ذكر فتحى جروان(999 19، هو) أن فى استراتيجية البحث عن المساعدة 
والمعلومات يستخدم الأفراد ما لديهم من معارف مكتسبة سابقة ومهارات من أجل الإستجابة

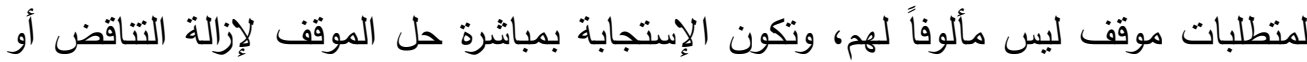
الغموض الذى بتضنده.

جلول ( • 1) توزيع استجابات أفراد العينة على استراتيجية(استخدام أسلوب حل المشكلات) ن = ع و ب (عينة الزوج والزوجة)

\begin{tabular}{|c|c|c|c|c|c|c|c|c|c|c|c|}
\hline \multicolumn{3}{|c|}{ الإجمالى } & \multicolumn{3}{|c|}{ الزوجة } & \multicolumn{3}{|c|}{ الزوج } & & \multirow{2}{*}{ العبارة } & \multirow{2}{*}{ م } \\
\hline نادراً & أحيانًاً & دائما & نادراً & أحياناً & دائما & نادراً & أحيانَاً & دائماً & & & \\
\hline VV & TYY & 190 & $\leqslant r$ & $7 \mathrm{~V}$ & $\Lambda \Lambda$ & ro & 00 & $1 \cdot V$ & عدد & \multirow{3}{*}{ 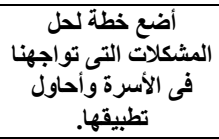 } & \multirow{3}{*}{1} \\
\hline 19.0 & M.. & $\leqslant 9.0$ & Y.r. & $r \leqslant .$. & $\leq \varepsilon . V$. & IV.A & YV.q & $0 \leqslant . T$ & $\%$ & & \\
\hline \multicolumn{3}{|c|}{$* * 0 \leqslant . .0$} & \multicolumn{3}{|c|}{$* * 17.10 r$} & \multicolumn{3}{|c|}{$* * \leq r_{.} \cdot v 1$} & & & \\
\hline$\wedge 9$ & $1 \cdot r$ & $r \cdot r$ & $\varepsilon \varepsilon$ & 09 & $9 \leq$ & $\leqslant 0$ & $\varepsilon r$ & 1.9 & عدد & \multirow{3}{*}{ 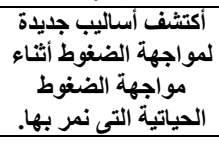 } & \multirow{3}{*}{ r } \\
\hline YY.Y & ro.9 & 01.0 & YY.Y. & r9.9. & $\leq v . V$. & YY.A & Y1.ᄉ & $00 . r$ & $\%$ & & \\
\hline \multicolumn{3}{|c|}{$* * 09 . r .0$} & \multicolumn{3}{|c|}{$* * r \cdot .01$} & \multicolumn{3}{|c|}{$* * \leq Y .9 Y \leq$} & كاץ & & \\
\hline$T r$ & 110 & YIV & $\leqslant \mu$ & OV & $9 \mathrm{~V}$ & 19 & 01 & ir. & عدد & \multirow{3}{*}{ 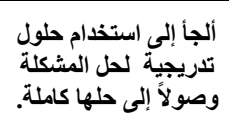 } & \multirow{3}{*}{$r$} \\
\hline $10 . V$ & rq. & 00.1 & Y..人. & $r \wedge .9$. & $\leqslant 9 . Y$. & 9.7 & rq.5 & $9 . .9$ & $\%$ & & \\
\hline \multicolumn{3}{|c|}{$* * 9 \leq .01 \%$} & \multicolumn{3}{|c|}{$* * r r . q 19$} & \multicolumn{3}{|c|}{$* * \vee 9.10$} & 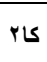 & & \\
\hline$\sqrt{ } 1$ & $|r|$ & $Y \cdot Y$ & $r \leq$ & VY & 91 & $r v$ & $\leqslant 9$ & 111 & عدد & \multirow{3}{*}{ ألتعامل بثكل مباشت التى مع ألى الثى } & \multirow{3}{*}{$\varepsilon$} \\
\hline $11 . \cdot$ & $r \cdot . v$ & $01 . r$ & IV.r. & M.0. & $\leqslant 7 . Y$. & $1 \wedge . \wedge$ & $r \leqslant .9$ & $07 . r$ & $\%$ & & \\
\hline \multicolumn{3}{|c|}{$* * 77.00 \%$} & \multicolumn{3}{|c|}{$* * Y 0.700$} & \multicolumn{3}{|c|}{$* * \leqslant \wedge . \cdot \leq 1$} & كاץ & & \\
\hline AT & $1 \mathrm{TN}$ & IVT & 01 & $v$. & $\sqrt{87}$ & rY & 71 & $9 \mathrm{~V}$ & عدد & أبذل كل جهاى لمنع أى & \multirow{3}{*}{ 0 } \\
\hline YI.1 & ro. & $\leq 4.9$ & ro.9 & $r 0.0$ & $r \wedge .7$ & 17.4 & $r \leqslant .0$ & $29 . Y$ & $\%$ & موقف ضاغط يعوق & \\
\hline \multicolumn{3}{|c|}{$* * r, r \leq 0$} & & 1 0.1 & & & TY.Y & & كLاY & حل المشكلة. & \\
\hline$v$. & 111 & YIT & $r \Lambda$ & 79 & 94 & rY & $\leqslant 0$ & Tr. & عدد & أعيد النظر فى الحلول & \\
\hline $1 V . \wedge$ & $r \wedge . Y$ & $0 \leqslant .1$ & $19 . r$ & rT.o & $\leq V . r$ & $17 . r$ & YY.A & $7 . .9$ & $\%$ & بعد تطبقها بناءُ علي & 7 \\
\hline & $* \Lambda r_{.} \circ$ & & & *rr. & & & $\because \Lambda . \vee$ & & كاץ & أضغوط. & \\
\hline 174 & ITV & $9 \leq$ & 78 & $v \cdot$ & 11 & $9 \mathrm{~V}$ & IV & $r r$ & عدد & أستخدم طرق عشوائية & \\
\hline$\leq 1.5$ & $r \leqslant . \Lambda$ & rr.q & $r r .0$ & $r 0.0$ & $r 1 . \cdot$ & $\sum 9.4$ & $r \varepsilon_{.}$ & 17.1 & $\%$ & عند حل المثكلة التى & \\
\hline & $* 1 \wedge .\{$ & & & 1. غير د & & & Y & & كاץ & الفورية دون النظّ النتانت عما & $\mathrm{v}$ \\
\hline$\Lambda \wedge$ & 110 & 191 & 0. & 70 & $\Lambda r$ & $r \Lambda$ & o. & 1.9 & عدد & أعمل على التقليل من & \\
\hline YY.r & Yq.r & $\leqslant \Lambda .0$ & Yo.s & rr.. & $\leq 1.7$ & $19 . r$ & Yo.s & $00 . r$ & $\%$ & الآثار السيئة للمواقف & $\Lambda$ \\
\hline & $* \leqslant$ * & & & $* \vee . \wedge \cdot \vee$ & & & $\leqslant \leqslant .9$ & & كاץ & الضاغطة التي تمر بها & \\
\hline 78 & 147 & $r+1$ & $\leqslant Y$ & 71 & $\Lambda V$ & ro & $\Delta \wedge$ & $11 \leq$ & عدد & أجرب طرق وبدائل & \\
\hline IV.. & rY. & 01. & $r . r$ & $r \leqslant .0$ & $\leq \leqslant . Y$ & IY.V & Y9.5 & $0 V .9$ & $\%$ & مختلفة تساعدنى فى & 9 \\
\hline & $* 4 \wedge .7$ & & & $* 10.0 \leq$ & & & 97.7 & & كاY & حل المشكلة. & \\
\hline 99 & 97 & 199 & Tr & $\leq 9$ & 14 & $r v$ & $\varepsilon V$ & 114 & 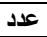 & أتحكم فى المواقف & \\
\hline ro.1 & $Y \leqslant . \xi$ & 0.0 & $\$ 1.0$. & $r \leq .9$. & $\varepsilon r . V$. & $1 \wedge .1$ & Yr.q & OV. & $\%$ & الحياتية التى تعوق & 1. \\
\hline & *Or.r & & & $. v+1$ & & & .949 & & كاY & مواجهة الضنوط. & \\
\hline
\end{tabular}


عدد خاص من مجلة "بحوث في العلوم والقنون النوعيه" العزيه

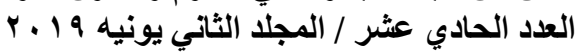

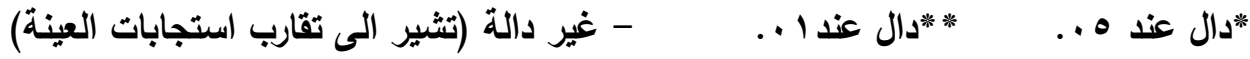
يتضح من نتائج جدول (· (1) تقارب استجابات الزوجات فى استخدام استراتيجية حل المشكلات فى العبارات أرقام (0، V) بينما جاءت باقى العبارات دالة، وجاءت جميع عبارات

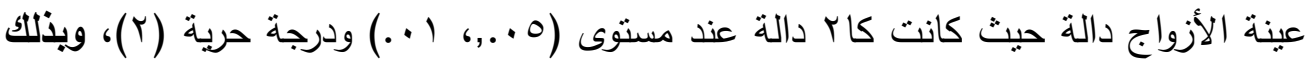
كاتت استجابات إجمالى عينة البحث من الزوجين عن استخدامهم (لإستراتيجية حل حله

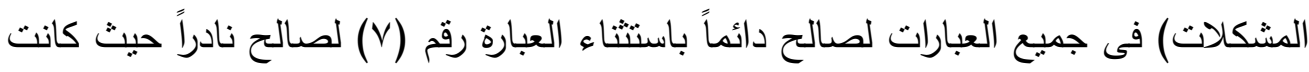

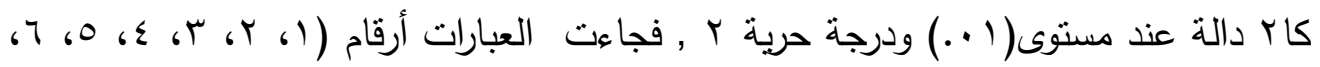

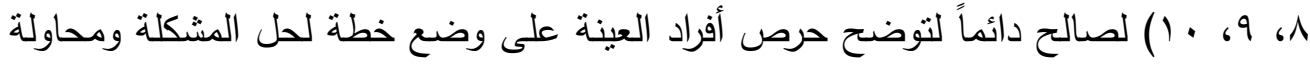

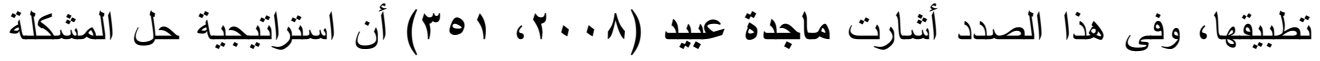
تثير إلى قدرة الفرد على إدراك وفهم عناصر الموقف أو المشكلة وصولاً إلى وضع خطة

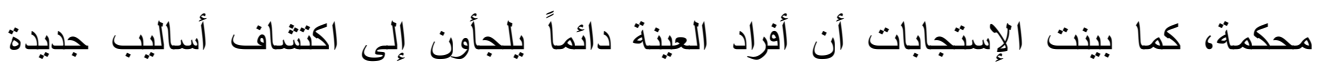
لمواجهة الضغوط أثناء مواجهة الضغوط الحياتية التى يمرون بها، ويعيدون النظر في الحلول بعد تطبيقها بناءً على مدى نجاحها لمواجهة الضغوط. وقد ذكر D'Zurilla\&,Nezu, (2007,19) أن أسلوب حل المشكلات عملية سلوكية تُمكن الفرد بمقتضاها من تحديد أو اكتتاف أساليب للتعامل مع المشكلات، كما يلجأ أفراد

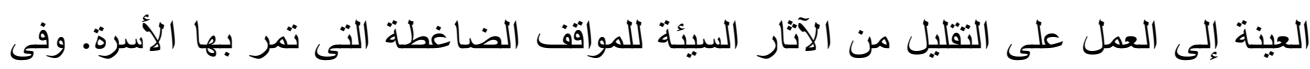

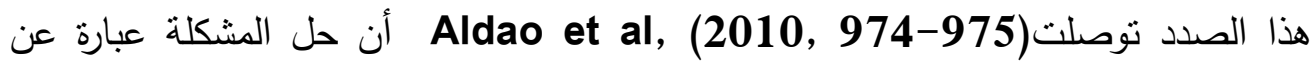
استجابات يحاول الفرد بواسطتها تغيير المواقف الضاغطة أو إحتواء آثارها. ويصف مصعب

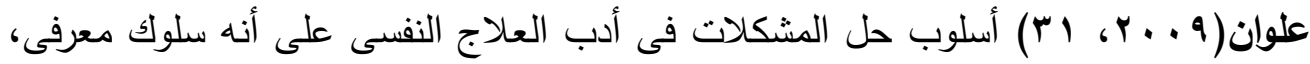

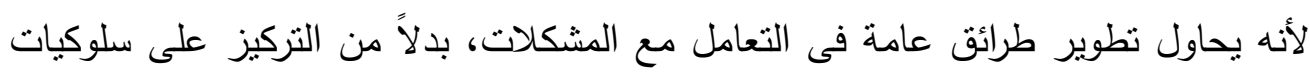

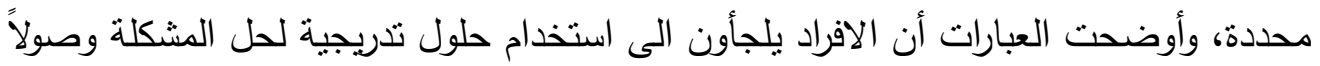
إلى حلها كاملةً، ويتعاملون بشكل مباشر مع الأسباب التى أدت الى حدوث الثناث المشكلة وهذا 


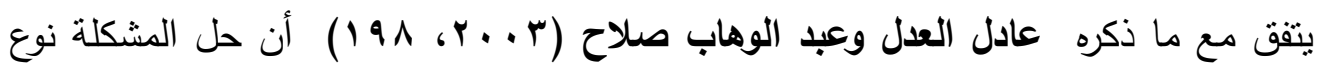
من الأداء يتقدم فيه الفرد من الحقائق المعروفة للوصول إلى الحقائق المجهولة التى يود اكتشافها وذللك عن طريق فهم وإدرالك الأسباب والعوامل المتداخلة فى المشكلات التى يقوم

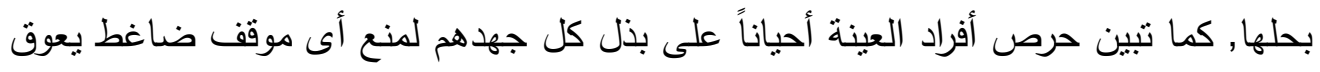
حل الشكلة وقد أكدت دراسة Huffman et al, (1997) أنه من مصادر مواجهة الأفراد الضغوط التحكم فى كافة المواقف الحياتية التى يمرون بها، بينما جاءت العبارة رقم

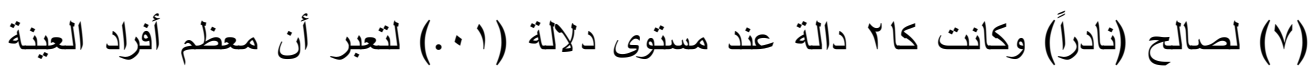

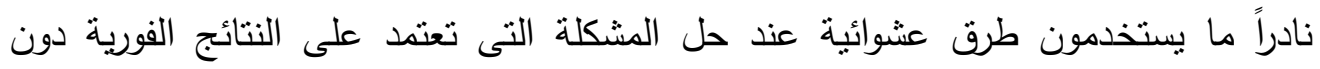

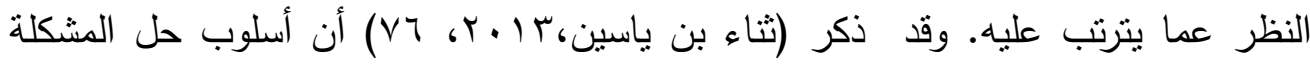

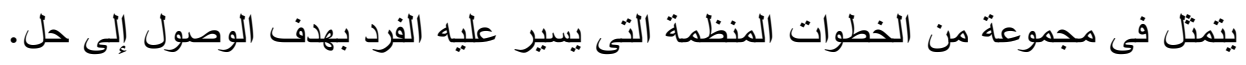

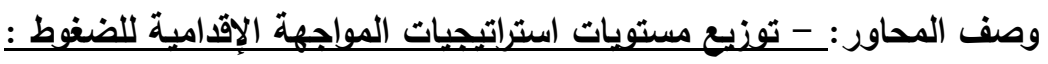

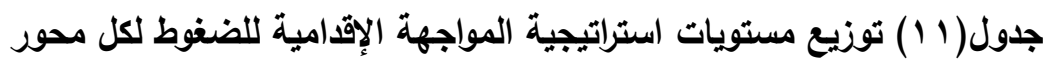

\begin{tabular}{|c|c|c|c|c|c|c|c|}
\hline \multicolumn{2}{|c|}{ 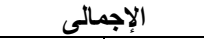 } & \multicolumn{2}{|c|}{ 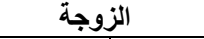 } & \multicolumn{2}{|c|}{ 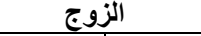 } & \multirow{2}{*}{ 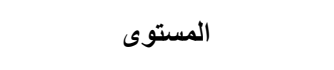 } & \multirow{2}{*}{ 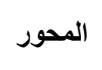 } \\
\hline$\%$ & العدد & $\%$ & العدد & $\%$ & العدد & & \\
\hline Y1.0V & 10 & ro.9 & 01 & IV.r & $r \varepsilon$ & منذفض (1 ا ( ) & \multirow{7}{*}{ 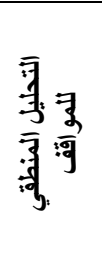 } \\
\hline$\$ 1.1 Y$ & 174 & $\varepsilon . .1$ & v9 & \&..1 & $\Lambda \mu$ & متوسط (r>|r|r) & \\
\hline rv.ri & $1 \leqslant V$ & $r \varepsilon_{.}$ & TV & $\varepsilon \cdot .7$ & A. & مرتفع (^ افأكثر) & \\
\hline $1 \ldots$ & rq & $1 \ldots$ & $19 \mathrm{~V}$ & $1 \ldots$ & $19 \mathrm{~V}$ & 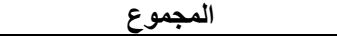 & \\
\hline \multicolumn{2}{|c|}{$17 . r r$} & \multicolumn{2}{|c|}{$10.94 \varepsilon$} & \multicolumn{2}{|c|}{17.211} & المتوسط الحسابي & \\
\hline \multirow{2}{*}{\multicolumn{2}{|c|}{ 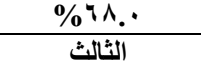 }} & \multicolumn{2}{|c|}{$\% 94.49$} & \multicolumn{2}{|c|}{$\% 99.74$} & النسب الترجيحية للازووان النسبية & \\
\hline & & \multicolumn{2}{|c|}{ الرابع الرابع } & \multicolumn{2}{|c|}{ الثاني - الثاني } & الترتيب & \\
\hline$r \cdot . \leqslant 4$ & ir. & $r \cdot . r$ & $\varepsilon \cdot$ & $\varepsilon \cdot .7$ & $\Lambda$. & منخفض (10>9) & \\
\hline rO.YA & 149 & rv.1 & $\frac{V T}{V T}$ & $r+{ }^{2}$ & 74 & متوسط (Yl>10) & $\frac{9}{7}$ \\
\hline एะ.Y & 1ro & $\varepsilon$ «. & $\Lambda \varepsilon$ & ro.9 & 01 & مرتفع (ابفأكثر) & \\
\hline $1 \ldots$ & $r 9 \leqslant$ & $1 \cdots$ & $19 V$ & $1 \ldots$ & $19 \mathrm{~V}$ & المجموع & \\
\hline \multicolumn{2}{|c|}{$1 V .97$} & \multicolumn{2}{|c|}{$19.1 \% 0$} & \multicolumn{2}{|c|}{$17 . \wedge 91$} & المتوسط الحسابي & \\
\hline \multicolumn{2}{|c|}{$\% 49.0$} & \multicolumn{2}{|c|}{$\% \vee v \cdot .4$} & \multicolumn{2}{|c|}{$\% \leqslant 4.9 \leqslant$} & النسب الترجيحية للازوان النسبية & i: \\
\hline \multicolumn{2}{|c|}{ الرابع } & \multicolumn{2}{|c|}{ الثالث } & \multicolumn{2}{|c|}{ 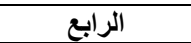 } & الترتيب & \\
\hline $19 . \wedge$. & $\vee \wedge$ & $10 . \mathrm{V}$ & rI & $r+.9$ & $\leqslant V$ & منخفض (10>9 (10) & \\
\hline$r \wedge . \wedge r$ & 104 & $r v .7$ & $V \varepsilon$ & $\varepsilon \cdot .1$ & v9 & متوسط (Y1>10) & $\overline{7} \overline{7}$ \\
\hline$\$ 1 . \mathrm{rv}$ & 174 & $\$ 4 . V$ & 94 & $r .$. & $\sqrt{11}$ & مرتفع (ابفأكثر) & \\
\hline $1 \ldots$ & एव & $1 \ldots$ & $19 \mathrm{~V}$ & $1 \ldots$ & $19 \mathrm{~V}$ & المجموع & \\
\hline \multicolumn{2}{|c|}{19.74} & \multicolumn{2}{|c|}{ r..rro } & \multicolumn{2}{|c|}{11.919} & المتوسط الحسابي & \\
\hline
\end{tabular}


عدد خاص من مجلة "بحوث في العلوم والقنون النوعيه" التوبه

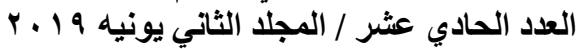

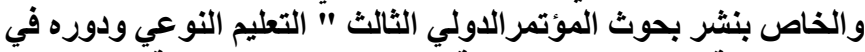

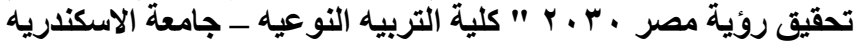

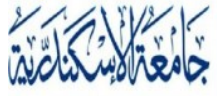

ALEXANDRIA

U N I V E R S I T Y

AlexU Press

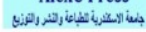

\begin{tabular}{|c|c|c|c|c|c|c|c|}
\hline \multicolumn{2}{|c|}{ الإجمالي } & \multicolumn{2}{|c|}{ 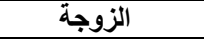 } & \multicolumn{2}{|c|}{ 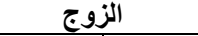 } & \multirow{2}{*}{ 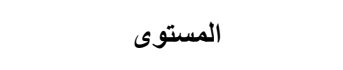 } & \multirow{4}{*}{ المحور } \\
\hline$\%$ & العدد & $\%$ & العدد & $\%$ & العدد & & \\
\hline \multicolumn{2}{|c|}{$\%$ \% Y.V } & \multicolumn{2}{|c|}{$\%$ \% } & \multicolumn{2}{|c|}{$\%$ \%४.०0 } & النسب الترجيحية للازووان النسبية & \\
\hline \multicolumn{2}{|c|}{ الثاني - الثي } & \multicolumn{2}{|c|}{ الأول } & \multicolumn{2}{|c|}{ الثالث } & الترتيب & \\
\hline$\overline{r Y . \wedge \varepsilon}$ & 9. & 19.1 & rq & TY.V & ro & منخفض (• ( & \\
\hline rI. $\leqslant v$ & $T \ll$ & $\$ 1.7$ & AY & $r \leqslant .0$ & $\checkmark \wedge$ & متوسط (Y) & \\
\hline$£ 0.79$ & 11. & $r \wedge .7$ & V & or.A & $1 . \varepsilon$ & مرتفع ( ؟ بفأكثر) & \\
\hline $1 \ldots$ & $r q \leqslant$ & $1 \ldots$ & $19 \mathrm{~V}$ & $1 \ldots$ & $19 \mathrm{~V}$ & 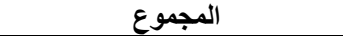 & \\
\hline \multicolumn{2}{|c|}{ YY.q } & \multicolumn{2}{|c|}{51.990} & \multicolumn{2}{|c|}{ YT.AVA } & المتوسط الحسابي & \\
\hline \multirow{2}{*}{\multicolumn{2}{|c|}{$\%$}} & \multicolumn{2}{|c|}{ \%Vr.rY } & \multicolumn{2}{|c|}{$\% \vee 9.09$} & النسب الترجيحية للأزوان النسبية & 3 \\
\hline & الأول & \multicolumn{2}{|c|}{ الثاني } & \multicolumn{2}{|c|}{ الأول } & الترتيب & \\
\hline$r \leqslant . \wedge V$ & $9 \wedge$ & $1 \leqslant . V$ & rq & 10.5 & r. & منخفض (ף ( & \\
\hline$\leqslant 0.11$ & 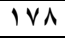 & $\sum V . r$ & 94 & 01.4 & 1.1 & 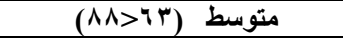 & \\
\hline r9.90 & 111 & $r \Lambda .1$ & vo & $r r .0$ & 74 & مرتفع (^^ فأكثر) & 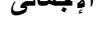 \\
\hline $1 \ldots$ & $r q \leq$ & $1 \cdots$ & $19 \mathrm{~V}$ & $1 \ldots$ & $19 \mathrm{~V}$ & المجموع & \\
\hline
\end{tabular}

يتضح من نتائج جدول (11) أن النسب التزجيحية لإستراتيجية البحث عن المساعدة والمعلومات جاءت لعينة الزوجة فى المرتبة الأولى بنسبة اس.V0\%، تلى ذلك استخدام أسلوب حل المشكلات فى المرتبة الثانية بنسبة بr.\% \% ثم إعادة التقييم الإيجابى فى

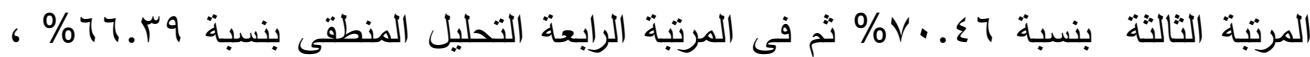
بينما جاءت عينة البحث للزوج فى المرتبة الأولى لاستخدام استراتيجية حل المشكلات بنسبة 9.09.\% \% ث فى المرتبة الثانية التحليل المنطقى بنسبة س79.7\% ثم البحث عن المساعدة والمعلومات فى المرتبة الثالثة بنسبة 00.0 \% ثم فى المرتبة الرابعة إعادة التقييم الإيجابى

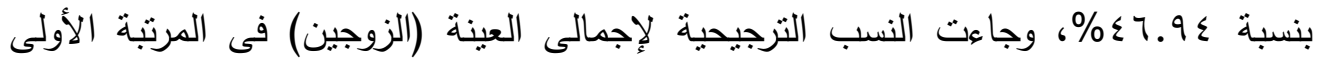

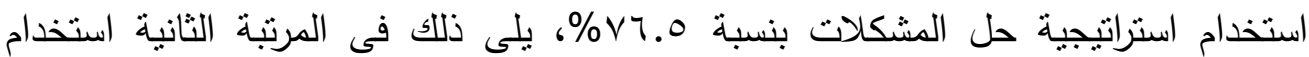
إستراتيجية البحث عن المساعدة والمعلومات بنسبة ثV.V. \% جاء فى المرتبة الثالثة لإستراتيجية التحليل المنطقى للمواقف بنسبة .4\%\% وجاءت إستراتيجية إعادة التقييم الإيجابى فى المرتبة الرابعة بنسبة هـ7\% . وقد اتضح أن مستوى إجمالى استراتيجيات المواجهة الإقدامية للضغوط ككل للعينة متوسط بنسبة 11 ـ0؛ و وتقارب المستوى المنخفض

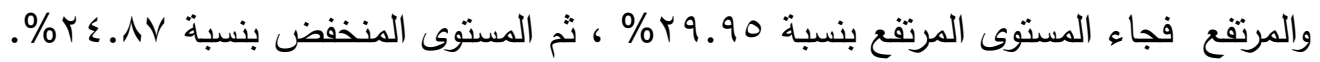

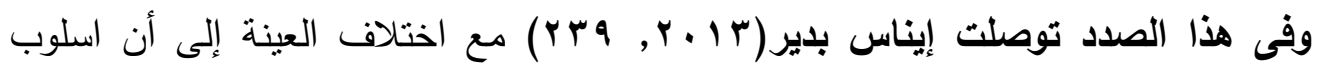


عدد خاص من مجلة "بحوث في العلوم والقنون النوعيه" التونيه

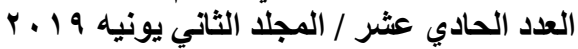

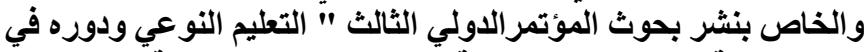

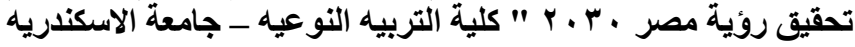

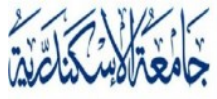

ALEXANDRIA

U N I VER S I T Y

البحث عن المساعدة والمعلومات احتل المرتبة الأولى لدى الذكور، بينما كان فى المرتبة الثالثة لدى الإناث، واحتل أسلوب التحليل المنطقى المرتبة الثانية للذكور، بينما كان فى المرتبة الرابعة والأخيرة للإناث، واحنل أسلوب إعادة التقييم الإيجابى المرتبة الثانية للذكور، بينما كان فى المرتبة الثانية لاى الإناث، واحتل أسلوب حل المشكلات المرتبة الرابعة للذكور، بينما احتل الأولى لدى الإناث, كما توصلت نجيه عبد الله (1 . . r) مع اختلاف العينة إلى أن الذكور أكثر استخداما للأساليب الإقدامية عن الإناث حيث استخدموا أسلوبى التحليل المنطقى وحل المشكلة وكان التحليل المنطقى أول مرتبة للذكور واحتل المرتبة الثالثة عند النساء والمرتبة الثانية للعينة كلها، والتقييم الإيجابى فى المرتبة الثالثة للذكور والأولى للإناث والعينة كلها، والبحث عن المساعدة الأخير للذكور والثانية للإناث، وحل المشكلات فى المرتبة الأخيرة لدى الإناث والثانية لدى الذكور .

Y - وصف استجابات أفراد العينة على استبيان جودة الحياة الأسرية: جدول(r I ) توزيع استجابات أفراد العينة على عبارات (جودة الحياة الزوجية) ن= ؛ و ب(عينة الزوج والزوجة)

\begin{tabular}{|c|c|c|c|c|c|c|c|c|c|c|c|}
\hline \multicolumn{3}{|c|}{ الإجمالى } & \multicolumn{3}{|c|}{ الزوجة } & \multicolumn{3}{|c|}{ الزوج } & & \multirow{2}{*}{ العبارة } & \multirow{2}{*}{ b } \\
\hline نادراً & أحياناً & دائماً & نادراً & أحياناً & دائماً & نادراً & أحيانًا & دائماً & & & \\
\hline 114 & 7.9 & vo & 0. & 99 & $\leqslant 9$ & $7 \varepsilon$ & $1 \cdot V$ & rT & عدد & \multirow{3}{*}{ 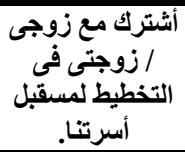 } & \multirow{3}{*}{1} \\
\hline$r \wedge . V$ & OY.r & 19.0 & ro.r & $0 \cdot . \cdot$ & $r \leqslant . V$ & TY.O & $0 \leqslant .1$ & $T H . Y$ & $\%$ & & \\
\hline \multicolumn{3}{|c|}{$* * 99.1 \vee r$} & \multicolumn{3}{|c|}{$* * r \Delta, r \wedge I$} & \multicolumn{3}{|c|}{$* * \bullet \cdot . r$} & & & \\
\hline 11. & $|Y|$ & 174 & 01 & V. & $V V$ & 09 & or & $\wedge \uparrow$ & عدد & \multirow{3}{*}{ 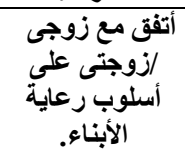 } & \multirow{3}{*}{$r$} \\
\hline rV.q & $r \cdot . v$ & $\leqslant 1 . \leqslant$ & ro. $\Lambda$ & ro.s & $r \wedge . q$ & $r 9.9$ & r..ร & $\varepsilon \Gamma . V$ & $\%$ & & \\
\hline \multicolumn{3}{|c|}{$* * 11.91 \leq$} & \multicolumn{3}{|c|}{1 • ـ. ه غير دالة } & \multicolumn{3}{|c|}{$* q . \wedge 1 \mathrm{~V}$} & كاץ & & \\
\hline $10 \mathrm{~V}$ & $11 r$ & $1 \% 0$ & $\vee \wedge$ & 7. & 09 & 89 & Or & 79 & عدد & \multirow{3}{*}{ 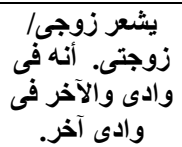 } & \multirow{3}{*}{$r$} \\
\hline$r 9.1$ & $r \wedge . \varepsilon$ & TI.V & $r 9.7$ & $r \cdot .0$ & r9.9 & $\varepsilon \cdot .1$ & Y Y. & rr.o & $\%$ & & \\
\hline \multicolumn{3}{|c|}{$* \wedge .171$} & \multicolumn{3}{|c|}{ r ^ ـ. غ غير دالة } & \multicolumn{3}{|c|}{ rهه.0 غير دالة } & كاץ & & \\
\hline 17. & 119 & 90 & Ar & $V$. & $\leqslant 0$ & $\vee \wedge$ & 79 & 0. & عدد & \multirow{3}{*}{ 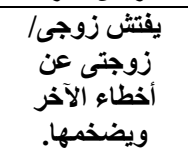 } & \multirow{3}{*}{$\varepsilon$} \\
\hline$\varepsilon . .7$ & $r o . r$ & $r \leq .1$ & $\$ 1.7$ & ro.0 & rY.A & $r 9.7$ & ro.. & ro.s & $\%$ & & \\
\hline \multicolumn{3}{|c|}{$* * 17 . \vee 04$} & \multicolumn{3}{|c|}{$* 1$. Aor } & \multicolumn{3}{|c|}{ * } & كاr & & \\
\hline 181 & $1 \times 9$ & $9 \leq$ & $9 \wedge$ & 71 & $r \wedge$ & $V r$ & 71 & 04 & عدد & \multirow{2}{*}{ يتجنب زوجى/ } & \multirow{2}{*}{0} \\
\hline$\varepsilon r . \varepsilon$ & rY.V & rr.q & $\leqslant 9 . V$ & r... & $19 . r$ & 11.0 & IV.r & $1 \leq . Y$ & $\%$ & & \\
\hline
\end{tabular}

؛ أشارع محمد أمين شهيب ـ مصطفى كامل ـ الاسكندريه ـ مصر تليفون : 203/5454313 Alexandria - Egypt, Tel. : 203/5454313 - 203/5442776 Fax :203/5442776

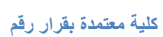
$r \cdot \mid \Lambda / v / r \cdot-(1 \Lambda \cdot)$ E-mail : journal.edusp@alexu.edu.eg Web site: RSSA.edusp@lexu.edu.eg rq 
عدد خاص من مجلة "بحوث في العلوم والقنون النوعيه" التونيه

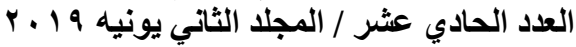

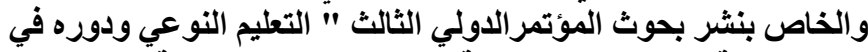

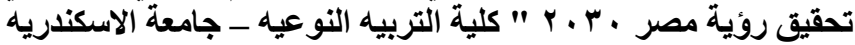

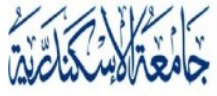

ALEXANDRIA

U N I V E R S I T Y

AlexUPress

(vip)

\begin{tabular}{|c|c|c|c|c|c|c|c|c|c|c|c|}
\hline \multicolumn{3}{|c|}{ الإجمالى } & \multicolumn{3}{|c|}{ الزوجة } & \multicolumn{3}{|c|}{ الزوج } & & \multirow{3}{*}{ منعاً للمشاجشات معى العبارة. } & \multirow{3}{*}{ b } \\
\hline نادراً & أحياناً & دائماً & نادراً & أحياناً & دائماً & نادراً & أحيانًاً & دائماً & & & \\
\hline \multicolumn{3}{|c|}{ **r.rTo } & \multicolumn{3}{|c|}{$* * r \vee . q . q$} & \multicolumn{3}{|c|}{ ه ץ.ب. غير دالة } & كاץ & & \\
\hline 00 & Ir. & $r . q$ & $r V$ & $7 V$ & $1 \cdot r$ & $r \wedge$ & 74 & 1.7 & عدد & يحترم زوجى/ & \\
\hline $1 \leqslant . \cdot$ & rr.e & or.. & $1 T . V$ & $r \varepsilon$. & OY.r & $1 \leq . Y$ & rY.P & or.A & $\%$ & & 7 \\
\hline \multicolumn{3}{|c|}{$* * q \cdot . r 1$} & \multicolumn{3}{|c|}{$* * \varepsilon \varepsilon ., r}$. & \multicolumn{3}{|c|}{$* * \leq ५ . \leqslant \wedge \vee$} & كاץ & & \\
\hline 17. & 149 & 90 & $\wedge 1$ & vo & $\leqslant 1$ & $\theta \wedge$ & 10 & $0 \leq$ & عدد & & \\
\hline$\varepsilon \cdot .7$ & ro.r & $r \leqslant .1$ & $\leqslant 1.1$ & $r \wedge .1$ & $r \cdot . \wedge$ & rq.5 & $\varepsilon r .1$ & YV.\& & $\%$ & تقيزى دا & V \\
\hline \multicolumn{3}{|c|}{$* * 17 . \vee 04$} & \multicolumn{3}{|c|}{$* * 1 \leqslant .1 V r$} & \multicolumn{3}{|c|}{$* 1.77}$. & كاr & مقتع. & \\
\hline 19 & 149 & 187 & $\leqslant 0$ & $\Delta \wedge$ & $9 \leq$ & $\varepsilon \leqslant$ & VI & $\Lambda Y$ & عدد & يقوم زوجي/ & \\
\hline YY.T & rY.V & $\varepsilon \varepsilon . V$ & YY.A & rq. & $\varepsilon V . V$ & YY.r & r... & $\leqslant 1.7$ & $\%$ & زوجتى. بدوره & $\wedge$ \\
\hline \multicolumn{3}{|c|}{$* * \gamma \wedge . \wedge \vee \wedge$} & \multicolumn{3}{|c|}{$* * 19.7 \% \leq$} & \multicolumn{3}{|c|}{$* * 11.7 \leq 0$} & SL & داخل الأسرة. & \\
\hline $11 \varepsilon$ & Iro & 100 & $\leqslant 9$ & 74 & Ao & 70 & $7 r$ & $V \cdot$ & عدد & يسود جو من & \\
\hline$r \wedge . q$ & MI.V & $r q . r$ & $r \leq .9$ & r.. & $\leq r .1$ & rr.. & r.o & $r 0.0$ & $\%$ & الإحترام بينى & 9 \\
\hline \multicolumn{3}{|c|}{$* \eta . \wedge 0 \wedge$} & \multicolumn{3}{|c|}{$* 1 \cdot . \cdot r}$. & \multicolumn{3}{|c|}{ V \ ـ غير دالة } & كاץ & وينين زوجىى & \\
\hline Ar & 1.9 & $r \cdot r$ & $\leqslant 1$ & 09 & $9 V$ & $\leqslant 1$ & 0. & 1.7 & عدد & يساندنى زوجى & \\
\hline$r \cdot . \Lambda$ & YV.V & 01.0 & $r \cdot . \wedge$ & r9.9 & $\leqslant 9 . Y$ & $r \cdot . \wedge$ & Yo.s & or.A & $\%$ & /زوجتى عند & 1. \\
\hline \multicolumn{3}{|c|}{$* * 41 . \leqslant r V$} & \multicolumn{3}{|c|}{$* * r \leq . \wedge q$} & \multicolumn{3}{|c|}{$* * r V . \vee \vee V$} & كاr & صحية. المرور بأزمة & \\
\hline$\wedge 9$ & 170 & $1 \leqslant$. & $r \Lambda$ & $\Lambda 1$ & $\vee \wedge$ & 01 & $\Lambda \varepsilon$ & 74 & عدد & يحرص زوجى/ & \\
\hline YY.T & $\leqslant 1.9$ & ro.0 & $19 . r$ & $\$ 1.1$ & $r 9.7$ & ro.9 & \&Y.7 & $r 1.0$ & $\%$ & & \\
\hline \multicolumn{3}{|c|}{$* * Y Y . \wedge \leq \Lambda$} & \multicolumn{3}{|c|}{$* * 1 V .00 r$} & \multicolumn{3}{|c|}{$* 1.099$} & كاץ & والمشاعزة & 11 \\
\hline $1 \ldots$ & $1 \leq 1$ & 104 & $\leqslant 0$ & 79 & $\wedge \uparrow$ & 00 & Vo & $7 V$ & عدد & أعمل مع زوجى / & \\
\hline Yo.s & $r 0 . \Lambda$ & $r \wedge . \wedge$ & YY.A & rr.o & $\varepsilon r . V$ & rV.q & $r \wedge .1$ & $r \varepsilon$. & $\%$ & & \\
\hline \multicolumn{3}{|c|}{$* * 11.871$} & \multicolumn{3}{|c|}{$* * \mid r . \wedge \cdot r$} & \multicolumn{3}{|c|}{ ד ^ •.ب غير دالة } & كاץ & والضغوط الضرات التى & Ir \\
\hline
\end{tabular}

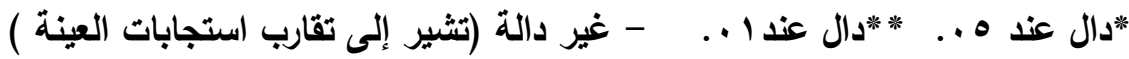
يتضح من نتائج جدول (Y) (Y) تقارب استجابات عينة الأزواج فى إدراكهم لجودة الحياة الزوجية فى العبارات أرقام (Y، 0، 9، Y I)، بينما تقاربت استجابات عينة الزوجات في العبارات أرقام (r، r) وكانت باقى العبارات لكل من الزوج والزوجة دالة حيث كانت كاب دالة عند مستوى (0 ..، 1 . .) ودرجة حرية (Y)، ويذلك اتضح أن إستجابات إجمالى عينة البحث

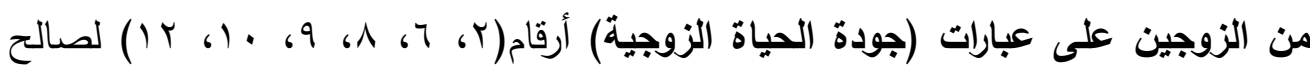


(دائماً) حيث كانت كاب دالة عند مستوى (0..، 1 ...) ودرجة حرية (Y) لتعبر أن معظم أفراد العينة دائماً يتفقون على أسلوب رعاية الأبناء، ويحترمون كلِ منهم أسرار حياة الآخر

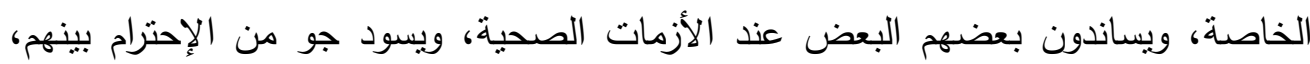

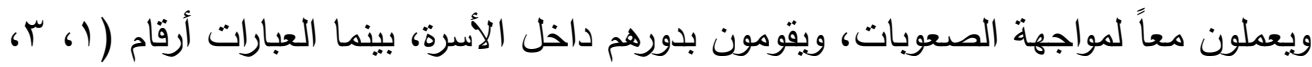

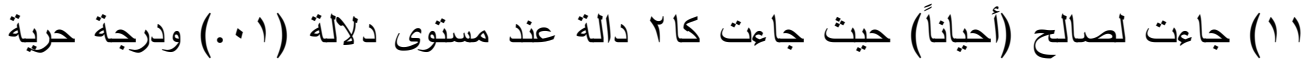

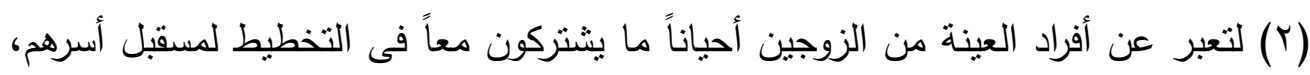

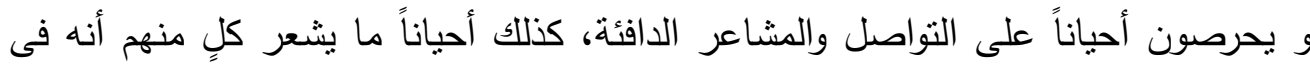

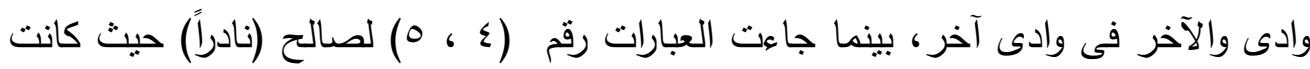
كاr دالة عند مستوى (1 ..) ودرجة حرية (r) لتعبر عن أنه من النادر أن يفتش أى منهم

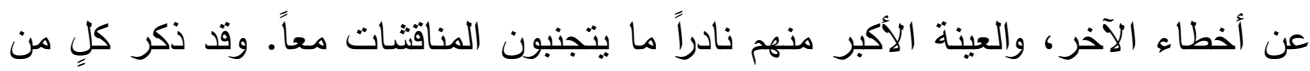

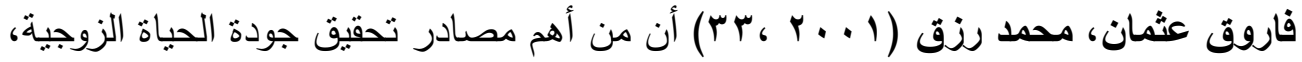

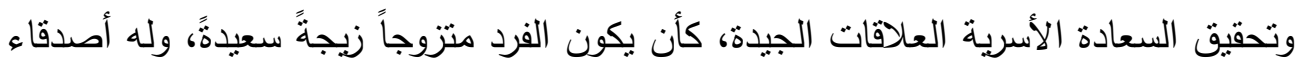
أوفياء، وأن تكون علاقاته جيدة مع أفراد الأسرة .

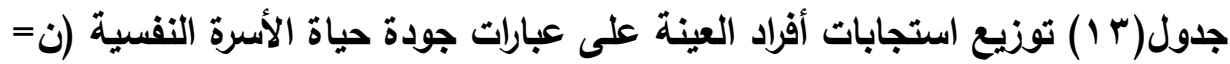

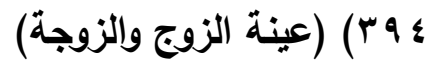

\begin{tabular}{|c|c|c|c|c|c|c|c|c|c|c|c|}
\hline \multicolumn{3}{|c|}{ الإجمالى } & \multicolumn{3}{|c|}{ الزوجة } & \multicolumn{3}{|c|}{ الزوج } & & \multirow{2}{*}{ العبارة } & \multirow{2}{*}{ b } \\
\hline نادراً & أحياناً & دائماً & نادراً & أحياناً & دائماً & نادراً & أحياناً & دائماً & & & \\
\hline$V 7$ & $r \cdot \Lambda$ & 11. & $\varepsilon \varepsilon$ & $1 \ldots$ & $0 \leqslant$ & rT & 1.1 & 09 & عدد & \multirow{3}{*}{ تأثتع بالن أسرتى } & \multirow{3}{*}{1} \\
\hline $19 . r$ & OY.A & rV.q & YY.Y & 0.0 & $r V . r$ & 17.1 & $0 \leqslant . \wedge$ & $r \Lambda . \varepsilon$ & $\%$ & & \\
\hline \multicolumn{3}{|c|}{$* * V 1.0 r r$} & \multicolumn{3}{|c|}{$* * r \vee . \wedge \leqslant \Lambda$} & \multicolumn{3}{|c|}{$* * \varepsilon \leqslant .97 \leqslant$} & كاץ & & \\
\hline $1 . r$ & 110 & $1 . v$ & 00 & 91 & 01 & $\leq V$ & $9 \leq$ & 09 & عدد & \multirow{3}{*}{ 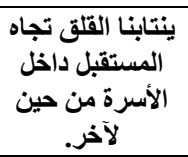 } & \multirow{3}{*}{$r$} \\
\hline$r 0.9$ & $\varepsilon V_{.} \cdot$ & rV.r & $r V . \Lambda$ & $\sum 7 . Y$ & $r 0.1$ & rr.q & $\varepsilon V . V$ & $r \wedge . \varepsilon$ & $\%$ & & \\
\hline \multicolumn{3}{|c|}{ **r Y.99. } & \multicolumn{3}{|c|}{$* * \mid \leq . \vee \wedge r$} & \multicolumn{3}{|c|}{$* * 11.90 \leq$} & كاץ & & \\
\hline IV. & $1 \cdot 1$ & IrT & 94 & $\varepsilon \wedge$ & 07 & VV & Or & $7 V$ & عدد & \multirow{3}{*}{ نتزعج بشكل كبير } & \multirow{3}{*}{$r$} \\
\hline$\varepsilon r .1$ & ro.7 & $r . r$ & $\varepsilon V . Y$ & $r \leqslant . \leqslant$ & $r \wedge . \varepsilon$ & $r q .1$ & 57.9 & $r \varepsilon$. & $\%$ & & \\
\hline \multicolumn{3}{|c|}{$* * 11.919$} & \multicolumn{3}{|c|}{$* * \mid v .00 r$} & \multicolumn{3}{|c|}{ צ ץ ع ــ غير دالة } & كاץ & & \\
\hline$V V$ & $1 \%$. & $1 \wedge V$ & $r q$ & $7 \varepsilon$ & $9 \leq$ & $r \Lambda$ & 79 & 94 & عدد & نؤمن فى الأسرة & $\varepsilon$ \\
\hline
\end{tabular}


عدد خاص من مجلة "بحوث في العلوم والفنون النوعيه"

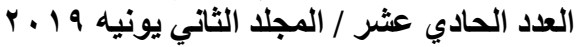

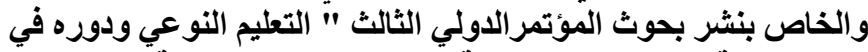

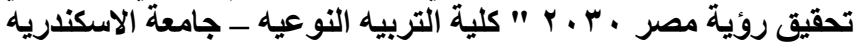

\begin{tabular}{|c|c|c|c|c|c|c|c|c|c|c|c|}
\hline \multicolumn{3}{|c|}{ الإجمالي } & \multicolumn{3}{|c|}{ الزوجة } & \multicolumn{3}{|c|}{ الزوج } & & \multirow{4}{*}{ بأنتا علينا تقبل القبارة } & \multirow{4}{*}{ 阝 } \\
\hline نادراً & أحياناً & دائماً & نادراً & أحيانًاً & دائماً & نادراً & أحيانًا & دائماً & & & \\
\hline 19.0 & rr.e & $\varepsilon V .0$ & 19.1 & rY.o & $\varepsilon V . V$ & 19.4 & rT.0 & $\varepsilon V . Y$ & $\%$ & & \\
\hline \multicolumn{3}{|c|}{$* * \varepsilon\rceil . \wedge \uparrow$} & \multicolumn{3}{|c|}{$* * Y r . .97$} & \multicolumn{3}{|c|}{$* * Y r . \cdot r q$} & SL & & \\
\hline$\Lambda$. & 19. & IY & $\leqslant 0$ & 91 & $0 \leq$ & ro & qr & $V \cdot$ & عدد & \multirow{4}{*}{ يسود في أسرتي } & \multirow{3}{*}{ • } \\
\hline$r \cdot r^{r}$ & $\leqslant \wedge . r$ & M.0 & YY.A & $\varepsilon 9 . V$ & $r V . \varepsilon$ & $1 V . \Lambda$ & $\leq 7 . V$ & $r 0.0$ & $\%$ & & \\
\hline \multicolumn{3}{|c|}{$* * \varepsilon 7.71}$. & \multicolumn{3}{|c|}{$* * r \leq . \leq q v$} & \multicolumn{3}{|c|}{$* * Y 0.171$} & كاץ & & \\
\hline 180 & $11 \leq$ & 1.0 & 99 & Or & $\leqslant 0$ & V & 71 & 7. & عدد & & \multirow{3}{*}{7} \\
\hline$\varepsilon \varepsilon . \varepsilon$ & $r \wedge .9$ & Y.. & $0 . . r$ & ry.9 & YY.A & $r \wedge .7$ & ri.. & $r \cdot .0$ & $\%$ & \multirow{2}{*}{ الأسراجية بالضغوطال. } & \\
\hline \multicolumn{3}{|c|}{$* * Y r . \wedge r$} & \multicolumn{3}{|c|}{$* * Y \bullet . \wedge ५ \wedge$} & \multicolumn{3}{|c|}{ 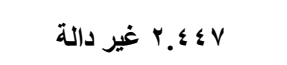 } & كاr & & \\
\hline $9 V$ & $r \cdot r$ & 90 & $\leqslant 7$ & 1.1 & o. & 01 & 1.1 & $\leqslant 0$ & عدد & & \\
\hline$Y \leqslant .7$ & $01 . r$ & $Y \leqslant .1$ & $r r . \varepsilon$ & $01 . r$ & $r 0 . \varepsilon$ & ro.9 & $01 . r$ & YY.A & $\%$ & & $y$ \\
\hline \multicolumn{3}{|c|}{$* * 0 \vee . .01$} & \multicolumn{3}{|c|}{$* * \curlyvee \wedge .7 \leq$} & \multicolumn{3}{|c|}{ 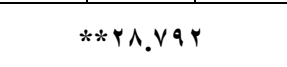 } & كاr & بها داخل الأسرة. & \\
\hline$|Y|$ & 170 & $1 \cdot 1$ & $0 \leqslant$ & $\wedge 9$ & $0 \leq$ & $7 V$ & V & $0 \leqslant$ & عدد & & \\
\hline$r \cdot . v$ & $\$ 1.9$ & $r V . \varepsilon$ & $r V . \varepsilon$ & $\varepsilon 0 . Y$ & $r V . \varepsilon$ & $r \varepsilon$. & $r \wedge .7$ & $r V . \varepsilon$ & $\%$ & & $\Lambda$ \\
\hline \multicolumn{3}{|c|}{$* * 1 r .0 \wedge 9$} & \multicolumn{3}{|c|}{$* * \mid r . \varepsilon r V$} & \multicolumn{3}{|c|}{ דr. Y غير دالة } & كاr & & \\
\hline ITr & 197 & 97 & 7. & $\Lambda \wedge$ & $\leqslant 9$ & VY & $\vee \wedge$ & $\leqslant V$ & عدد & \multirow{3}{*}{ يسود فى أسرتى الرضا } & \multirow{3}{*}{9} \\
\hline rr.o & $\leq Y .1$ & $Y \leqslant . \varepsilon$ & $r \cdot .0$ & $\varepsilon \leqslant . V$ & $r \leqslant .9$ & 19.0 & $r 9.7$ & rr.9 & $\%$ & & \\
\hline \multicolumn{3}{|c|}{$* * 1 \wedge .74}$. & \multicolumn{3}{|c|}{$* * \mid r . r 10$} & \multicolumn{3}{|c|}{$* \Lambda . Y T \leq$} & كاץ & & \\
\hline Ir. & 199 & 70 & Tr & $1 \cdot r$ & rr & 71 & 97 & $r r$ & عدد & نتمتع داخل & \\
\hline rr.e & 0.0 & 17.0 & $r 1.0$ & OY.r & 17.4 & $r \leq .0$ & $\varepsilon \Lambda . \vee$ & 17.1 & $\%$ & الأسرة بعواطف & \\
\hline & $* \neg \wedge . \%$ & & & $=r \wedge .7$ & & & $r \cdot r$ & & كاr & تجاه أنفسناعر إيجابيه & 1. \\
\hline 10. & 1199 & 1.0 & $\vee \wedge$ & VI & $\varepsilon \wedge$ & $V Y$ & 71 & $\Delta V$ & عدد & نعانى فى الأسرة & \\
\hline$r \wedge .1$ & ro.r & Y.. & $r 9.7$ & r.. & $r \leqslant . \varepsilon$ & M. & $r \leqslant .0$ & $r \wedge . q$ & $\%$ & & 11 \\
\hline & $* \wedge . r \wedge 1$ & & & $=.0$. & & & ا. & & كاr & متذبذبه تجاه الآخرين. & 11 \\
\hline $1 V$. & IYr & $1 \cdot r$ & 9. & 00 & Or & $\Lambda \cdot$ & $9 V$ & 0. & عدد & أشعر أن أسرتى & \\
\hline$\varepsilon r .1$ & ri." & 10.9 & $\varepsilon 0 . V$ & rV.q & YY.द & $\varepsilon \cdot .7$ & $r \varepsilon$. & ro.s & $\%$ & & \\
\hline & $* 11.09$ & & & $.1 \% .0$ & & & 4.194 & & كاr & الإحبرض لألى عوضف & Ir \\
\hline
\end{tabular}

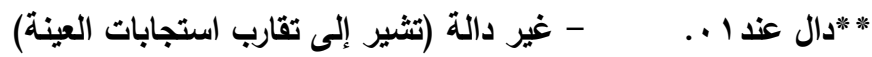
دال عند 0... يتضح من نتائج جدول (r I) أن استجابات عينة الزوجات فى إدراكهن لجودة الحياة النفسية

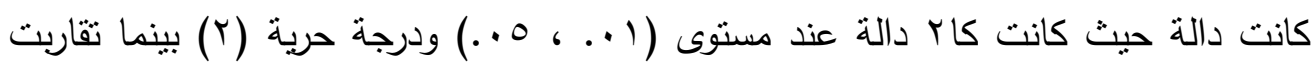

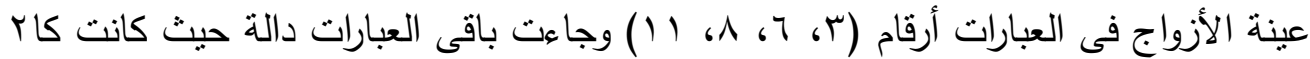

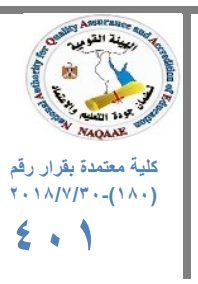

203/5454313 : شارع محمد أمين شهيب ـ مصطفى كامل ـ الاسكندريه ـ مصر تليفون

Alexandria - Egypt, Tel. : 203/5454313 - 203/5442776 Fax :203/5442776

E-mail : journal.edusp@alexu.edu.eg Web site: RSSA.edusp@lexu.edu.eg 
دالة عند مستوى ( ( . , 0. ..) ودرجة حرية (ץ)، ويذلك اتضح أن إستجابات إجمالى عينة

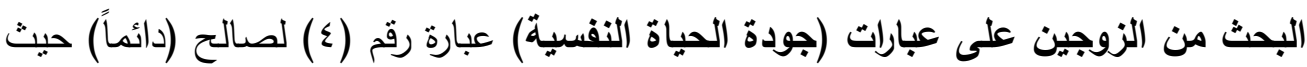
كانت كاب دالة عند مستوى ( ( ..) ودرجة حرية (Y)، لتعبر عن أن الغالبية العظمى من أفراد العينة يؤمنون بأن عليهم تقبل القضاء والقدر، وذلك يُعد من مؤشرات جودة الحياة النفسية

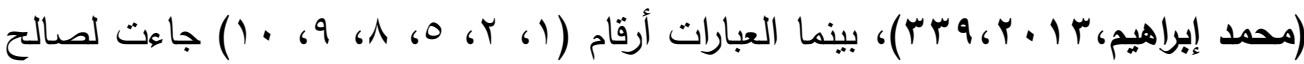

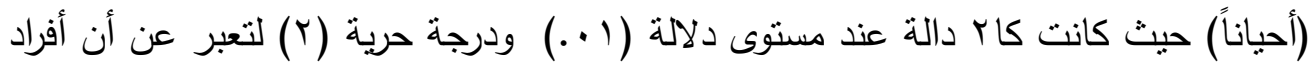
العينة أحياناً ما يشعرون أن أسرهم تتمتع بالإستقرار والهدوء النفسى، ومع ذلانه ذلك أحياناً ما

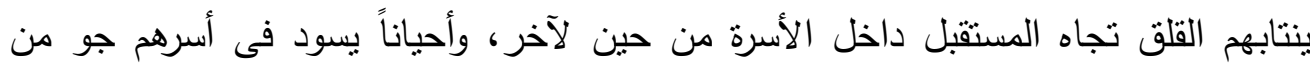
الحيوية والإقبال على الحياة والسعادة، وأحياناً لديهم القدرة على حلى الهين أى مشكلة نواجهها الأسرة، وأحياناً يسود فى أسرهم جو من الرضا وحسن الحال، ويتمتعون أحياناً داخل الأسرة بعواطف ومشاعر إيجابية تجاه أنفسهم وتجاه الآخرين. هذا وقد ارتبطت جودة الحياة النفسية

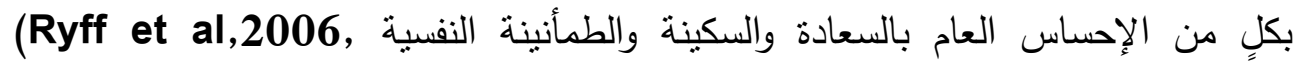
(85:95، كما أنها تتواجد عندما ينوازن داخل الثخص مدى واسع من المشاعر منها الحيوية والإقبال علي الحياة، الثقة في الذات، الصراحة والأمانة مع الذات ومع الآخرين، والبهجة والمرح، السعادة، الهدوء، والإهتمام بالآخرين(Stewart-Brown2000,35 )، وجاءت وله

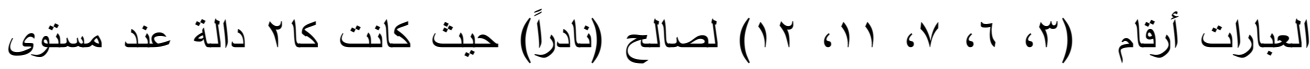

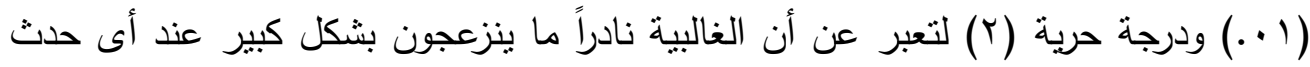

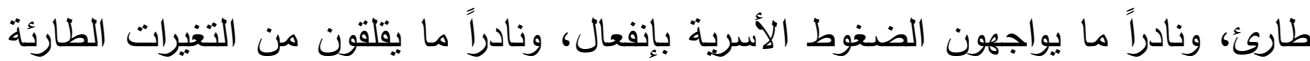

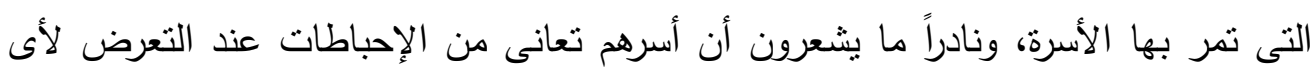

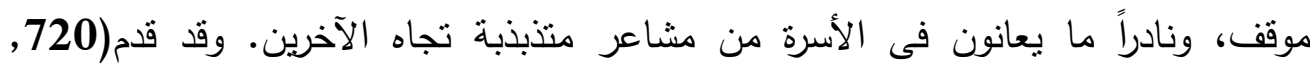
نموذج لجودة الحياة النفسية اشتمل على الحياة الهادفة، وتقبل 
الذات، والسيطرة على البيئة، والإستقلالية، والنمو الثخصى، والتوازن الإنفعالى الذى يتمثل فى ضبط الإنفعالات سواء كانت سلبية أو إيجابية.

جدول(؛ 1) توزيع استجابات أفراد العينة على جودة حياة الأسرة الإجتماعية (ن= ؟ ؟ب) (عينة

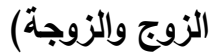

\begin{tabular}{|c|c|c|c|c|c|c|c|c|c|c|c|}
\hline \multicolumn{3}{|c|}{ الإجمالى } & \multicolumn{3}{|c|}{ الزوجة } & \multicolumn{3}{|c|}{ الزوج } & & \multirow{2}{*}{ العبارة } & \multirow[t]{2}{*}{ p } \\
\hline نادراً & أحيانًاً & دائماً & نادراً & أحياناً & دائماً & نادراً & أحيانًاً & دائماً & & & \\
\hline ITr & 187 & $\Lambda 7$ & 79 & 19 & $\leqslant 9$ & 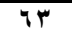 & $9 \mathrm{~V}$ & $r v$ & عدد & \multirow{3}{*}{ لنزيار أيام العطلة وقت العائلية. } & \multirow{3}{*}{1} \\
\hline rr.o & $\varepsilon \varepsilon . V$ & rI.A & ro.. & $\varepsilon \cdot .1$ & $r \leqslant .9$ & rY.P & $\leqslant 9.4$ & 11.1 & $\%$ & & \\
\hline \multicolumn{3}{|c|}{$* * r \cdot . \wedge \leq r$} & \multicolumn{3}{|c|}{$* v .1 \cdot v$} & \multicolumn{3}{|c|}{$* * Y V . \diamond V \varepsilon$} & كاץ & & \\
\hline $11 \mathrm{~V}$ & 119 & 101 & or & 00 & 9. & 70 & $7 \leqslant$ & 71 & عدد & نلتزم كأسرة & \\
\hline rq.V & $r \cdot . r$ & $\varepsilon \cdot .1$ & YY. & $r V .9$ & $\varepsilon 0 . V$ & rr.. & rY.o & $r \varepsilon .0$ & $\%$ & بالعادات والتقاليا & \\
\hline \multicolumn{3}{|c|}{$* \Lambda .1 T V$} & \multicolumn{3}{|c|}{$* * 1 r .09 \leq$} & \multicolumn{3}{|c|}{ ץr ـ غير دالة } & كLY & الإجنمن بهاعيه أفراد النى & Y \\
\hline 10. & 180 & 79 & Vo & $\wedge \wedge$ & $r \leq$ & Vo & $\Lambda V$ & ro & عدد & تحرص أسرتى & \\
\hline$r \wedge .1$ & $\varepsilon \leqslant . \varepsilon$ & $1 V .0$ & $r \wedge .1$ & $\leqslant \leqslant . V$ & IV.r & $r \wedge .1$ & $\varepsilon \varepsilon . Y$ & $1 V .1$ & $\%$ & على حضور & \\
\hline \multicolumn{3}{|c|}{$* * \leqslant ५ . \vee \diamond ५$} & \multicolumn{3}{|c|}{$* * r \leq .19 r$} & \multicolumn{3}{|c|}{$* * r r . \Delta \vee q$} & كاץ & الخاصة بالجيرانة الإنتانة & $r$ \\
\hline $1 \leq$. & 19. & $7 \varepsilon$ & $7 \varepsilon$ & $1 \ldots$ & r & $V 7$ & 9. & $r 1$ & عدد & يتشاررك أفراد & \\
\hline$r 0.0$ & $\varepsilon \Lambda . r$ & 17.9 & rY.O & $0 \cdot .1$ & 17.1 & $r \wedge .7$ & $\leqslant 0 . V$ & $10 . V$ & $\%$ & أسرتى مع & \\
\hline \multicolumn{3}{|c|}{$* * 91.499$} & \multicolumn{3}{|c|}{$* * r \leq . r \leq \varepsilon$} & \multicolumn{3}{|c|}{$* * r \wedge .9 \leq \varepsilon$} & كاץ & مشاعر الفرح & \\
\hline $1+\Lambda$ & 110 & VI & 74 & 97 & $r \Lambda$ & vo & 19 & $r r$ & عدد & نشعر بالمسؤلية & \\
\hline ro.. & $\varepsilon V_{.} \cdot$ & $11 . \cdot$ & rr.P & $\varepsilon \wedge . V$ & $19 . r$ & $r \wedge .1$ & $\varepsilon 0 . Y$ & 17.1 & $\%$ & تجاه الجيران & \\
\hline \multicolumn{3}{|c|}{$* * \varepsilon 9.9 \wedge 0$} & \multicolumn{3}{|c|}{$* *$ * ४.VVV } & \multicolumn{3}{|c|}{$* * \curlyvee \bullet . \wedge \uparrow \wedge$} & كLY & معهم فى & \\
\hline 107 & IYE & 118 & 10 & $7 r$ & 0. & VI & $7 r$ & $7 \leq$ & عدد & يحدث انقسام & \\
\hline$r 9.7$ & $r 1.0$ & $r \wedge . q$ & $\varepsilon r .1$ & 1.0 & Yo.s & r.." & $r 1.0$ & Tr.o & $\%$ & داخل أسرتى & \\
\hline \multicolumn{3}{|c|}{ *V.rr. } & \multicolumn{3}{|c|}{ *9.7\%0 } & \multicolumn{3}{|c|}{ • ^ ^. غير دالة } & كاץ & لأى موقف & 7 \\
\hline IrV & 181 & 97 & $0 \leqslant$ & $\Lambda V$ & 07 & $V T$ & $\Lambda \varepsilon$ & $\varepsilon \cdot$ & عدد & لاينا علاقات & \\
\hline MY.Y & $\varepsilon r . \varepsilon$ & $r \varepsilon . \varepsilon$ & YV.E & $\varepsilon \varepsilon . Y$ & $r \wedge . \varepsilon$ & $r v .1$ & $\varepsilon Y .7$ & $r \cdot . r$ & $\%$ & طيبة إيجابية مع & \\
\hline \multicolumn{3}{|c|}{$* * r 1.7 r q$} & \multicolumn{3}{|c|}{$* 1 \cdot . \leqslant Y q$} & \multicolumn{3}{|c|}{$* * 10.9 \mathrm{~V}}$. & كاץ & الاقمارب يسود من الثقة & $V$ \\
\hline IYr & 107 & 117 & $7 \varepsilon$ & IV & 77 & $0 \wedge$ & 19 & 0 . & عدد & يحترم أفراد & $\Lambda$ \\
\hline
\end{tabular}

؛ أشارع محمد أمين شهيب ـ مصطفى كامل ـ الاسكندريه ـ مصر تليفون : 203/5454313 Alexandria - Egypt, Tel. : 203/5454313 - 203/5442776 Fax :203/5442776

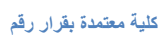
$r \cdot 1 \Lambda / v / r \cdot-(1 \Lambda \cdot)$ E-mail : journal.edusp@alexu.edu.eg Web site: RSSA.edusp@lexu.edu.eg 
عدد خاص من مجلة "بحوث في العلوم والقنون النوعيه" التوديه

العدد الحادي عشر / المجلد الثاني يونيه

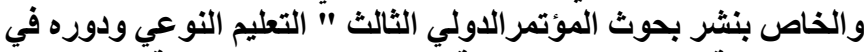

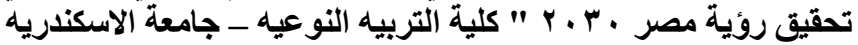

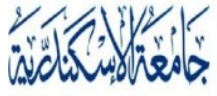

ALEXANDRIA

U N I V E R S I T Y

AlexUPress

(vip)

\begin{tabular}{|c|c|c|c|c|c|c|c|c|c|c|c|}
\hline \multicolumn{3}{|c|}{ الإجمالّى } & \multicolumn{3}{|c|}{ الزوجة } & \multicolumn{3}{|c|}{ الزوج } & & \multirow{2}{*}{ العبارة } & \multirow[t]{2}{*}{ s } \\
\hline نادراً & أحياناً & دائماً & نادراً & أحياناً & دائماً & نادراً & أحيانًاً & دائماً & & & \\
\hline ri.. & $r 9.7$ & rq. & rY.o & $r \varepsilon$. & rr.o & rq. & $\leqslant 0 . Y$ & ro.s & $\%$ & أسرتى حقوق & \\
\hline \multicolumn{3}{|c|}{$* V_{.} \cdot \wedge \mathrm{q}$} & \multicolumn{3}{|c|}{ I • • غير دالة } & \multicolumn{3}{|c|}{$* * 1$ Y.q $\{\varepsilon$} & كاץ & & \\
\hline $1 \leqslant r$ & 100 & 97 & 70 & $\sqrt{9 q}$ & or & $\overline{v \wedge}$ & V & $\varepsilon r$ & عدد & يلتقي أفراد & \\
\hline$r 4 . r$ & $r q . r$ & $r \leqslant . \varepsilon$ & rr.. & $\varepsilon \cdot .1$ & 57.9 & $r 9.7$ & $r \wedge .7$ & YI.A & $\%$ & & \\
\hline \multicolumn{3}{|c|}{$* * 1 \leqslant . \wedge \cdot V$} & \multicolumn{3}{|c|}{ V ا ه غير دالة } & \multicolumn{3}{|c|}{$* * 11 . \vee 79$} & كاr & الإجتماع بشكل دورى. & 1 \\
\hline 179 & $1 Y 9$ & $1 . r$ & 94 & $\Delta V$ & $\leqslant \Lambda$ & $V \leqslant$ & 79 & $0 \leqslant$ & عدد & يـهتم كل فرد فى & \\
\hline \&Y.1 & $r r_{.} \cdot$ & ro.9 & $\leqslant 7 . V$ & $r \wedge .9$ & $r \leqslant . \varepsilon$ & rv. 7 & ro.. & PV.\& & $\%$ & أسرتى بنفسه & \\
\hline \multicolumn{3}{|c|}{$* * 10.919$} & \multicolumn{3}{|c|}{$* * 17 . \leqslant 0 \mathrm{~V}$} & \multicolumn{3}{|c|}{ q ج . ب غير دالة } & كاr & والخاصتة اكله & 1. \\
\hline $10 \%$ & ITY & 1.9 & $\wedge 9$ & $0 \wedge$ & o. & $7 \varepsilon$ & $V \varepsilon$ & 09 & عدد & \multirow{3}{*}{ إلىى الإنعزال عن أسرتى } & \multirow{3}{*}{11} \\
\hline$r \wedge . \wedge$ & rr.o & rV.V & $\leqslant 0 . r$ & Y9. & ro.s & rY.o & $r V .7$ & 19.9 & $\%$ & & \\
\hline \multicolumn{3}{|c|}{$* \vee . Y \vee T$} & \multicolumn{3}{|c|}{$* * 1$ r.q r $\varepsilon$} & \multicolumn{3}{|c|}{ I.vVV غير دالة } & كاץ & & \\
\hline
\end{tabular}

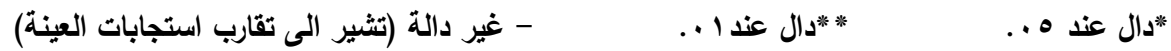

يتضح من نتائج جدول (ع ا) تقارب استجابات عينة الأزواج فى إدراكه لجودة الحياة الإجتماعية فى العبارات أرقام (T، T، I I I I ) بينما تقاربت عينة البحث من الزوجات في العبارات أرقام (V، ^، 9) وكانت باقى العبارات لكل من الزوجين دالة حيث كانت كاب دالة عند مستوى (0 . .، 1 . .) ودرجة حرية (Y). ويذلك اتضح أن إستجابات إجمالى عينة البحث من الزوجين على عبارات جودة الحياة الإجتماعية العبارة رقم (Y) جاءت لصالح (دائماً) حيث كانت كاب دالة عند مستوى (0 . .) ودرجة حرية (r), فدائماً ما يلتزمون كأسرة بالعادات

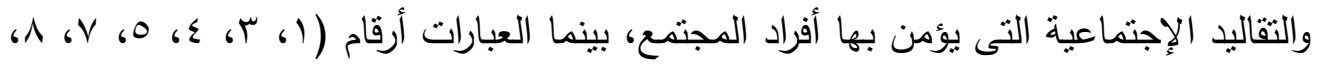
9) جاءت لصالح (أحياناً) حيث كانت كاب دالة عند مستوى دلالة (0 . ، 1 (.) ودرجة حربة (Y)، لتعبر عن أن أفراد العينة أحياناً ما يخصصون وقت أيام العطلات للزيارات العائلية، ومشاركة أسرهم فى المناسبات الإجتماعية الخاصة بالعائلة أو الجيران، ومشاركة أفراد أسرتهم مع بعضهم البعض مشاعر الفرح والحزن، وشعورهم بالمسؤلية تجاه الجيران وإتجاههم للوقوف 
معهم فى الأزمات، و علاقاتهم الطيبة الإيجابية مع الأقارب التى يسودها جو من الثقة

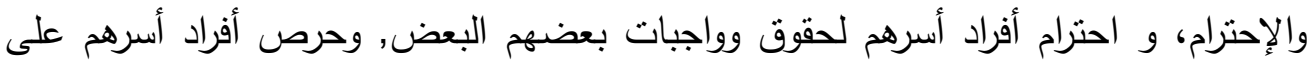

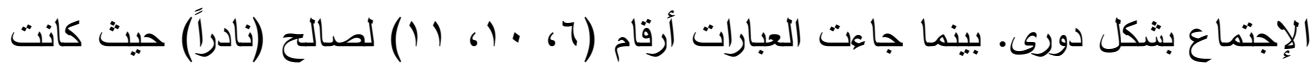
كاب دالة عند مستوى (0... 1 ...) ودرجة حرية (r) لتعبر عن أن أفراد العينة نادراً ما يحدث انقسام داخل أسرهم عندما يتعرضون لأى موقف ضاغط, ونادراً ما بهنم كل فرد في أسرانه أسرهم

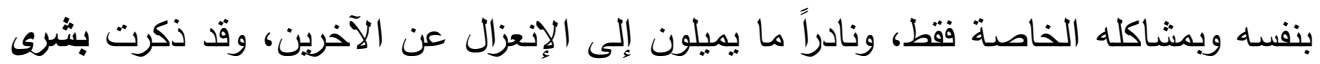

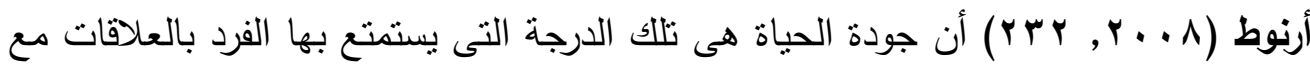

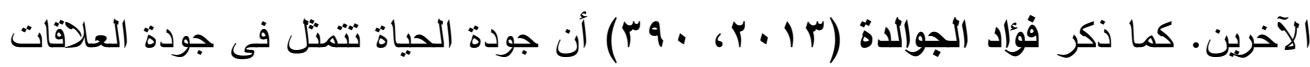

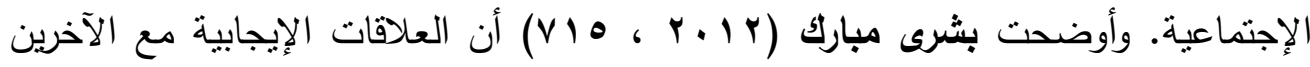
تساعد على تحقيق الأهداف فى الحياة، ومن ثم جودة الحياة. ب-توزيع مستويات جودة الحياة الأسرية لكل محور: جدول(0 1 ) توزيع مستويات جودة الحياة الأسرية لكل محور

\begin{tabular}{|c|c|c|c|c|c|c|c|}
\hline \multicolumn{2}{|c|}{ الإجمالى (الزوجين) } & \multicolumn{2}{|c|}{ الزوجة } & \multicolumn{2}{|c|}{ الزوج الزوج } & \multirow[t]{2}{*}{ المستوى } & المحور \\
\hline$\%$ & العدد & $\%$ & العدد & $\%$ & العدد & & \multirow{8}{*}{ 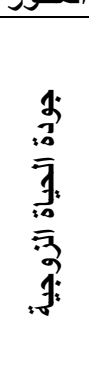 } \\
\hline $\mid \sum . Y 1$ & 09 & IY.V & ro & $10 . V$ & $r 1$ & 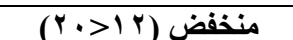 & \\
\hline$\leqslant \leqslant .17$ & $1 V \varepsilon$ & $r \wedge .7$ & $\sqrt{79}$ & $\varepsilon 9 . V$ & 91 & متوسط (r^>r) & \\
\hline$\varepsilon 1.7 r$ & $17 \varepsilon$ & $\varepsilon \Lambda . \vee$ & 97 & $r \leqslant .0$ & 71 & مرتفع (^ rفأكثر) & \\
\hline $1 \ldots$ & एq & $1 \ldots$ & $19 V$ & $1 \ldots$ & $19 V$ & المجموع & \\
\hline \multicolumn{2}{|c|}{ ro.9 } & \multicolumn{2}{|c|}{ Y7. $\leqslant \varepsilon$} & \multicolumn{2}{|c|}{ YO.YY } & المتوسط الحسابي & \\
\hline \multicolumn{2}{|c|}{$\% \vee 1.9$} & \multicolumn{2}{|c|}{$\% \vee r . \varepsilon$} & \multicolumn{2}{|c|}{$\% v \cdot . r$} & النسب الترجيحية للازوان & \\
\hline \multicolumn{2}{|c|}{ الأول } & \multicolumn{2}{|c|}{ الأول } & \multicolumn{2}{|c|}{ الأول } & الترتيب & \\
\hline $19.1^{9}$ & $\sqrt{ } 7$ & $1 V .1$ & ro & $Y \cdot . \Lambda$ & \&1 & 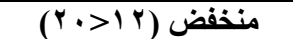 & \multirow{4}{*}{$\begin{array}{l}j \\
\overline{3} \\
\overline{3} \\
\overline{10}\end{array}$} \\
\hline $0 . Y_{0}$ & 191 & $0 . .1$ & $1 \ldots$ & $\leqslant 9 . V$ & $9 \wedge$ & متوسط ( • & \\
\hline$r \cdot . \leqslant 7$ & Ir. & $\mu 1.0$ & $4 r$ & Yq.६ & $0 \wedge$ & مرتفع (^ ץفأكثر) & \\
\hline$\ldots$ & एव & $1 \ldots$ & $19 V$ & $1 \ldots$ & $19 V$ & المجموع & \\
\hline \multicolumn{2}{|c|}{$r \varepsilon . \wedge$} & \multicolumn{2}{|c|}{ ro.Pr } & \multicolumn{2}{|c|}{$r \leqslant . \leqslant q$} & المتوسط الحسابي & $\overline{7}$ \\
\hline \multicolumn{2}{|c|}{$\% \curlyvee \wedge . \wedge$} & \multicolumn{2}{|c|}{$\% 79.0$} & \multicolumn{2}{|c|}{$\%$ \%.• } & النسب الترجيحية للأزوان & בצ: \\
\hline \multicolumn{2}{|c|}{ الثانى } & \multicolumn{2}{|c|}{ الثانى } & \multicolumn{2}{|c|}{ الثانى } & الترتيب & 3 \\
\hline
\end{tabular}

؛ 1 شارع محمد أمين شهيب - مصطفى كامل ـ الاسكندريه ـ مصر تليفون : 203/5454313 Alexandria - Egypt, Tel. : 203/5454313 - 203/5442776 Fax :203/5442776

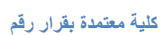
E-mail : journal.edusp@alexu.edu.eg Web site: RSSA.edusp@lexu.edu.eg 
عدد خاص من مجلة "بحوث في العلوم والقنون النوعيه" العزيه

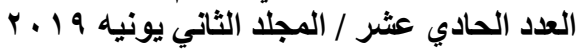

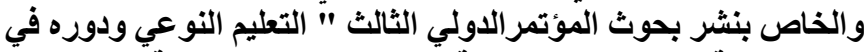

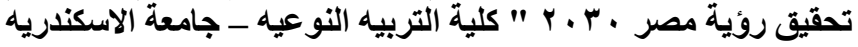

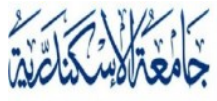

ALEXANDRIA

U N I VER S I T Y

Alexu Press

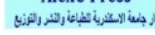

\begin{tabular}{|c|c|c|c|c|c|c|c|}
\hline Yq. & 117 & $\leqslant 9.1$ & $9 \mathrm{~V}$ & 0.9 & $11 \leqslant$ & منخفض (1/1) & \\
\hline$r v . \cdot T$ & $1 \leq 7$ & $1 \leq . V$ & Yq & 10.1 & $M_{1}$ & متوسط (Y (1) & $\$$ \\
\hline rr.o. & TrY & rq. & vi & Y५.ร & OY & مرتفع (0َأكثر) & \\
\hline $1 \ldots$ & rqq & $1 \ldots$ & $19 \mathrm{~V}$ & $1 \ldots$ & $19 \mathrm{~V}$ & المجموع & \\
\hline \multicolumn{2}{|c|}{ Y1. } & \multicolumn{2}{|c|}{ rY.19 } & \multicolumn{2}{|c|}{$r 1 . \cdot r$} & المتوسط الحسابى & \\
\hline \multicolumn{2}{|c|}{$\% 70.4$} & \multicolumn{2}{|c|}{$\%$ TV. 1} & \multicolumn{2}{|c|}{$\%$ \%r.V } & النسب الترجيحية للأزوان & $\vec{q}$ \\
\hline \multicolumn{2}{|c|}{ الثالث } & \multicolumn{2}{|c|}{ الثالث } & \multicolumn{2}{|c|}{ الثالث } & الترتيب & \\
\hline $\mid \leqslant . M 1$ & 04 & Ir.r & $r \varepsilon$ & 17.1 & rr & منخفض (0r>r Pror) & \\
\hline $01 . r v$ & $r \cdot r$ & $\leqslant 9 . r$ & $9 V$ & $0 \varepsilon_{0} \wedge$ & $1 \cdot 1$ & متوسط (V9>07) & \\
\hline$r \leqslant .0 Y$ & $1+4$ & $r \wedge .7$ & V4 & $r \wedge .9$ & OV & مرتفع (qو \فأكثر) & 3 \\
\hline $1 \ldots$ & $r q \varepsilon$ & $1 \ldots$ & $19 V$ & $1 \ldots$ & $19 V$ & المجموع & \\
\hline
\end{tabular}

يتضح من نتائج جدول(ه l) اتفاق ترتيب النسب الترجيحية لعينة الزوج والزوجة والإجمالى

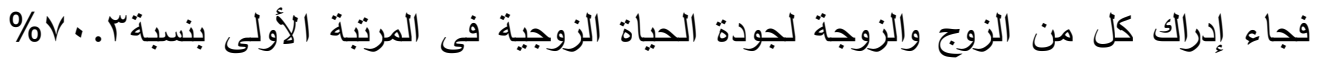

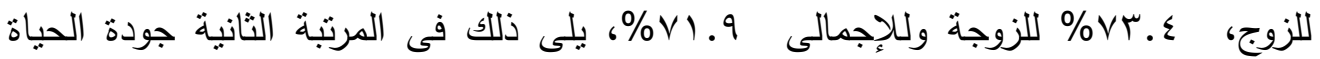
النفسية للأسرة بنسبة...

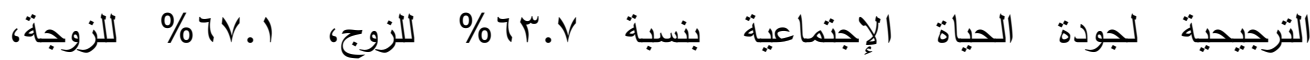

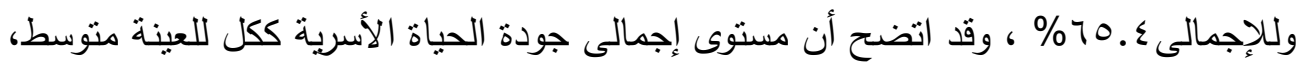

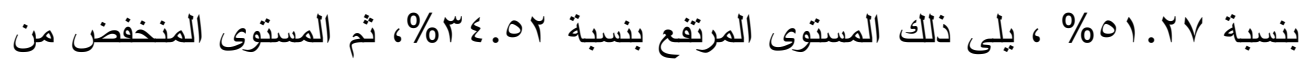

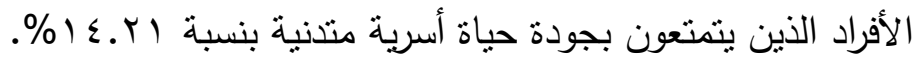

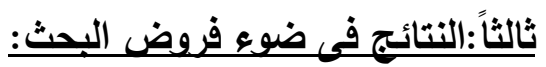
الفرض الأول: نوجد علاقة ارتباطية دالة إحصائياً بين استراتيجيات المواجهة الإقدامية

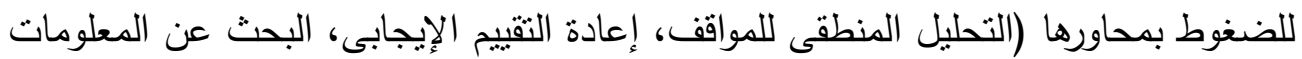

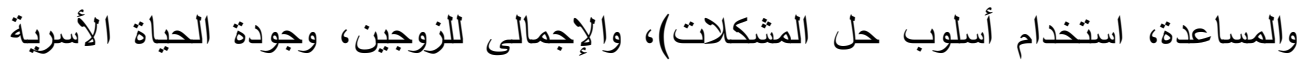
بمحاورها (جودة الحياة الزوجية، جودة حياة الأسرة النفسية، جودة حياة الأسرة الإجتماعية)

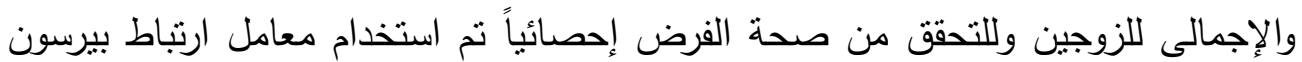
Correlation Pearson 
جدول (7 1 ) معامل الارتباط بين استراتيجيات المواجهة الاقدامية للضغوط للزوجين وجودة

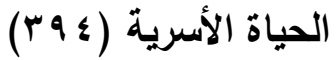

\begin{tabular}{|c|c|c|c|c|}
\hline 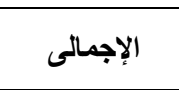 & الإجتماعية الحياة & جودة الحياة & جودة الزية & جودة الحياة الأسرية \\
\hline معامل الإرتباط & الإرتباط معامل & معامل الإرتباط & معامل الإرتباط & \\
\hline$* * .07 \leqslant$ & $* * .01$ & $* \% .0 . Y$ & $* * . \leqslant 90$ & التحليل المنطقى للمواقف \\
\hline$* * .0 r q$ & $* * .0 \cdot 4$ & $* * . \leqslant \leqslant 1$ & $* * . \leqslant 91$ & إعادة التفسير الإيجابى \\
\hline$* * .7 \cdot r$ & $* * .000$ & $* * .041$ & $* * .0 Y 1$ & البحث عن المساعدة و المعلومات \\
\hline$* * .7 \leq \leq$ & $* * .0 \wedge 9$ & $* * . \Delta V$. & $* * .07$. & استخدام أسلوب حل المشكلات \\
\hline$* * . \vee 70$ & $* * . V \cdot r$ & $* \% .77 V$ & $* * .7 V 1$ & الإجمالى \\
\hline
\end{tabular}

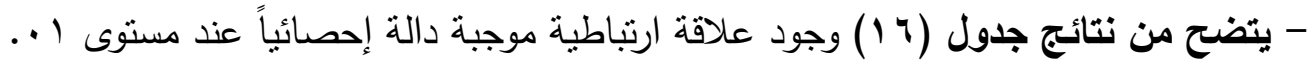
بين درجات عينة البحث (الزوجين) فى استراتيجيات المواجهة الإقدامية للضغوط بمحاورها (التحليل المنطقى، إعادة التقييم الإيجابى، البحث عن المساعدة والمعلومات، استخدام أسلوب حل المشكلات)، والإجمالى، وجودة الحياة الأسرية بمحاورها (جودة الحياة الزوجية، جودة حياة

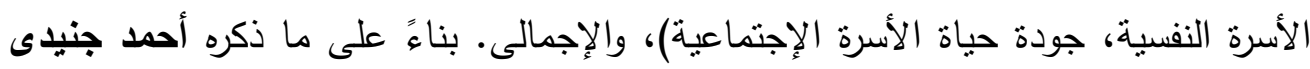

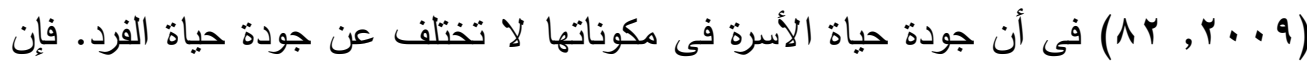

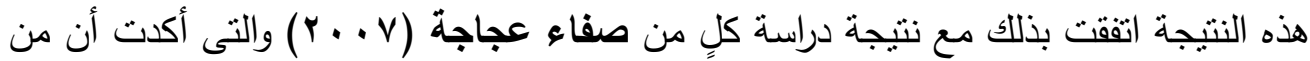

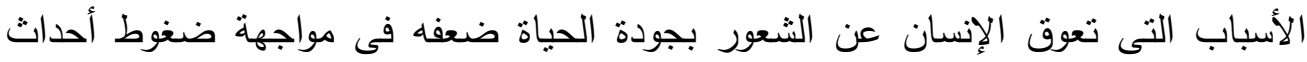
الحياة, ودراسة عزة عبد الحميد (11) التى الكدت وجود علاقة دالة سالبة بين المواقف الضاغطة والإحساس بجودة الحياة، ودراسة أميرة بخش) ج ج . ب (والتى أكدت أن الطريقة التى نتعامل بها مع المواقف الضاغطة فى حياتتا تؤثر على صحتتا الجسدية والنفسية، كما

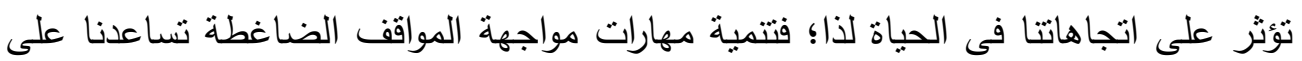

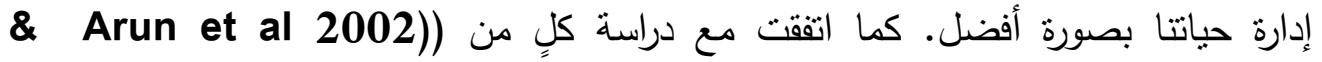
Mathew et al (2009) للضغوط تُحسن إدراك الفرد لجودة الحياة، كذلك اتفقت مع دراسة كلٍ من (2006, 374 
(Morrison \& Bennett بشكلٍ فعالٍ يؤثر سلباً على أهدافهم، وعلى حياتهم بطرق مختلفة. واتفقت كذلك مع نتيجة كلٍ من (Kemp , 2010) حيث أكد أن الفرد الذى يتمتع بجودة حياة عالية يستطيع مواجهة

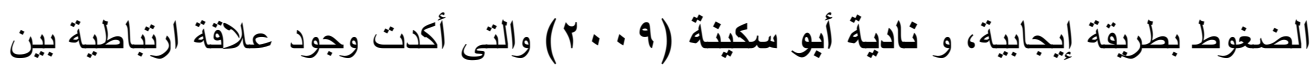

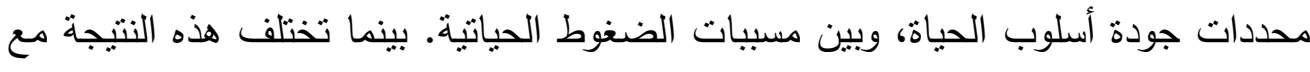
ما توصلت إليه نتيجة دراسة (2004) , Krause والتى أكد فيها على أنه لا توجد علاقة بين أساليب التعامل مع الضغوط وجودة الحياة ؛ لأن الإحساس بجودة الحياة يعتمد على ذات الفرد وليس ما يقابله من ضغنوط.

نستخلص مما سبق وجود علاقة ارتباطية موجبة دالة إحصائياً بين استراتيجيات المواجهة الإقدامية للضغوط بمحاورها والإجمالى، وجودة الحياة الأسرية بمحاورها والإجمالى. ويذلك يكون الفرض الأول قد تحقى كلياً.

الفرض الثانى: توجد فروق بين المتوسطات فى استراتيجيات المواجهة الإقدامية للضغوط بمحاورها والإجمالى وجودة الحياة الأسرية بمحاورها والإجمالى لاى عينة البحث من بن

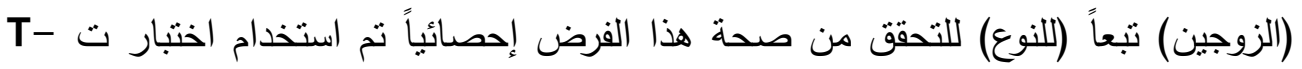
test للوقوف على دلالة الفروق بين متوسطات درجات العينة فى استراتيجيات المواجهة

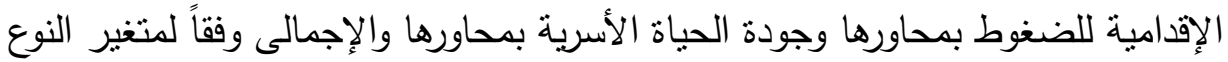

\section{1 - بالنسبة لإستراتيحيات المواجهة الإقدامية للضغوط :}

جدول (I V) دلالة الفروق بين متوسطات درجات عينة البحث فى استراتيجيات المواجهة

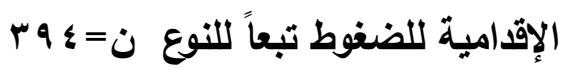


عدد خاص من مجلة "بحوث في العلوم والقنون النوعيه" / التوبه

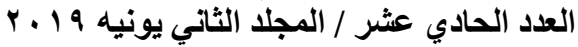

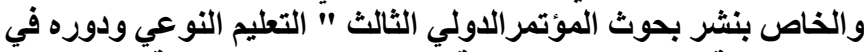

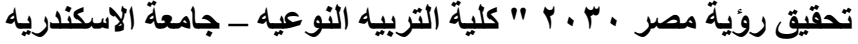

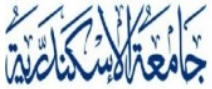

ALEXANDRIA

U N I V E R S I T Y

Alexu Press

Viple

\begin{tabular}{|c|c|c|c|c|c|c|c|}
\hline مستوى الدلالة & قيمة & متوسطات الفرق بين & الإلمعراف افى & المستوسط الحسب & ن & المتغير & المحاور \\
\hline \multirow{2}{*}{ 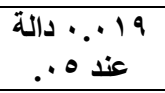 } & \multirow{2}{*}{$r .191$} & \multirow{2}{*}{$\because V \vee V$} & $r . \leqslant 0$ & 17.81 & $19 V$ & الزوج & \multirow{2}{*}{ التحليل المنطقى } \\
\hline & & & $r .0 V$ & 10.94 & $19 V$ & الزوجة & \\
\hline \multirow{2}{*}{ دالة عند 1 •. } & \multirow[b]{2}{*}{$0_{0} .00_{-}$} & \multirow{2}{*}{ r.I rV- } & $\varepsilon . M 1$ & 17.9. & $19 V$ & الزوج & \multirow{2}{*}{ إعادة التفسير } \\
\hline & & & $\varepsilon .+\mu$ & 19.4 & $19 V$ & الزوجة & \\
\hline \multirow[b]{2}{*}{ دالة عند 1 •. } & \multirow{2}{*}{ Y. .०9- } & \multirow{2}{*}{1.817} & $0 . M \varepsilon$ & 11.94 & $19 V$ & الزوج & \multirow{2}{*}{ المعثلث عنات } \\
\hline & & & $0 . M r$ & $r \cdot r \varepsilon$ & $19 V$ & الزوجة & \\
\hline \multirow{2}{*}{ دالة عند 1 •. } & \multirow{2}{*}{ צr } & \multirow{2}{*}{$1 . \wedge \wedge \mu$} & 0.99 & $r r . \wedge \Lambda$ & $19 V$ & الزوج & \multirow{2}{*}{ استخدام أسلوب حل } \\
\hline & & & $0.9 \mathrm{~V}$ & 11.99 & $19 V$ & الزوجة & \\
\hline \multirow{2}{*}{ غير دالة } & \multirow{2}{*}{$\because \diamond \wedge V_{-}$} & \multirow{2}{*}{$\bullet \wedge \wedge \mu$} & $1 \leq .19$ & V7. $\$ 1$ & $19 V$ & الزوج & \multirow[t]{2}{*}{ الإجمالى } \\
\hline & & & $1 \varepsilon .9 V$ & VV.Yq & $19 V$ & الزوجة & \\
\hline
\end{tabular}

يتضح من نتائج جدول (IV ) وجود فروق دالة إحصائياً بين متوسطات درجات عينة البحث فى استراتيجيات المواجهة الإقدامية للضغوط (التحليل المنطقى للمواقف، استخدام أسلوب حل

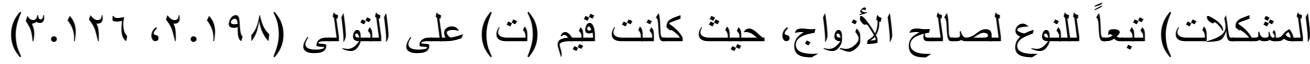
عند مستوى(0..، ...) وتتفق هذه النتيجة مع ما توصلت إليه دراسة كلٍ من مع اختلاف

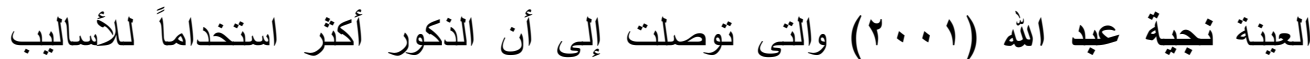
الإقدامية عن النساء؛ حيث استخدما استراتيجيتى(التحليل المنطقى، وحل المشكلات)،

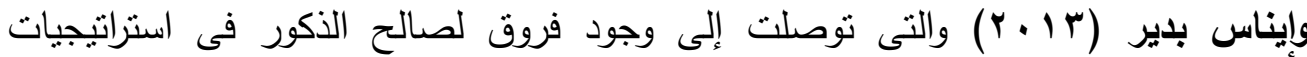
المواجهة الإقدامية فى كل من إعادة التحليل المنطقى، واستخدام أسلوب حل المشكلات. وجود فروق دالة إحصائياً بين متوسطات درجات عينة البحث فى استراتيجيات المواجهة الإقدامية للضغوط (إعادة التفسير الإيجابى، البحث عن المعلومات والمساعدة) تبعاً للنوع لصالح

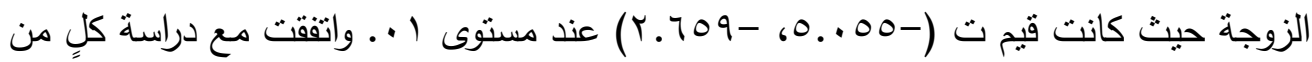

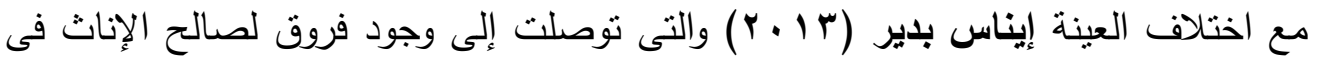

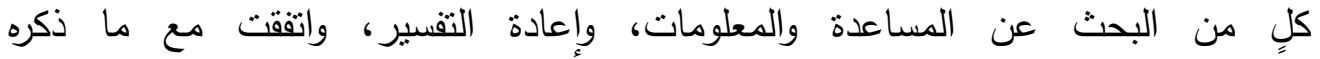
Kumar \& Ramamurti $(1991,227)$

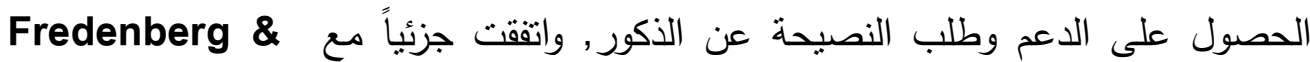

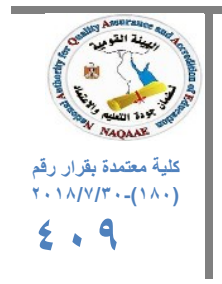

203/5454313 : شارع محمد أمين شهيب ـ مصطفى كامل ـ الاسكندريه ـ مصر تليفون

Alexandria - Egypt, Tel. : 203/5454313 - 203/5442776 Fax :203/5442776

E-mail : journal.edusp@alexu.edu.eg Web site: RSSA.edusp@lexu.edu.eg 
والتى توصلت إلى أن الإناث كن أكثر استخدامًا لكلٍ من (استراتيجية

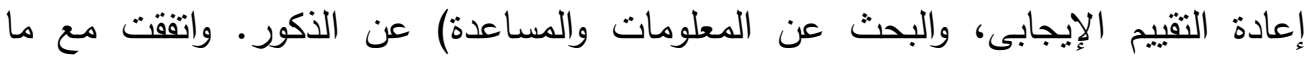
توصلت إليه دراسة King أن الذكور أكثر ميلاً لإستخدام التخطيط لحل المشكلة، و النساء أكثر ميلاً إلى الدعم الإجتماعى, كما تبين عدم وجود فروق دالة إحصائياً

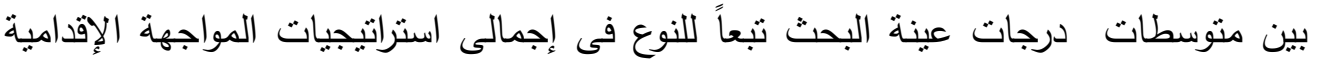

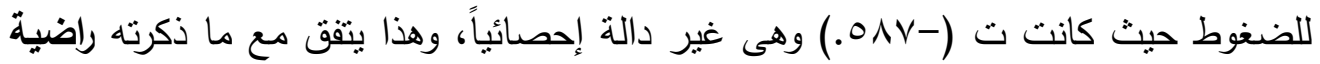

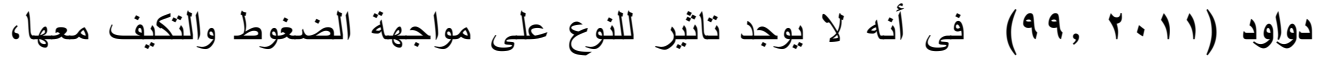
واتفقت كذللك مع ما توصلت اليه دراسة كلٍ من رجب شعبان (1990) أنه لا فرق بين الجنسين فى استخدام الأساليب الإقدامية لمواجهة الضغوط، واختلفت مع ما توصلت إليه دراسة كل من(2001) Rokach \& Ami والتى توصلت أن النساء كن أكثر استخداماً

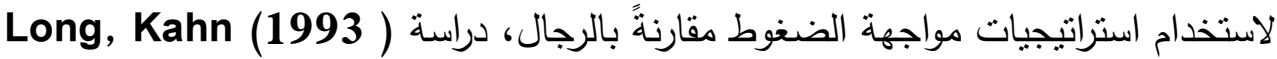

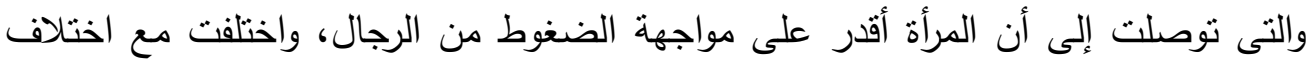

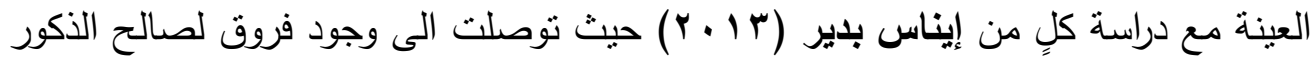

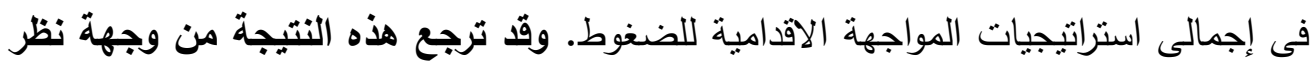

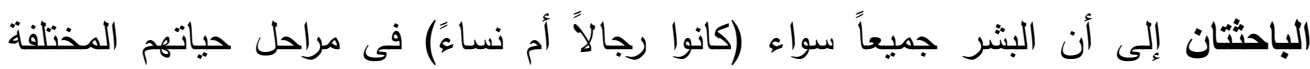
يواجهون العديد من المواقف والأحداث الضاغطة، ويختلف الأفراد فى كيفية التعامل مع هذه اهـ المواقف؛ وهذا يرجع إلى كيفية إدراك الموقف الضاغط، وكيفية تقييمه بغض النظر عن

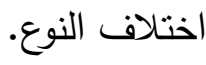

\section{r - بالنسبة لجودة الحباة الأسرية:}

جدول (1 1) دلالة الفروق بين متوسطات درجات عينة البحث فى جودة الحياة الأسرية تبعاً بو 
عدد خاص من مجلة "بحوث في العلوم والقنون النوعيه" العزيه

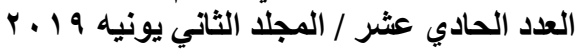

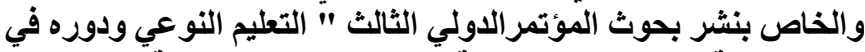

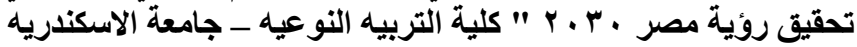

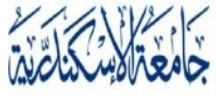

ALEXANDRIA

U N I V E R S I T Y

AlexU Press

(بن

\begin{tabular}{|c|c|c|c|c|c|c|c|}
\hline مستوى الدلالة & قيمة & المتوسطات & الإنحراف & الحستوسط & ن & المتغير & المحاور \\
\hline \multirow{2}{*}{ 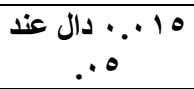 } & \multirow{2}{*}{ Y.\& \&.- } & \multirow{2}{*}{$1.11 \mathrm{~V}$} & ร. $9 q$ & ro.ru & $19 V$ & زوج & \multirow{2}{*}{ جودة الحية } \\
\hline & & & 8.79 & YY. $\{\varepsilon$ & $19 \mathrm{~V}$ & زوجة & \\
\hline \multirow{2}{*}{ ד ץ . · غير دال } & \multirow{2}{*}{ I.YIT- } & \multirow{2}{*}{. OTr_ } & $\varepsilon . \leqslant \psi$ & $r \leqslant . \leqslant 9$ & $19 V$ & زوج & \multirow{2}{*}{ جودة الحياة } \\
\hline & & & $\varepsilon .9^{2}$ & YO.. r & $19 V$ & زوجة & \\
\hline \multirow{2}{*}{ 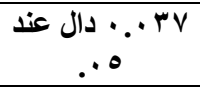 } & \multirow{2}{*}{ r..q1- } & \multirow{2}{*}{$1.1 \leqslant r_{-}$} & $0 . \leqslant r$ & $r 1 . \cdot r$ & $19 \mathrm{~V}$ & زوج & \multirow{2}{*}{ الإجتماعية الحياة } \\
\hline & & & $0 . \leqslant Y$ & YY.IT & $19 \mathrm{~V}$ & زوجة & \\
\hline \multirow{2}{*}{ 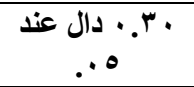 } & \multirow{2}{*}{ r.IV _ } & \multirow{2}{*}{ r.Var- } & IY.VE & $V \cdot . \wedge r$ & $19 V$ & زوج & \multirow{2}{*}{ الإجمالى } \\
\hline & & & Ir.Vo & Vr.TI & $19 V$ & زوجة & \\
\hline
\end{tabular}

يتضح من نتائج جدول (1) (1) وجود فروق دالة إحصائياً بين منوسطات درجات عينة البحث فى إدراك الأزواج لجودة الحياة الأسرية (الزوجية - الإجتماعية - الإجمالى) لصالح

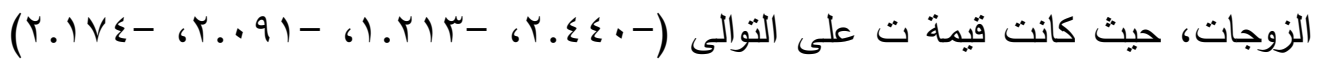

وهى قيم دالة عند مستوى 0. . وقد اتفقت هذه النتيجة مع أمانى عبد المقصود، سميرة شند

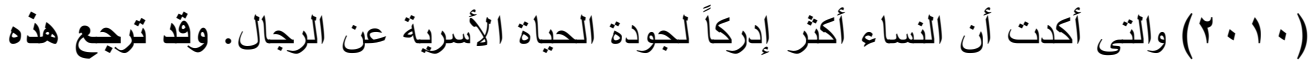
النتيجة من وجهة نظر الباحثثان إلى كبر حجم المسؤليات الملقاة على الرجل فهو المسؤل

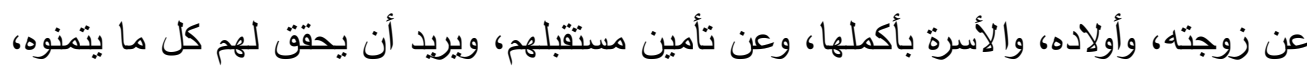

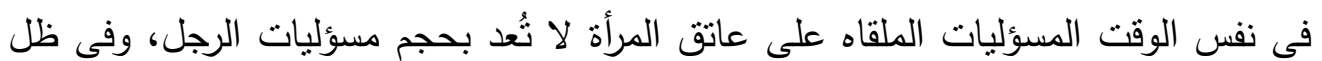

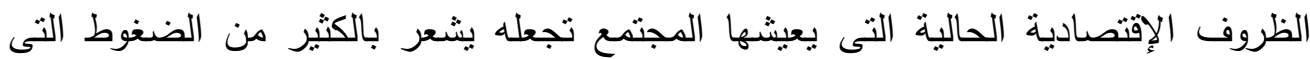
تفقده لذة الحياة والثعور بجودتها. بينما اختلفت مع نتيجة Richmond et al (2000) والتى أكدت عدم وجود فروق بين الرجال والنساء فى جودة الحياة الأسرية. كما اتضح أيضاً عدم وجود فروق دالة إحصائياً بين متوسطات درجات عينة البحث فى إدراك الزوجين لجودة لرداء

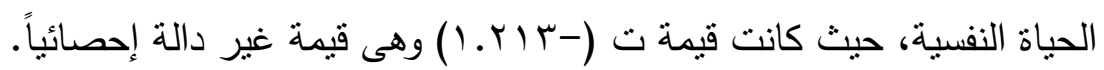

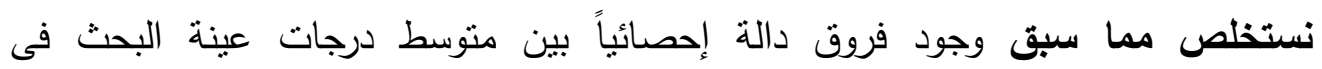
استراتيجيات المواجهة الإقدامية للضغوط بمحاورها وعدم وجود فروق فى الإجمالى تبعاً للنوع. عدم وجود فروق بين متوسطات درجات عينة البحث فى إدراك الزوجين لجودة الحياة النفسية، 
ووجود فروق فى إدرالك الزوجين لجودة الحياة (الزوجية، و الإجتماعية، والإجمالى) لصالح

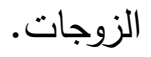

ويذلك يكون الفرض الثانى قد تحقى جزئياً. الفرض الثالث:- توجد فروق بين المتوسطات فى استراتيجيات المواجهة الإقدامية للضغوط

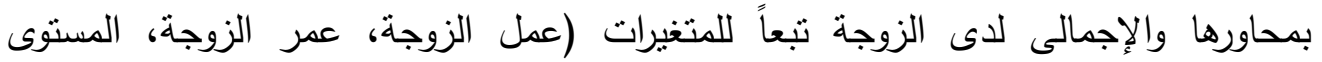

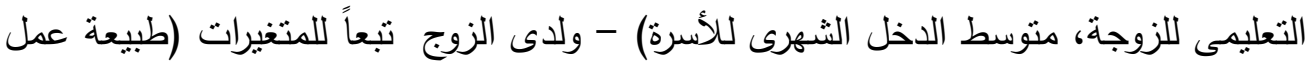

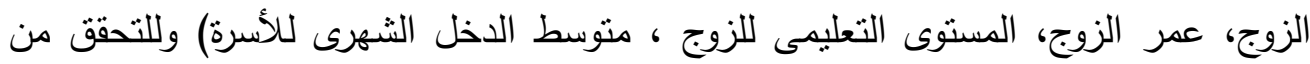
صحة الفرض إحصائياً نم إستخدام إختبار T test للإقوف على التى دلالة الفروق بين متوسطات درجات عينة البحث فى استراتيجيات المواجهة الإقدامية للضغوط بمحاورها

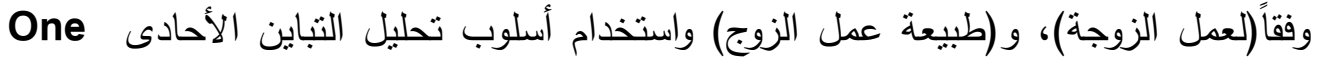
Way Anova

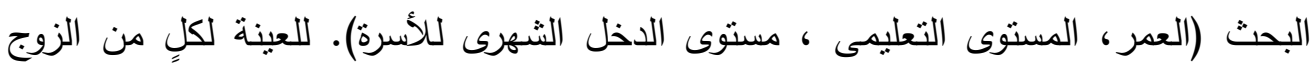

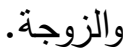

\section{أولاً: عينة البحث من الزوجات:} - بالنسبة لعمل الزوجة:

جدول (9 1 ) دلالة الفروق بين متوسطات درجات عينة البحث فى استراتيجيات المواجهة

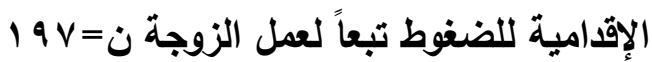


عدد خاص من مجلة "بحوث في العلوم والقنون النوعيه" التونيه

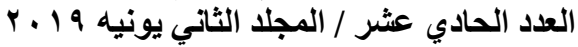

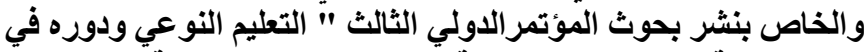

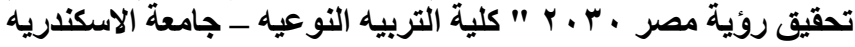

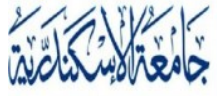

ALEXANDRIA

U N I VER S I T Y

AlexUPress

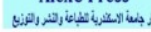

\begin{tabular}{|c|c|c|c|c|c|c|c|}
\hline مستوى الدلالة & قيمة & المتوسط بين & الإلحعراف & الحستوسط & ن & المتغير & المحاور \\
\hline \multirow{2}{*}{ مستوى 1 ـ. } & \multirow[b]{2}{*}{$V_{.} \wedge \cdot \varepsilon$} & \multirow[b]{2}{*}{$r . \leqslant 9 \leqslant$} & $r .107$ & $1 \vee . \wedge \wedge \theta$ & $\Lambda \mathrm{V}$ & تعمل & \multirow{2}{*}{ اللمنطقيل التحقى } \\
\hline & & & $r .99 r$ & $1 \leq . r q 1$ & 11. & لا تعمل & \\
\hline \multirow{2}{*}{ مستوى 1 ـ. } & \multirow{2}{*}{$\varepsilon . Y 07$} & \multirow{2}{*}{ r.rur } & 7.090 & $r \cdot r \leqslant 0$ & $\Lambda \mathrm{V}$ & تعمل & \multirow{2}{*}{ إعادة التقييم } \\
\hline & & & $\varepsilon . v r$ & $1 V .91 Y$ & 11. & لا تعمل & \\
\hline \multirow{2}{*}{ مستوى 1 ـ. } & \multirow[b]{2}{*}{ 7. YYr } & \multirow[b]{2}{*}{$\varepsilon . r \vee q$} & $\varepsilon .7 V V$ & YY.VY & $\Lambda V$ & تعمل & \multirow{2}{*}{ المعلث عات المساعدة } \\
\hline & & & $\varepsilon . \wedge \wedge 1$ & $11 . \leqslant \leqslant 4$ & 11. & لا تعمل & \\
\hline \multirow{2}{*}{ مستوى 1 •. } & \multirow[b]{2}{*}{$\wedge .9 \wedge 9$} & \multirow[b]{2}{*}{$7 . \leqslant 9 r$} & $0.01 \leq$ & $r 0.7 Y 1$ & $\Lambda \mathrm{V}$ & تعمل & \multirow{2}{*}{ أسلوب حلث المشكلات } \\
\hline & & & $\varepsilon .7 Y r$ & $19.1 \mathrm{rV}$ & 11. & لا تعمل & \\
\hline \multirow{2}{*}{ مستوى الة عـ ـ. } & \multirow{2}{*}{ Q.rV } & \multirow{2}{*}{$17.7 \times 9$} & IY.OYY & Aร.0V० & AV & تعمل & \multirow[t]{2}{*}{ الإجمالى } \\
\hline & & & $1 r . \leqslant V 9$ & $79.9 \leq 7$ & 11. & لا تعمل & \\
\hline
\end{tabular}

يتضح من نتائج جدول (9 1 ) وجود فروق دالة إحصائياً بين متوسطات درجات عينة البحث (الزوجات) فى استراتيجيات المواجهة الإقدامية للضغوط (التحليل المنطقى للمواقف، إعادة التقييم الإيجابى، البحث عن المعلومات والمساعدة، استخدام أسلوب حل المشكلات) والإجمالى تبعاً لعمل الزوجة لصالح الزوجات العاملات حيث كانت قيم ت على التوالى

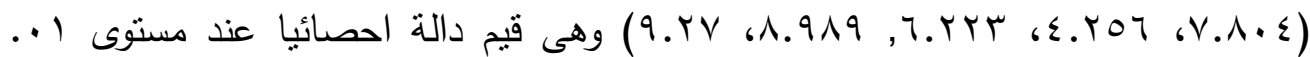

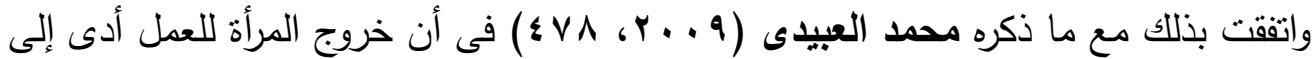

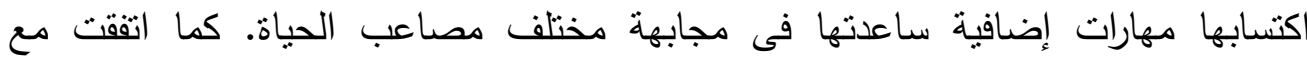

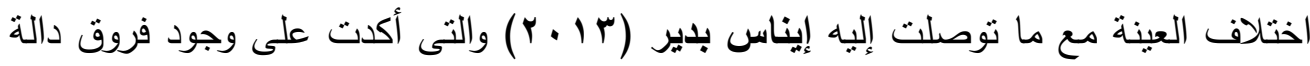

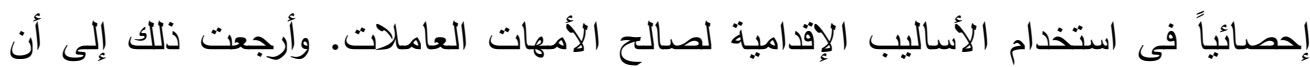
خروج المرأة للعمل يكسبها قدرة ودراية بأساليب التعامل مع أحداث الحياة، ويمنحها المعرفة الإنة والمهارات الإيجابية والاقدامية لمواجهة تلك الأحداث نتيجة الى إحتكاكها مع مشكلات بلهات المجتمع المحيط وبالتالى تتقلها لأبنائها. 


\section{r-بالنسبة لعمر الزوجة:}

جدول ( • r) تحليل التباين أحادى الإتجاه للفروق بين متوسطات درجات عينة البحث من الزوجات

فى استراتيجيات المواجهة الإقدامية للضغوط تبعاً لعمر الزوجة (ن = I I )

\begin{tabular}{|c|c|c|c|c|c|c|}
\hline مستوى & ق فيمة & متوسط المربعات & الحربة & المربعات & مصدر التباين & المحاور \\
\hline \multirow{3}{*}{ دال عند } & \multirow[t]{3}{*}{$1 \leqslant .1 .0$} & 101.19 & r & ג & بين المجموعات & \multirow{3}{*}{ التحليل المنطقى } \\
\hline & & $11 . Y Y$ & 198 & YIVO.VV & داخل المجموعات & \\
\hline & & & 199 & $r \leq 9 Y .1 \leq$ & التباين الكلى & \\
\hline \multirow{3}{*}{ 1ال عند } & \multirow[t]{3}{*}{$1 \cdot . \cdot 41$} & $1 \leqslant 9.0 r$ & r & ห११. ४ & بين المجموعات & \multirow{3}{*}{ إعادة التقييم الإيجابى } \\
\hline & & $1 \leq .91$ & 198 & $r \wedge 91 . \wedge 1$ & داخل المجموعات & \\
\hline & & & 197 & $199 . . \wedge V$ & التباين الكلى & \\
\hline \multirow{3}{*}{ دال عند } & \multirow[t]{3}{*}{ Ir. } & $r .0 .0$ & $r$ & $91 . .1$. & بين المجموعات & \multirow{3}{*}{ البحث عن المعلومات } \\
\hline & & $r \leqslant .0 r$ & 198 & $\varepsilon \vee \bullet V . V q$ & داخل المجموعات & \\
\hline & & & 197 & 0ั4V.१q & التباين الكلى & \\
\hline \multirow[t]{3}{*}{ دال عند } & \multirow[t]{3}{*}{$10 . Y 1 Y$} & $\varepsilon \vee r . \wedge \wedge$ & $r$ & $q \leqslant V . \vee 0$ & بين المجموعات & \multirow{3}{*}{ استخدام أسلوب حل } \\
\hline & & 1.10 & 198 & $7 . \leqslant$ Y.Yo & داخل المجموعات & \\
\hline & & & 199 & $9991 . .$. & التباين الكلى & \\
\hline \multirow[t]{3}{*}{ 1ال عند } & \multirow[t]{3}{*}{$r 1.90 r$} & $\varepsilon .0 Y .1$ & r & $\wedge 1 . \leq . Y \leq$ & بين المجموعات & \multirow{3}{*}{ الإجمالى } \\
\hline & & $11 \leq .09$ & 198 & $r \Delta \wedge 1 \cdot . r v$ & داخل المجموعات & \\
\hline & & & 199 & $\leq r q 1 \leqslant .01$ & التباين الكلى & \\
\hline
\end{tabular}

يتضح من نتائج جدول (·r) وجود تباين دال إحصائياً بين متوسطات درجات عينة البحث من (الزوجات) فى استراتيجيات المواجهة الإقدامية للضغوط تبعاً لعمر الزوجة فى كلٍ من (التحليل المنطقى للمواقف، إعادة التقييم الإيجابى، البحث عن المعلومات والمساعدة، استخدام أسلوب حل المشكلات) والإجمالى لصالح العمر الأكبر للزوجة حيث كانت قيم ف على إنى

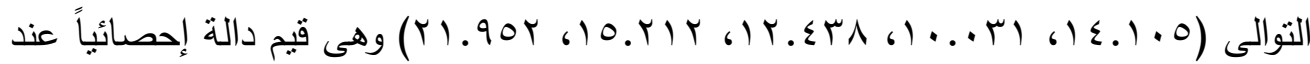

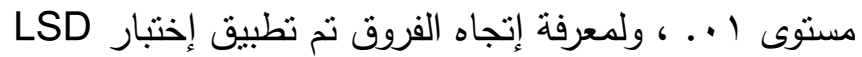
جدول LSD (Y I لمعرفة إتجاه القروق فى استراتيجيات المواجهة الإقدامية للضغوط تبعاً

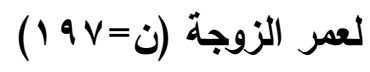


عدد خاص من مجلة "بحوث في العلوم والقنون النوعيه" العزيه

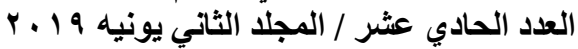

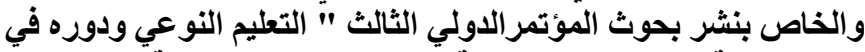

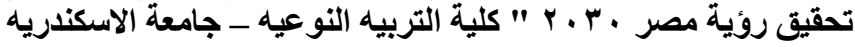

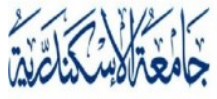

ALEXANDRIA

U N I V E R S I T Y

Alexu Press

(i)

\begin{tabular}{|c|c|c|c|c|c|}
\hline$V Y=\dot{U}$ & $70=\dot{0}$ & $7 \cdot=\dot{0}$ & عمر الزوجة & المتوسط الحسابى & المحاور \\
\hline & & - & أقل من هـ & $1 \varepsilon .17 \mathrm{~V}=0$ & التحليل \\
\hline & - & $* 1.9 r 04$ & من •ب> 0ع & $17.99=8$ & المنطقح \\
\hline \multirow[t]{3}{*}{-} & $* 1.1817$ & $* r_{.} . q V r_{-}$ & من م ع سنة فأكبر & IV.Y $Y \leq=p$ & \\
\hline & & - & أقل من هب & $1 V .00=p$ & \multirow{3}{*}{ إعادة التقيبم } \\
\hline & - & $1 . \mid V M 1$. & من 0r> 0 ع & $1 \Lambda . V Y M=P$ & \\
\hline \multirow[t]{3}{*}{-} & $* 1 . \wedge \cdot 0_{-}$ & $* Y . q \vee \Lambda_{-}$ & من 0 ؛ سنة فأكبر & $r \cdot . \Delta r \Lambda=P$ & \\
\hline & & - & أقل من هب & $1 \Lambda . \cdot \mu=p$ & \multirow{3}{*}{ المعلو عات المساعدة } \\
\hline & - & $* Y_{.} 19 V_{-}$ & من 0ب> 0 ؛ & $r \cdot r r^{r}=p$ & \\
\hline \multirow[t]{3}{*}{-} & $* r_{.} \mid V_{-}$ & $* \varepsilon . \mu \mid \varepsilon$ & من 0 ؛ سنة فأكبر & $r r . r \leq V=P$ & \\
\hline & & - & أقل من هب & $19 . \varepsilon 1 V=p$ & \multirow{3}{*}{ أسلوب حلّ المثلات } \\
\hline & & $1.971 \cdot-$ & من هب> 0؛ & r. $r \wedge \theta=p$ & \\
\hline \multirow[t]{3}{*}{ - } & $* r . r \cdot 1 \cdot-$ & $* 0 . Y \vee \Lambda_{-}$ & من 0 ؛ سنة فأكبر & $r \varepsilon .79 \varepsilon=p$ & \\
\hline & & - & أقل من هب & $79.17 V=0$ & \multirow{3}{*}{ الإجمالى } \\
\hline & - & *V. Y צ & من 0r> & $V q . \varepsilon r \mid=p$ & \\
\hline- & $* \Lambda . \varepsilon \cdot \mu_{-}$ & $* 10.77 \mathrm{~V}=$ & من 0 ؛ سنة فأكبر & 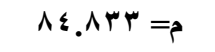 & \\
\hline
\end{tabular}

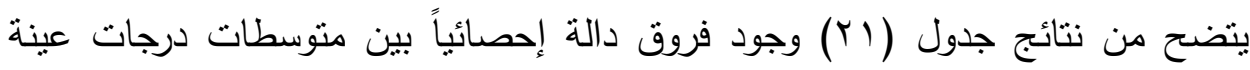

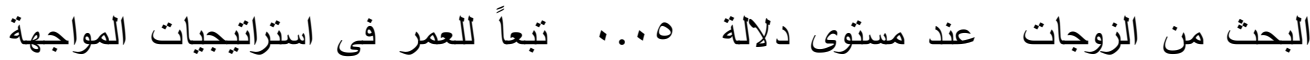
الإقدامية للضغوط (التحليل المنطقى للمواقف، البحث عن المعلومات والمساعدة, الإجمالى) حيث وجد أن ذوات العمر من 0؛ سنة فأكثر كن أكثر قدرة على التحليل المنطقى، والبحث عن المعلومات والمساعدة عن ذوات العمر >هب و العمر المتوسط من هب>0ء، كما تبين

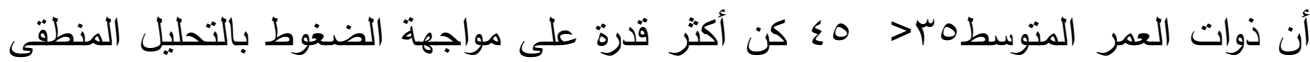

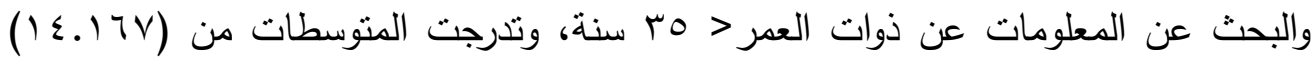

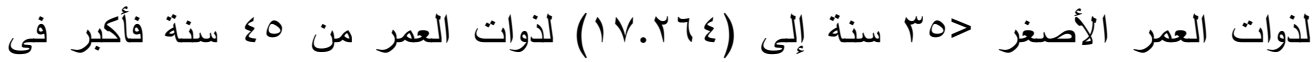

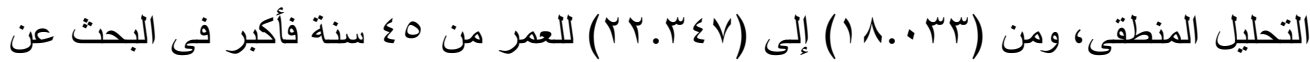

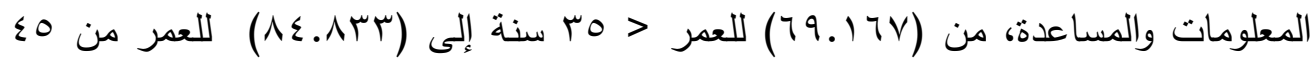


سنة فأكثر فى إجمالى استراتيجيات المواجهة الإقدامية للضغوط، كما تبين أن ذوات العمر من 0؛ سنة فأكثر كن أكثر قدرة على (استخدام أسلوب حل المشكلات، وإعادة النقييم الإيجابى)

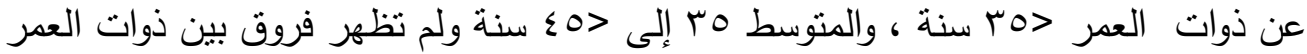

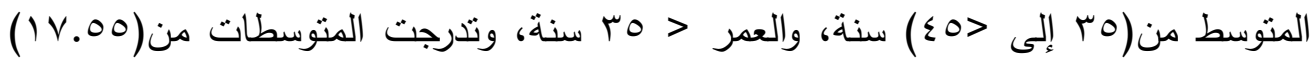

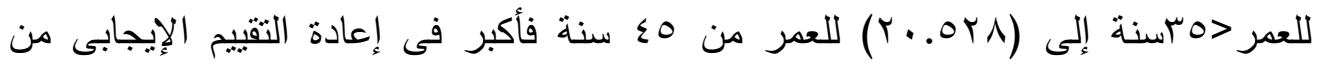

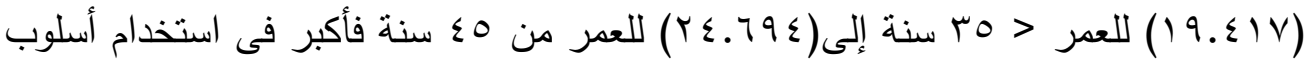

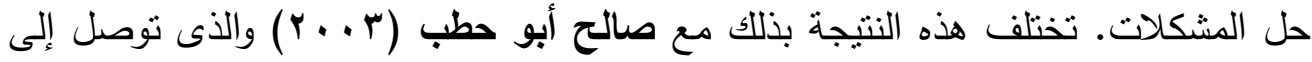

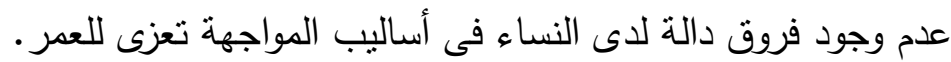

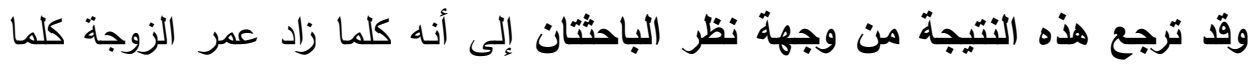
اتسعت مداركها، وزادت خبراتها؛ وذلك بسبب عامل الخبرة المتراكمة التى عايشتها عبر مراحل

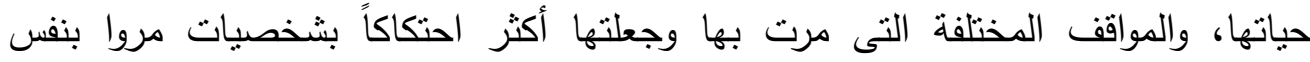
المواقف والظروف، وأكثر معرفةً بالإستراتيجيات التى تعينها على مواجهة المشكلات والتصدى بهى 
عدد خاص من مجلة "بحوث في العلوم والقنون النوعيه" التونيه

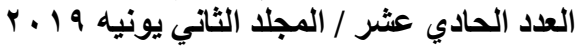

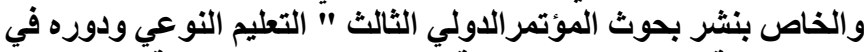

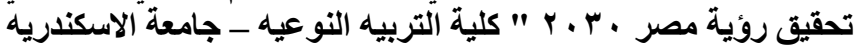

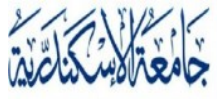

ALEXANDRIA

U N I V E R S I T Y

\section{ب- بالنسبة للمستوى التعليمى للزوجة:}

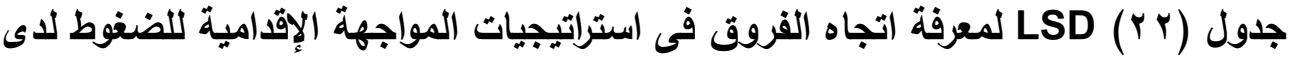

الزوجة تبعاً للمستوى التعليمى للزوجة (ن

\begin{tabular}{|c|c|c|c|c|c|c|}
\hline مستوى الدلالة & ق قيمة & متوبط المربعاث & الحرية & مجموع المربعاث & مصدر التباين & المحاور \\
\hline \multirow{3}{*}{ دالة عند } & \multirow{3}{*}{ IV.rYT } & $\mid \wedge \wedge . \wedge \leq 1$ & r & rVV.YA & بين المجموعات & \multirow{3}{*}{ التمنطيل } \\
\hline & & $1 . .199$ & $19 \leq$ & $Y 1 \leq . \leq 7$ & داخل المجموعات & \\
\hline & & & 197 & $r \leq 9 r .1 \leq$ & التباين الكلى & \\
\hline \multirow{3}{*}{ مستوى الة عند . . } & \multirow[t]{3}{*}{$1 \cdot . \leqslant Y r$} & $10 \leq . \vee 9$ & r & $P .9 .01$ & بين المجموعات & \multirow{3}{*}{ إعادة التقييم } \\
\hline & & $1 \varepsilon . \wedge \circ r$ & $19 \leq$ & $r \wedge \wedge 1 . r q$ & داخل المجموعات & \\
\hline & & & 197 & $M / 9 \cdot . \wedge v$ & التباين الكلى & \\
\hline \multirow{3}{*}{ مستوى I ـ ـ . . } & \multirow[t]{3}{*}{11.194} & rar.IrV & $r$ & О^ร.YV & بين المجموعات & \multirow{3}{*}{ البحث عن المعلومات } \\
\hline & & $r \leq .7 \leq \Lambda$ & $19 \leq$ & $\varepsilon V \wedge 1.7 r$ & داخل المجموعاث & \\
\hline & & & 197 & Orqv.Aq & التباين الكلى & \\
\hline \multirow{3}{*}{ مستوى I ـ ـ ـ . } & \multirow{3}{*}{ Yl. vo } & $9 r+911$ & r & Ir $\leqslant V . \wedge r$ & بين المجموعات & \multirow{3}{*}{ أسلوب المشدام } \\
\hline & & r9.7. & $19 \leq$ & $0 V \leqslant r .1 V$ & داخل المجموعات & \\
\hline & & & 197 & $7991 \ldots$ & التباين الكلى & \\
\hline \multirow{3}{*}{ مستوى الة عند . . } & \multirow{3}{*}{ ro..9V } & $\varepsilon 0 \mid$ r.pq1 & r & 9.74 .01 & بين المجموعات & \multirow{3}{*}{ الإجمالى } \\
\hline & & IVq.人ro & 198 & $r \varepsilon \wedge \wedge \vee .9 r$ & داخل المجموعات & \\
\hline & & & 197 & $\varepsilon+q \mid \leq .01$ & التباين الكلى & \\
\hline
\end{tabular}

يتضح من نتائج جدول (Yr) وجود تباين دال إحصائياً بين منوسطات درجات عينة البحث (الزوجات ) فى استراتيجيات المواجهة الإقدامية للضغوط (التحليل المنطقى للمواقف، إعادة الثقييم الإيجابى، البحث عن المساعدة والمعلومات، استخدام أسلوب حل المشكلات)

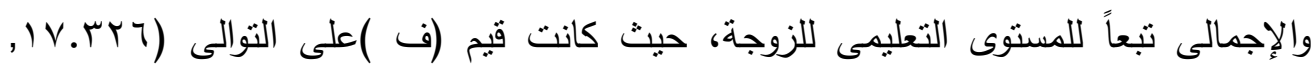

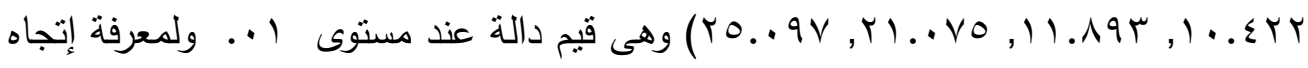

LSD الفروق نم تطبيق إختبار

ع أشارع محمد أمين شهيب - مصطفى كامل ـ الاسكندريه ـ مصر تليفون : 203/5454313

Alexandria - Egypt, Tel. : 203/5454313 - 203/5442776 Fax :203/5442776

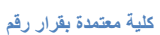

E-mail : journal.edusp@alexu.edu.eg Web site: RSSA.edusp@lexu.edu.eg 
عدد خاص من مجلة "بحوث في العلوم والقنون النوعيه" التونيه

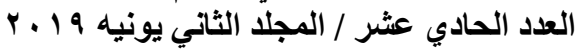

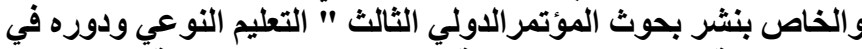

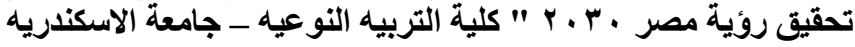

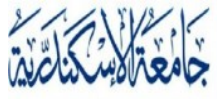
ALEXANDRIA

U N I V ER S I T Y

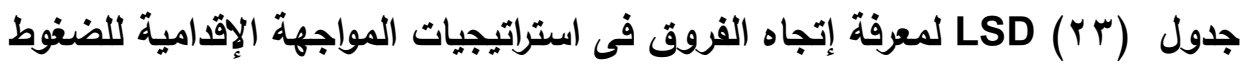

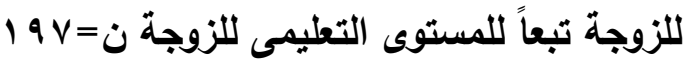

\begin{tabular}{|c|c|c|c|c|c|}
\hline$\Delta \wedge=\dot{U}$ & $v \bullet=\dot{U}$ & ن & اللزوجتوى التعليمى & الحستوسطى & المحاور \\
\hline & & - & مستوى تعليمى منخفض & $1 \leq . r Y \wedge=P$ & التحليل \\
\hline & - & $* 1 . \leqslant 99$ & مستوى تعليمى متوسط & $10 . \wedge Y V=p$ & المنطقى \\
\hline \multirow[t]{3}{*}{ - } & $* Y_{.} \cdot 1 \Lambda_{-}$ & $* r .01 V_{-}$ & مستوى تعليمى مرتفع & $I V . \wedge \leq 0=p$ & للمواقف \\
\hline & & - & مستوى تعليمى منخفض & $1 V .0 \ldots=p$ & إعادة \\
\hline & - & $* 1.0 \leq \cdot-$ & مستوى تعليمى متوسط & $19 . \cdot \varepsilon \cdot=8$ & التقييم \\
\hline \multirow[t]{3}{*}{ - } & $* 1.7 \leq 9 V_{-}$ & $* r .1 \wedge 9 V_{-}$ & مستوى تعليمى مرتفع & $r \cdot .79 \cdot=p$ & الإيجابي \\
\hline & & - & مستوى تعليمى منخفض & $11.107=p$ & \multirow{3}{*}{ المعلث عن المسات } \\
\hline & - & *Y.rrv- & مستوى تعليمى متوسط & $r \cdot . \leqslant 9 r=p$ & \\
\hline \multirow[t]{3}{*}{ - } & $* Y_{.} \cdot \varepsilon_{-}$ & $* \varepsilon . r \vee \Lambda_{-}$ & مستوى تعليمى مرتفع & YY.OYO=P & \\
\hline & & - & مستوى تعليمى منخفض & $19 . \wedge 1 Y=p$ & \multirow{3}{*}{ أسلوب الملثدام } \\
\hline & - & $1 . \cdot \Lambda \cdot \Lambda_{-}$ & مستوى تعليمى متوسط & $r \cdot . \wedge 9 r=p$ & \\
\hline \multirow[t]{2}{*}{-} & $* \varepsilon .9 r \varepsilon-$ & $* 4 .+17 .-$ & مستوى تعليمى مرتفع & $r \Delta . \wedge Y \Lambda=p$ & \\
\hline & & - & مستوى تعليمى منخفض & $79 . \vee 9 V=p$ & \multirow{3}{*}{ الإجمالى } \\
\hline - & - & $* 7 . \leqslant 0 V_{-}$ & مستوى تعليمى متوسط & $V Y . Y O Y=P$ & \\
\hline- & $* 1 \cdot .7 \leq-$ & $* 1 V_{.} .99 V_{-}$ & مستوى تعليمى مرتفع & $\wedge \neg . \wedge 9 \vee=p$ & \\
\hline
\end{tabular}

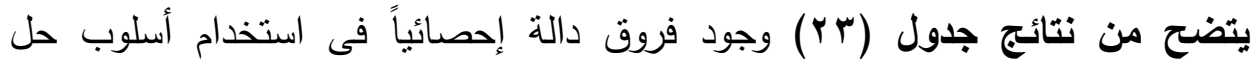
المشكلات بين متوسطات درجات عينة البحث (الزوجات) تبعاً لتعليم الزوجة عند مستوى داته دلالة ه..

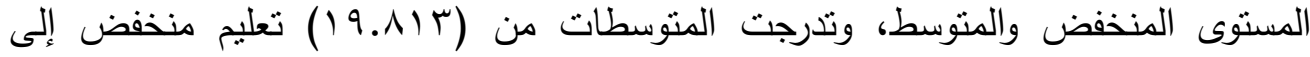

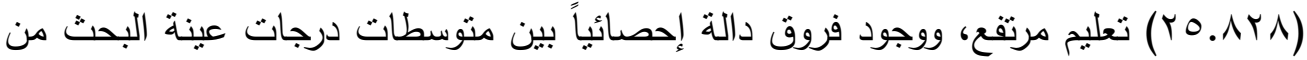
الزوجات عند مستوى دلالة ه... فى استراتيجيات المواجهة الإقدامية للضغوط (التحليل

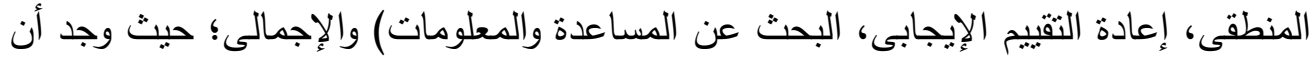
ذوات المستوى التعليمى المرتفع، والمتوسط كن أكثر قدرة على استخدام استراتيجيات المواجهة الاقدامية للضغوط عن ذوات التعليم المنخف، كما أن ذوات التعليم المتوسط كن أكثر قدرة 
على استخدام استراتيجيات المواجهة الإقدامية للضغوط عن ذوات التعليم المنخفض، وتدرجت

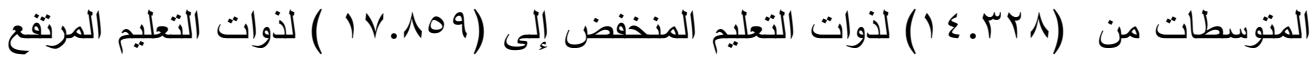

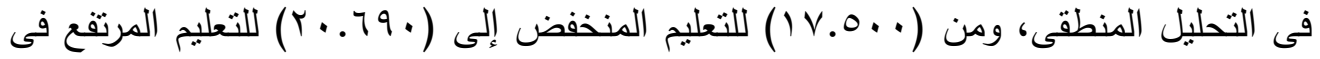

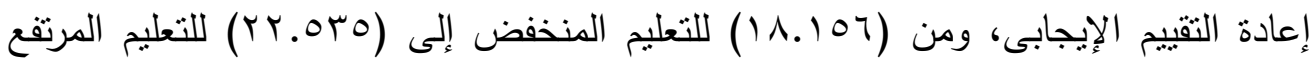
فى استراتيجية البحث عن المساعدة والمعلومات، ومن (9.V9V) لتعليم المنخفض إلى إنى

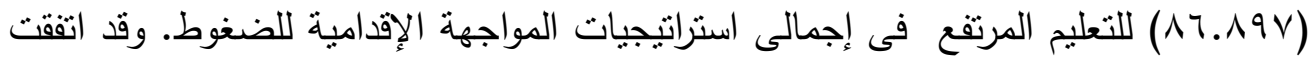

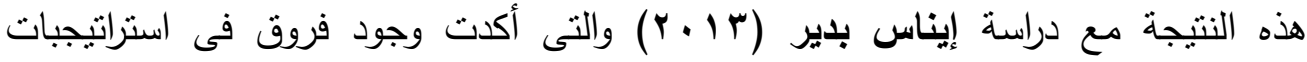
المواجهة الإقدامية للضغوط لصالح مستوى التعليم الأعلى لكل من الأمهات والآباء. واختلفت مع صالح أبو حطب (r . . r) والذى توصل إلى عدم وجود فروق دالة لدى النساء فى أساليب المواجهة تعزى للمؤهل العلمى. وقد ترجع هذه النتيجة من وجهة نظر الباحثتان إلى أن المستوى التعليمى المرتفع للزوجة يجعلها أكثر دراية ومعرفة بأفضل الأساليب لمواجهة الضخوط، بحيث بمكن التخفيف منها والتصدى لها، كما أن المستوى التعليمى المرتفع يجعل الظروف المحيطة بالفرد مناسبة للتفكير والسيطرة على الموقف الضاغط بأساليب إقدامية. 
عدد خاص من مجلة "بحوث في العلوم والقنون النوعيه" التونيه

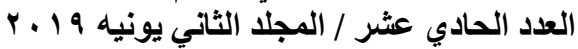

ع - بالنسبة لمستوى الاخل الشهرى للأسرة:

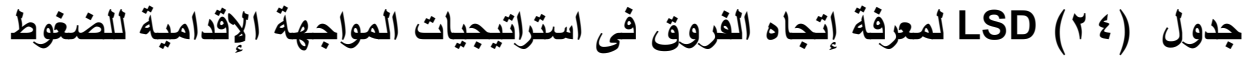

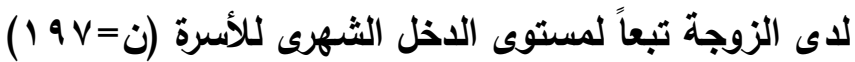

\begin{tabular}{|c|c|c|c|c|c|c|}
\hline مستوى الدلالة & قَّة & المربعات متوسط & الحرية & المربعاث مجوع & مصدر التباين & المحاور \\
\hline \multirow{3}{*}{ مستوى الة عند . } & \multirow{3}{*}{ T.MYY } & Vq. rrq & r & IOY.EVA & بين المجموعات & \multirow{3}{*}{ للمو اقنطقى التحلى } \\
\hline & & $1 Y .9$ & $19 \leq$ & Frrq.74 & داخل المجموعات & \\
\hline & & & 197 & $r \leq q Y .1 \leq$ & التباين الكلى & \\
\hline \multirow{3}{*}{ مستوى 1 •. } & \multirow{3}{*}{$V . \varepsilon r q$} & 114.591 & $r$ & PY7.997 & بين المجموعات & \multirow{3}{*}{ إعادة الإيجابيى } \\
\hline & & $10 . \mathrm{rVA}$ & $19 \varepsilon$ & Yq४r.AVV & داخل المجموعات & \\
\hline & & & 199 & $r / 9 \cdot . \wedge V r$ & التباين الكلى & \\
\hline \multirow{3}{*}{ مستوى 1 • ـ } & \multirow{3}{*}{$0 . V 1 V$} & $1 \leq 9 . r \wedge \varepsilon$ & $r$ & 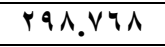 & بين المجموعات & \multirow{3}{*}{ البحث عن المعدة } \\
\hline & & r. 1 rq & 198 & 0.79 .11 & داخل المجموعات & \\
\hline & & & 197 & 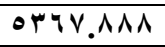 & التباين الكلى & \\
\hline \multirow{3}{*}{ مستوى 1 • . } & \multirow{3}{*}{$|Y . \& Y|$} & 199.V91 & $r$ & V94.090 & بين المجموعات & \multirow{3}{*}{ أسلوب حلخدام المشكلات } \\
\hline & & $1.9 \leqslant 0$ & 198 & $919 V . \varepsilon$ & داخل المجموعات & \\
\hline & & & 197 & $799 \cdot .990$ & التباين الكلى & \\
\hline \multirow{3}{*}{ مستوى 1 ـ . } & \multirow{3}{*}{ Ir.Y१ } & YYEV.YY & $r$ & $0 Y 9 \leqslant . \leqslant \mu \wedge$ & بين المجموعات & \multirow{3}{*}{ الإجمالى } \\
\hline & & $199.0 \mathrm{Vr}$ & 195 & $r \wedge \neg r \cdot . \cdot V$ & داخل المجموعات & \\
\hline & & & 197 & $\varepsilon 4 q 1 \leq .01$ & التباين الكلى & \\
\hline
\end{tabular}

يتضح من نتائج جدول (Y Y) وجود تباين دال إحصائياً بين متوسطات درجات عينة البحث من الزوجات فى استراتيجيات المواجهة الإقدامية للضغوط بمحاورها (التحليل المنطقى للمواقف، إعادة التقييم الإيجابى، البحث عن المساعدة والمعلومات، استخدام أسلوب حل المشكلات) والإجمالى تبعاً لمستوى الدخل الثهرى للأسرة حيث كانت قيم (ف) على إنى التوالى ونى

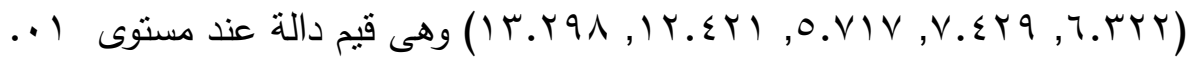
ولمعرفة إتجاه الفروق تم تطبيق إختبار LSD 
عدد خاص من مجلة "بحوث في العلوم والقنون النوعيه" التونيه

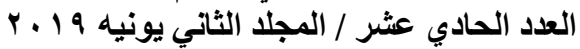

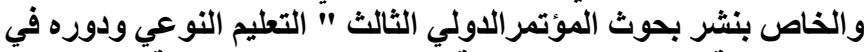

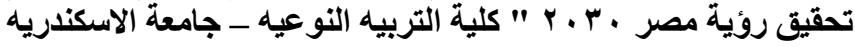

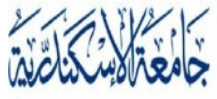

ALEXANDRIA

U N I V ER S I T Y

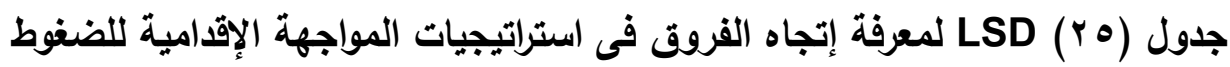

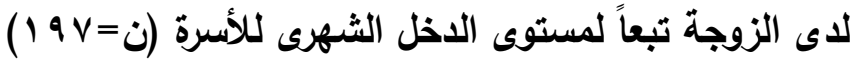

\begin{tabular}{|c|c|c|c|c|c|}
\hline ن & $v i=\dot{U}$ & ن & المستوى الاخل الثهرى & المتوسط الحسابى & المحاور \\
\hline & & - & لدخل شهرى منخفض & $10.977=8$ & \multirow{3}{*}{ المواقفى التحلى } \\
\hline & - & $.29 \vee \wedge 1-$ & لخل شهرى متوسط & $10.07 r=p$ & \\
\hline \multirow[t]{2}{*}{-} & *1.091- & ${ }^{*} Y_{.} \cdot \wedge \Lambda_{-}$ & دخل شهرى مرتفع & $1 V .10 \varepsilon=p$ & \\
\hline & & - & دخل شهرى منخفض & $11 . \cdots=p$ & \multirow{3}{*}{ الإلتقاديبم } \\
\hline- & - & ororl- & لدخل شهرى متوسط & $11.040=8$ & \\
\hline \multirow[t]{2}{*}{-} & $* 1.9 \wedge \wedge$ & ${ }^{*}$ Y.OYY- & دخل شهرى مرتفع & $r \cdot . \Delta r=P$ & \\
\hline & & - & لدخل شهرى منخفض & $19 . \wedge r=p$ & \multirow{3}{*}{ المعلو عن المسات } \\
\hline- & - &.$V \vee V Y_{-}$ & لذخل شهرى متوسط & $19 . \wedge 09=p$ & \\
\hline \multirow[t]{3}{*}{-} & ${ }^{*} Y_{.} I V r_{-}$ & "Y. १ะ १- & دخل شهرى مرتفع & $r Y_{.} \cdot r I=P$ & \\
\hline & & & لدل شهرى منخفض & $19 . \vee \wedge V=p$ & \multirow{3}{*}{ أسلوب حلّدام المشكلات } \\
\hline & - & 1.745 & لدل شهرى متوسط & YI. $\{Y r=p$ & \\
\hline \multirow[t]{3}{*}{-} & "Y.Y Y9A_ & *ะ.9.0. & دخل شهرى مرتفع & $r \leqslant .79 r=p$ & \\
\hline & & - & لخل شهرى منخفض & $V 1.9 r \varepsilon=p$ & \multirow{3}{*}{ الإجمالى } \\
\hline & - & r.ะะร- & لدخل شهرى متوسط & $V \Delta, r \Lambda \cdot=p$ & \\
\hline - & ${ }^{*} q . \cdot 19 V_{-}$ & ${ }^{*} \mid r_{.} \leqslant V_{-}$ & دخل شهرى مرتفع & $\Lambda \varepsilon . \varepsilon=p$ & \\
\hline
\end{tabular}

يتضح من نتائج جدول (Y0) وجود فروق دالة إحصائياً بين متوسطات درجات علات عينة

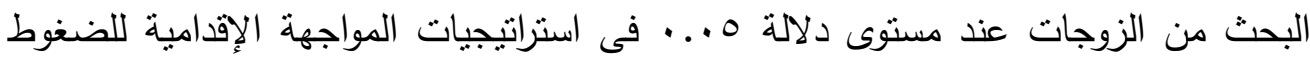
(التحليل المنطقى للمواقف، إعادة التقييم الإيجابى، البحث عن المساعدة والمعلومات، استخدام

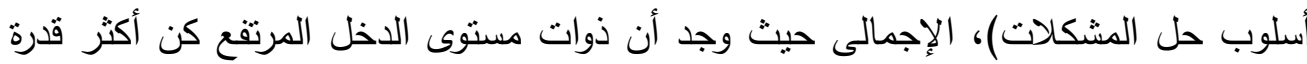
على استخدام استراتيجيات المواجهة الإقدامية للضغوط بمحاورها والإجمالى عن ذوات الاخل المتوسط، والمنخف. ولم نظهر فروق بين ذوات الدخل المنخفض والمتوسط. وتدرجت

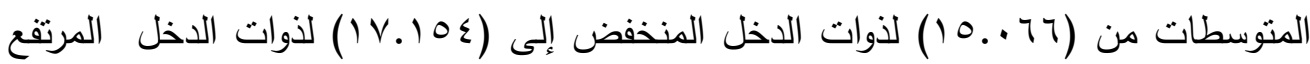

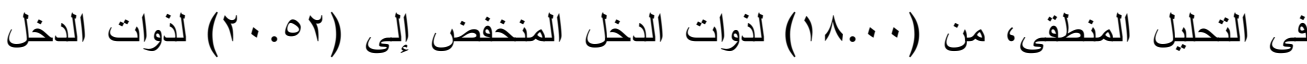

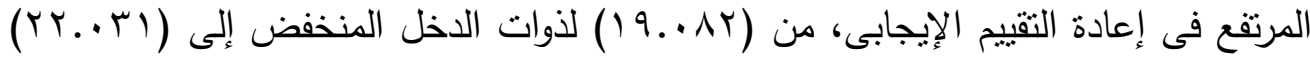

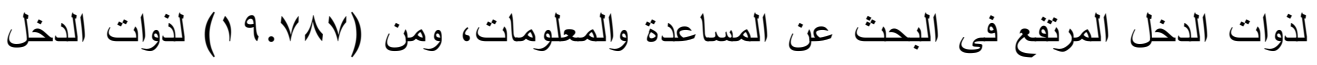




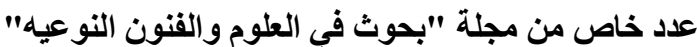

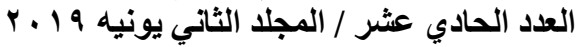

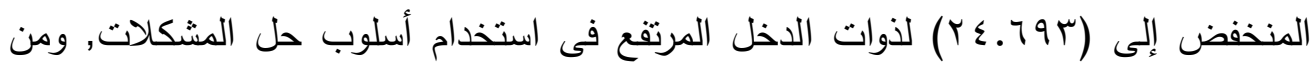

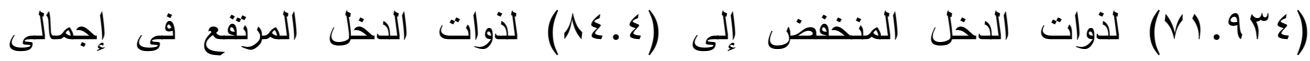

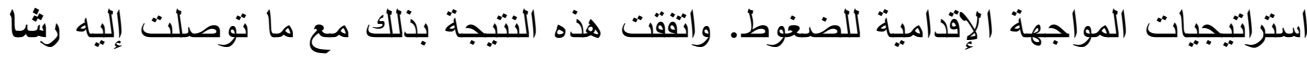

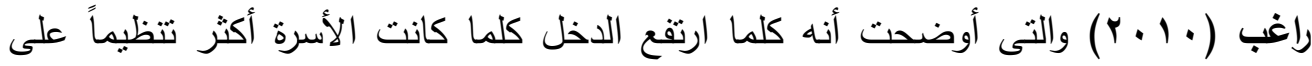

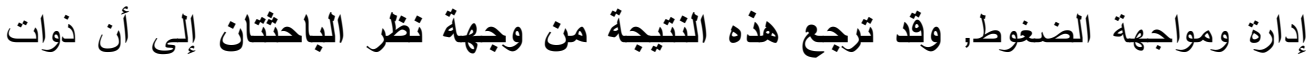

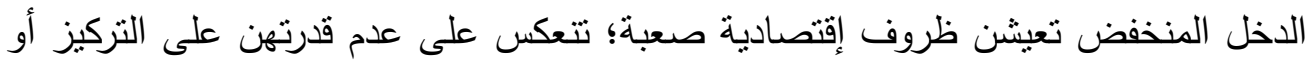

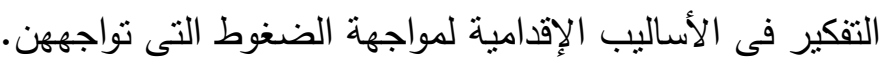

\section{ثانباً: عينة البحث من الأزواجي:}

\section{- بالنسبة لطبيعة عمل الزوج:}

جدول ( Y Y) دلالة الفروق بين متوسطات درجات عينة البحث فى استراتيجيات المواجهة

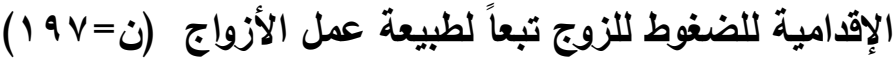

\begin{tabular}{|c|c|c|c|c|c|c|c|}
\hline مستوى الدلائة & قيمة & متوسطات & المعيارى الإنحراف & الحستوسط & ن & المتغير & المحاور \\
\hline \multirow{2}{*}{ غير دالهة } & \multirow[b]{2}{*}{$1 . r \times 1}$. & \multirow[b]{2}{*}{. TV० } & $r .0 r \Lambda$ & $17.5 \leqslant \varepsilon$ & 9. & حكومى & \multirow{2}{*}{ المنطقيل التحليل } \\
\hline & & & $r . r \circ \mu$ & $1 V . .19$ & $1 \cdot v$ & حر & \\
\hline \multirow{2}{*}{ غير دالهة 74} & \multirow{2}{*}{$\because \leqslant r 0$} & \multirow{2}{*}{$\because r 4 \wedge$} & $\varepsilon . r q 1$ & $1 V_{.} \cdot \varepsilon \varepsilon$ & 9. & حكومى & \multirow{2}{*}{ إعادة التقيجم } \\
\hline & & & \&.Y7r & $17.8 \vee 7$ & $1 \cdot V$ & حر & \\
\hline \multirow{2}{*}{ غير دالهة 1010} & \multirow[b]{2}{*}{$1 . \leqslant \leqslant r_{-}$} & \multirow[b]{2}{*}{1.999} & $0.0 \leq$ & TA.TYY & 9. & حكومى & \multirow{2}{*}{ والمساعدث عن } \\
\hline & & & $0.0 r q$ & $19 .\{r \mid$ & $1 \cdot v$ & حر & \\
\hline \multirow{2}{*}{ ه د. • غير } & \multirow[b]{2}{*}{. } & \multirow{2}{*}{.$\mapsto \wedge 9$} & $0.9 r \leq$ & rr.79V & 9. & حكومى & \multirow{2}{*}{ أسلوب حلّل } \\
\hline & & & 7.01 & $r \leqslant .04$ & $1 \cdot v$ & حر & \\
\hline \multirow{2}{*}{ غير داله } & \multirow{2}{*}{.$\wedge \wedge Q_{-}$} & \multirow{2}{*}{$1 . \wedge 9 \%$} & $1 \leq . T \leqslant T$ & V०.rVA & 9. & حكومى & \multirow[t]{2}{*}{ الإجمالى } \\
\hline & & & $10.1 \cdot V$ & VV.YVI & $1 \cdot V$ & حر & \\
\hline
\end{tabular}

يتضح من نتائج جدول (YT) عدم وجود فروق دالة إحصائياً بين منوسطات درجات عينة

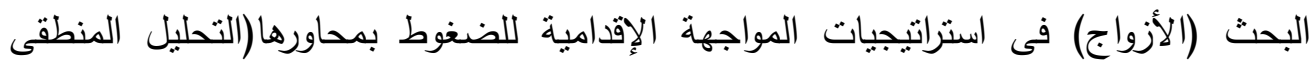

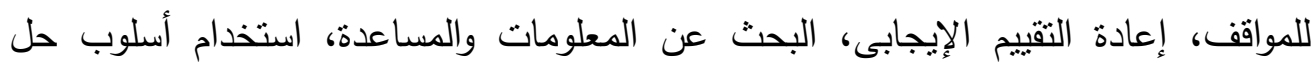




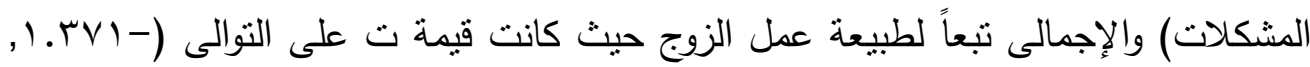

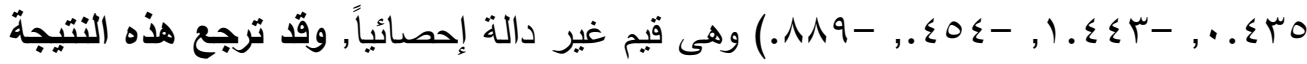
من وجهة نظر الباحثتان إلى أن العمل سواء كان حراً أو حكومياً يقابل فيه الفرد أثخاص

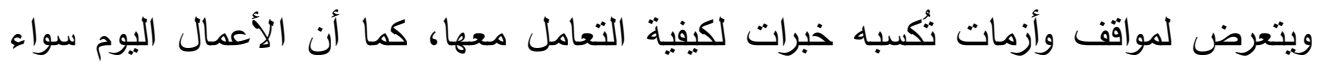

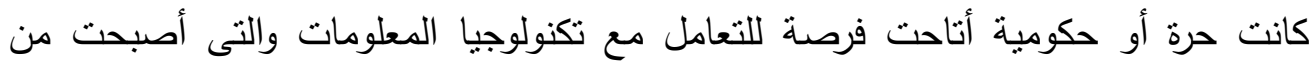
متطلبات العصر؛ وبالتالى أصبح الفرد أكثر قدرة على الحصول على أفضل الأساليب التى التى تُعينه على مواجهة الضغوط.

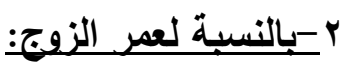

جدول ( LSD (YV) لمعرفة اتجاه الفروق فى استراتيجيات المواجهة الإقدامية للضغوط

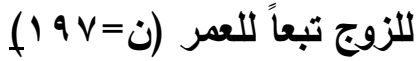

\begin{tabular}{|c|c|c|c|c|c|c|}
\hline مستوى الالالة & 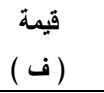 & متوسط المريعات & لدرجات & مجموع المريعات & مصدر التباين & المحاور \\
\hline \multirow{3}{*}{ دال عند 1 مستوى .. } & \multirow{3}{*}{$I T . \leqslant V$} & $1 \leqslant 1.97$ & r & rAr.qrA & بين المجموعات & \multirow{3}{*}{ التحليل المنطقى } \\
\hline & & 1.009 & $19 \leq$ & $Y . \leq \varepsilon .0 \Lambda$ & داخل المجموعات & \\
\hline & & & 197 & rrrA.0.A & التباين الكلى & \\
\hline \multirow{3}{*}{ غير دالة 1 ـ } & \multirow{3}{*}{ r.rug } & $\$ 1.1 \mathrm{rV}$ & r & AY.rVE & بين المجموعات & \multirow{3}{*}{ إعادة التقييم } \\
\hline & & IN.rV & $19 \leq$ & rotr.790 & داخل المجموعات & \\
\hline & & & 197 & M $40.9 V$ & التباين الكلى & \\
\hline \multirow{3}{*}{ غير دالة } & \multirow[t]{3}{*}{ r.OYA } & $v \cdot .9 r q$ & r & $1 \leq 1 . \wedge v V$ & بين المجموعات & \multirow{3}{*}{ البحث عن المعاعدة } \\
\hline & & rA..0Y & 195 & D\&\&Y.AYr & داخل المجموعات & \\
\hline & & & 197 & $00 \wedge \leq . \vee \cdot 1$ & التباين الكلى & \\
\hline \multirow{3}{*}{ دال عند 1 مستوى } & \multirow[t]{3}{*}{$11 . \wedge \wedge 7$} & rAT.rtr & $r$ & Vัצ. $4 \leqslant V$ & بين المجموعات & \multirow{3}{*}{ حل المشكلام أسلوب } \\
\hline & & rY.ro & $19 \leq$ & צ Y०Y.\&Yq & داخل المجموعات & \\
\hline & & & 197 & V.rr.evq & التباين الكلى & \\
\hline \multirow{3}{*}{ دال عند 1 مستوى . . } & \multirow[b]{3}{*}{ I. rvr } & $r \cdot \Lambda \cdot r \leq \leq \leq$ & r & $\leqslant 17 . . \leqslant \wedge \wedge$ & بين المجموعات & \multirow{3}{*}{ الإجمالى } \\
\hline & & r.r.orr & $19 \leq$ & rqYAq.. Y & داخل المجموعات & \\
\hline & & & 197 & $\varepsilon r \leq \varepsilon .01 r$ & التباين الكلى & \\
\hline
\end{tabular}

يتضح من نتائج جدول (YV) عدم وجود تباين دال إحصائياً بين منوسطات درجات عينة البحث (من الأزواج) تبعاً للعمر فى استراتيجيات المواجهة الإقدامية للضغوط (إعادة التقييم 


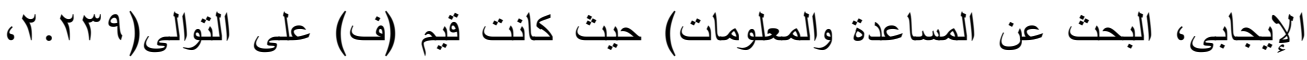

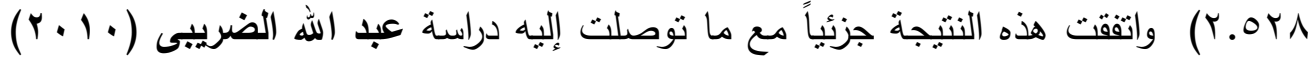

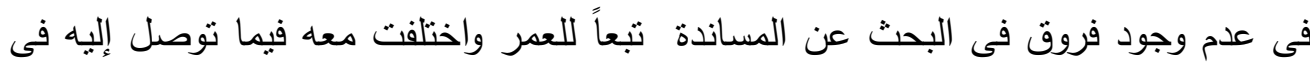
وجود فروق فى إعادة التقييم الإيجابى لصالح العمر الأعلى. ووجود نباين دال إحصائياً (بين

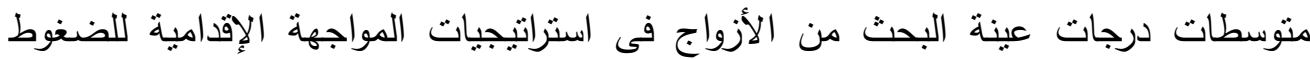

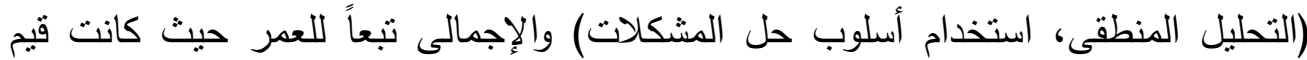

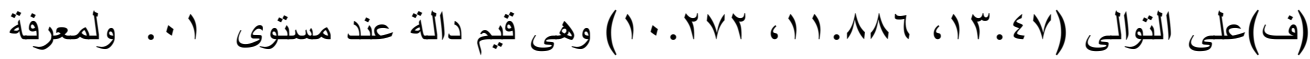

LSD إتجاه الفروق نم تطبيق إختبار

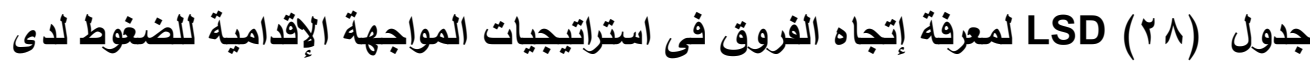
الزوج تبعاً لعمر الزوج (ن

\begin{tabular}{|c|c|c|c|c|c|}
\hline ^. & $\checkmark \varepsilon=\dot{0}$ & ن & عمر الزوج & المتوسط الحسابى & المحاور \\
\hline & & - & أقل من ^r سنة & $10 . V 1 V=p$ & \multirow{3}{*}{ اللمواقفى التحلى } \\
\hline & - & $\ldots \mid v v-$ & من ^ ^> ^ \&سنة & $10.219=p$ & \\
\hline \multirow[t]{3}{*}{-} & "Y..$\leqslant \leqslant \mu \wedge-$ & "Y. $\leqslant \leqslant Y-$ & من ^ \&سنة فأكثر & $11.1740=0$ & \\
\hline & & - & أقل من ^r سنة & r..rqq=p & \multirow{3}{*}{ أسلوب حل المشلملام } \\
\hline & - & I.vrq- & من ^ ^> ^ \&سنة & rr.lro $=p$ & \\
\hline \multirow[t]{3}{*}{-} & "r.... & "ะ.VYq- & من ^ §سنة فأكثر & rT.1 ro $=p$ & \\
\hline & & - & أقل من ^r سنة & V1.7. $=$ P & \multirow{3}{*}{ الإجمالى } \\
\hline & - & $1 . \wedge \cdot \wedge-$ & من ^r> ^ «سنة & Vr. $\{7 q=p$ & \\
\hline- & "ᄉ.\&ए।- & 1..r $\leq-$ & من ^ «سنة فأكثر & $11.9 \cdot=p$ & \\
\hline
\end{tabular}

يتضح من نتائج جدول (†^) وجود فروق دالة إحصائياً بين متوسطات درجات عينة البحث

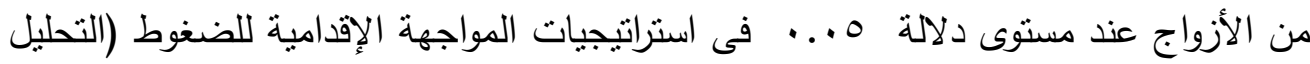

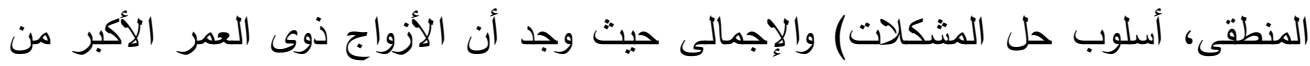

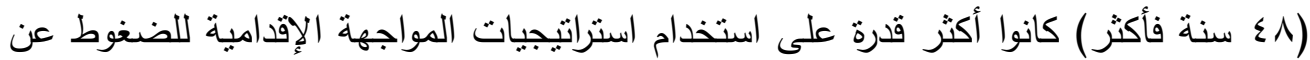

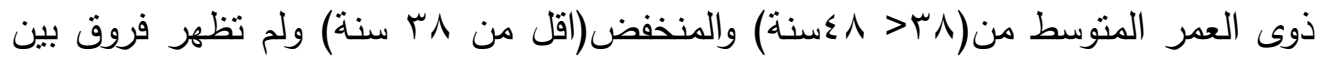


ذوى السن المنخفض والمتوسط, وتدرجت المتوسطات من (10.VIV) أقل من رب سنة إلى

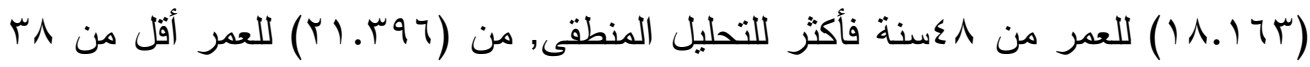

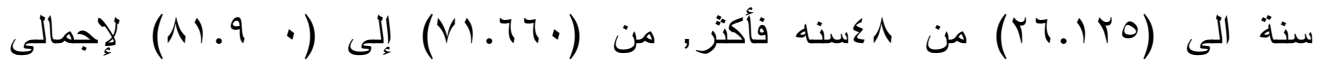
استراتيجيات المواجهة الإقدامية للضغوط. واتفقت بذلك مع ما توصلت إليه فاطمة جاد الله

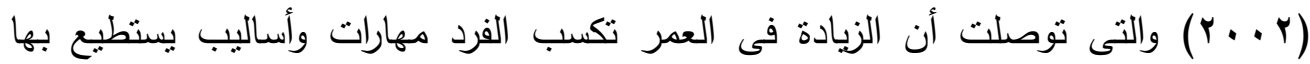
التكيف مع الضغوط ـ وقد ترجع هذه النتيجة من وجهة نظر الباحثتان إلى أنه كلما زاد سن الزوج كلما اتسعت مداركه، وزادت خبراته؛ وذلك بسبب عامل الخبرة المتراكمة عبر مراحل

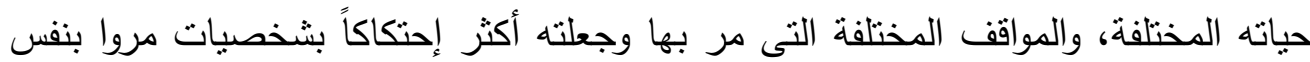
المواقف والظروف، وأكثر معرفةً بالإستراتيجيات الإيجابية التى تعينه على مواجهة المشكلات

والتصدى لها.

\section{r- بالنسبة للمستوى التعليمى للزوج:}

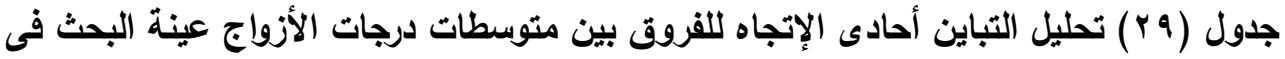

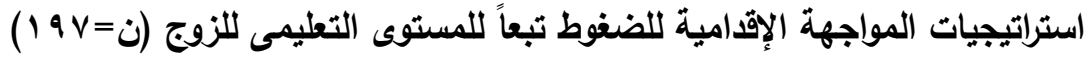

\begin{tabular}{|c|c|c|c|c|c|c|}
\hline مستوى الدلالة & قيمة & متوبط المربعات & الحرية & مجموع & مصدر التباين & المحاور \\
\hline \multirow{3}{*}{ دال عند } & \multirow[t]{3}{*}{$1 . .71 \varepsilon$} & $11 \leq . \wedge r q$ & r & rrq.701 & بين المجموعات & \multirow{3}{*}{ التحليل المنطقى } \\
\hline & & $1 . .119$ & $19 \varepsilon$ & $r .9 \wedge . \wedge 0$ & داخل المجموعات & \\
\hline & & & 199 & 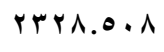 & التباين الكلى & \\
\hline \multirow{3}{*}{ دال عند } & \multirow[t]{3}{*}{$\varepsilon .917$} & AV.q & r & IV०.АтV & بين المجموعات & \multirow{3}{*}{ إعادة التقييم } \\
\hline & & IV.A^V & $19 \leq$ & $r \varepsilon v \cdot .1 \cdot r$ & داخل المجموعات & \\
\hline & & & 197 & $r q \leq 0.9 V$ & التباين الكلى & \\
\hline \multirow{3}{*}{ غير د. . . } & \multirow[t]{3}{*}{$1.0 \wedge r$} & $\leq \varepsilon . \wedge \cdot 1$ & $r$ & $\wedge 9.7 \cdot r$ & بين المجموعات & \multirow{3}{*}{ البحث عن المساعدة } \\
\hline & & rA.rYO & 198 & $0 \leq 90 . .91$ & داخل المجموعات & \\
\hline & & & 197 & $00 \wedge \varepsilon . \vee .1$ & التباين الكلى & \\
\hline دال عند & $\mid \leq \ldots \leq 1$ & $\varepsilon \leq \varepsilon \ldots$ & r & $\wedge \wedge \wedge . .01$ & بين المجموعات & استخدام أسلوب \\
\hline
\end{tabular}

؛ 1 شارع محمد أمين شهيب ـ مصطفى كامل ـ الاسكندريه ـ مصر تليفون : 203/5454313 : 203/5454313

Alexandria - Egypt, Tel. : 203/5454313 - 203/5442776 Fax :203/5442776

E-mail : journal.edusp@alexu.edu.eg Web site: RSSA.edusp@lexu.edu.eg 
عدد خاص من مجلة "بحوث في العلوم والقنون النوعيه" التونيه

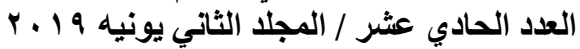

\begin{tabular}{|c|c|c|c|c|c|c|}
\hline \multirow[t]{2}{*}{.1} & & M. & 198 & צr. & داخل المجموعات & \multirow[t]{2}{*}{ حل المشكلات } \\
\hline & & & 197 & $v \cdot r r . \cdot v q$ & التباين الكلى & \\
\hline \multirow{3}{*}{ دال عند } & \multirow[t]{3}{*}{$11.1 \% 7$} & rrrO.rAr & r & $\varepsilon \varepsilon V . . V 70$ & بين المجموعات & \multirow{3}{*}{ الإجمالى } \\
\hline & & $r \ldots 9 r 1$ & $19 \leq$ & 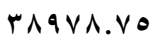 & داخل المجموعات & \\
\hline & & & 197 & $\leq r \leq \varepsilon 9.01$ & التباين الكلى & \\
\hline
\end{tabular}

يتضح من نتائج جدول (Y9) عدم وجود تباين دال إحصائياً بين منوسطات درجات عينة البحث من الأزواج فى استراتيجيات المواجهة الإقدامية للضغوط (فى البحث عن المعلومات

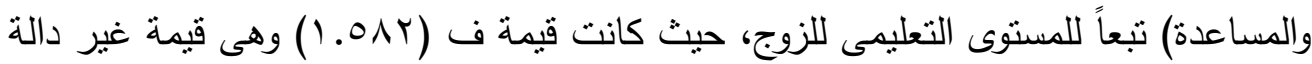
إحصائياً، ووجود تباين دال إحصائياً بين متوسطات درجات عينة البحث من الأزواج فى كلٍ

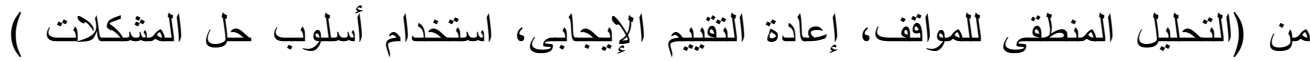

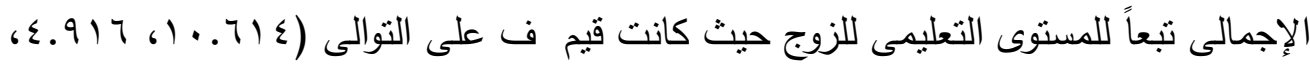

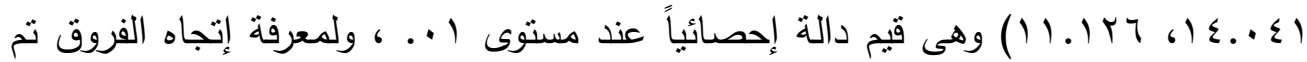

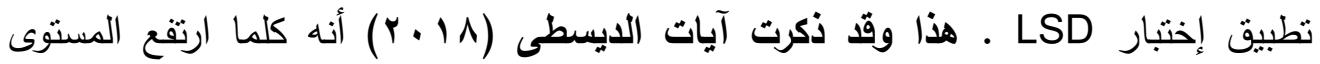

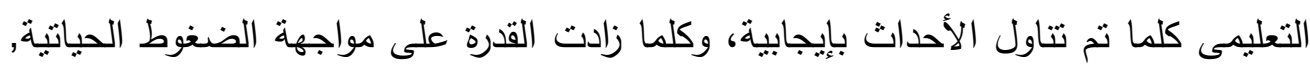

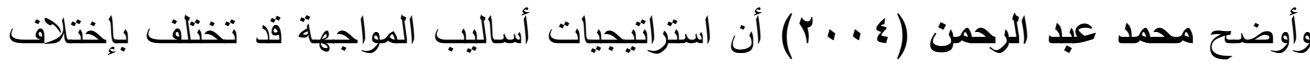
المستوى الثقافى فى المجتمع الواحد. جدول ( • LSD (r) لمعرفة اتجاه الفروق فى استراتيجيات المواجهة الإقدامية للضغوط لدى

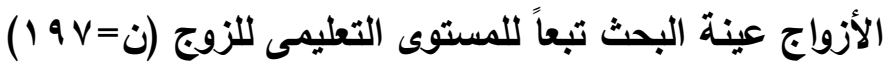

\begin{tabular}{|c|c|c|c|c|c|}
\hline Vr & $v \cdot=\dot{ }$ & ن & مستوى تعليم الزوج & المتوسط الحسابى & 1 \\
\hline & & - & مستوى تعليمى منخفض & $10 . r q=p$ & \multirow{3}{*}{ التحليل المنطقى } \\
\hline & - & $.9 \div \wedge r-$ & مستوى تعليمى متوسط & $17 . r 4=p$ & \\
\hline \multirow[t]{3}{*}{-} & $1.7 \mathrm{~V}-$ & "т.7rq- & مستوى تعليمى مرتفع & $1 \Lambda . . r=p$ & \\
\hline & & - & مستوى تعليمى منخفض & $17 . . r V=p$ & \multirow{3}{*}{ إعادة التقييم } \\
\hline & - & $. r \leqslant \wedge \vee-$ & مستوى تعليمى متوسط & 1Y.Y^Y = & \\
\hline- & "I.ArA- & "Y..ヘฯ- & مستوى تعليمى مرتفع & P & \\
\hline
\end{tabular}


عدد خاص من مجلة "بحوث في العلوم والقنون النوعيه" التوبه

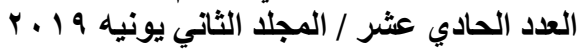

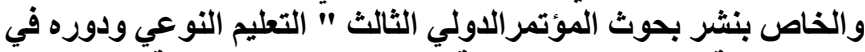

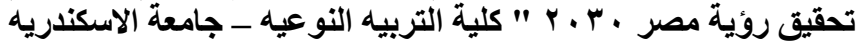

\begin{tabular}{|c|c|c|c|c|c|}
\hline & & - & مستوى تعليمى منخفض & ק & \multirow{3}{*}{ حل المشدام أسلوب } \\
\hline & - & "Y.OOV - & مستوى تعليمى متوسط & Pr.OOV & \\
\hline \multirow[t]{3}{*}{-} & "Y.V०^- & $0 . \mu 10-$ & مستوى تعليمى مرتفع & P & \\
\hline & & - & مستوى تعليمى منخفض & $V \cdot . \neg \leqslant \Lambda=p$ & \multirow{3}{*}{ الإجمالى } \\
\hline & - & $\varepsilon .1 \cdot 9-$ & مستوى تعليمى متوسط & $V \varepsilon . V \otimes V=p$ & \\
\hline- & $* \vee . \varepsilon \wedge 9-$ & $11.091-$ & مستوى تعليمى مرتفع & $\Lambda Y . r \leqslant V=\beta$ & \\
\hline
\end{tabular}

يتضح من نتائج جدول (·r) وجود فروق دالة إحصائياً بين متوسطات درجات عينة البحث

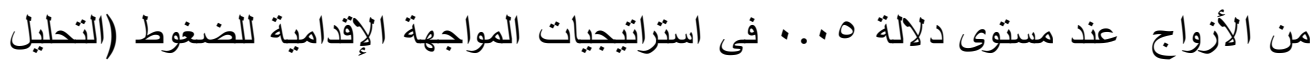

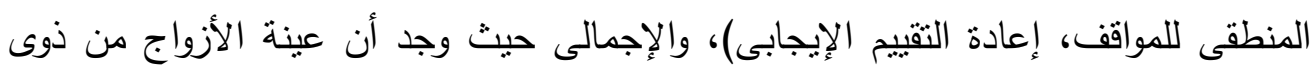
المستوى التعليمى المرتفع كانوا أكثر قدرة على التحليل المنطقى، وأكثر إيجابية فى إعادة تقييم المشكلات، عن ذوى المستوى التعليمى المنخفض، ولم تظهر فروق بين ذوى التعليم

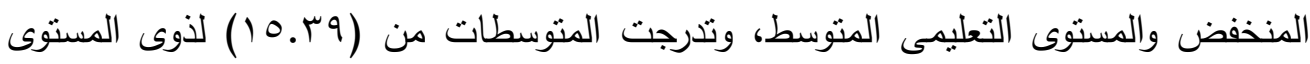
التعليمى المنخفض إلى (r...1) لذوى المستوى التعليمى المرتفع للتحليل المنطقى, ومن

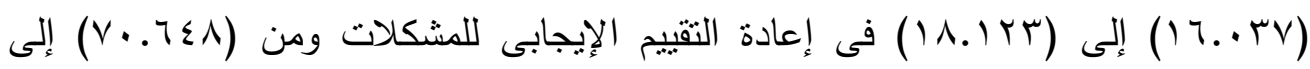

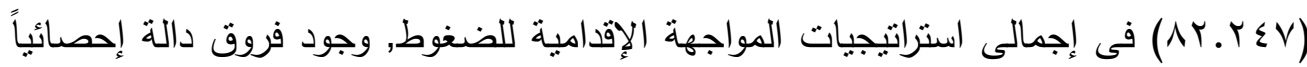
بين متوسطات درجات عينة البحث عند مستوى دلالة ه... فى استخدام فى حل المشكلات

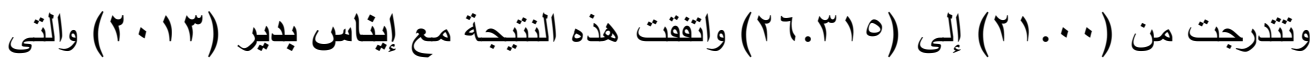
توصلت إلى وجود فروق فى استراتيجبات المواجهة الإقدامية للضغوط لصالح مستوى التعليم

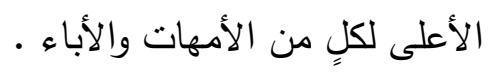

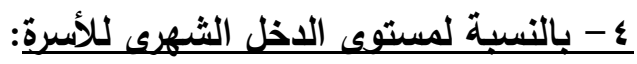

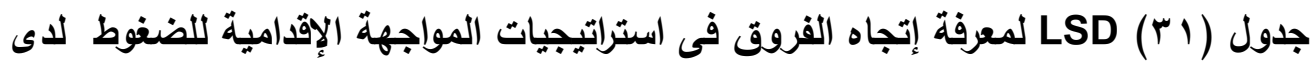

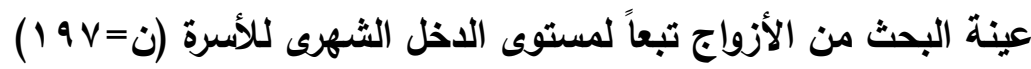




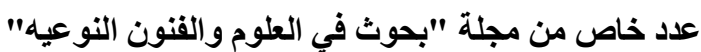

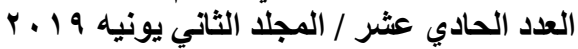

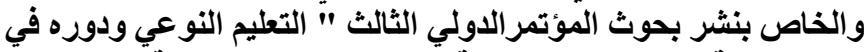

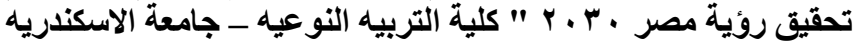

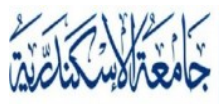

ALEXANDRIA

U N I VER S I T Y

AlexUPress

Viple

\begin{tabular}{|c|c|c|c|c|c|c|}
\hline مستوى الدلالة & قيمة & متوسط المربعاث & الحرية & المربعاث & مصدر التباين & المحاور \\
\hline \multirow{3}{*}{ 1ال عند } & \multirow{3}{*}{$10.7 \vee 9$} & $101 . \leqslant 49$ & $r$ & $17 . \wedge 0 \wedge$ & بين المجموعات & \multirow{3}{*}{ التليل المنطقى اقف } \\
\hline & & $1 . .599$ & 198 & 9.11 .70 & داخل المجموعات & \\
\hline & & & 197 & 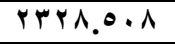 & التباين الكلى & \\
\hline \multirow{3}{*}{ 1ال عند } & \multirow[t]{3}{*}{$1 . V O r$} & $111.9 \cdot r$ & r & $r 4 r . \wedge .0$ & بين المجموعات & \multirow{3}{*}{ إعادة التقبيم } \\
\hline & & 17.911 & 198 & YYAY.ITE & داخل المجموعات & \\
\hline & & & 197 & $P 4 \leq 0.9 \mathrm{~V}$ & التباين الكلى & \\
\hline \multirow{3}{*}{ ال عال عند } & \multirow[t]{3}{*}{ V.VYr } & $r .0 .9 Y 7$ & $r$ & $\& 11 . \wedge \circ r$ & بين المجموعات & \multirow{3}{*}{ البحث عناعدة المعلومات } \\
\hline & & P..79 & $19 \leq$ & $01 V Y . \wedge \leq 9$ & داخل المجموعات & \\
\hline & & & 197 & $00 \wedge \varepsilon . \vee \cdot 1$ & التباين الكلى & \\
\hline \multirow{3}{*}{ ال دال عند } & \multirow[t]{3}{*}{11.799} & $r v V . q r r$ & $r$ & $100 . \wedge 70$ & بين المجموعات & \multirow{3}{*}{ حل المشكلام أسلوب } \\
\hline & & ru.r.o & $19 \leq$ & TrTV.rII & داخل المجموعات & \\
\hline & & & 197 & $V \cdot r r_{.} \cdot V q$ & التباين الكلى & \\
\hline \multirow{3}{*}{ 1ال عند } & \multirow[t]{3}{*}{18.049} & rrro.11r & $r$ & $770 \cdot . Y Y 0$ & بين المجموعات & \multirow{3}{*}{ الإجمالى } \\
\hline & & $1 \wedge 9.71 \mathrm{~V}$ & 198 & 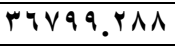 & داخل المجموعات & \\
\hline & & & 197 & $\leq r \leq \varepsilon 9.01 r$ & التباين الكلى & \\
\hline
\end{tabular}

يتضح من نتائج جدول (1) وجود تباين دال إحصائياً بين متوسطات درجات عينة البحث من الأزواج فى استراتيجيات المواجهة الإقدامية للضغوط بمحاورها (التحليل المنطقى للمواقف، إعادة التقييم الإيجابى، البحث عن المساعدة والمعلومات، استخدام أسلوب حل

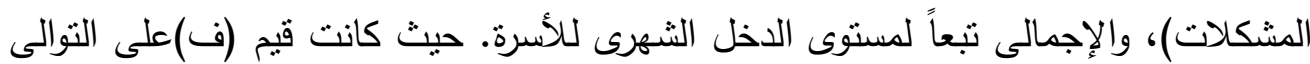

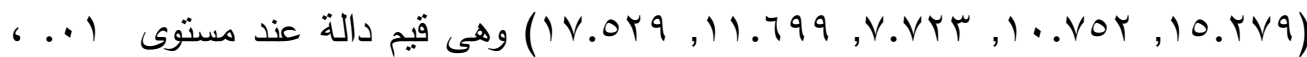

LSD ولمعرفة إتجاه الفروق نم تطبيق إختبار

جدول LSD (YY) لمعرفة إتجاه الفروق فى استراتيجيات المواجهة الإقدامية للضغوط للأزواج تبعاً لمستوى الاخل الثهرى للأسرة 
عدد خاص من مجلة "بحوث في العلوم والقنون النوعيه" العزيه

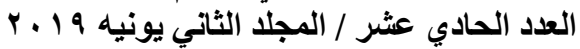

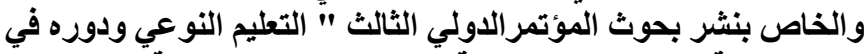

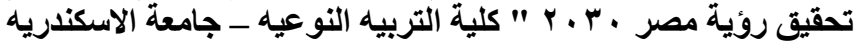

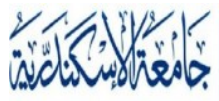

ALEXANDRIA

U N I VER S I T Y

Alexu Press

Vip

\begin{tabular}{|c|c|c|c|c|c|}
\hline ن & $v i=\dot{U}$ & ن & مستوى الاخل الثهرى & المتوسط الحسابى & المحاور \\
\hline & & - & مستوى دخل منخفض & $1 \leq . \wedge \wedge \theta=p$ & التحليل \\
\hline & - & "Y.YOY- & مستوى دخل متوسط & $\mid V .1 \leq 1=p$ & المنطقى \\
\hline \multirow[t]{2}{*}{-} & $. \wedge 1 \% .-$ & "r.. . 9- & مستوى دخل مرتفع & $1 V .90 \leq=5$ & للمواقف \\
\hline & & - & مستوى دخل منخفض & $10.7 r r=p$ & \multirow{3}{*}{ إعادة التقييم } \\
\hline- & - & $.74 .7-$ & مستوى لخل متوسط & 1Y.Y० & \\
\hline \multirow[t]{3}{*}{-} & $* Y .0 \leq V-$ & r.IVV- & مستوى دخل مرتفع & $11 . \cdots=5$ & \\
\hline & & - & مستوى دخل منخفض & $|V \cdot V Y|=P$ & \multirow{3}{*}{ المعث عن المسات } \\
\hline & - & $. r \leq q 1-$ & مستوى دخل متوسط & ln..V. $=5$ & \\
\hline \multirow[t]{3}{*}{-} & *ฯ.^৭^- & $r . r \leq \Lambda-$ & مستوى دخل مرتفع & $r .979=5$ & \\
\hline & & - & مستوى دخل منخفض & MI.r4I=s & \multirow{3}{*}{ أسلوب حل المشكام } \\
\hline & - & "Y. ६११- & مستوى لخل متوسط & $r r . \wedge \bullet q=5$ & \\
\hline \multirow[t]{3}{*}{-} & $* Y . \varepsilon \cdot r-$ & "ะ.91.- & مستوى دخل مرتفع & r4.r4r =5 & \\
\hline & & - & مستوى دخل منخفض & $79.09 .=8$ & \multirow{3}{*}{ الإجمالى } \\
\hline & - & O.Vr $\leq-$ & مستوى لخل منوسط & VO.rTE $=p$ & \\
\hline- & *А.รษ1- & "1 $1 \leq .490-$ & مستوى دخل مرتفع & $\wedge r . q \wedge \theta=p$ & \\
\hline
\end{tabular}

يتضح من نتائج جدول (YT) وجود فروق دالة إحصائياً بين متوسطات درجات عينة

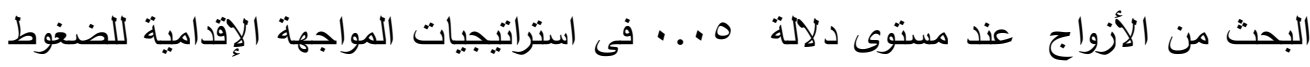

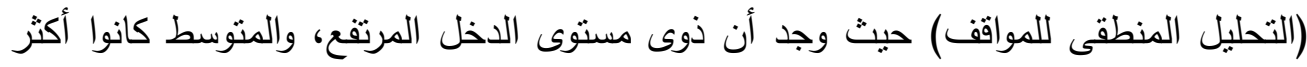
قدرة على استخدام استراتيجيات المواجهة الإقدامية للضغوط عن ذوى مستوى الدخل المنخفض، ولم تظهر فروق بين مستوى الدخل المتوسط والمرتفع وتدرجت المتوسطات من الإنه

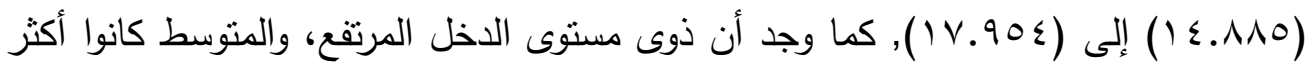
قدرة على استخدام إستراتيجيات المواجهة الإقدامية للضغوط عن ذوى مستوى الدخل المنخفض، ولم تظهر فروق بين مستوى الدخل المنخفض و المتوسط فى (إعادة التقييم

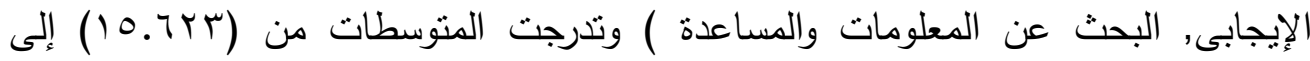

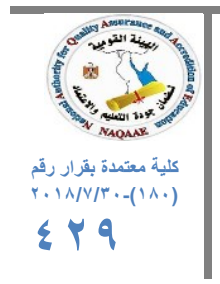

؛ أشارع محمد أمين شهيب ـ مصطفى كامل ـ الاسكندريه ـ مصر تليفون : 203/5454313

Alexandria - Egypt, Tel. : 203/5454313 - 203/5442776 Fax :203/5442776

E-mail : journal.edusp@alexu.edu.eg Web site: RSSA.edusp@lexu.edu.eg 


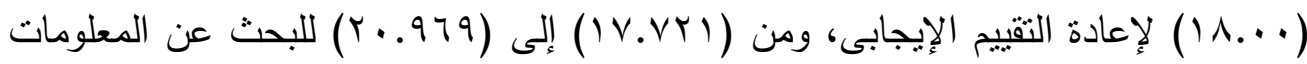

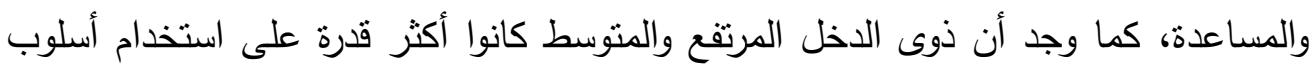

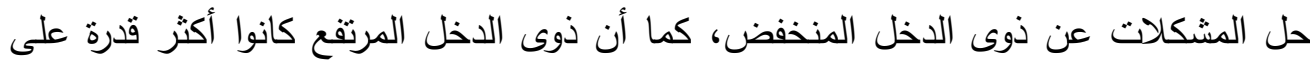

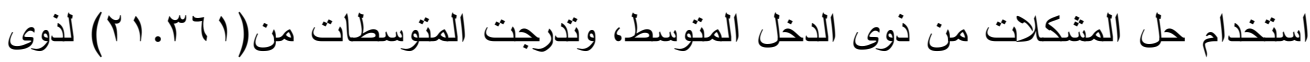

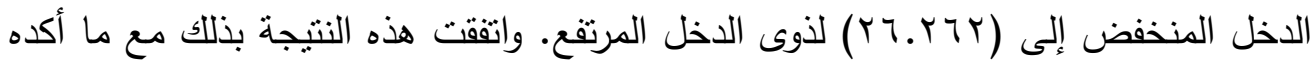

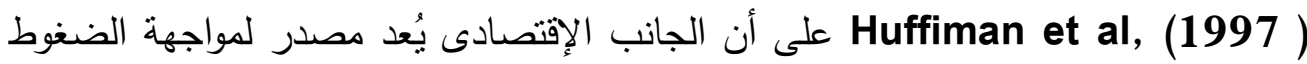

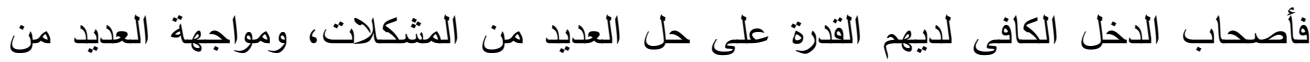
الضغوط فيمكنه توفير عمل جيد ومميز، ومنزل مجهز ، وأجهزة ومعدات حديثة للحياة، بينما أصحاب الدخل المتدنى نجدهم مسنسلمين للضغوط أو يهربون منها أو يصابون بالإحباط واليأس والأمراض النفسية والجسمية المختلفة. - نستخلص مما سبق وجود فروق بين متوسطات درجات عينة البحث من الزوجات فى استراتيجيات المواجهة الإقدامية للضغوط بمحاورها (التحليل المنطقى للمواقف، إعادة التقييم

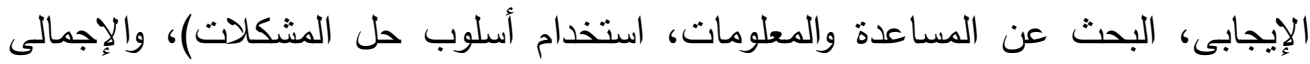

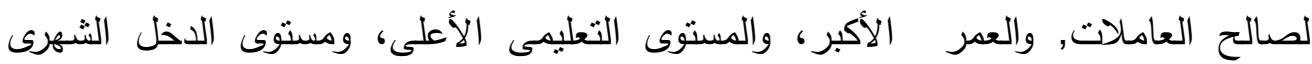

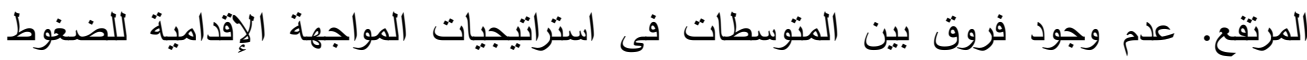
(التحليل المنطقى للمواقف، إعادة التقييم الإيجابى، البحث عن المساعدة والمعلومات، استخدام

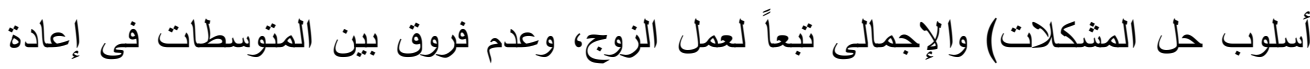

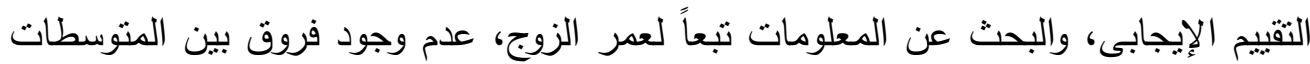

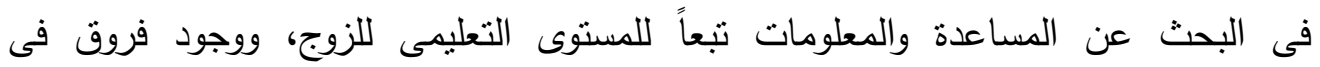

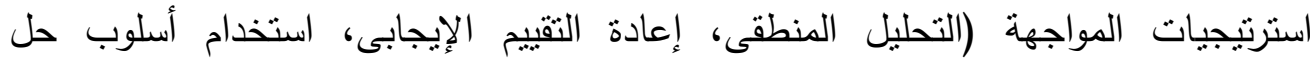

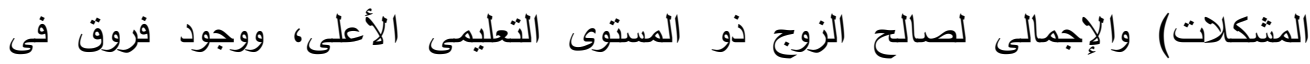
المتوسطات فى كلٍ من (التحليل المنطقى، استخدام أسلوب حل المشكلات) والإجمالى لصالح 
العمر الأكبر، ووجود فروق بين المنوسطات فى استراتيجيات المواجهة الإقدامية للضغوط،

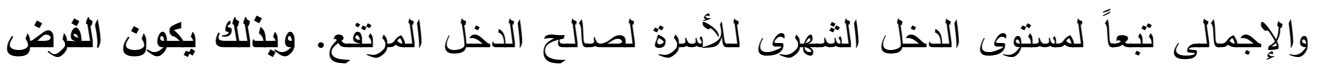

الثالث قد تحقق جزئياً.

الفرض الرايع: توجد فروق بين متوسطات درجات عينة البحث من الزوجين فى جودة الحياة

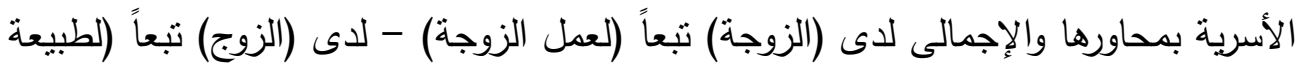
عمل الزوج).

للتحقق من صحة هذا الفرض إحصائياً تم إستخدام إختبار T test للوقوف على دلالة الفروق بين متوسطات درجات عينة البحث فى جودة الحياة الأسرية بمحاورها.

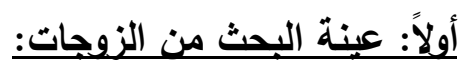

جدول (rr ) دلالة الفروق بين متوسطات درجات عينة البحث من الزوجات فى جودة الحياة الأسرية تبعاً للعمل

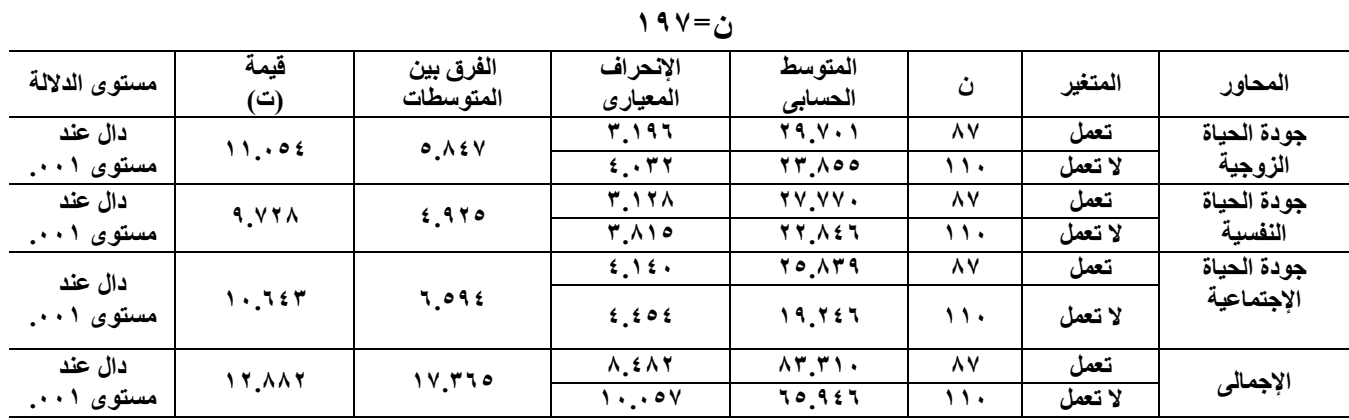

- يتضح من نتائج جدول (Tr/) وجود فروق دالة إحصائياً بين متوسطات درجات عينة البحث من الزوجات فى إدراكهن لجودة الحياة الأسرية (الزوجية، النفسية، الإجتماعية،

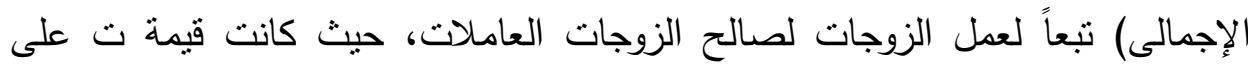

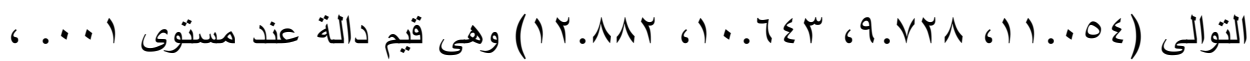

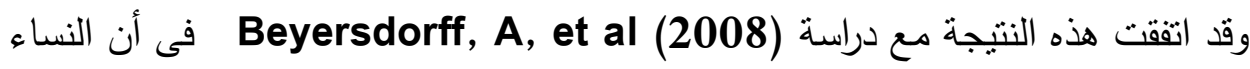
العاملات أوفر حظاً من غير العاملات فى الثعور بجودة الحياة الأسرية، وكذلك دراسة Hee Hong, S. \& Winder, M (2008) والتى توصلت إلى أن عمل بعلى 
الزوجين يزيد من الدخل الإقتصادى ومن ثم زيادة جودة الحياة الأسرية بصفة خاصة،

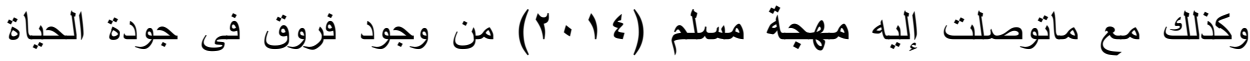

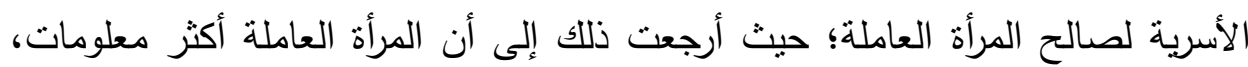

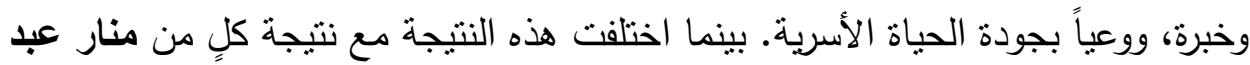

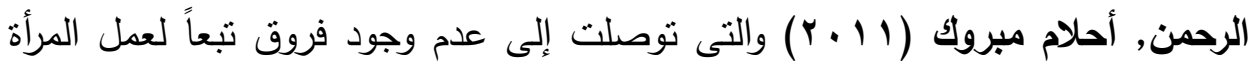
فى جودة الحباة الزوجية، وكذلك عدم وجود فروق فى إجمالى جودة الحياة الأسرية. - -

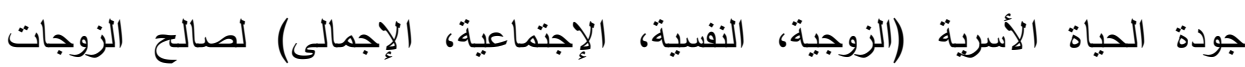
العاملات.

\section{ثُانياً: عينة البحث من الأزواج:}

جدول (؟ ب) دلالة الفروق بين المتوسطات فى جودة الحياة الأسرية للزوج تبعا لطبيعة العمل (ن V V l )

\begin{tabular}{|c|c|c|c|c|c|c|c|}
\hline مستوي الدلالة & قيمة & المتوسطات & المعيارى الإنحراف & الحستوسط & $\dot{ن}$ & المتغير & المحاور \\
\hline \multirow{2}{*}{ غير دَّاّة } & \multirow{2}{*}{$1 .+4{ }_{1}$} & \multirow{2}{*}{$.70 \cdot-$} & \&.rrq & $r \& .97 V$ & 9. & حكومى & \multirow{2}{*}{ جودة الزوجية } \\
\hline & & & $\{.011$ & ro.7IV & $1 . v$ & حر & \\
\hline \multirow{2}{*}{ غير دالة . } & \multirow{2}{*}{.$\wedge १ \wedge$} & \multirow{2}{*}{$. \Delta V \cdot-$} & $\varepsilon .1 \cdot \varepsilon$ & $r \leqslant . \mid V \wedge$ & 9. & حكومى & \multirow{2}{*}{ جودة الحياة } \\
\hline & & & $\varepsilon .790$ & $r \leq . V \leqslant \Lambda$ & $1 . v$ & حر & \\
\hline \multirow{2}{*}{ غير دالة } & \multirow{2}{*}{.$V V r_{-}$} & \multirow{2}{*}{$.7 \cdot 1-$} & 0. Y O & $r \cdot .7 \wedge q$ & 9. & حكومى & \multirow{2}{*}{ الإجتماعية الحياة } \\
\hline & & & o.vor & rI.rq. & $1 \cdot v$ & حر & \\
\hline \multirow{2}{*}{ غير دالة 9 آة } & \multirow{2}{*}{$.999-$} & \multirow{2}{*}{ I.AYI- } & II.VVV & צ.৭.Arr & 9. & حكومى & \multirow[t]{2}{*}{ الإجمالى } \\
\hline & & & r. & $v 1.70 \leq$ & $1 . v$ & حر & \\
\hline
\end{tabular}

يتضح من نتائج جدول (§؟) عدم وجود فروق دالة إحصائياً بين المتوسطات فى جودة

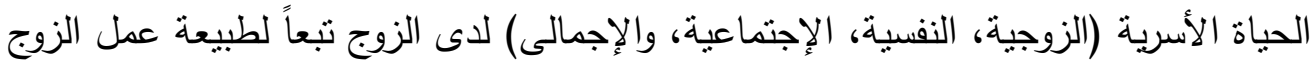

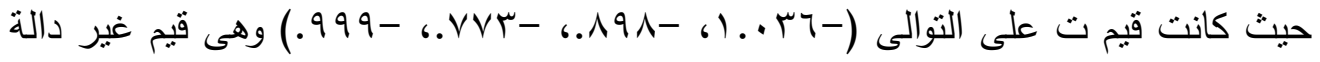
إحصائياً. وقد ترجع هذه النتيجة من وجهة نظر الباحثتان إلى أن العمل سواء كان حراً أو 
حكومياً لكلٍ منهم إيجابياته وسلبياته، وسعادة الأفراد ورضاهم بأحوالهم، وقدرتهم على التغلب على الضغوط ومواجهتها سواء فى العمل الحر أو الحكومى من مؤشرات جودة الحياة بصفة ولهة عامة، والأسرية بصفة خاصة. نستخلص مما سبق وجود فروق بين متوسطات درجات عينة البحث فى جودة الحياة الأسرية (المحاور والإجمالى لصالح الزوجة العاملة، وعدم وجود فروق بين متوسطات درجات الأزواج

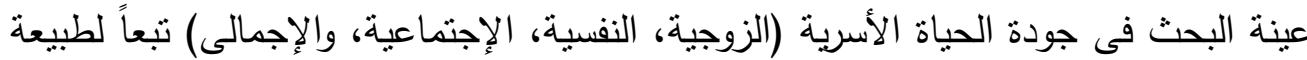
عمل الأزواج. - مان.

\section{ويذلك يكون الفرض الرابع قد تحقق جزئياً.}

الفرض الخامس:توجد علاقة ارتباطية دالة إحصائياً بين جودة الحياة الأسرية بمحاورها والإجمالى لدى الزوجة وكلٍ من متغيرات البحث (عمر الزوجة، المستوى التعليمى للزوجة،

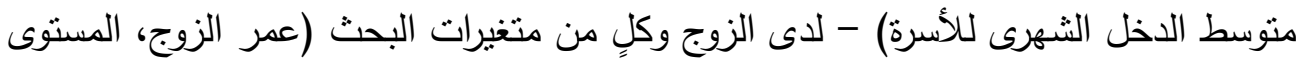

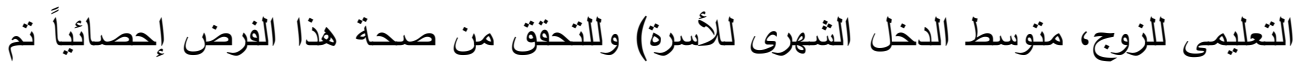

إستخدام معامل إرتباط بيرسون Correlation Pearson

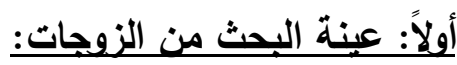

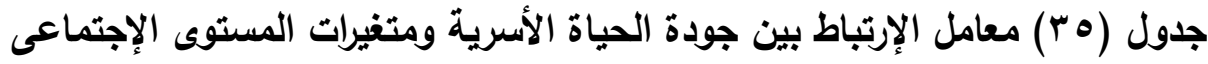

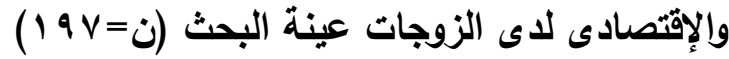

\begin{tabular}{|c|c|c|c|c|}
\hline الإجمالى & الإجتماعيةّة الحياة & جودة الحياة & جودة الزية & جودة الحياة الأسرية \\
\hline معامل الإرتباط & معامل الإرتباط & معامل الإرتباط & معامل الإرتباط & إجتماعى والإقتصادىى \\
\hline$* * .0 Y r$ & $* * . \leqslant 94$ & $\% \div . \$ 41$ & $* * . \leqslant Y 0$ & عمر الزوجة \\
\hline$* * .0 .4$ & $* * . \leqslant$ ४q & $* * . \leqslant \leqslant 1$ & $* * .47 Y$ & المستوى التعليمى للزوجة \\
\hline **.rTr & $* * . r \varepsilon$ & $* * . Y 0 \leqslant$ & $* * . r V V$ & مستوى الاخل الثهرى للأسرة \\
\hline
\end{tabular}

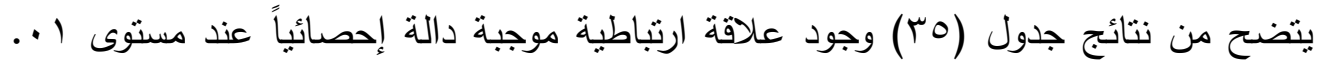
بين درجات عينة البحث من الزوجات فى جودة الحياة الأسرية بمحاورها (الزوجية، النفسية،

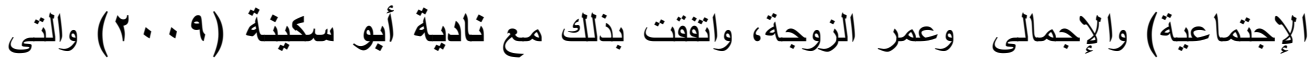


أكدت اختلاف جودة أسلوب الحياة الأسرية للمرأة تبعاً لاختلاف العمر (لصالح العمر

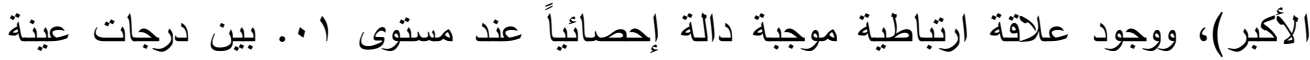
البحث فى جودة الحياة الأسرية بمحاورها (الزوجية، النفسية، الإجتماعية، والإجمالى) تبعاً النهاً

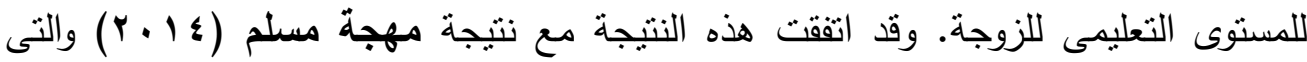
توصلت إلى وجود علاقة ارتباطية موجبة ذات دلالة إحصائية بين جودة الحياة الأسرية ومستوى تعليم الزوجة. كما اتفقت هذه النتيجة مع نتيجة كلٍ من منار عبد الرحمن, أحلام

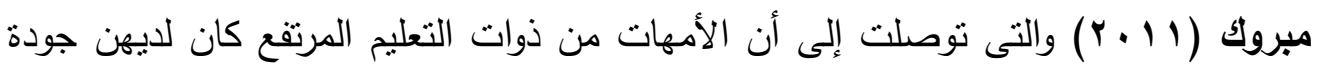

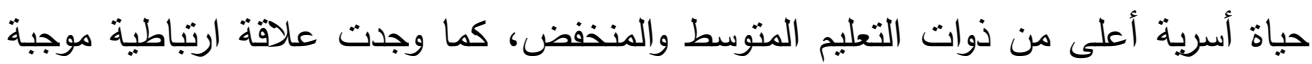

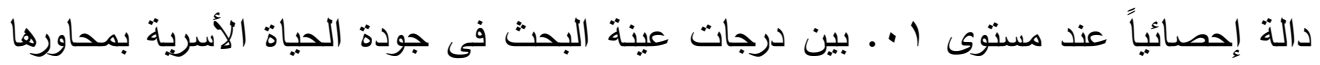
(الزوجية، النفسية، الإجتماعية، والإجمالى) تبعاً لمستوى الدخل الثهرى للأسرة. وقد اتفقت

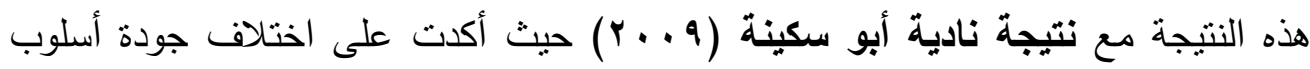
الحياة الأسرية للمرأة تبعاً لإختلاف بعض متابه ابو سكينه لهيرات المستوى الإجتماعى والإقتصادى للأسرة.

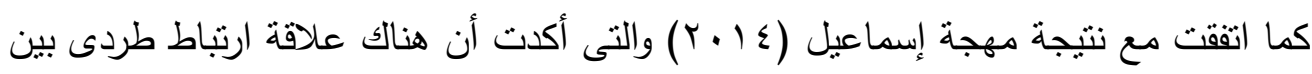
الدخل الثهرى للأسرة وزيادة الوعى بجودة الحياة الأسرية بأبعادها (الإجتماعية، والنفسية،

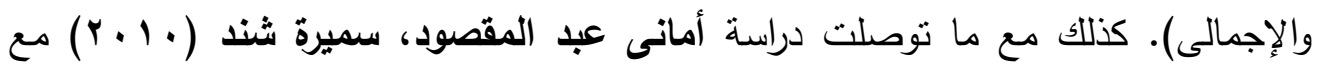
اختلاف العينة إلى تأثنير المستوى الإجتماعى الإقتصادى على جودة الحياة الأسرية للأسرة لصالح ذوى المستوى المرتفع ثانياً: عينة البحث من الأزواج:

جدول (†ץ) معامل الإرتباط بين جودة الحياة الأسرية ومتغيرات المستوى الإجتماعى

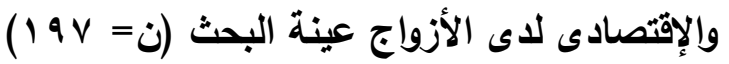

\begin{tabular}{|c|c|c|c|c|}
\hline الإجمالى & جودة الإجتماعية & جودة الحياة & جودة الحياة & جودة الحياة الأسرية \\
\hline
\end{tabular}


عدد خاص من مجلة "بحوث في العلوم والقنون النوعيه" العيه

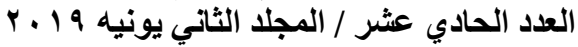

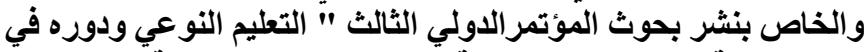

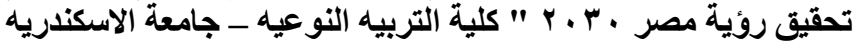

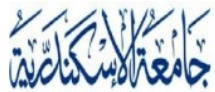

ALEXANDRIA

U N I VER S I T Y

AlexuPress

Viple

\begin{tabular}{|c|c|c|c|c|}
\hline معامل الإرتباط & معامل الإرتباط & معامل الإرتباط & معامل الإرتباط & متغيرلت لالمستوى \\
\hline$* * . r \leq q$ & **.Y Y & $* * . Y \backslash 1$ & $* * .|\wedge|$ & عمر الزوج \\
\hline r * & $* * . r T V$ & **. หา & *.rqr & المستوى التعليمى للزوج \\
\hline **.pqV & **.r & $* * . r$. & $* * . \varepsilon \cdot r$ & مستوى الاخل الشهرى \\
\hline
\end{tabular}

- يتضح من نتائج جدول (؟ץ) وجود علاقة ارتباطية موجبة دالة إحصائياً عند مستوى ا .. بين درجات عينة البحث من الأزواج فى جودة الحياة الأسرية بمحاورها (الزوجية - النفسية -

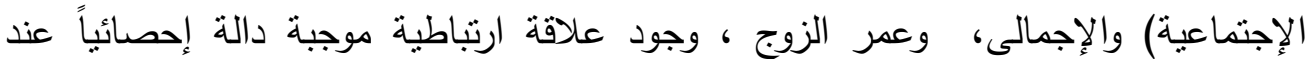

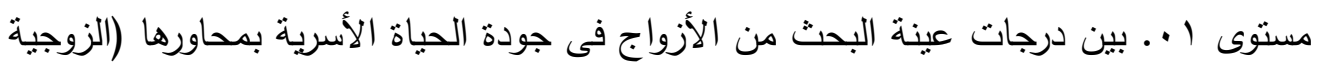

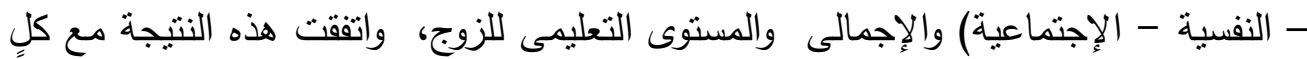
من منار عبد الرحمن، أحلام مبروك (11 (1) والتى توصلت إلى وجود فروق فى جودة

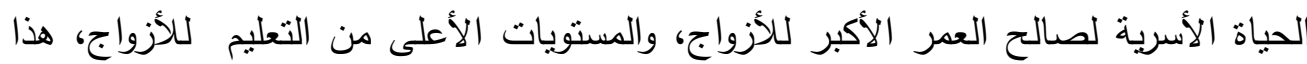

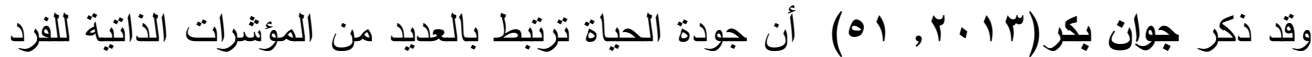

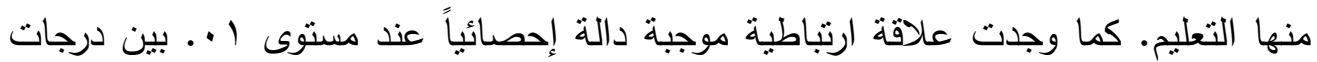
عينة البحث من الأزواج فى جودة الحياة الأسرية بمحاورها (الزوجية، النفسية، الإجتماعية،

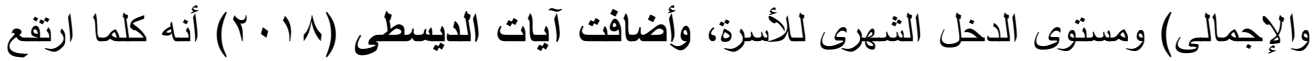

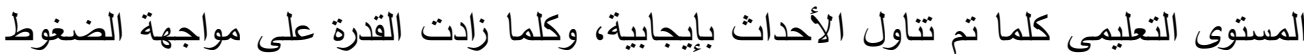
الحياتيةالأمر الذى يؤدى للإحساس بجودة الحياة الأسرية.

وتتفق مع ما توصلت إليه دراسة كلٍ من Brown, R (2009) أن توافر الموارد المالية للأسرة يعتبر من العوامل الخارجية المحددة لجودة الحياة الأسرية، منار عبد الرحمن، أحلام مبروك (11 +r) والتى توصلت إلى وجود فروق فى جودة الحياة الأسرية لصالح Hee Hong, S. \& 2008) المستويات المرتفعة من الدخل، كما توصلت دراسة Winder, M أن عمل الزوجين يزيد من الاخل الإقتصادى ومن ثم زيادة جودة الحياة 
عدد خاص من مجلة "بحوث في العلوم والقنون النوعيه" التونيه

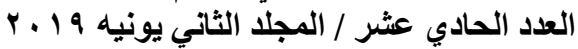

الأسرية. نستخلص مما سبق وجود علاقة ارتباطية موجبة دالة إحصائياً بين جودة الحياة الأسرية المحاور ، والإجمالى وكل من عمر الزوجة, المستوى التعليمى للزوجة، مستوى الدخل

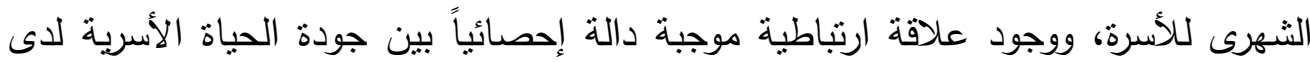
الزوج وكلٍ من عمر الزوج، والمستوى التعليمى للزوج، ومتوسط الدخل الثهرى للأسرة. ويذلك يكون الفرض الخامس قد تحقى كلياً. الفرض السادس: تختلف نسبة مشاركة المتغيرات المستقلة (استراتيجية المواجهة الإقدامية للضغوط) فى تقسير نسبة التباين على المتغير التابع (جودة الحياة الأسرية) تبعاً لأوزان التهانه معاملات الإنحدار ودرجة الإرتباط. وللتحقق من صحة هذا الفرض نم حساب الأهمية النسبية بإستخدام معامل الإنحدار (الخطوة المتدرجة إلى الأمام) لمعرفة درجة تأثثر استراتيجية المواجهة الإقدامية للضغوط على جودة الحياة الأسرية. جدول (rv) الإنحدار الخطى للعلاقة بين المتغيرات والمتغير التابع

\begin{tabular}{|c|c|c|c|c|c|c|c|}
\hline (ت) & \multicolumn{2}{|c|}{ معامل الإنحدار } & $\mathbf{F}$ & R2 & $\mathbf{R}$ & المتغيرات & \\
\hline \multirow{2}{*}{ ****17.7人 } & $\varepsilon \cdot .9 \cdot 9$ & الثابت & \multirow{2}{*}{ 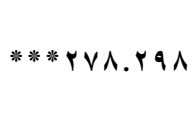 } & \multirow{2}{*}{$\leqslant 1.0$} & \multirow{2}{*}{$.7 \leq \leq$} & استخدام أسلوب & $\overline{3}$ \\
\hline & 1.570 & B & & & & حل المشكلات & \\
\hline \multirow{2}{*}{ 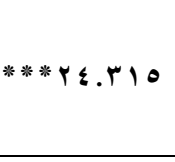 } & \& & الثابت & \multirow{2}{*}{ ***\%rr.AAr } & \multirow{2}{*}{ r.. } & \multirow{2}{*}{$.7 . r$} & عن البحث & \\
\hline & $1 . \leqslant 0$. & B & & & & والمعلومات & 称 \\
\hline \multirow{2}{*}{ ***ir.orv } & r^.VrV & الثابت & \multirow{2}{*}{$* * * \wedge r, r r \wedge$} & \multirow{2}{*}{$r 1.9$} & \multirow{2}{*}{ 8 } & التحليل المنطقى & $\mathcal{F}^{2}$ \\
\hline & r...01 & B & & & & للمواقف & \\
\hline \multirow{2}{*}{ ****T.T人ץ } & $\varepsilon r . r q Y$ & الثابت & \multirow{2}{*}{$* * * 17 . . \wedge \vee$} & \multirow[t]{2}{*}{ r..1 } & \multirow{2}{*}{.049} & إعادة التقييم & \\
\hline & $1.7 \cdot r$ & B & & & & الإيجابى & \\
\hline
\end{tabular}

يتضح من نتائج جدول (rv) أن استخدام أسلوب حل المشكلات كإستراتيجية من استراتيجيات مواجهة الضغوط كان من أكثر العوامل المؤثثة على جودة الحباة الأسرية حيث

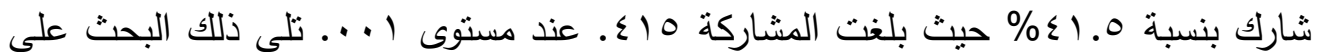


عدد خاص من مجلة "بحوث في العلوم والقنون النوعيه" العزيه

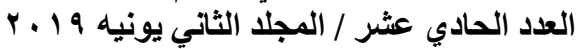

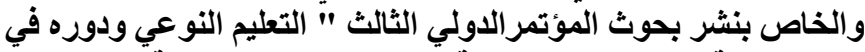

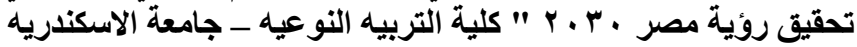

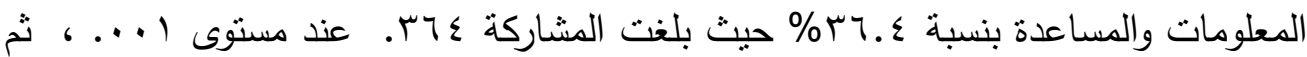

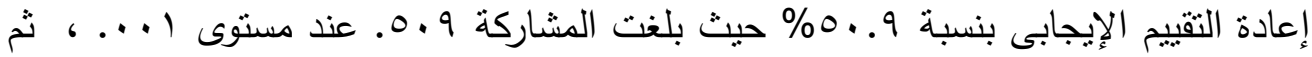
التحليل المنطقى للمواقف بنسبة 9. اس\% حيث بلغت المشاركة 9 اب. ثم اعادة التفسير

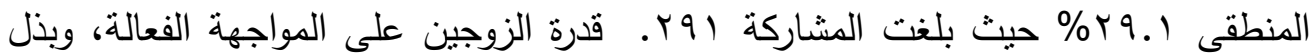
الجهر والتعامل مع الموقف بصورة ملموسة؛ للتحكم فى الموقف الضاغط وذللك من خلال القيام ببعض السلوكيات والتى من شأنها التعامل مباشرةً مع المشكلة واستتباط أفكار، وحلول

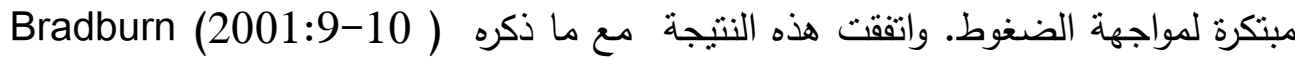
أن الإحساس بجودة الحياة متغير تابع يتوقف على أسلوب تعامل الفرد أو مواجهته للمشكلات التي تقابله في حياته. نستخلص مما سبق أن استخدام أسلوب حل المشكلات كإستراتيجية من استراتيجيات مواجهة الضغوط قد شارك بنسبة أكبر فى التأثنر على جودة الحياة الأسرية، يليه البحث عن المساعدة والمعلومات، ثم التحليل المنطقى للمواقف، ثم إعادة التقييم

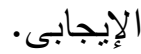

ويذلك يكون الفرض السادس قد تحقق كلياً.

توصيات البحث: فى ضوء نتائج البحث تم التوصل إلى مجموعة من التوصيات التالية: توصيات البحث: في ضوء نتائج البحث تم التوصل إلى مجموعة من التوصيات التالية: 1- أصبحت الجودة هدف؛ لذا ضرورة السعى قدماً من قبل المتخصصين، والمهتمين بمجال الإرشاد الأسرى لإدراج مصطلح جودة الحياة الأسرية فى بعض المقررات التى تُدر فى المراحل التعليمية المختلفة، مما يساعد جميع الطلاب على حد السواء لإدراك معناها وأهميتها فى الحياة؛ وبالتالى إعداد جيل قادر على تتمية المجتمع، وقادر على مواجهة أحداث الحياة والتعامل معها بشكل إيجابى. r- إعداد دورات تدريبية من قبل الجهات المعنية بالأسرة، يقوم بها متخصصين فى مجال الإرشاد الأسرى، تهدف إلى إكساب الأزواج، والمقبلين على الزواج الأساليب الإقدامية 
لمواجهة الضغوط مثل دورات فى مهارة حل المشكلات، دورات فى كيفية إعادة التقييم الإيجابى...إلخ. وذللك حتى يمكن امتلاكها كمهارات حياتية لدى كلٍ من الجنسين. r- مساهمة وسائل الإعلام فى تقديم برامج حوارية تليفزيونية، وإذاعية من قبل المتخصصين

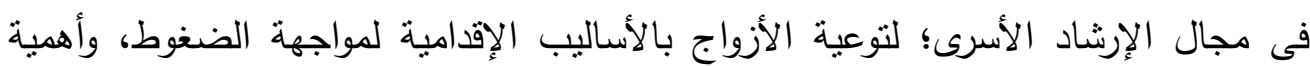

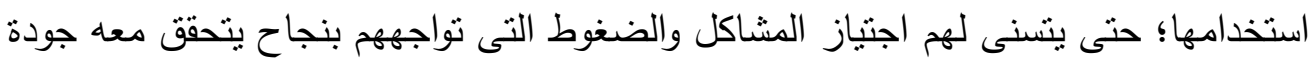
الحياة الأسرية التى تتعكس على أسرهم وبالتالى على المجتمع ككل.

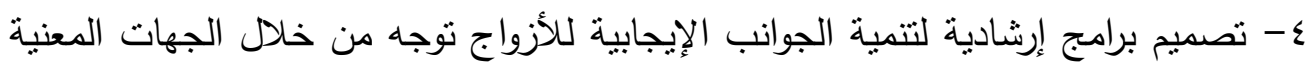

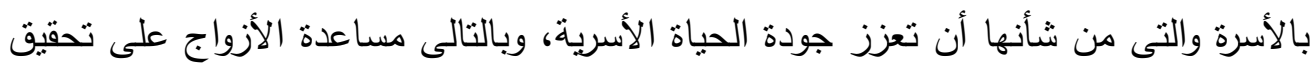

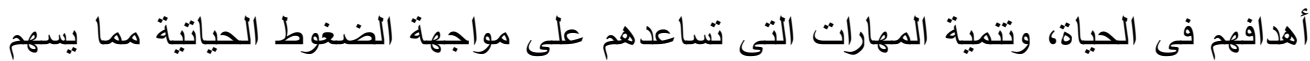
فى جودة الحياة الأسرية وضمان استقرارها.

\section{المراجع :}

1- أحمد نايل الغرير , أحمد عبد اللطيف أبو أسعد (9 . . ب): التعامل مع الضغوط النفسية،

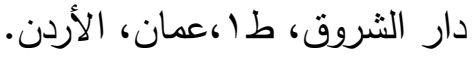




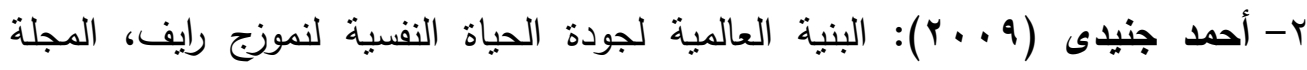

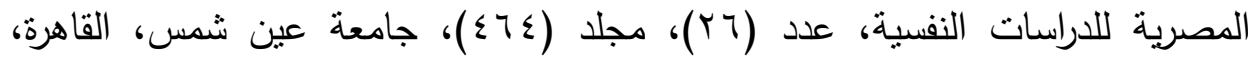

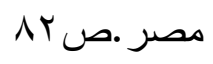

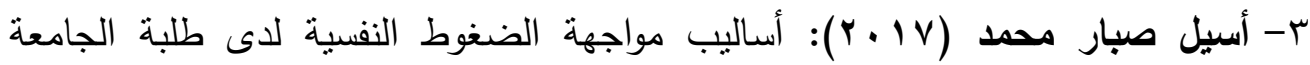

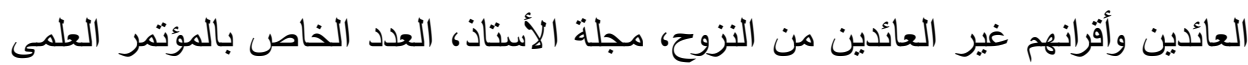
الخامس، كلية التربية للعلوم الإنسانية، جامعة الأنبار ، العراق.

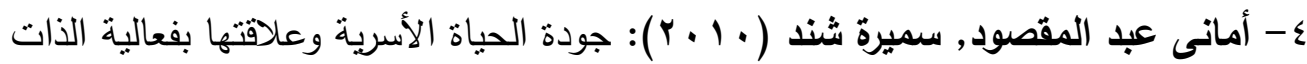

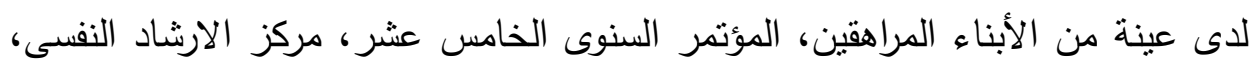

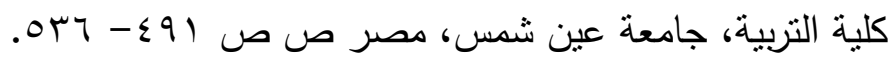

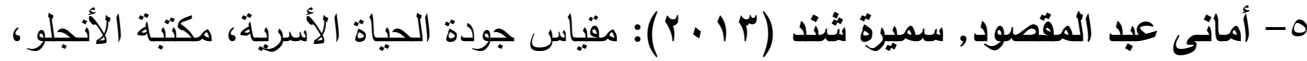

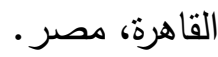

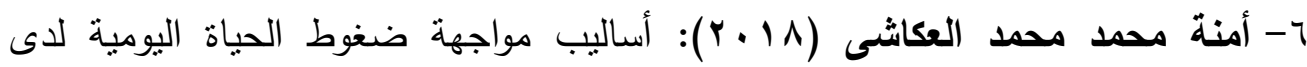

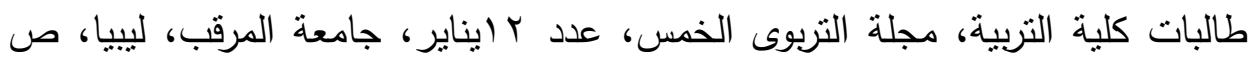

$$
\text { ص ص } 9-11 \Lambda
$$

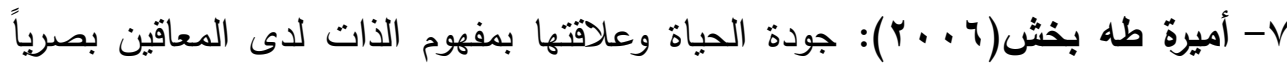
والعاديين بالمملكة العربية السعودية، مجلة كلية التربية، عدد( (1)، مجلد (هب)، جامعة

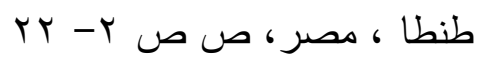

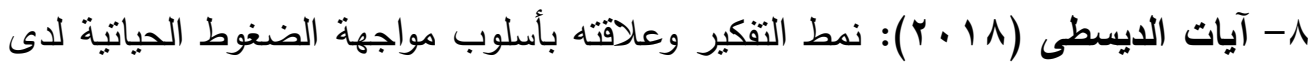

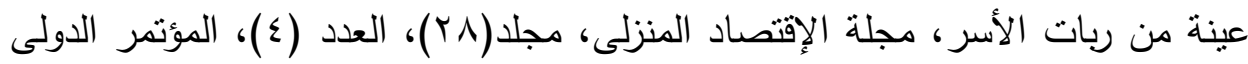

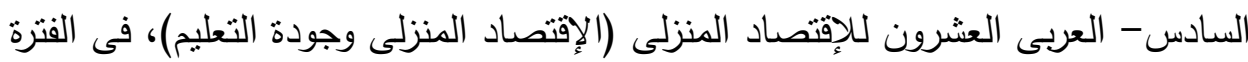

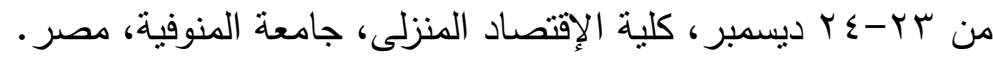


9- إيناس ماهر الحسينى بلير (r ا ب): الدعم الأسرى وعلاقته بأساليب مواجهة أحداث الحياة الضاغطة للشباب الجامعى، مجلة علوم وفنون، دراسات وبحوث، جامعة حلون،

مصر

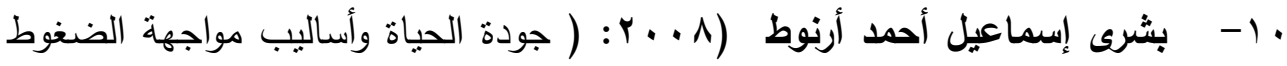
وعلاقتهما بقلق الموت والإكتئاب لدي المسنين، مجلة علم النفس المعاصر والعلوم

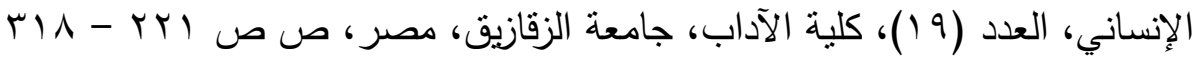

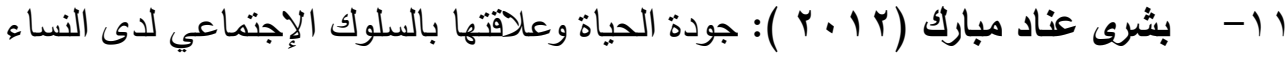

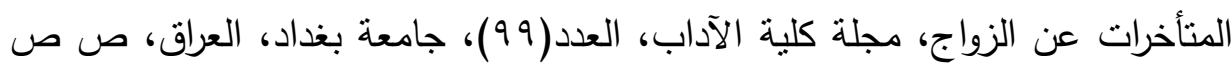
$V V^{\prime}-V_{1} \leq$

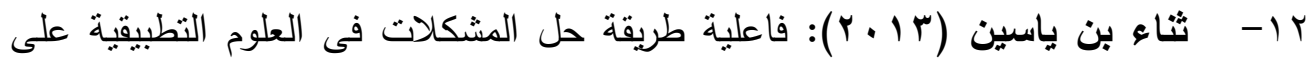
التحصيل الدراسى وتتمية مهارات التفكير الإبداعى لدى طالبات الصف الثانى المتوسط

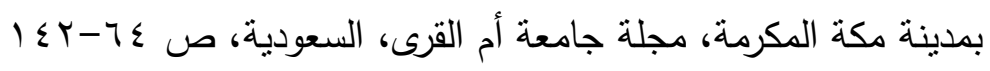

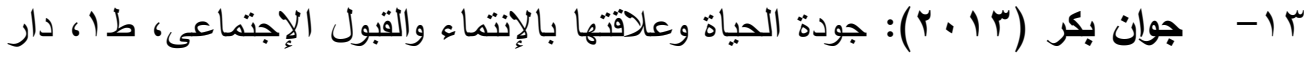

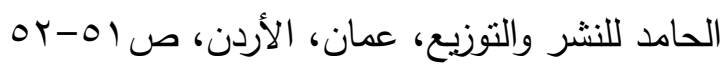

ع ا- حسام الدين محمد عزب، أثرف محمد عبد الحليم, سارة محمد عبد الفتاح

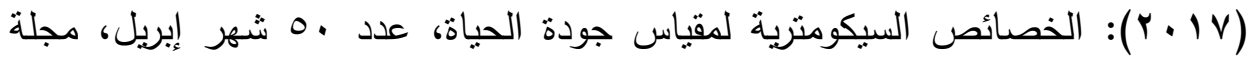
الإرشاد النفسى، جامعة عين شمس، القاهرة، مصر ، ص ص

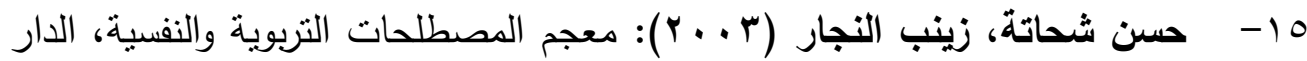

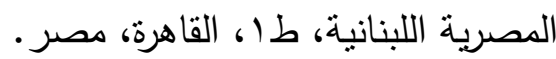

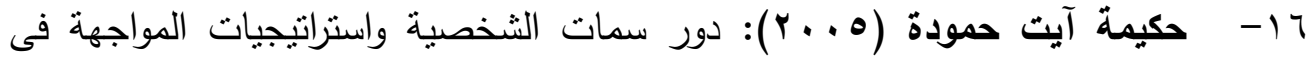
تعديل العلاقة بين الضغوط النفسية والصحة الجسدية والنفسية، رسالة دكتوراة، جامعة

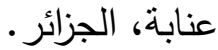




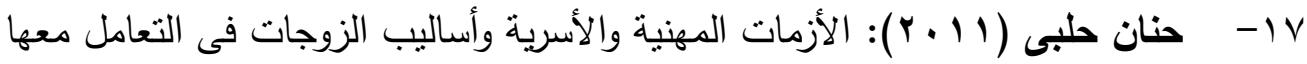
دراسة ميدانية على عينة من الزوجات فى محافظة دمشق، المجلد VY، العدد الثالث

$$
\text { والرابع، مجلة جامعة دمشق. }
$$

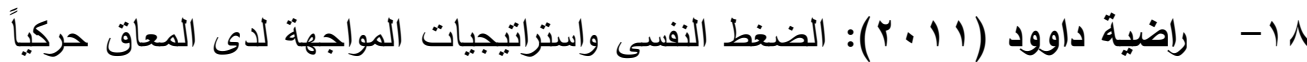
دراسة ميدانية على عينة من مستشفى رأس الماء - سطيف، رسالة ماجستير ، كلية العلوم الإنسانية والإجتماعية، قسم علم النفس وعلوم التربية، جامعة فرحات عباس، سطيف،

$$
\text { الجزائر }
$$

19- رجب على شعبان (1990): الفروق الجنسية والعمرية فى أساليب التكيف مع

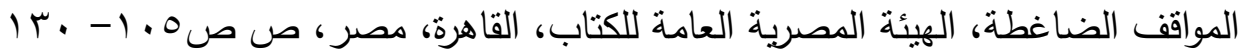

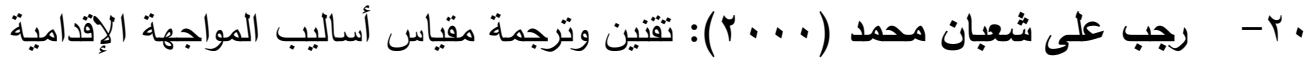

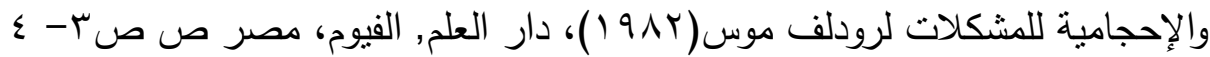

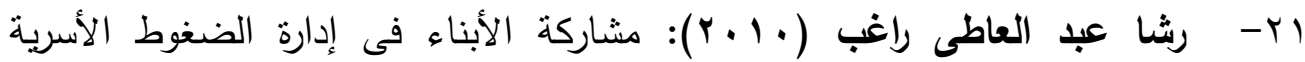

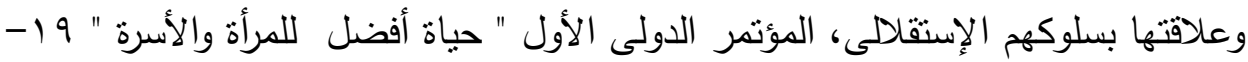
• ب إبريل، كلية الزراعة قسم الإقتصاد المنزلى، جامعة الإسكندرية، الإسكندرية، مصر .

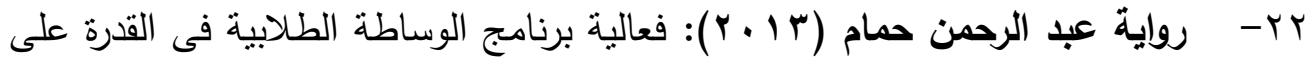
حل المشكلات والتحكم بالغصب لدى الوسائط فى المرحلة الأساسية العليا، رسالة ماجستير، الجامعة الإسلامية، غزة، فلسطين.

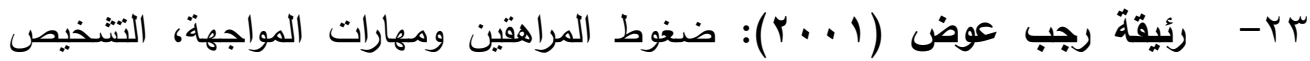
والعلاج، مكتبة الأنجلو، القاهرة، مصر • البه

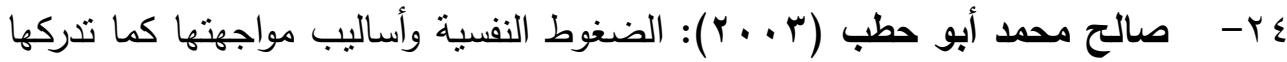

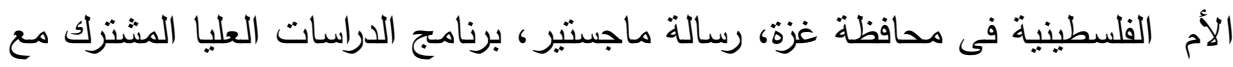
جامعة الأقصى، غزة، فلسطين. 


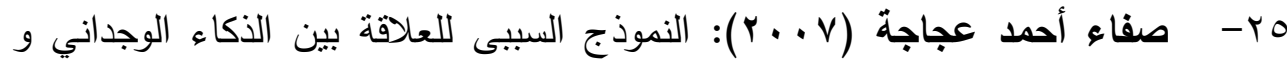
أساليب مواجهة الضغوط وجودة الحياة لدى طلاب الجامعة، رسالة ماجستير، كلية

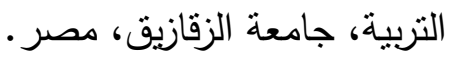

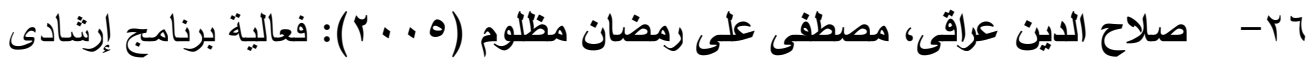
لتحسين جودة الحياة لدى الطلاب المكتئبين، مجلة كلية التربية، جامعة طنطا، مجلا

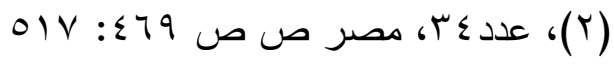

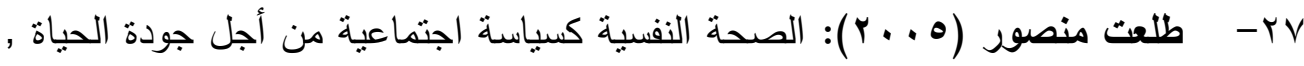
بحث مقدم إلى المؤتمر الثانى (الصحة النفسية فى الكويت)، مكتب الإنماء الإجتماعى الته

$$
\text { إبريل, الكويت. }
$$

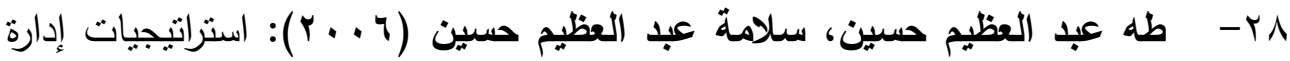
الضغوط التربوية والنفسية، دار الفكر للنشر والتوزيع، طا، ال، عمان ، الأردن.

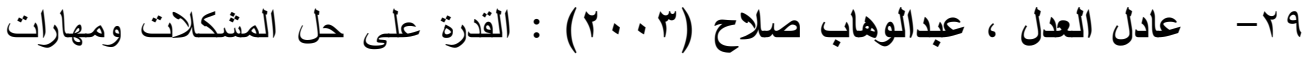

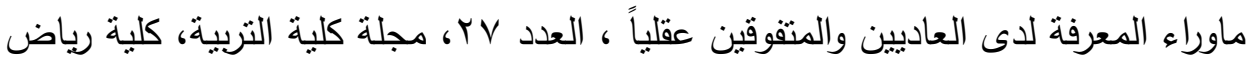
الأطفال، مصر . ماءوراء

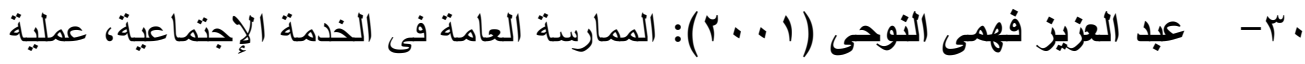

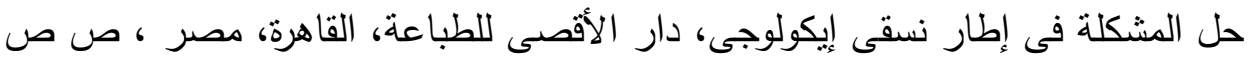
$99-9 \vee$

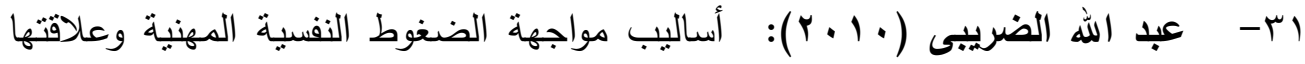
بعض المتغيرات (دراسة ميدانية على عينة من العاملين بمصنع زجاج القدم بدمشق)،

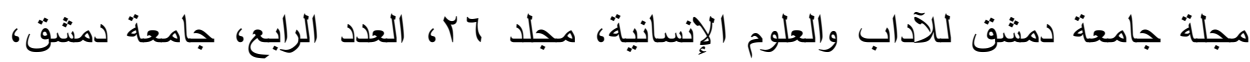




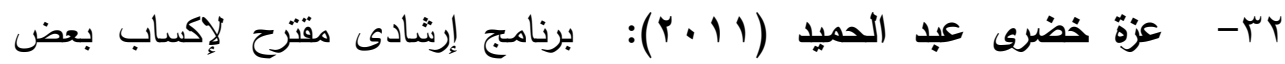
إستراتيجيات المواجهة لعينة من المراهقين المصابين بالسرطان، رسالة دكتوراه، كلية

$$
\text { التربية، جامعة حلوان، مصر • }
$$

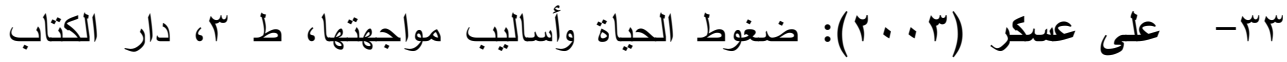

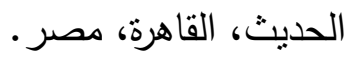

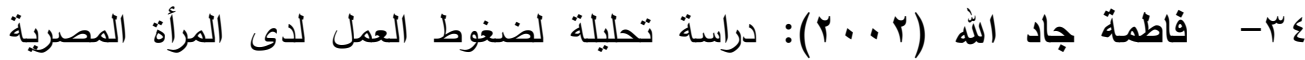
بالتطبيق على ديوان عام هيئة كهباء مصر ، المجلة العربية للإدارة ، مجلد ب ب، عدد ا،

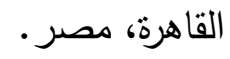

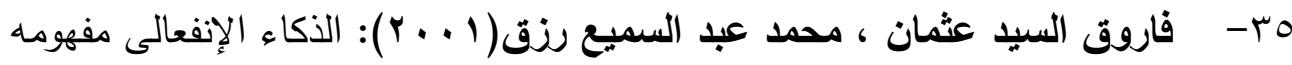

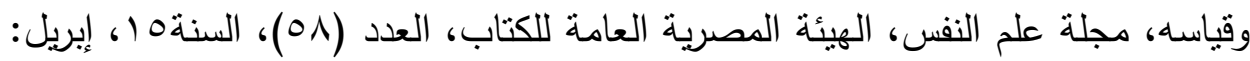

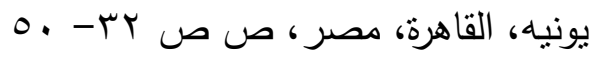

דr- فتحى عبد الرحمن جروان (999 (9 )): تعليم التقكير - مفاهيم وتطبيقات، دار الكتاب

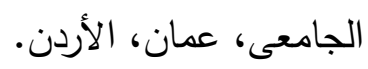

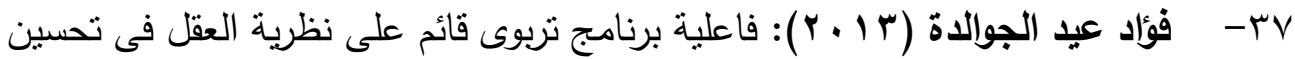

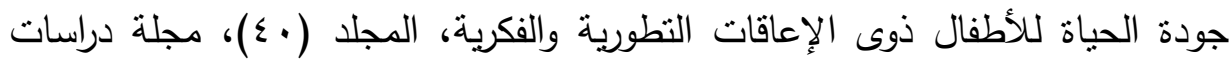
العلوم التزبوية، كلية العلوم التربوية والنفسية، جامعة عمان، الأردن.

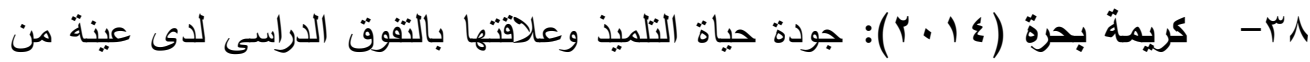

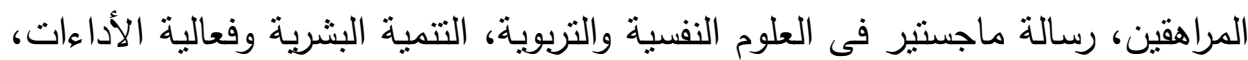

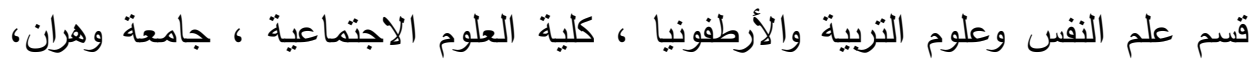
- الجزائر 
عدد خاص من مجلة "بحوث في العلوم والقنون النوعيه" العيه

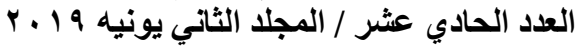

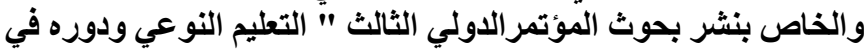

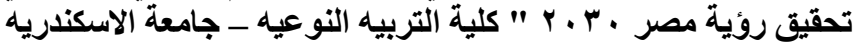

9 ب- لولو بنت صالح رشيد الرشيد (999 19 ) : أساليب التعامل مع الضغوط النفسية لاى بعض ذوات الظروف الخاصة والعاديات وعلاقتها ببعض سمات الثخصية ، رسالة

ماجستير، قسم علم النفس، كلية التربية، جامعة الملك سعود، السعودية.

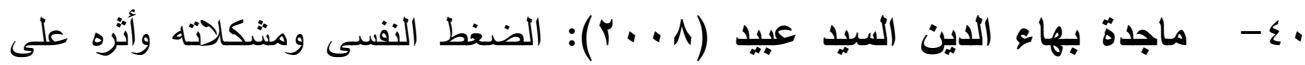

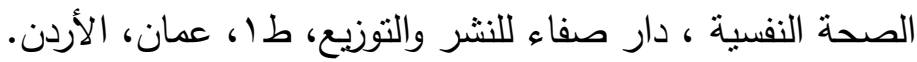

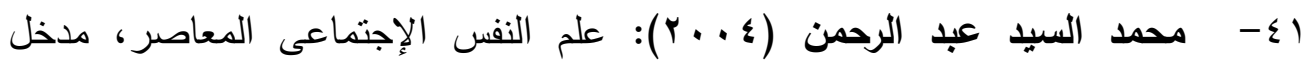
معرفى، دار الفكر العربى، القاهرة، مصر . مدمبل

r الإصدار الثانى، دار الثقافة للنشر والتوزيع، مصر.

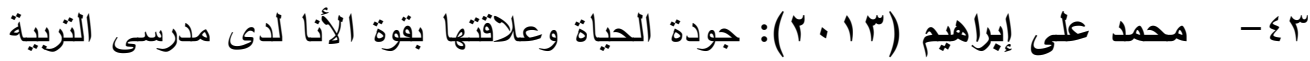

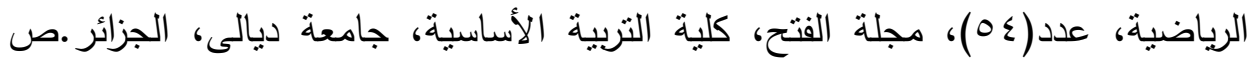

rrq

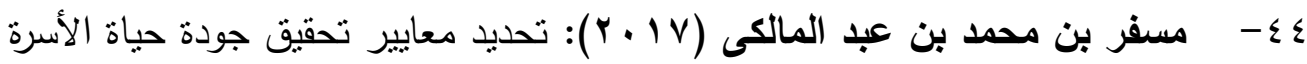
السعودية، دراسة مبدانية ، مجلة الخدمة الإجتماعية، عدد 01، مجلد ^، كلية العلوم

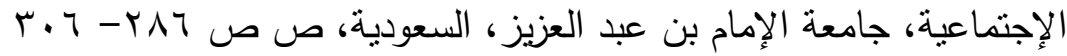

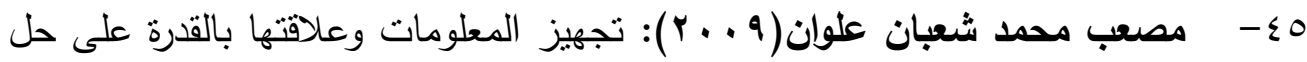
المشكلات لاى طلبة المرحلة الثانوية، رسالة ماجسنير، الجامعة الإسلامية، غزة، فلسطين.

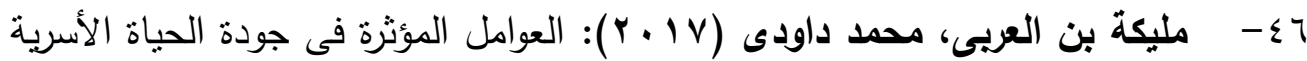

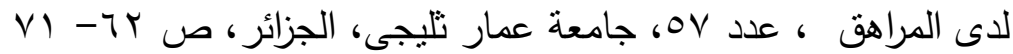

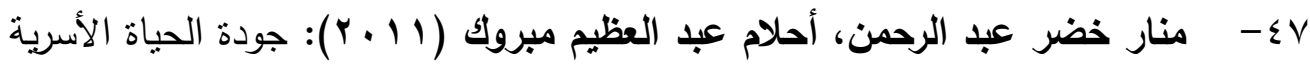

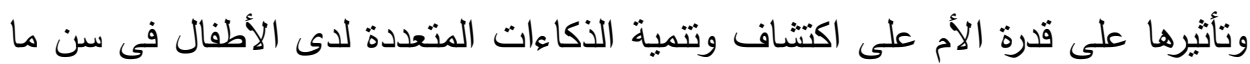


عدد خاص من مجلة "بحوث في العلوم والفنون النوعيه"

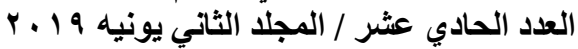

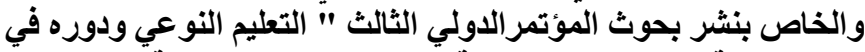

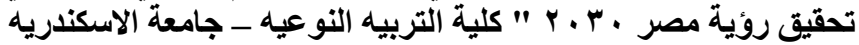

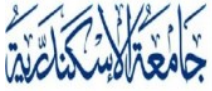

ALEXANDRIA

U N I V E R S I T Y

Alexu Press

(i)

قبل المدرسة ، مجلة بحوث التربية النوعية، العدد (YY) يوليو، الجزء الأول، جامعة

المنصورة ، مصر

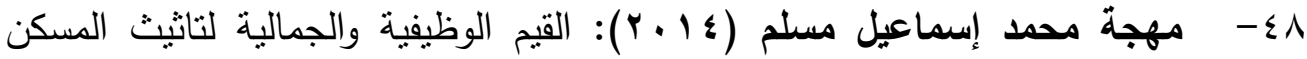
وعلاقتها بجودة الحياة الأسرية ، المؤتمر السنوى العربى التاسع الدولى السادس التعليم النوعى وتتمية الإبداع فى مصر والعالم العربى، من V- > مايو، كلية التربية النوعية،

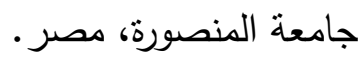

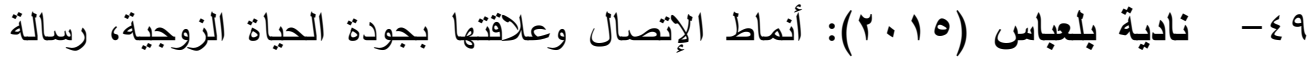
دكتواره، قسم علم النفس وعلوم التربية والأرطفونيا، كلية العلوم الإجتماعية، جامعة وهران، - الجزائر

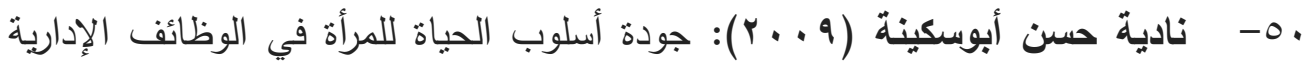
العليا وعلاقتها بمسببات الضغوط، مجلة بحوث الإقتصاد المنزلي، مجلد (9 ()، العدد (Y) إبريل، جامعة المنوفية، مصر (r)

ا0- نجية اسحق عبد الله (1 (Y): أساليب مواجهة الضغوط وبعض متغيرات الثخصية لدى الجنسين (دراسة مقارنة)، مجلة علم النفس المعاصر والعلوم الإنسانية،

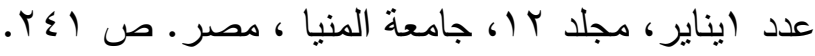

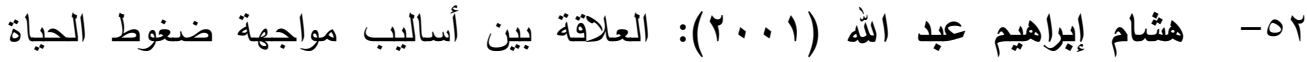
والثعور بالوحدة النفسية لدى عينة من المسنين، المؤتمر السنوى الثامن لمركز الإرشاد النفسى بجامعة عين شمس، القاهرة، مصر ، ص ص مهب- 97.

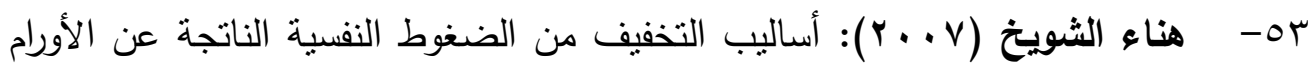
السرطانية، طا (، إيتراك للطباعة والنشر ، مصر • 

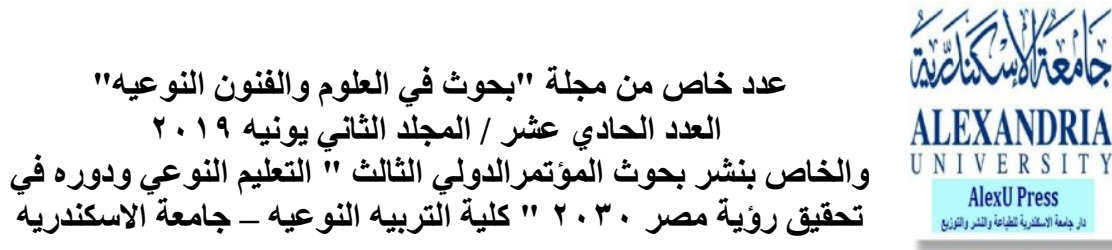

63- Aldao, Amelia. Hoeksem, Susan Nolen. (2010): a Specificity of cognitive emotion regulation strategies: A transdiagnostic examination. Behaviour Research and Therapy 48, p: 974-983.

64- Arun, V. ; Kimberly, M. ; Jenna, G. ; Zul, M. \& Hymie, A. (2002): Stress ,coping, up lifts, and quality of life in subtypes of depression. Aconceptual frame and emerging date . J. of Affective Disorders, Vol. 71, No. 1-3, Pp. 121-130

65- Beyersdorff,A,H,W,Luise,L,Ebner,A,Fusch,C,\&Peter,H.(2008): Survey of neonates in Pomerania(Snip)Apopulation based analysis of the mothers quality of life after delivery with Special relations to their Social integration,international journal of Public health, vol (53),number(2), April.

66- Bootzin, R. \& Richard, R. (1999): Psychology today: an introduction, $\left(7^{\text {th }}\right)$ ed. McGraw- Hill, Inc

67- Bradburn,N. (2001): The Structure of Psychological Well being. Chicago: Aldine Pub.Co

68- Bruchon-Scweitzer, Marilou.,(2002). Psychologie de la santé modèles concepts et méthodes. Paris: Armand colin.p.p350-412

69- Brown, Roy. (2009): Individual and family quality of life:Issues of aging and intellectual disability. Hong KongJoint Council for people with Disabilities/Hong KongCouncil of Social Service.

70- Dillon, D. G., \&LaBar, K. S. (2005): Startle modulation during conscious emotion regulation is arousal-dependent. Behavioral neuroscience, 119(4), 1110-1120

71- D'Zurilla\&,Nezu,A.M(2007): Problem- solving therapy:Apositive approach to clinical intervention $3^{\text {rd }}$ ed New York: Springer

72- Foehrkolb,c.(2007): Quality of life as a Factor of self- esteem . Americn Psychologist, 46, pp333- 341

73- $\quad$ Fredenberg,E.\& Lewis,R.(1991): Adolescent coping the different ways in which boys and girls cope, Journal of Adolescence ,Vol(14) No(2) pp.119133

74- Garnefski N.,\&Kraaij,V.(2006): Relationships between cognitive emotion regulation strategies and depressive symptoms:A comparative study of life specific samples.journal of Personality and Individual Differences, 40:1659-1669

75- Gullberg, Hollman, Christian.(2010): Reference values for the Quality of life inex in the general Swedish population 18:80 years of age, Quality of life, vol, 19N(1) 

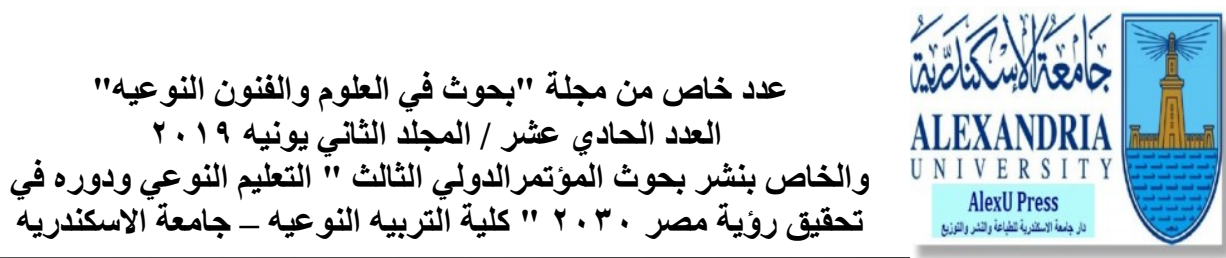

76- Hee Hong, Sung; Winter, Mary (2008): Time management stratigies and quality of life in family business. Journal of Family and Economic Issue, 13 (3), PP. 279-297

77- Huffman, k. Vernoy, M. Vernoy , j. (1997): Psychology in Action , john vley, sons inc, 410- 429.

78- Isaacs, B.; Brown, I.; Brown, R.; Baum, N.; Myerscough, T.;Neikrug, S.; Roth, D.; Shearer, J. \& Wang, M. (2007): Theinternal family quality of life project: Goals and practice in Intellectual Disabilities, vol.4, no.3, pp. 177-185.sep

79- James, K. Haveman. (2002): Statewide quality of life and service satisfaction study for children and families. Division of Quality Management and Planning Quality Management and Customer Services Administration.

80- Kemp, B (2010): Quality of Life Issues While Aging with A Disability, Rehabilitation Research and Training Center on Aging with a Disability, University of California at Irvine Press

81- King,Martin Luther Jr.(1991): The Essential Writings and speeches of Martin Luther King, Jr.Editied by James ,M.Washington . New York : Harper San Francisco

82- Krause, N. (2004): Traumatic events, and Quality of life exploring variations in the Older age. Aging and Society, Vol. 25, No. 4, Pp. 501-525

83- Kumar,R, \& Ramamurti, P.(1991): Stress and Coping Strategies of the Rural Aged. Journal of Personality and clinical studies, Vol. (6) No. (2)PP. 227-230-79

84- Lazarus, R(2000): "Toward Better Research on stress and coping", American Psychologist, Vol 155, No 6, pp 665-673

85- Long, Kahn (1993): Women, work and coping:A multidisciplinary to Workplace stress. Montreal: McGill -Queen's University Press

86- Mathew, M. ; George, L. \& Paniyadi, N. (2009): Comparative Study on Stress Coping Strategies and Quality of Life of Institutionalizedand Noninstitutionalized Elderly in Kottayam District. Kerala ,Indian Journal of Gerontology, Vol. 23, No. 1, Pp. 79-87.

87- Morrison, V. \& Bennett, P. (2006): An Introduction to Health Psycholog.London, Pearson Prentice Hall, Pp. 374: 397

88- Park, J.; Hoffman, L.; marquis, J.; Turnbull, A.; Poston, D.;Mannan, H.; Weny, M. \& Nelson, L. (2003): Towardassessing family outcomes of service delivery: validation of family quality of life survery. Journal of Intellectual Disability Research, 47 (415), 367-384.

؛ 1 شارع محمد أمين شهيب ـ مصطفى كامل ـ الاسكندريه ـ مصر تليفون : 203/5454313 : 203/5454313

Alexandria - Egypt, Tel. : 203/5454313 - 203/5442776 Fax :203/5442776

E-mail : journal.edusp@alexu.edu.eg Web site: RSSA.edusp@lexu.edu.eg

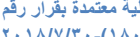

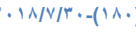



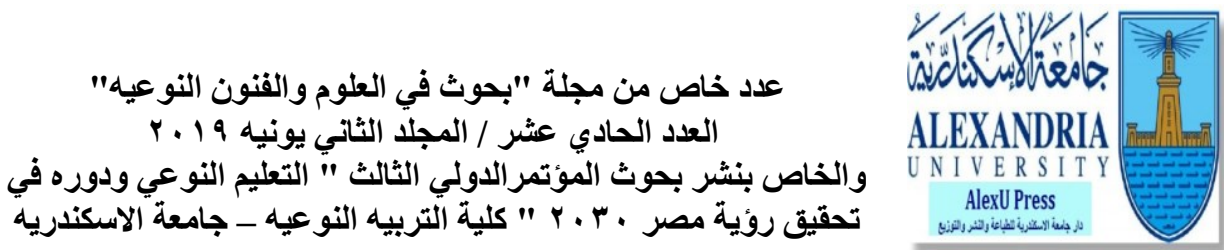

89- Richmond, L., Filson, G.C., Paine, C., Pfeiffer, W.C., and Taylor, J.R. (2000): Non-farm rural Ontario residents' perceived quality of life. Social Indicators Research 50: 159-186.

90- Rokach, A. \& Ami , A. (2001). Strategies of coping with loneliness throughout the life span, current psychology, development,learning, Personality, social, spr, Vol. 20, No. 1 .

91- Ryff,C,Love,G.,Urry,H.,Muller,D.,Rosen_Kranz.M.,Friedman.E.,David son.R,\&Singer.B.(2006):Psychological Well-Being and Ill-Being:Do They Have Distinct or Mirrored Biological Correlates?. Psychotherapy Psychosomatics, 75, 85-95.

92- Ryff, C.\&Keyes, (1995): The Structure of PsychologicalGood Being Revisited.Journal of Personality and Social Psychology, Vol (69), No (4), pp719-727

93- Stewart-Brown ,S(2000): Parenting, well- being, health and disease.In Buchanan,A.,\&Hudsen,B.(eds).Promoting Children's Emotional Wellbeing. Oxford: Oxford University press

94- Summers, T. Poston, D.; Turnbull, A.; Marquis, J.; Hoffman, L.; Mannan, H. Wang, M. (2005): Conceptualizing and measuring family quality of life. Journal of Intellectual Disability Research, Vol. 49, PP. 777783. 

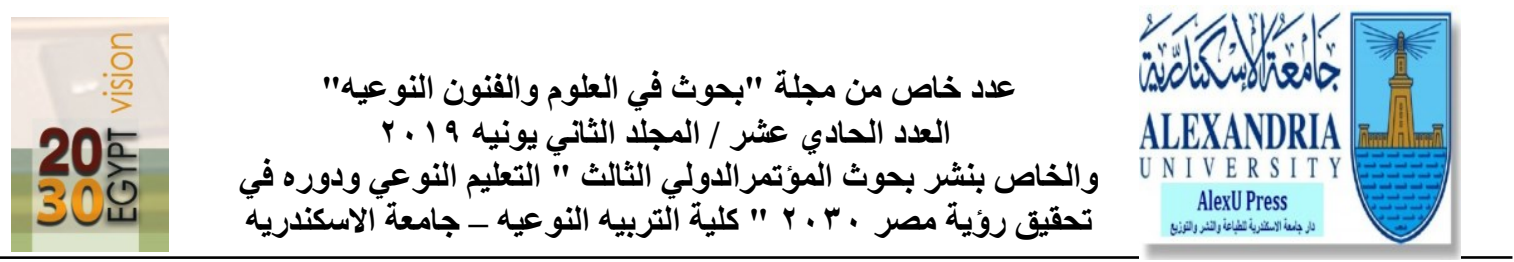

Strategies for the progressive confrontation of the pressures of the couple and their relation to the quality of family life

\author{
Dr. Abeer Moheb Abdel \\ Moneim \\ Doctor of philosophy in specific \\ education. Home Economics \\ (Home Management)
}

\section{Dr. Hanan Hanna Aziz}

Lecture of home management

Economic department

The faculty of specific education

El Mansoura university

\section{English Abstract:}

The current research aims primarily at identifying the relationship between predatory coping strategies for couple stress and quality of family life. The data were obtained through the application of the research tools (by the researchers) to each of the spouses, in the form of the general data form, and the strategies of the protracted confrontations of stress in their fields (logical analysis of attitudes, positive reevaluation, seeking assistance and information, (Quality of married life, quality of family life, quality of family life), on a purposeful sample of 394 individuals (197 husbands and 197 wives) belonging to different socioeconomic levels, The following cities (Mit Ghamer, Aja, and Mansoura) Dakahlia Governorate. This research was followed by the analytical descriptive method. The data were analyzed and the appropriate statistical treatments were performed using the Spss program. The most important results of the research:

a positive correlation between the strategies of the frontal response to the pressure in its axes (logical analysis of attitudes, positive reevaluation, search for assistance and information, use of problem solving), total, quality of family life The quality of social life of the family) and the total, there are differences between the average scores of the research sample in the strategies of the frontal pressure of the husbands in the logical analysis, the use of the method of problem solving, and for the benefit of the wives in positive re-evaluation, And the search for assistance and information, there are differences between the average scores of the sample of wives in the strategies of the frontal confrontation of pressure in their axes, and the total for the benefit of working wives, the absence of differences between the

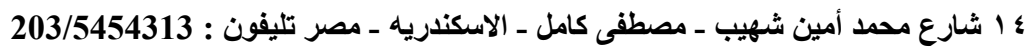

Alexandria - Egypt, Tel. : 203/5454313 - 203/5442776 Fax :203/5442776

كلية معتمدة بقز ار رقم

E-mail : journal.edusp@alexu.edu.eg Web site: RSSA.edusp@lexu.edu.eg 
average scores of the sample of couples in the strategies of the frontal confrontation of pressures in their axes, Government - free), There were statistically significant differences between the averages in the total coping strategies of the pressures of the spouses in favor of the higher educational level, the older age, and the high monthly income level of the family. There were differences between the averages of the sample of the research in the quality of family life according to the type in favor of the wives. The study of wives in the quality of family life according to work for working wives, and the absence of differences between the average score of the sample of couples in the quality of family life according to the husband's work, and the existence of positive correlation relationship statistically significant at 0.01 , 0.05 between the quality of life For families in both spouses and each of the older age, higher educational level, and higher monthly household income level.

\section{The most important recommendations were:}

- Design guidance programs for the development of the positive aspects of couples of both sexes directed by family stakeholders that will enhance the quality of family life, and thus help couples achieve their goals in life.

- Preparation of training courses by the concerned bodies of the family, carried out by specialists in the field of family guidance, aimed at giving couples and those who are close to marriage the methods of advanced stress management such as courses in problem solving skills, courses on how to re-evaluate the positive ... etc. So that they can be acquired as life skills of both sexes.

- The need to go ahead by specialists, and those interested in the field of family guidance to include the term quality of family life in some of the courses taught in different educational stages, which helps all students alike to realize its meaning and importance in life; and thus prepare a generation capable of community development. 